\title{
A!
}

This is an electronic reprint of the original article.

This reprint may differ from the original in pagination and typographic detail.

Focke, Florens; Ruenzi, Stefan; Ungeheuer, Michael

\section{Advertising, Attention, and Financial Markets}

Published in:

Review of Financial Studies

DOI:

$10.1093 / \mathrm{rfs} / \mathrm{hhz} 142$

Published: 01/10/2020

Document Version

Peer reviewed version

Please cite the original version:

Focke, F., Ruenzi, S., \& Ungeheuer, M. (2020). Advertising, Attention, and Financial Markets. Review of Financial Studies, 33(10), 4676-4720. https://doi.org/10.1093/rfs/hhz142

This material is protected by copyright and other intellectual property rights, and duplication or sale of all or part of any of the repository collections is not permitted, except that material may be duplicated by you for your research use or educational purposes in electronic or print form. You must obtain permission for any other use. Electronic or print copies may not be offered, whether for sale or otherwise to anyone who is not an authorised user. 


\title{
Advertising, Attention, and Financial Markets
}

\author{
Florens Focke \\ University of Mannheim \\ Stefan Ruenzi \\ University of Mannheim \\ Michael Ungeheuer \\ Aalto University
}

August 2019

Review of Financial Studies, forthcoming

\begin{abstract}
Using daily advertising data, we analyze the short-term effects of advertising on investor attention and on financial market outcomes. Based on various investor attention proxies, we show that advertising positively affects attention. However, it has only little impact on turnover and liquidity. Most importantly, short-term stock returns are not significantly influenced by advertising. Further results suggest that previous findings of an economically significant positive relation between advertising and returns are due to reverse causality. Thus, the belief that stock prices can be temporarily inflated via advertising is misguided. (JEL G10, G12, G14, M37)
\end{abstract}

Acknowledgements: We are grateful to Joey Engelberg, Cam Harvey, Terrance Odean, Vivian Mai, Jan Schneemeier and Philipp Schuster; seminar participants at the University of Mannheim, the HSE Moscow, the HSE St. Petersburg, and the University of Essex; participants at the German Economic Association 2015, the German Finance Association 2015, the IFABS 2015, the Swiss Society for Financial Market Research 2016, and the FMA 2016 conferences for valuable comments. This work was supported by the Graduate School of Economic and Social Sciences of the University of Mannheim, which is sponsored by the German Research Foundation, and the Stiegler Memorial Foundation. All errors are our own. 
We examine the interplay between product market advertising, investor attention, and shortterm capital market reactions. Our paper makes two main contributions: first, we provide evidence that firms can attract investor attention and increase short-term trading activity in their stocks through product market advertising. Second, we show that advertising does not significantly affect short-term stock returns. Thus, we challenge the view expressed in the literature (e.g., Lou, 2014) that advertising inflates short-term stock prices and can be used to strategically boost short-term stock market valuations.

Opportunistic managers have incentives to artificially inflate short-term stock market valuations in many situations, for example, prior to seasoned equity offerings (SEOs), during M\&A transactions, or prior to insider sales. Product market advertising seems like a promising way to do so, because it might increase investor attention and participation (e.g., Grullon, Kanatas, and Weston, 2004, Frieder and Subrahmanyam, 2005). Increased investor attention can lead to temporarily inflated stock prices (e.g., Barber and Odean, 2008; Da, Engelberg, and Gao, 2011).1 Previous research indeed provides evidence of a positive contemporaneous correlation between product market advertising and returns on stock markets. In an influential paper for the literature on the interplay of advertising and financial markets, Lou (2014) finds that "managers adjust firm advertising, in part, to attract investor attention and influence short-term stock returns" (abstract, p. 1797).

However, this earlier work typically relies on annual advertising data and focuses on the contemporaneous relationship between advertising and stock market returns. Thus, results are subject to a severe endogeneity problem: it is possible that firms with good news and correspondingly high stock market returns early in a year do particularly well over that year, for example in terms of cash flows or sales growth, and correspondingly increase their advertising budgets later in the year or vice versa. Ample evidence shows that advertising expenditures are (besides R\&D expenditures) one of the first types of expenditures to be reduced to meet earnings goals in difficult times (Graham,

${ }^{1}$ The theoretical motivation behind attention-induced overpricing goes back to $\mid$ Lintner $|(1969)$,$| Miller \mid$ (1977), and Mayshar (1983), who analyze the effects of heterogeneous beliefs combined with short-sale constraints on asset prices. Barber and Odean (2008) add that individual investors' search problem is greater for buying decisions than for selling decisions, so that attention may lead to buying pressure even from investors who are not short-sale constrained. 
Harvey, and Rajgopal, 2005; Deleersnyder, Dekimpe, Steenkamp, and Leeflang, 2009). If so, one would find a positive relationship between advertising and contemporaneous stock market returns on a yearly frequency without there necessarily being a causal impact of advertising on returns.

To solve this identification issue, we use a novel data set to examine the impact of product market advertising on investor attention and subsequent financial market outcomes on a daily level. As advertising is typically predetermined over longer horizons than a few days, our high-frequency analysis allows us to assess whether the correlations observed based on yearly advertising data indeed represent causal effects of advertising. Furthermore, high frequency data allows us to better capture any potential impact of advertising on attention and eventually capital market outcomes as these are supposedly mainly short-term effects, which might be blurred or reversed in lowerfrequency data: for example, Barber and Odean (2008) find that attention grabbing events lead to retail buying pressure on the day after the attention event. Seasholes and $\mathrm{Wu}(2007)$ and Da, Engelberg, and Gao (2011) find a significant price impact of attention only during the 2 weeks directly after an attention spike. In line with short-lived attention effects, Ungeheuer (2018) shows that attention toward firms after earnings announcements, Form 8K filings, and newspaper coverage fades out within less than a week, suggesting that an analysis of the effects of advertising on capital markets via investor attention is best conducted at a high frequency.

For our analysis, we use information on daily advertising expenditures in the U.S. of all firms that advertise in a large sample comprising all national and a large number of local newspapers, as well as most important local and national TV channels. To the best of our knowledge, this is the most comprehensive sample of advertising expenditures of U.S. firms with high-frequency information on advertising used in the literature so far. In addition, we compile a database containing the number of page views of a firm's Wikipedia page aggregated on a daily level, which we use as a new proxy for investor attention, next to Google search volume, downloads from the SEC EDGAR platform and Bloomberg searches for a firm. 
For the years 2007 to 2012, for which the advertising and attention databases overlap, we find a significant impact of advertising on investor attention after controlling for time- and firm-fixed effects. The impact is strongest during the first 3 days after an advertisement and becomes insignificant after at most 2 weeks, consistent with the short-lived attention effects found in the previous literature in finance (Barber and Odean, 2008, Da, Engelberg, and Gao, 2011) and marketing (Joo, Wilbur, Cowgill, and Zhu, 2013; Aravindakshan and Naik, 2010). Our results obtain for newspaper as well as for TV advertising. Furthermore, they hold and are of virtually identical magnitude after controlling for the impact of important firm-related news events like earnings announcements or coverage of the firm in newspapers, showing that our results are not driven by investor attention created by fundamental news. Additionally, we find that advertising in business and news channels has a stronger impact on investor attention than advertising in entertainment channels, in particular for institutional investors. Similarly, the impact of advertising is also stronger for advertising in national newspapers and in particular the Wall Street Journal as compared to local newspapers.

However, the existence of a positive influence of advertising on attention is a necessary, but not a sufficient, condition, for advertising to directly influence stock markets. In the second main part of our analysis, we thus link our advertising data with financial markets data. We find a highly significant positive impact of TV as well as newspaper advertising on turnover on the same and the following 1 to 3 days. These findings are consistent with the idea that attention causes trading activity (Barber and Odean, 2008). However, the effects are very small in terms of economic magnitudes, showing that the impact of advertising-induced attention on stock markets is modest at best. We also find only very limited evidence of a positive influence of advertising on liquidity.

Most importantly, advertising does not discernibly affect contemporaneous and subsequent daily returns. This result obtains independent of the specific advertising channel we look at. Even advertising in the Wall Street Journal or in business and news TV channels - which we show to have the strongest impact on attention - does not affect daily returns. This finding also holds in cross-sectional sample splits based on firm characteristics and for firms with high and low media 
coverage. Some of our subsample analyses are motivated by the marketing literature, which shows that advertising is particularly effective in less concentrated industries (Edeling and Fischer, 2014), on the regional as opposed to national level (Sridhar, Germann, Kang, and Grewal, 2016), and for TV instead of print advertising (Sethuraman, Tellis, and Briesch, 2011). In a last attempt to find the supposed short-term impact of advertising on returns, we analyze firms for which attention is more sensitive to changes in advertising. To do so, for each individual firm we first determine how strongly Wikipedia page views react to advertising. Then, we sort firms according to this advertising sensitivity into subsamples. We do find that turnover reacts more strongly to advertising among high sensitivity firms. However, even among those firms, advertising does not significantly affect stock returns.

It is important to note that-unlike in the literature on advertising and sales, where it is very difficult to make empirical statements about a potential impact because of very large confidence intervals (Lewis and Rao, 2015) - our nonresult is not due to noisy estimates or low power, but rather due to precise estimates close to zero. Using the method recently proposed by Harvey (2017), we can reject an economically meaningful impact of advertising on short-term stock returns even if we give the alternative long-shot odds. In that sense, we provide "evidence of absence," which makes our results meaningful in particular also regarding claims in the literature about economically large attention-induced short-term effects of advertising (Lou, 2014).

To reconcile our findings with the results from the earlier literature that document a positive contemporaneous correlation between low-frequency advertising and stock market returns, we conduct panel vector autoregressions with monthly advertising expenditures and stock market returns. We find that higher returns Granger-cause future increases in advertising, but not the other way around. This result suggests that reverse causality is an explanation for the positive contemporaneous correlation between yearly advertising and stock returns found in prior research. We propose two plausible explanations for such reverse causality. First, negative news about a firm's products should drive down stock prices directly and are likely to be followed by decreased advertising when 
future cash flows are lower or when managers cut expenditures to reach earnings goals Graham, Harvey, and Rajgopal, 2005; Deleersnyder, Dekimpe, Steenkamp, and Leeflang, 2009). Second, positive returns now might predict increased cash flows later, which could lead to inefficiently high advertising due to agency problems (Joseph and Richardson, 2002). In line with these explanations, we find that positive earnings surprises predict economically significant advertising growth in the subsequent year, providing evidence for one potential economic channel explaining the reverse causality documented above.

It should be mentioned that our results do not in any way preclude long-term effects of advertising on sales, cash flows, stock liquidity, or firm valuations. However, any attempt to identify these from low-frequency data should be mindful of the reverse causality problem that we document here. Furthermore, if such long-term effects exist, they are unlikely to be driven by investor attention, as attention after advertisements quickly fades out and the impact of attention on capital markets that is documented in earlier studies also always occurs on a very short horizon of at most 2 weeks (see, e.g., Barber and Odean, 2008; Da, Engelberg, and Gao, 2011).

Our paper contributes to different strands of the finance literature. First, it complements the literature on the link between investor attention and stock markets. Barber and Odean (2008) document a positive impact of investor attention on retail buy-sell imbalances, arguing that attention leads to retail trading and due to short-sale constraints more buying than selling. In line with attention-induced price pressure, Gervais, Kaniel, and Mingelgrin (2001) show that increased turnover affects the subsequent price of a stock. Da, Engelberg, and Gao (2011) find inflated stock prices during periods of increased investor attention and a subsequent reversal. They use Google search volume for ticker symbols to capture investor attention. Furthermore, Fang and Peress 2009 find that increased media coverage leads to lower subsequent returns ${ }^{2}$ We contribute to the literature on attention methodologically by showing that easily available Wikipedia data are a

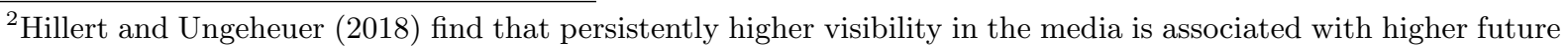
stock returns, particularly on earnings announcement days, consistent with undervaluation of the positive effects of persistent visibility via a monitoring and an advertising channel. 
reliable direct measure of attention that is available for a large number of firms. Our later tests also suggest that Wikipedia data are able to capture retail investor attention, similar to Google search volume, rather than attention from more sophisticated, institutional investors. We show that our results are robust to using Google search volume, downloads from SEC's EDGAR platform, or search activity on Bloomberg as attention proxies. While the above literature focuses on the effect of endogenous shocks to attention on financial markets, our study investigates the effects of predetermined advertising and thus plausibly exogenous shocks to attention on financial markets.

Second, we contribute to the literature on advertising and financial markets. Evidence suggests that the attention created by marketing activity influences household portfolio choice. For example, Branikas (2019) documents that households tilt their portfolio holdings towards firms that sponsor local sports teams in their region ${ }^{3}$ However, he does not analyze the impact on aggregate financial market outcomes. Earlier studies (e.g., Chemmanur and Yan, 2019, Lou, 2014) that analyze the link between advertising and financial markets use low-frequency advertising expenditures and thus face the endogeneity problem discussed above. An exception is a contemporaneous paper by Madsen and Niessner (2019). Consistent with our findings, they document that Google searches are higher on days with print advertising of a company, but that stock returns are not affected. However, the availability of our advertising data for all stocks on a daily level for all important traditional advertising channels - TV and newspapers - enables us to estimate the economic significance of advertising for financial markets in general, as opposed to for certain firms, days, or outlets only. $\mathbb{4}^{4}$

\footnotetext{
${ }^{3}$ Consistent with this finding, Keloharju, Knüpfer, and Linnainmaa (2012) document that investors are more likely to invest in stocks of automotive companies of which they are also customers.

${ }^{4}$ Another paper trying to understand the short-term effects of advertising is Fehle, Tsyplakov, and Zdorovtsov (2005): they conduct an event study based on a small sample of firms that advertise during the Super Bowl. They find that firms that place more than one ad during a Super Bowl have positive abnormal returns of about 45 bp on the following trading day (but firms that place one ad during a Super Bowl tend to have negative returns). Moreover, because the timing of the Super Bowl cannot be influenced by firms, managers cannot use Super Bowl advertising to strategically inflate their stock price prior to important corporate events. In a similar vein, Mayer (2019) shows that firms that sponsor NCAA Division I college football bowl games generate transitory positive abnormal returns of 64 bp among games with above-median TV ratings, but no significant return effects for below median TV ratings. Most recently, Liaukonyte and Zaldokas (2019) document the minute-by-minute impact of TV advertising on information acquisition, trading activity, and prices. In line with our results, they find a positive impact of advertising on information acquisition and trading, but no significant price impact on daily returns.
} 
Third, by analyzing the impact of advertising our study also relates to the rich literature on advertising from marketing. The main goal of advertising is to reach potential customers and to eventually increase sales. A positive impact of advertising on sales has been documented in many studies $5^{5}$ Edeling and Fischer (2014) also highlight that work that does try to measure the impact of advertising on firm value or stock returns often faces severe endogeneity concerns due to low datafrequency and they recommend to use data on a higher frequency "such as daily or weekly data, that more closely capture investors' reaction time." Several attempts have been made to overcome endogeneity problems by conducting field experiments (Lewis and Reiley, 2014a b). However, in an influential paper, Lewis and Rao (2015) show that even in such settings it is extremely difficult to obtain reliable results due to the small signal-to-noise ratio that plagues the analysis of the impact of advertising on sales ${ }^{6}$ Generally, the insights on the impact of advertising on customer attention, sales, and profits are not necessarily linked to our analysis of investor attention and financial markets. As an illustration, while TV advertising might on average be more effective in increasing sales compared to print advertising (Sethuraman, Tellis, and Briesch, 2011), it seems plausible that investors are particularly likely to read newspapers, so that advertising effects on financial markets via investor attention might still be stronger for newspaper advertising.

While the marketing literature naturally focuses on advertising as an important tool for consumer communication, it does not focus on the role of advertising for investor communication. Othermore direct-measures of investor communication like the investor relations activity of firms have been shown to lead to lower cost of capital (Brown and Hillegeist, 2007) and positively affect media coverage (Solomon, 2012), liquidity (Brennan and Tamarowski, 2000; Kirk and Vincent, 2014), and eventually firm valuations (Bushee and Miller, 2012; Karolyi and Liao, 2017). In contrast to this literature, we focus on product market advertising which is not necessarily targeted at investors.

\footnotetext{
${ }^{5}$ See, for example, Sethuraman, Tellis, and Briesch (2011).

${ }^{6}$ Another conceptual problem is highlighted in Blake and Coey (2014), who show that results from marketplace experiments are plagued by the fact that in equilibrium, the change in the demand of the treated group can affect the supply available to the control group.
} 
Finally, our study also informs the emerging literature on the strategic use of advertising. This growing branch of the literature focuses on the ways in which firms can use advertising for purposes beyond direct effects on sales. Reuter and Zitzewitz (2006) and Focke, Niessen-Ruenzi, and Ruenzi (2016) show that firms can use advertising to influence media reports, whereas Cohen and Gurun (2018) find evidence that firms systematically increase local advertising in areas where they are facing jury trials. In a financial context, it has been argued that firms can use advertising strategically around insider sales (Lou, 2014), IPOs and SEOs (Chemmanur and Yan, 2009), as well as M\&A transactions (Fich, Starks, and Tran, 2016, Hillert, Kunzmann, and Ruenzi, 2017). We think that our finding that advertising does not have a significant impact on returns - despite being a "nonresult" - has important implications for this literature because it casts serious doubts on the underlying view that advertising is an efficient way to boost short-term stock market valuations. This finding implies that managers would be wrong in assuming that they can use advertising, for example, around corporate events or insider transactions, to artificially increase the stock price in the short run.

\section{Data and Methodology}

In this section, we first describe the financial markets data we use, including liquidity proxies based on high-frequency data and media coverage data (Section 1.1). We then introduce the Wikipedia page view data, our new measure for investor attention, and discuss its relation to our other attention proxies based on Google search volume, SEC EDGAR downloads, and Bloomberg search activity (Section 1.2). Finally, we introduce our advertising data set and our measures of (abnormal) advertising (Section 1.3). The appendix defines all variables.

\subsection{Financial markets, analyst coverage, and media coverage data}

Our initial stock market sample universe consists of all common stocks (share code 10 or 11) from the Compustat/CRSP universe traded on NYSE, AMEX, or NASDAQ. Daily financial market data, 
specifically daily stock turnover, returns, and market capitalization, are taken from CRSP's daily stock file. Balance sheet data come from Compustat. Panel A of Table 1 presents summary statistics for the sample period used in the analysis of the impact of advertising on attention (i.e., from 2007 - the year in which our Wikipedia data starts, see Section 1.2 to 2012). Panel B shows summary statistics for the sample period used in the analysis of the impact of advertising on financial markets (from 1996 to 2010, the years for which we have the TAQ data required to calculate our liquidity proxies).

In our analysis of advertising's impact on liquidity in Section 3, we use Trade and Quote (TAQ) data to calculate the effective spread as the daily transaction-weighted average of transaction prices relative to prevailing quote midpoints.7 We obtain earnings announcement dates and analysts' earnings expectations from I/B/E/S and national media coverage (Wall Street Journal, New York Times, Washington Post, USA Today) is from LexisNexis $8^{8}$

\subsection{Investor attention proxies: Wikipedia, Google, EDGAR, and Bloomberg}

Our new measure of attention is based on the daily number of page views of firms' Wikipedia pages (WIKI) for the time period from December 2007 (when Wikipedia data are first available) to December 2012. For details on the procedure we use to extract Wikipedia page view counts, see Internet Appendix A.1. To our knowledge, we are the first to use WIKI data for a broad panel of firms 9 On average, the Wikipedia pages of 2,019 distinct publicly listed companies are visited per day, generating 461,741 daily page views. The most similar alternative measures of investor attention are Google Search Volume (GSV) for tickers (most prominently used by Da, Engelberg, and Gao, 2011), downloads from the SEC's EDGAR platform (used in, e.g., Drake, Roulstone,

${ }^{7}$ We thank Olga Lebedeva and Stefan Obernberger for providing us with their data set. This data set also has been used in Lebedeva (2012) and Hillert, Maug, and Obernberger (2016).

${ }^{\circ}$ We thank Alexander Hillert for providing us with the media coverage data. This data set also has been used in Hillert, Jacobs, and Mueller (2014).

"Moat, Curme, Avakian, Kenett, Stanley, and Preis (2013) use weekly page views for the 30 DJA stocks. They aggregate firm-level page view counts for all 30 stocks each week to measure market-level investor attention and analyze a market timing strategy. 
and Thornock, 2015), and search activity for firms on Bloomberg terminals (introduced by BenRephael, Da, and Israelsen, 2017). We use all of these investor attention measures in our analysis. We download and filter GSV, EDGAR, and Bloomberg data as in Drake, Roulstone, and Thornock (2015), Ryans (2017), and Ben-Rephael, Da, and Israelsen (2017), respectively. WIKI - just like GSV, SEC EDGAR downloads, and search activity on Bloomberg - is a direct measure of attention, in contrast to indirect measures based on financial market variables like trading volume or volatility, which are used in Barber and Odean (2008). This is an important feature of WIKI, because it allows us to disentangle the impact of advertising on investor attention from the subsequent impact on financial markets.

Additionally, WIKI has several distinguishing features relative to GSV, EDGAR downloads, and Bloomberg search volume. Some of these features are particularly relevant for our study.

First, WIKI can be directly linked to firms. Internet searches for company names can be ambiguous (like "Apple"), even searches for ticker symbols (e.g., ISIS Pharmaceuticals used to have the ticker symbol "ISIS", which is also associated with a terror organization), or linked to consumer searches for a firm's products (e.g., the ticker "IBM" for IBM products and "BUD" for AnheuserBusch / Budweiser beer). In contrast, our WIKI data are based on an unambiguous identification of a firm's Wikipedia page. We have manually checked - for example, via headquarter location and ticker symbol - that each page we use refers to the correct respective firm in CRSP/Compustat. Furthermore, product pages (e.g., for the beverage "Coca-Cola") can usually be separated from firm pages (e.g., for the "The Coca-Cola Company") in cases in which one can plausibly assume that users might often search for the product rather than the company. This feature ensures that we are mainly measuring investor attention rather than consumer attention, which is particularly important when analyzing the effect of product market advertising on investor attention.

Second, WIKI is easy to compare across firms and time, because it directly represents the number of page views for a firm's Wikipedia page. In contrast, GSV is scaled by the maximum search volume within a firm and truncated below an unknown and time-varying threshold for each time window 
downloaded. Bloomberg search volume is only available as a categorical variable that captures unusually high levels of search volume.

Third, WIKI is likely to capture a different subset of relatively unsophisticated, retail investor attention, compared to Google search volume for tickers or downloads from the SEC EDGAR platform and Bloomberg searches. GSV for tickers can only be driven by investors who know a firm's ticker, that is, typically more sophisticated investors. Some attention stimuli (e.g., business newspaper or TV coverage in certain programs) regularly contain stock tickers. However, product market advertising usually does not include information on a firm's ticker, whereas it often includes the firm name, making it possible to look up the firm on Wikipedia. Similarly, unsophisticated retail investors are unlikely to know SEC EDGAR or to own Bloomberg terminals, making these institutional rather than retail investor attention proxies 10 Thus, WIKI is an investor attention proxy that is particularly well-suited to measure retail investor attention spikes for less sophisticated investors. These investors are arguably the ones most likely to cause the attention-induced buying pressure we aim to analyze here (see Barber and Odean, 2008).

We provide evidence that the resultant Wikipedia-based attention proxy is indeed closely connected to investor attention and not noisier than GSV for tickers: First, abnormal Wikipedia page views are 2 to 3 times more highly correlated with abnormal attention measured via the SEC's EDGAR platform or Bloomberg searches, which clearly measure investor attention without being confounded by consumer attention or searches that are not related to the firm (see Table C9 in the Internet Appendix). Second, earnings announcements - information events that should be associated with shocks in investor attention, but not consumer attention - are accompanied by an increase in attention measured by Wikipedia page views of $10.06 \%$ and a Google SVI increases of $9.83 \%$, indicating a similar quality of both measures.

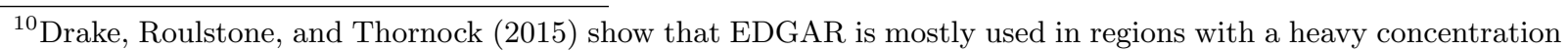
of institutional investors. Ben-Rephael, Da, and Israelsen (2017) discuss the usage of Bloomberg by institutional investors. 
To be clear, this is a collection of features and nuances of Wikipedia firm page views as an investor attention proxy. We do not claim general superiority of this measure. In certain contexts, investor attention proxies that focus on more sophisticated investors (who know tickers) or institutional investors (who use SEC's EDGAR platform or Bloomberg) are more suitable. We later make use of these nuances in our interpretation of differences between advertising effects based on the four investor attention measures.

Analogous to the normalization of GSV in Da, Engelberg, and Gao (2011) and Drake, Roulstone, and Thornock (2012), we do not use the number of page views directly, but normalize $\ln (\mathrm{WIKI})$ by subtracting the logarithm of the median of WIKI on the same weekday during the last 8 weeks. This normalization captures deviations from a firm- and weekday-specific normal level of investor attention. Abnormal WIKI for firm $i$ on day $t$ is thus defined as:

$$
A W I K I_{i, t}=\ln \left(\frac{W I K I_{i, t}}{\text { median }_{k \in\{7,14, \ldots, 56\}}\left(W I K I_{i, t-k}\right)}\right)
$$

Finally, in our analysis of advertising's impact on investor attention, we also use daily Google Search Volume (GSV) for tickers from 2004 to 2012, downloads of firm filings from SEC's EDGAR platform from 2003 to 2012, as well as search activity for firms in Bloomberg from March 2010 to 2012. Abnormal attention proxies for GSV and EDGAR are analogous to abnormal WIKI. Bloomberg provides a categorical variable that is already scaled relative to search volume during the last month, so that we do not normalize this variable ourselves, but rather use the abnormal institutional investor attention variable, AIAC, as suggested by Ben-Rephael, Da, and Israelsen (2017), which is a transformation of the categorical variable provided by Bloomberg to percentiles of a normal distribution. Summary statistics on the GSV, SEC EDGAR, and Bloomberg data are presented in Internet Appendix C, Tables C6, C7, and C8, respectively. 


\subsection{Kantar advertising data}

Our advertising data set comes from Kantar Media and is similar to the data used in Focke, Niessen-Ruenzi, and Ruenzi (2016). The data set starts in 1995 and ends in 2012. Kantar tracks advertising of public and private firms. They provide estimates for firms' advertising expenditures in USD via all important marketing channels: TV (intradaily time stamps when an advertisement was broadcast), newspapers and magazines (daily time stamps of publication date), as well as internet, radio and outdoors / billboards (monthly). For TV and newspapers, these estimates are based on "rate cards" that indicate advertising prices in USD depending, for example, on the length and timing of a TV spot or the size and day of the week of a newspaper advertisement. The cost for an ad is recorded on the date on which the ad appears, not the date on which the firm pays for the ad. In contrast to Compustat's advertising expenditures, which may include broader promotion-related expenses such as production costs for a TV ad or catalog costs, only costs directly associated with the attention-stimulus of advertising are included. Furthermore, firms have significant discretion in whether and how to disclose advertising expenditures in their 10-K filings. Liang (2018) finds that $30 \%$ of the firms that have to report advertising expenditures fail to do so, making Compustat data (which is collected from these filings) unreliable. Despite these differences, a Kantar based yearly measure of advertising expenditures is highly correlated with Compustat advertising at 0.79. More importantly for our study, high-frequency TV and newspaper data enables us to cleanly identify effects of advertising. Advertising at lower frequencies (like Compustat's yearly advertising variable from financial statements) can be driven by the same latent factors that drive investor attention and financial market activity (omitted variable bias), or it can be directly caused by them (reverse causality). In the short run-typically per quarter, but at least within a couple of weeks - advertising is predetermined, which enables us to avoid these identification issues. Therefore, we focus on the TV and newspaper channels, which are available at the daily level ${ }^{11}$

\footnotetext{
${ }^{11}$ We do not use data on magazine advertising, because magazines are published at lower frequencies (e.g., weekly or monthly) and are read throughout the time period between issues. In contrast, TV spots are immediately viewed,
} 
Kantar's newspaper advertising data covers a large proportion of newspaper advertising in the United States. Kantar tracks all advertisements in 155 U.S. newspapers, which include all four national as well as most important local newspapers. Total newspaper advertising expenditures tracked by Kantar from 1995 to 2012 are $\$ 328$ bn, whereas the Newspaper Association of America (NAA) estimates a total of $\$ 693 \mathrm{bn}$ for the entire newspaper industry from self-reported figures by newspaper publishing companies during this period. Thus, Kantar's tracking percentage for the whole period is nearly 50\%. However, Kantar only began coverage of local newspapers in 1999. From 1999 to 2012, Kantar's tracking percentage is even higher at about $60 \%$.

Kantar's TV advertising data covers 990 TV stations in 15 networks. In particular, it includes several news and business TV channels (CNN, CNBC, Fox News, MSNBC, and CNN Headline News). The total TV advertising expenditures tracked by Kantar from 1995 to 2012 is $\$ 1,299 \mathrm{bn}$. To the best of our knowledge, Kantar is the most comprehensive source of TV advertising data. ${ }^{12}$ According to Kantar, TV (newspaper) advertising accounts for 59.25\% (15.00\%) of total advertising from 1995 to 201213

For our analysis of advertising's impact on investor attention and financial markets in Sections 2 and 3 we do not use advertising dollars directly. Rather, in order to avoid omitted variable bias through correlations between persistent latent factors (e.g., visibility of a company's products to consumers) and our dependent variable, we first normalize advertising. Because of large differences in the nature of TV and newspaper advertising, we normalize these two channels' advertising expenditures differently.

TV advertising is dominated by continuous campaigns. The average length of subsequent strictly positive expenditures for daily TV advertising by a firm in our data set is 12 days. We run an

and daily newspapers are mostly read on the same day, which allows us to attribute advertising to specific days more precisely. We also do not analyze internet advertising (which was still less important than traditional advertising during our sample period) as we only have monthly data available for this channel.

${ }^{12}$ Nielsen, MagnaGlobal, and eMarketer, three other companies that offer advertising tracking data, provide significantly smaller ad expenditure samples.

${ }^{13}$ This finding is confirmed by eMarketer, another ad tracking agency with a focus on digital marketing. According to their estimates, the percentage for TV (newspaper) advertising in 2012 was 39.1\% (11.15\%). See http://www.emarketer.com/Article/US-Total-Media-Ad-Spend-Inches-Up-Pushed-by-Digital/1010154 
AR(7) model of current TV advertising on lagged TV advertising. Results (see Table C10 in Internet Appendix C) show that TV advertising expenditures from $t-1$ are most relevant when predicting TV advertising in $t$. There is also a slightly increased coefficient estimate for TV advertising expenditures from $t-7$, but the magnitude of the impact of TV advertising in $t-1$ is 4 to 5 times as large. Thus, to prevent highly correlated regressors across the different lags, we use simple logdifferences as our measure of abnormal TV advertising. We add a scalar of one to avoid excluding observations where advertising is 0 and divide by 1,000 for better readability of the results 14

$$
A d v_{T V, i, t}=\ln \left(\frac{1+T V A d v_{i, t}}{1+T V A d v_{i, t-1}}\right) \times \frac{1}{1,000}
$$

In contrast, newspaper advertising is dominated by campaigns in which a firm advertises on the same day of the week for several weeks, but not in between. We again run an AR(7) model of current newspaper advertising on lagged newspaper advertising. In this case, newspaper advertising expenditures of the same firm on the same day one week before $(t-7)$ is by far the most important predictor of current advertising (see Table C10 in Internet Appendix C). Its impact is nearly four times as large as the impact of advertising on the previous day. We therefore normalize by subtracting the logarithm of one plus the median of newspaper advertising on the same day of the week during the last 8 weeks. Abnormal newspaper advertising for firm $i$ on day $t$ is defined as:

$$
A d v_{N P, i, t}=\ln \left(\frac{1+N \text { ewspaper } A d v_{i, t}}{1+\text { median }_{k \in\{7,14, \ldots, 56\}}\left(\text { Newspaper } A d v_{i, t-k}\right)}\right) \times \frac{1}{1,000}
$$

This normalization is similar to the abnormal attention measure from Da, Engelberg, and Gao (2011). They argue that the median of GSV over the last 8 weeks captures the normal level of attention without being affected by recent jumps. We add a scalar of one to avoid losing observations where the median of advertising is 015

\footnotetext{
${ }^{14}$ To show that our results are not driven by this particular normalization, we report results from robustness checks based on alternative definitions of abnormal advertising in Tables C13 and C27 in the Internet Appendix.

${ }^{15}$ To show that our results are not driven by this particular normalization, we report results from robustness checks
} 
Summary statistics in Table 1, panel A, show that firms spend around $\$ 80,000(\$ 14,000)$ per day on TV (newspaper) advertising during the Wikipedia sample period from 2007 to 2012, confirming that TV is the dominant advertising channel. This is also the case for the TAQ sample period from 1995 to 2012 (panel B). Despite the higher dollar-magnitude of TV advertising, newspaper advertising might be more strongly related to financial markets if investors are particularly likely to read newspapers. Our separation into abnormal TV and newspaper advertising enables us to analyze such nuances of the effects of advertising on attention and financial markets. The separate analysis of TV and newspaper advertising effects additionally makes our results comparable to the contemporaneous literature on daily advertising and financial markets, which tends to focus on either newspaper advertising (e.g., Madsen and Niessner, 2019) or TV advertising (e.g., Liaukonyte and Zaldokas, 2019), but not both. Interestingly, the correlation between $A d v_{T V}$ and $A d v_{N P}$ on a daily level is close to zero, suggesting that abnormal TV and newspaper advertising are not strongly related at a high frequency, so that separately analyzing them will not lead to different results. We confirm the robustness of our results in joint analyses of TV and newspaper advertising.

To arrive at our final data set, we begin with all observations for which financial market data are available. We then merge these data with the control variables and information on advertising and WIKI (TAQ) in Section 2 (Section 3). For our analysis of investor attention, we include weekends, as investors can of course search for information on investment alternatives then, too. To mitigate the impact of outliers on our results, we require that a firm has positive advertising on at least 1 day within the previous 8 weeks. Summary statistics on the firm-day level as used in our regressions can be found in Internet Appendix C, in Tables C1, C2 C3 and C4 for the data used in our investor attention regressions (Section 2) and in Table C19 for the data used in our financial markets regressions (Section 3).

based on alternative definitions of abnormal advertising in Tables C13 and C29 in the Internet Appendix. 


\section{Advertising and Attention}

\subsection{Main results}

The ultimate goal of our empirical analysis is to test whether advertising affects important capital market variables like turnover, liquidity, and in particular stock market returns in the short term. One necessary condition for such an effect is that advertising creates attention among potential investors in the first place. Thus, we start our empirical analysis by investigating whether advertising has an impact on investor attention as measured by the number of views of a company's Wikipedia page, as well as Google search volume, downloads of firm filings from the EDGAR platform and Bloomberg searches.

Specifically, we regress daily abnormal attention for firm $i$ on day $t$, for example, for Wikipedia page views $A W I K I_{i, t}$, on abnormal advertising of firm $i$ on the same day, $A d v_{i, t}$, as well as 3 lags of abnormal advertising, controls lagged by 7 days, and the seventh lag of the dependent variable: ${ }^{16}$

$$
A W I K I_{i, t}=\alpha+\beta_{0} \cdot A d v_{i, t}+\sum_{j=1}^{3} \beta_{j} \cdot A d v_{i, t-j}+\gamma \cdot \text { Controls }_{t-7}+\delta \cdot A W I K I_{i, t-7}+\epsilon_{i, t}
$$

All regressions include firm fixed effects (to control for firm-specific increases in attention and advertising) and week fixed effects (to control for time trends in changes in attention and advertising). Furthermore, attention can vary substantially depending on the day of the week (with much lower levels of attention on weekends). Although our normalization of attention measures should already at least partially control for this, we follow Drake, Roulstone, and Thornock (2012) and also include day-of-week fixed effects to purge any remaining intraweekly seasonalities. We include the seventh lag of the dependent variable to account for a possible time-varying, firm-specific mean-

\footnotetext{
${ }^{16}$ Including the lagged dependent variable and firm fixed effects can lead to biased estimators in panel regressions (Nickell, 1981). However, this problem is only relevant in shorter panels. For example, our panel for Wikipedia page views encompasses 1,836 days and including the lagged dependent variable is thus unproblematic in our context. Excluding the lagged dependent variable also leads to very similar results.
} 
reversion level that is not captured by control variables or time fixed effects 17 Standard errors are clustered by firm. All firm-day observations with positive advertising spending on any day within the previous 8 weeks are included in the regression. Results using contemporaneous and lagged abnormal advertising on TV, $A d v_{T V}$, as independent variables, but not including any controls, are shown in Column 1 of panel A in Table 2, Analogous results for abnormal newspapers advertising, $A d v_{N P}$, are shown in Specification (1) of panel B. ${ }^{18}$

We find a highly significant positive impact of contemporaneous abnormal TV advertising on Wikipedia page views (see Specification (1) of panel A in Table 2). The effect is statistically significant at the $1 \%$ level. The effect of lagged advertising on days $t-1$ to $t-3$ is also positive and highly significant, with coefficient estimates being even higher than for contemporaneous abnormal advertising. A slightly lower coefficient of the contemporaneous impact of TV advertising is expected, as some advertising is aired only late on the day and viewers might often not have enough time to react on the same day by looking up the firm. The coefficient estimate is smaller for the impact of abnormal advertising on day $t-3$. If we include further lags, estimates become smaller and eventually insignificant (see Section 2.2). These findings show that the attention effect of advertising lasts only for a couple of days.

Results on abnormal advertising in newspapers, $A d v_{N P}$, show a very similar pattern as TV advertising results (see Specification (1) of panel B in Table 2). We again find a positive impact of abnormal advertising on page views and the effect is statistically significant at the $1 \%$ level for contemporary as well as all 3 lags of abnormal advertising. Now, the highest estimate is observed for

\footnotetext{
${ }^{17}$ We use the seventh (instead of the first) lag of the dependent variable and of the controls in order to avoid endogeneity with the lags of abnormal advertising: lagged advertising may directly affect these variables, and we want to capture direct and indirect effects of abnormal advertising on the contemporaneous dependent variable jointly.

${ }^{18}$ We include $A d v_{T V}$ and $A d v_{N P}$ in separate regressions to make results directly comparable to the contemporaneous literature on daily advertising, which analyzes either newspaper or TV advertising, but not both. This choice is innocuous as the correlation between daily TV and newspaper advertising is close to zero (e.g., the correlation between $A d v_{T V, i, t}$ and $A d v_{N P, i, t}$ is 0.0022 ), so that results in joint regressions with $A d v_{T V}$ and $A d v_{N P}$ in the same regression are very similar. Results for such joint regressions are included in the Internet Appendix in Tables C15. C16, C17, and C18. We thank Fabian Brunner for preparing the data on EDGAR downloads. This data set also has been used in Brunner and Ungeheuer (2019).
} 
contemporaneous advertising and decreases for lagged advertising. The fact that we now find the strongest impact of contemporaneous advertising also makes intuitive sense, as most newspapers appear in the morning and readers still have the full day to react.

The daily frequency of our data and the rich fixed effects that we include allow us to mitigate potential endogeneity concerns. As advertising is predetermined at least in the short term, it is very unlikely that advertising would be increased on a specific day because the firm observes that attention has increased. However, one endogeneity concern remains: it is possible that firms strategically advertise more around corporate news events that are known to them some time in advance and which they expect to trigger attention. Furthermore, Focke, Niessen-Ruenzi, and Ruenzi (2016) show that firms that advertise more are covered by newspapers more frequently. Thus, our results could be driven by increased news coverage that eventually causes attention (and is positively correlated with advertising) rather than by advertising directly.

To address these concerns, we add dummy variables indicating whether there was an earnings announcement for firm $i$ on day $t, E A_{i, t}$, and whether there was a newspaper article about firm $i$ on day $t, N e w s_{i, t}$. There might of course be other news events that create attention, that no newspaper writes about and that are not associated with earnings announcements. However, even if that is the case, our variables would capture the largest part of news-driven attention. Thus, if the effect we observe is really driven by strategic advertising around attention-inducing news events, we should at least see a very substantial reduction in our coefficient estimates after controlling for such news events. In Column 2 we repeat the same regression as in Column 1 but include the two event dummies. We also include further control variables to capture firm characteristics. These consist of previous turnover, previous return, and previous realized stock market volatility over the 4 week period ending 1 week prior to the day of the respective observation and firm size on day $t-7$ as additional controls.

As expected, we find a very strong positive impact of our two event dummies, EA and News, on $A W I K I$ (see Specification (2) of panels A and B in Table 2). Both coefficient estimates are 
positive and highly statistically significant at the $1 \%$ level, showing that $A W I K I$ is also a very good proxy for news-induced attention by investors. However, the impact of our abnormal advertising variables, $A d v_{T V}$ and $A d v_{N P}$, on attention is not affected at all by the inclusion of the news event dummies. They all remain highly significant and the economic magnitude of the coefficient estimates is virtually identical. As the two dummies added in these regressions should certainly capture the most important news events, not even observing a slight reduction in coefficient estimates for the impact of abnormal advertising strongly suggests that our results are not driven by high abnormal advertising around news events that create attention 19

The size of the coefficient estimate for the impact of the abnormal advertising variables also can be interpreted economically. As they are measured as natural logarithms and $A W I K I$ is also a natural logarithm, we can directly interpret the coefficient estimate as an elasticity. Based on Column 2, we find that increasing abnormal newspaper (TV) advertising by 1 standard deviation on a specific day leads to an increase in abnormal page views of $0.399 \%(0.184 \%)$ on the same day. To put these numbers into perspective, they can be compared to the impact of major news events like earnings announcements. The impact of $E A$ in Column 2 of panel $\mathrm{A}$ is 0.1006 , that is, page views on an earnings announcement day are $10.06 \%$ higher than on other days. Similarly, on a day with corporate news that a newspaper reports, page views are $8.61 \%$ higher. While the impact of $E A$ and $N E W S$ is clearly much larger than the impact of a 1-standard-deviation increase in daily advertising expenditures, one has to bear in mind that earnings announcements only happen 4 times per year and the average firm in our sample is covered on only 6.6 days per year in a newspaper article, while advertising can occur on a daily level and large percentage changes in advertising from one day to the next happen very frequently (see Table C1 in Internet Appendix C).

\footnotetext{
${ }^{19} \mathrm{~A}$ potential concern could be strategic advertising for day $t$ in anticipation of earnings announcements or other anticipated corporate news on that day. Although we already control for such events using the two event dummies, we also reproduce our main results excluding firm-day observations when there is an earnings announcement or national newspaper article in the time window from 3 days before to 3 days after the current period. Results are qualitatively the same and quantitatively similar for both TV and newspaper advertising (see Internet Appendix C, Table C14).
} 
While the coefficient estimates for the impact of lagged abnormal advertising are somewhat larger for TV than for newspapers but generally of comparable magnitude, note that the amount of advertising dollars spent on TV is a magnitude larger than the amount spent on newspaper ads; while the firms in our sample spend on average 14,108 USD per day for newspaper advertising, this number is nearly 6 times as large (79,846 USD) for TV advertising (see Table1, panel A). Thus, on a per-dollar basis, newspaper advertising has a stronger impact than TV advertising. For example, a 100,000 USD increase in advertising expenditures (which is a little bit more than the average daily aggregate advertising expenditures in TV and newspapers of the firms in our sample) leads to an increase in $A W I K I$ of $0.069 \%$ for TV advertising and $0.263 \%$ for newspaper advertising.

In Columns 3 and 4, we use abnormal Google Search Volume (SVI) as our proxy for investor attention. We still observe a highly significant effect of contemporaneous newspaper advertising and its first two lags. However, all coefficient estimates for the impact of TV advertising are insignificant. As discussed above, this finding could be driven by the nuances of ticker search volume in Google as an attention proxy: unsophisticated investors, who are stimulated by product market advertising, especially on TV, might not know a firm's ticker, so that they only influence Wikipedia page views. When we include the control variables in Column 4, the estimates of the impact of abnormal advertising are again virtually unchanged. In terms of economic significance, increasing abnormal newspaper advertising by 1 standard deviation increases SVI by $0.10 \%$. Meanwhile, we still observe a highly significant impact of $E A$ and News on Google search volume, as for Wikipedia page views.

Finally, in Columns 5 and 6 we look at alternative proxies for investor attention that have been used in the finance literature before, namely downloads from the SEC's EDGAR platform, and search activity for a firm on Bloomberg terminals. Both of these attention measures are likely to measure attention of more sophisticated, institutional investors. We replace our dependent variable by the analogue measure $A R P V_{i, t}$ based on SEC EDGAR downloads, and the abnormal Bloomberg search activity $A I A C_{i, t}$ from Ben-Rephael, Da, and Israelsen (2017) 20

\footnotetext{
${ }^{20}$ See the end of Section 1.2 and the variable description in the appendix for definitions and more details on our additional abnormal attention measures.
} 
Results in Column 5 are based on SEC EDGAR file downloads. Evidence clearly indicates an investor attention spike after newspaper advertising (see panel B), whereas TV advertising does not significantly affect EDGAR downloads (see panel A). Hence, even for this measure of sophisticated and likely institutional investor attention, we find a clear impact of newspaper advertising, but economic effects remain small: a 1-standard-deviation increase in abnormal newspaper advertising is followed by $0.17 \%$ higher EDGAR downloads on the same day, whereas earnings announcements are associated with $67.27 \%$ more download activity. This reduced effect, in particular for TV advertising, is consistent with the prior that sophisticated, institutional investors are less susceptible to product market advertising as an attention stimulus, particularly for channels that are less directly linked to fundamental news (TV instead of newspapers). Further supporting this interpretation, we find that news-TV advertising (e.g., on CNN or CNBC) significantly predicts EDGAR downloads whereas non-news-TV advertising does not, see discussion of robustness tests in Section 2.2.

In Column 6, we report results based on Bloomberg search activity. This data set is available starting only in March 2010, so that the overlap with our data set is less than 3 years. Despite the associated loss of power, we find statistically significant effects of both, newspaper and TV advertising, on Bloomberg searches. The reduced statistical significance (at the $5 \%$ or $10 \%$ instead of $1 \%$ level) relative to our main attention proxy is likely due to the much shorter data set and the coarse, categorical attention proxy provided by Bloomberg. Most of the time, the measure is in the lowest attention category, as this category includes all firms with attention below the 80th percentile relative to the last month throughout the current day. This coarse categorization also makes comparisons of economic significance difficult, in particular for the economically moderate effects we estimate, which are rarely enough to cause a change of category. However, clear evidence shows that even the attention of sophisticated institutional Bloomberg users is affected by TV and newspaper advertising to a certain extent.

We interpret the results in Columns 5 and 6 as effects on the attention of more sophisticated, likely institutional investors. Expensive Bloomberg terminals are mostly owned by professional 
investors. Less sophisticated retail investors are unlikely to know and use the EDGAR platform. Below, we provide further evidence that our results for EDGAR downloads hold for institutional investors.

\subsection{Advertising channels and further stability tests}

We first examine different advertising channels in more detail by distinguishing advertising in news and business channels and other TV channels and between advertising in local and national newspapers and specifically the Wall Street Journal (WSJ), which is presumably the most important national newspaper for investors ${ }^{21}$ This allows us to test the hypothesis that advertising in media outlets more targeted towards investors have a stronger impact on investor attention. Moreover, we can further explore differences in our proxies for investor attention. In Tables C11 and C12 we generally find a stronger impact of advertising in TV news channels (compared with other, mainly entertainment TV channels) and of advertising in national newspapers (particularly in the WSJ) than in local newspapers on a per-dollar basis. These findings show that advertising is an efficient tool to raise attention of media consumers particularly via those channels that are more likely to be consumed by potential investors. The differences between channels are especially pronounced for EDGAR downloads and Bloomberg search activity, indicating that these attention proxies are particularly driven by more sophisticated, institutional and less by retail investors. For EDGAR, we can investigate this hypothesis further by only considering downloads made by institutional investors (downloads from $13 \mathrm{f}$ institutions, identified via IP addresses). The Internet Appendix in Table C17. Column 6, shows the results. Even in this subset, we observe a significant impact of abnormal advertising in newspapers on attention, in this case for unambiguously identified institutional investors.

We also investigate the robustness of our findings by looking at longer lags of advertising, crosssectional sample splits, assessing the temporal stability of the relationships, using alternative advertising definitions, and using firm as well as day fixed effects and clustering.

\footnotetext{
${ }^{21}$ All analysis mentioned in this section are described in more detail in Section A.2 and all results are presented in the tables in Section $\mathrm{C}$ of the Internet Appendix.
} 
We begin with a regression similar to that in Table 2, Column 2, but with 2 weeks of advertising coefficients. We find that the effects of TV advertising are concentrated to days $t=0$ and $t=1$ and that the effects of newspaper advertising are concentrated in the first 7 to 9 days (see Figures B1 and B2 in Internet Appendix B). We therefore conclude that the effects of TV and newspaper advertising on investor attention are most pronounced in the first few days after an advertisement.

Next, we use two sample splits intended to capture the degree of visibility of the firm to viewers, readers, and potential investors. We split the sample into consumer and nonconsumer firms, as well as by firms' media coverage over the last 12 months. We find that the effect of advertising on investor attention always remains significantly positive. It is stronger for low-visibility firms, defined as nonconsumer and low media coverage firms (see Table C13 in Internet Appendix C). This makes sense if investors use Wikipedia to learn more about low-visibility firms which are hitherto less known to them.

In further stability tests in Table C13, we split our sample period into the earlier years 2007 to 2009 and the later years 2010 to 2012 . We then report results for variations of our abnormal advertising measure, where we use 0.1 or 0.5 instead of 1 as a scaling constant, and the mean instead of the median advertising from the previous 8 weeks in the denominator. We also replace our abnormal advertising measures by more coarse and endogeneity-prone advertising measures, namely the logarithm of 1 plus the dollar amount spent on advertising by the respective firm, $\log (1+A d \$)$, and a dummy variable that takes on the value one if the firm spent at least one USD on advertising on the respective day, $\mathrm{I}_{A d \$>0}$. Finally, we augment our baseline specification by including firm as well as day fixed effects and by clustering the standard errors at the firm and day level. We can confirm our earlier findings in each case.

Overall, our results from Section 2 provide evidence that advertising does create attention. Effects are statistically highly significant, while economic magnitudes are moderate. The stronger impact of advertising in national newspapers and the WSJ and in news-TV and business TV channels clearly suggests that Wikipedia page views are a good way to capture attention not only in general 
but also among potential investors in particular. The relatively strong EDGAR download and Bloomberg search volume results for news-TV and WSJ advertising suggest that these attention proxies capture more sophisticated, institutional investor attention.

Based on our findings hitherto, one might wonder whether advertising is a good instrument to analyze the causal short-term effects of investor attention on financial markets in an instrumental variable framework. The statistically significant effect of product market advertising on investor attention, along with advertising being predetermined in the short run seem to support this idea. However, the economically weak effects of product market advertising on our attention proxieseven if they are statistically highly significant-make us cautious. First, when the relation between instruments and endogenous variable is economically weak even small remaining endogeneity can lead to large inconsistencies (Bound, Jaeger, and Baker, 1995; Jiang, 2017). Second, we have good reasons to believe that the effects of investor attention on financial markets are nonlinear. As an illustration, large attention spikes might be necessary to cause the trading activity and buy-sell imbalances that lead market makers with consequently significant inventory risk to adjust prices. The economically small investor attention effect of product market advertising might just not be large enough to allow generalizations about effects of commonly much larger endogenous variation in investor attention.

\section{Advertising and Financial Markets}

\subsection{Main results}

Having established the impact of advertising on investor attention, we now analyze the impact of advertising on turnover, liquidity, and returns. Turnover is measured as the log of daily trading volume, scaled by shares outstanding. Our main liquidity measure is the log of effective spread, based on TAQ-data, as in Grullon, Kanatas, and Weston (2004) ${ }^{22}$ Returns are measured in excess

\footnotetext{
${ }^{22}$ Our results are stable based on a variety of alternative liquidity proxies (see Section 3.3). For more detailed variable descriptions, see Section 1 and the variable description in the appendix.
} 
of that day's market return. We regress each dependent variable for firm $i$ on day $t, D V_{i, t}$, on daily contemporaneous abnormal advertising, $A d v_{i, t}$, as well as lags of abnormal advertising, controls and the seventh lag of the dependent variable 23

$$
\begin{gathered}
D V_{i, t}=\alpha+\beta_{0} \cdot A d v_{i, t}+\sum_{j=1}^{3} \beta_{j} \cdot A d v_{i, t-j}+ \\
\gamma \cdot E A_{i, t}+\delta \cdot N e w s_{i, t}+\zeta \cdot \text { Controls }_{t-7}+\eta \cdot D V_{i, t-7}+\epsilon_{i, t} .
\end{gathered}
$$

All regressions include firm fixed effects (e.g., to control for permanently higher turnover of firms with persistently increasing advertising expenditures) and week fixed effects (to control for marketwide time trends, e.g., business-cycle effects). Furthermore, we include day-of-week fixed effects to control for intraweekly seasonalities because, for example, turnover and liquidity tend to be lower on Mondays (Gallant, Rossi, and Tauchen, 1992) and dummy variables indicating whether there was any earnings announcement or news report on the firm on day $t$. We include the seventh lag of the dependent variable to account for a possible time-varying, firm-specific mean-reversion level that is not captured by control variables or time fixed effects. Control variables and the dependent variable are lagged by 7 days instead of 1 day in order to avoid endogeneity with the lags of abnormal advertising: lagged advertising may directly affect these variables, and we want to capture direct and indirect effects of abnormal advertising on the contemporaneous dependent variable jointly. Again, reverse causality or omitted variable bias should not be a problem for our analysis, because advertising is programmed more than a week before it is broadcast. Standard errors are clustered by firm to control for time-series dependence ${ }^{24}$, and we require firms to have advertised at least once during the last 8 weeks to be included in the regression.

Panel A for Table 3 shows the results for the impact of abnormal TV advertising, $A d v_{T V}$. In Column 1, we find a positive impact of contemporaneous TV advertising on turnover. The effect

\footnotetext{
${ }^{23}$ Our panel regressions use a minimum of 3,777 trading days and including the lagged dependent variable is thus unproblematic in this context (see Footnote 16 ).

${ }^{24}$ Dependence across days is particularly high for turnover and liquidity, so that panel regressions with firmclustered standard errors seem more appropriate than Fama-MacBeth regressions. We also report results from Fama-MacBeth regressions for returns — which exhibit less time-series dependence - in Internet Appendix A.3.
} 
is statistically significant at the $5 \%$ level. The impact of lagged TV advertising is also significant and larger than that of contemporaneous advertising; that is, an TV advertising campaign starting yesterday has a larger effect on today's turnover than on yesterday's turnover, probably because a lot of investors do not trade in response to an ad until after trading closes, in particular for ads that air late. However, the effect seems to be short-lived, because a campaign starting 2 or 3 days ago has a smaller effect on today's turnover than campaigns starting today or yesterday. Furthermore, the effect of TV advertising on turnover is quite small in economic terms: a 1-standard-deviation increase in $A d v_{T V}$ increases turnover by $0.10 \%$ contemporaneously and by $0.12 \%$ on the following day 25

The coefficient estimates for the impact of TV advertising on illiquidity in Column 2 is negative, but only statistically significant at the $10 \%$ level at lags 2 and 3 . This result is consistent with an increase in noise trading due to product market advertising. Increased noise trading lowers adverse selection costs, so that liquidity improves ${ }^{26}$ Grullon, Kanatas, and Weston (2004) find that firms' advertising expenditures on the yearly level are contemporaneously positively correlated with liquidity, which is consistent with our results. However, compared to their results, the economic significance we measure is small. A 1-standard-deviation increase in $A d v_{T V}$ leads to a reduction in the effective spread of $0.11 \% 27$ As an illustration, the estimated effect on a stock with an effective spread of 100 basis points (bps) is an order of magnitude less than 1 bp. Hence, consistent with a very small increase in noise trading activity, liquidity improves only to a very small extent. ${ }^{28}$ These

\footnotetext{
${ }^{25}$ Consider the following as a comparison: national newspaper coverage about a firm goes along with $15.95 \%$ more turnover on the same day and there is around $49.72 \%$ more trading on earnings announcement days. In comparing these numbers it should be noted that advertising varies on a daily level, whereas national newspaper coverage (on average less than 14 days per year during the sample period used in this regression, standard deviation of 0.22 ; see Table C19 in Internet Appendix C) and earnings announcements (4 times per year, standard deviation of 0.12) happen infrequently. However, even the respective 1 -standard-deviation effects of $0.22 \cdot 16 \%=3.51 \%$ (newspaper coverage) and $0.12 \cdot 50 \%=5.97 \%$ (earnings announcements) are by magnitudes larger than the impact of abnormal advertising.

${ }^{26}$ However, more in line with the model of Barber and Odean (2008), liquidity could also decrease because of increased inventory holding costs after attention-induced order imbalances.

${ }^{27}$ Consider the following as a comparison: Grullon, Kanatas, and Weston (2004) estimate an elasticity of relative spreads with respect to Compustat's advertising of $-4.7 \%$ for the years 1993 to 1998 .

${ }^{28}$ We find very similar results for relative spread, price impact, the intraday Amihud measure and absolute returns. These results are reported in Appendix C, Table C31. along with summary statistics in Table C20.
} 
results do not necessarily contradict the strong positive effect of yearly advertising on liquidity in Grullon, Kanatas, and Weston (2004), because we can identify the short-term effects of advertising. It can well be the case that product market advertising has long-term effects on noise trading due to familiarity effects, which are not linked to the attention shocks that directly follow ads.

We now analyze the impact of TV advertising on stock prices. One might expect an increase in prices due to attention-induced buying after increased advertising: Lou (2014) consistently finds a strong contemporary positive correlation between advertising and returns based on yearly advertising data, and interprets this finding as evidence of a short-term price impact of advertising. A short-term price impact of advertising should become even more visible at higher frequencies, because the price impact and reversal periods can be clearly separated. However, we find virtually no impact of TV advertising on returns in Column 3 of panel A in Table 3 . The only significant coefficient is for the second lag of $A d v_{T V}$ and implies a return effect of $0.003 \%$ for a 1-standarddeviation change in TV advertising, which is less than one-third of a basis point.

Panel B of Table 3 shows results for newspaper advertising, $A d v_{N P}$. As for TV advertising, we find a statistically significant, positive impact of contemporaneous newspaper advertising on turnover in Column 1. The impact is significant at the $1 \%$ level. Again, there are lagged reactions to advertising: increased advertising yesterday and the day before have a stronger impact on today's turnover than contemporaneous newspaper advertising. The effect, which becomes insignificant at higher lags, is short lived. A 1-standard-deviation increase in abnormal newspaper advertising today leads to $0.10 \%$ more contemporary turnover and $0.15 \%$ more turnover 2 days from today. As for TV advertising, this economic effect is one to two orders of magnitude below the estimates for earnings announcements and national newspaper coverage. Thus, we find a statistically significant but economically small effect of newspaper advertising on turnover.

The effect of newspaper advertising on illiquidity is negative for days $t-1$ to $t-3$ (see Column 2 in panel B of Table 3), but only statistically significant at the second lag. The economic significance remains small: we find a change in effective spread of $-0.12 \%$, which is an order of magnitude below 
$1 \mathrm{bp}$ for a stock with an effective spread of $100 \mathrm{bps} 29$ As for TV advertising — and again consistent with a small increase in noise trading activity_liquidity improves slightly. Most importantly, the impact of newspaper advertising on returns (see Column 3) is always insignificant and coefficient estimates are even smaller than for TV advertising, confirming our earlier results.

To convince the reader that our results can really be interpreted as "evidence of absence" of a meaningful effect, we apply a method suggested by Harvey (2017). To apply the method in our setting, we need to define a "meaningful effect," that is, an effect of advertising on returns that we consider economically significant. We let the results in Lou (2014) guide our choice. Lou (2014) finds a contemporaneous $12.85 \%$ annual price increase for stocks ranked by year-to-year advertising changes into high- vs. low-decile portfolios, and argues that this price increase measures the effect of advertising on "short-term stock returns" via investor attention. Considering the generally very short-lived, impact of attention shocks found in the literature (see Introduction) and the shortterm attention impact we measure (see Figures B1 and B2 in Internet Appendix B), one would expect this large annual impact to realize in large parts during the days directly after advertising shocks. One might expect an even larger than $12.85 \%$ annualized return effect on the days after advertising shocks, because the annual analysis should be biased down by reversal effects within the same year. Thus, dividing the yearly effect of $12.85 \%$ by 260 trading days to arrive at 5 bp per day underestimates what is actually implied by results in Lou (2014). To be conservative, we still use a return of 5 bp per day as an "economically meaningful" daily return effect in our tests.

The Harvey (2017) method relies on an assumption about a prior belief about the analyzed relationship. We find that our results for the effect of advertising on returns are robust to using different prior beliefs about this relationship. First, we can reject an economically still small $5 \mathrm{bp}$ return effect of a 2-standard-deviation increase of advertising, even if our prior belief was that the alternative hypothesis ("zero effect") is a long-shot, that is, if we assume a 1:99 prior belief against finding an effect different from 5 bp (see table III, SD-MBF panel of Harvey (2017),

\footnotetext{
${ }^{29}$ This is a representative spread during our sample period: the median of the effective spread's pooled stock-day observations for our sample period is $106 \mathrm{bp}$.
} 
statistical significance adjusted for 1:99 long-shot odds). $t$-statistics for the null hypothesis of a 5 bp return-effect for a 2-standard-deviation increase in advertising are at -18.13 (-18.78) for contemporaneous TV (newspaper) advertising 30 These large t-statistics reflect the high power we achieve by regressing 18 years of daily returns on a return-predictor that varies relatively strongly and idiosyncratically over time (unlike, e.g., market-beta, which is highly persistent, so that higherfrequency tests do not help to measure return effects more precisely). Our narrow confidence intervals imply that we also do not face a problem of "false misses" (Harvey and Yan, 2018). In other words, our nonresult is not due to noisy estimates, but rather due to precise estimates close to zero, which makes it meaningful in particular because of claims in the literature about economically large short-term effects of advertising (Lou, 2014). Second, with $t$-statistics below 1, we cannot reject the null hypothesis that the effect is zero, even if our prior belief was that the alternative hypothesis ("positive effect") is just as likely as the null hypothesis (see table III, SD-MBF panel in Harvey (2017), statistical significance adjusted for 1:1 even odds).

A potential endogeneity problem might be strategic scheduling of advertising for day $t$ in anticipation of effects of earnings announcements or, more generally, corporate news on that day. Although we include dummies to capture the impact of such events on our dependent variables, to further alleviate such concerns, we reproduce our main results excluding firm-day observations when there is an earnings announcement or national newspaper article in the time window from 3 trading days before to 3 trading days after the current period. Results are qualitatively the same and quantitatively similar for both TV and newspaper advertising (see Internet Appendix C, Table C21).

\footnotetext{
${ }^{30}$ These are $t$-statistics for the test of the null hypothesis that a 2 -standard-deviation change in abnormal advertising $+2 * \sigma(A d v)$ - see summary statistics in Table C19 of Internet Appendix C for $\sigma(A d v)$-increases returns by 5 bp contemporaneously, that is, t-statistic $=\frac{2 * \sigma(A d v) * \beta_{A d v}-0.05 \%}{2 * \sigma(A d v) * S \operatorname{Std} \operatorname{Err}\left(\beta_{A d v}\right)} \cdot t$-statistics do not markedly decrease in magnitude in our robustness checks (see Internet Appendix C.
} 


\subsection{Advertising channels and advertising sensitivity}

Although we find that the impact of general product market advertising on financial markets is economically small or even completely absent (in the case of returns), respectively, it may still be that advertising that is more visible to investors has a larger impact. To test this idea, we distinguish news and business channels from all other TV channels and consider the Wall Street Journal as well as other national and local newspapers separately. The separate analysis of local and national newspapers also can be motivated by the marketing literature: Sridhar, Germann, Kang, and Grewal (2016) find that regional advertising has stronger effect on firm value than national advertising. A detailed description of our analysis can be found in Section A.3, and results are presented in Tables $\mathrm{C} 22$ and $\mathrm{C} 23$ in the Internet Appendix.

Our results suggest a slightly stronger impact of news and business media advertising on illiquidity (for TV) and turnover (for newspapers), but overall effect sizes remain small. More importantly, there is no economically significant difference between the impact of advertising on returns across the different advertising channels. Our results show that even for news and business media advertising, which is more likely to reach investors, the effect on returns is still clearly economically meaningless.

In a final attempt to document an impact of advertising on stock market returns, we now turn to cross-sectional differences between firms. It may well be that the effects of advertising differ by firm. For example, some firms might be relatively unknown to investors ex ante or might have marketing plans that make their advertising more effective in attracting investor attention for them. We study some of these determinants, analyzing cross-sectional sample splits based on observable firm characteristics in our following robustness tests (Section 3.3). However, we now first take a more general approach by estimating the advertising sensitivity of each firm's investor attention directly and then splitting the sample based on this sensitivity. This approach offers the advantage that we do not require the identification of observable characteristics that determine the sensitivity of the firm's investor attention to advertising. First, to estimate firms' advertising sensitivity, we 
regress our investor attention proxy, $A W I K I$, on contemporaneous advertising as well as its first 3 lags, the full set of control variables, the seventh lag of the dependent variable, and day-of-week fixed effects. These regressions are computed for TV and newspaper advertising separately to allow advertising sensitivity to differ by medium. To reduce the noise in our results, we require at least 50 observations per firm. This procedure results in valid estimates for $998(1,098)$ firms in the TV (newspaper) regressions. The lower number of estimates for TV is because some firms do not advertise on TV. We define the advertising sensitivity for each firm as the sum of the four advertising coefficients. We then split the sample at the median of the estimated sensitivity and run the same regressions of excess returns on abnormal advertising as in Section 3.1. We expect the effect of advertising to be stronger in the high advertising sensitivity group.

In Column 1 of Table 4, we present results from this sample split for TV advertising. Panel A shows that there is no significant impact of advertising on returns in the low sensitivity group. For the high sensitivity group in panel B, we only find the coefficient on the second lag to be positive and significant at the $10 \%$ level. However, even in this case the coefficient is very small in magnitude, implying an impact of a 1-standard-deviation change in advertising on returns of $0.005 \%$. Thus, we conclude that the TV advertising effect appears to be somewhat stronger for high sensitivity firms, but still economically meaningless. Next, we conduct the same sample split for newspaper advertising. Column 2 of Table 4 presents the results. Panel A shows that we find virtually no effect of advertising on returns in the low sensitivity group. In the high sensitivity sample (panel B), we find that all coefficients are still small and statistically insignificant ${ }^{31}$ We report analogous results for turnover and liquidity in the Internet Appendix (see Tables C24 and C25 for TV and newspaper advertising, respectively). We find that advertising effects for turnover and liquidity are stronger for high sensitivity firms, but even in the high sensitivity group, where we would expect the strongest effect, the impact of advertising on turnover and liquidity remains economically small. In sum, even the strongest effects that we estimate for the high advertising

\footnotetext{
${ }^{31}$ This result also holds if we look at a subsample of top-quintile or top-decile (instead of above-median) advertising sensitivity firms.
} 
sensitivity subgroup of firms are still economically small and there is no economically meaningful impact of advertising on short-term returns.

\subsection{Stability tests and further results}

We now present results from a battery of stability tests and additional analyses to support our main findings. 32

We begin with various alternative sample splits intended to capture the degree of visibility of the firm's advertising to viewers, readers and investors. We split the sample according to firm size, analyst coverage, firms' media coverage over the last 12 months, consumer versus nonconsumer firms, as well as high- and low-concentration industries. The latter test can be motivated from the marketing literature, where Edeling and Fischer (2014) find advertising to be more effective in low concentration industries. Our main results are stable in all subsamples, both for TV and newspaper advertising. We find mostly positive effects of advertising on turnover and liquidity, but we can reject economically significant effects of advertising on returns. Even within the subsamples where we might expect a stronger effect of advertising on returns there is none. Importantly, our results are also unchanged for small firms, for which advertising-induced trading might be expected to affect prices. We also conduct a test similar to that from Section 3.2, but define advertising sensitivity of investor attention only based on firms' advertising in the Wall Street Journal (rather than to overall advertising). Again, results are confirmed.

To further analyze whether advertising has an impact at least in special cases, we analyze the impact of dummies that take on the value one if abnormal advertising is in the highest decile or percentile, respectively, or if a firm advertises for the first time (within our sample), and zero otherwise. We also split the sample according to whether the firm exhibits a high or low level of advertising during the prior 8 weeks. We never find any significantly positive impact on returns.

\footnotetext{
${ }^{32}$ All results and a more detailed description of the analysis and the findings are contained in the Internet Appendix Section A.3 and in Tables C26 to C34
} 
It is possible that return effects are extremely short-lived and advertising-induced inflated prices are arbitraged away very quickly by institutional investors even within a day. To examine this possibility, we analyze the impact of abnormal advertising on overnight (close-to-open) and intraday (open-to-close) returns separately. This approach follows the idea of Lou, Polk, and Skouras (2018), who argue that overnight returns are driven by higher retail investor activity, while institutional investors tend to correct mispricing with their trading during the day. Thus, in our context, it could be the case that advertising mainly influences retail investors and pushes up prices overnight, but they come back to fundamental levels quickly during the next daily trading period, such that any effect of advertising gets washed out in our main analysis based on daily (i.e., close-to-close) returns. However, we neither find an impact of advertising on overnight nor on intraday returns.

In a last set of tests for time periods that might exhibit a stronger advertising-return relation, we specifically focus on Mondays, as well as the month of December (advertising peaks on weekends and before the holidays) and NBER recession months. Analyzing recessions specifically can be motivated by the marketing literature, where Deleersnyder, Dekimpe, Steenkamp, and Leeflang (2009) find that advertising is more effective during these months. While some results are somewhat stronger during these periods, even including statistically significant return effects, economic magnitudes of point estimates and upper bounds of confidence intervals clearly remain economically weak. We also report results for days including an earnings announcement or national newspaper coverage in the 3 previous or next days, that is, the days we exclude in Table C21 because of potential endogeneity concerns. Again, our findings do not change.

In additional robustness tests, we include TV and newspaper advertising jointly, split our panel into two 9-year periods (1995-2003 and 2004-2012), and split by trading venue (NYSE/AMEX vs. NASDAQ). We report results for variations of our abnormal advertising measure, where we use 0.1 or 0.5 instead of 1.0 as a scaling constant, and the mean instead of the median advertising from the previous 8 weeks in the denominator. We also use the logarithm of raw advertising dollars and positive advertising dummies as alternative measures for advertising. We use alternative regression 
specifications with day and firm fixed effects and double clustered standard-errors, as well as a specification where dependent variables are normalized by the dependent variable on the same day of the previous week to control for firm-specific intraweekly seasonality. We then repeat our analysis on the weekly frequency. Additionally, for our analysis of the impact on returns, we also use daily and monthly Fama-MacBeth (1973) regressions (instead of daily panel regressions with fixed effects and clustered standard errors) to be consistent with the bulk of the empirical asset pricing literature. Furthermore, we employ alternative measures to proxy for liquidity (relative spread, price impact, and an intraday version of Amihud's illiquidity ratio). In each case, our main findings remain stable.

In further tests, we analyze determinants of liquidity and show that the effect of advertising on the volume of buys is similar to the effect of advertising on the volume of sells, so that the overall relation between advertising and order imbalances (the driver of price impact in the Barber and Odean (2008) model) is insignificant. This finding is consistent with the absence of any strong short-term impact of advertising on liquidity and returns. We also show that volatility does not significantly increase with advertising.

In summary, the stability checks show that our main results are robust: product market advertising does not have an economically significant (albeit sometimes statistically significant) positive impact on short-term turnover and liquidity. The effect on short-term returns is usually virtually zero and confidence bands are tight.

\subsection{Reconciliation of high- and low-frequency results}

The results based on daily data show that there is no evidence of a causal impact of advertising on stock returns. This finding is in contrast to the positive contemporaneous correlation observed using yearly data of advertising and stock returns (Chemmanur and Yan, 2019; Lou, 2014) 33 We hypothesize that reverse causality is an explanation for this discrepancy: increased stock returns

\footnotetext{
${ }^{33}$ When we aggregate our data to the yearly level, we can confirm the patterns found in these papers in our sample, too.
} 
driven by good news for the firm today are likely associated with higher future demand for the firm's products. This improved economic situation could lead to increased advertising in the future. On the one hand, it might make sense to advertise more during the next months to capture the increased demand. On the other hand, the increased cash flows due to the firm's good economic situation might lead to inefficiently high advertising spending as a result of agency problems Joseph and Richardson, 2002). Or vice versa, bad news for a firm might affect the stock price negatively right away and decrease advertising in the futures. Survey evidence uncovers that managers react to bad news by first cutting discretionary expenditures, like R\&D or advertising expenditures, to avoid missing short-term earnings benchmarks (Graham, Harvey, and Rajgopal, 2005; Deleersnyder, Dekimpe, Steenkamp, and Leeflang, 2009). As an illustration, the business media regularly report about advertising spending being cut when firms do badly, for example, during the recent great recession "Advertising budgets tend to be one of the first things cut when times get difficult..." (Economist, July 30, 2009) and after the dot.com bubble "Ad spending is hugely volatile, [...] It is one of the first costs that companies cut, and one of the last they restore." (Economist, October $30,2001)$.

Using yearly data, it is not possible to distinguish such reverse effects from a causal effect of advertising on stock returns, because both lead to a contemporaneous positive correlation. In contrast, we can explicitly test the reverse causality hypothesis. To do so, we estimate a panel vector autoregressive (PVAR) model with monthly stock returns and advertising as the components. We use 12 lags, that is, we include the entire past year in the model. In contrast to the daily level, TV and newspaper advertising are highly correlated at the monthly level $(\rho=0.55)$. Thus, we can for simplicity use the sum of the two variables in the following analysis. We further include firm and month fixed effects to take into account cross-sectional differences between firms as well as time trends. Because we are interested in how advertising and returns change in response to one another, and returns are price changes, we use log differences in advertising. Figure 1 illustrates the impulse response functions from our estimation of this model. The panel in the upper-right 
corner presents the effect of a 1-standard-deviation impulse in stock returns on cumulative changes in advertising. The estimates imply that 12 months after the impulse, advertising is about $4.57 \%$ higher, which is significant at the $1 \%$ level and economically meaningful. In contrast, 12 months after an impulse to advertising, stock returns are only an insignificant $0.03 \%$ higher (panel in the lower-left corner) 34

Table 5 displays the coefficient estimates as well as the results from formal Granger causality tests. Columns 1 and 2 confirm that past returns have a significantly positive impact on future advertising $(p$-value $=.00)$, while past advertising does not have a significant positive impact on future returns $(p$-value $=.33)$. Our results are robust to splitting advertising expenditures into TV and newspaper advertising (see Table C35 in the Internet Appendix), and using 6 or 24 lags for the PVAR components or omitting the time fixed effects. We therefore conclude that reverse causality from stock returns to advertising likely explains the positive correlation at the yearly level documented in the literature.

To illustrate the reverse causality channel with a concrete economic example, we next analyze how returns and advertising growth respond to news in the form of earnings surprises relative to consensus analyst forecasts. It is well known that positive earnings surprises are associated with contemporaneously high returns, but it is unclear whether they are then followed by increased advertising growth. This would be in line with the economic channels from returns to advertising we discuss above. Specifically, positive news should predict increased advertising, either efficient advertising to capture increased demand or excessive advertising as a response to high cash flows combined with agency problems (Joseph and Richardson, 2002). Similarly, after bad news mangers are more willing to cut advertising to avoid missing earnings benchmarks again (Graham, Harvey, and Rajgopal, 2005, Cohen, Mashruwala, and Zach, 2010). To test these channels, we regress advertising growth from the year before the earnings announcement to the year after the

\footnotetext{
${ }^{34}$ The impulse response functions are orthogonalized in the order advertising - stock returns, which means that the entire contemporary monthly correlation between advertising and stock returns is ascribed to a causal impact of advertising on returns. If anything, this biases against finding reverse causality from returns to advertising. Accordingly, our results become even more pronounced if we reverse the orthogonalization order.
} 
announcement - excluding the earnings announcement month - on the earnings surprise rank of this firm as compared to all other firms with earnings announcement in the same months. Ranks are uniformly distributed between zero and one. Table 6 reports the results. In Specification (1) we find a highly significant positive influence of earnings surprises on future advertising. The effect is also economically meaningful: going from the 10th to the 90th percentile of earnings surprises is associated with 19.62 percentage points more advertising growth in the following year. These effects remain significant when we control for advertising growth and returns during the last 3 years in Specification (2). Importantly, last year's return also positively predicts subsequent advertising growth, in line with our results from panel VARs. Specifically an increase in last years returns by 10 percentage points is associated with 3.73 percentage points more advertising growth in the following year. Controlling for this effect we still find that positive earnings surprises are followed by significantly higher advertising growth. Specifications (3) and (4) confirm, as expected, that contemporaneous returns in the earnings announcement month are positively affected by earnings surprises. Hence, results are in line with positive news today driving up stock prices contemporaneously and leading to increased advertising growth in the future (consistent with, e.g., Joseph and Richardson, 2002, Graham, Harvey, and Rajgopal, 2005; Cohen, Mashruwala, and Zach, 2010).

\section{Conclusion}

Using advertising to create investor attention and artificially inflate stock prices seems tempting for corporations and their managers. However, our results cast serious doubt on the view that short-term stock prices can be easily manipulated by advertising.

The findings in the first part of our study do show that advertising leads to increased investor attention. Our empirical setting using high-frequency advertising data and firm fixed effects alleviates endogeneity concerns. The effect is highly statistically significant, but economic magnitudes are moderate. This finding supports the idea that advertising can create investor attention and shows that advertising is a suitable proxy for (typically non-news-driven) investor attention. 
However, the effect of advertising on investor attention is only a necessary condition for advertising to affect capital market outcomes. Our further evidence shows that advertising has some impact on turnover, but the evidence for an impact on liquidity is mixed. In both cases, the economic significance of the effects is rather small.

Most importantly, we find no significant impact of abnormal advertising on short-term stock returns. Furthermore, our results are also obtained after controlling for news events like earnings announcements or newspaper articles. We concentrate on finding any return effect by specifically looking at cases in which the chances of finding any potential impact on returns should be best. In particular, we focus on TV channels and newspapers that are most likely to be used by potential investors and specifically analyze firms for which investor attention reacts most to advertising. Even in these cases, advertising does not affect short-term returns whatsoever. However, it should be mentioned that this finding does not preclude potentially slow-moving investor recognition effects or effects on sales (e.g., because of building brand recognition). Instead, the results in this study do clearly reject the idea that advertising leads to short-term attention effects that are strong enough to significantly influence daily stock prices.

In an attempt to reconcile our findings with the earlier literature, we document strong evidence of reverse causality from stock returns to advertising within a year. Additionally, negative earnings surprises are followed by immediate negative returns and later decreases in advertising, consistent with, for example, managers reacting to bad news by first cutting discretionary expenditures to avoid missing earnings benchmarks (Graham, Harvey, and Rajgopal, 2005: Deleersnyder, Dekimpe, Steenkamp, and Leeflang, 2009). Hence, we think that results in previous studies that find a positive relation between yearly advertising and contemporaneous returns are likely to be driven by the low data frequency and can not be interpreted as showing a causal link between advertising and short-term returns.

However, such short-term effects are necessary for firms to be able to use advertising to artificially inflate a firm's stock price prior to corporate events or insider sales. Given the ineffectiveness of 
such attempts documented in this paper, it is an open question why — as indicated by the results in Chemmanur and Yan (2009), Lou (2014), Hillert, Kunzmann, and Ruenzi (2017), and Fich, Starks, and Tran (2016) - managers still seem to do so. One potential reason could be that managers wrongly believe that advertising affects asset prices, but other potential explanations like omitted variables are also driving both - corporate actions and advertising - on the lower frequency: for example, the absence of free cash flows makes it less likely that a firm is taking over other firms (see Harford, 1999) and at the same time probably leads to cuts in advertising budgets. More generally, it could be that firms that follow an expansionary strategy have more financing needs (and thus issue more securities), broaden their product offerings (and thus advertise more), and at the same time try to grow via expansions (and thus engage more actively on the M\&A market). Similarly, omitted variables might drive both advertisements and stock market returns at the same time: the marketing literature (e.g., Mian, Sharma, and Gul, 2018) shows that advertising spending increases in periods of high investor sentiment, while the finance literature shows that high sentiment leads to high stock market returns (e.g., Neal and Wheatley, 1998, Shiller, 2000) and eventual reversal. 


\section{References}

Abrigo, M. R. M., and I. Love, 2016, "Estimation of Panel Vector Autoregression in Stata," Stata Journal, 16(3), 778-804.

Anderson, A. M., and E. A. Dyl, 2007, "Trading Volume: NASDAQ and the NYSE," Financial Analyst Journal, 63(3), 79-86.

Aravindakshan, A., and P. Naik, 2010, "How does awareness evolve when advertising stops? The role of memory," Marketing Letters, 22(3), 315-326.

Atkins, A. B., and E. A. Dyl, 1997, "Market Structure and Reported Trading Volume: NASDAQ Versus the NYSE," Journal of Financial Research, 20(3), 291-304.

Barber, B. M., and T. Odean, 2008, "All That Glitters: The Effect of Attention and News on the Buying Behavior of Individual and Institutional Investors," Review of Financial Studies, 21(2), $785-818$.

Ben-Rephael, A., Z. Da, and R. D. Israelsen, 2017, "It Depends on Where You Search: Institutional Investor Attention and Underreaction to News," Review of Financial Studies, 30(9), 3009-3047.

Blake, T., and D. Coey, 2014, "Why Marketplace Experimentation is Harder Than It Seems: The Role of Test-Control Interference," Proceedings of the Fifteenth ACM Conference on Economics and Computation, EC '14, 567-582.

Bound, J., D. A. Jaeger, and R. M. Baker, 1995, "Problems with Instrumental Variables Estimation When the Correlation Between the Instruments and the Endogeneous Explanatory Variable is Weak," Journal of the American Statistical Association, 90(430), 443-450.

Branikas, I., 2019, "Advertising Exposure and Portfolio Choice: Estimates Based on Sports Sponsorships," Working Paper. 
Brennan, M. J., and C. Tamarowski, 2000, "Investor Relations, Liquidity, and Stock Prices," Journal of Applied Corporate Finance, 12(4), 26-37.

Brown, S., and S. A. Hillegeist, 2007, "How disclosure quality affects the level of information asymmetry," Review of Accounting Studies, 12(2-3), 443-477.

Brunner, F., and M. Ungeheuer, 2019, "The Power of Prices: Information, Trade, and Salient Returns," Working paper.

Bushee, B. J., and G. S. Miller, 2012, "Investor Relations, Firm Visibility, and Investor Following," The Accounting Review, 87(3), 867-897.

Chemmanur, T., and A. Yan, 2009, "Product market advertising and new equity issues," Journal of Financial Economics, 92(1), 40-65.

— , 2019, "Advertising, Attention, and Stock Returns," Quarterly Journal of Finance, 3(3), $1-51$.

Cohen, D., R. Mashruwala, and T. Zach, 2010, "The use of advertising activities to meet earnings benchmarks: evidence from monthly data," Review of Accounting Studies, 15(4), 808-832.

Cohen, L., and U. G. Gurun, 2018, "Buying the Verdict," NBER Working Paper.

Da, Z., J. E. Engelberg, and P. Gao, 2011, "In search of attention," Journal of Finance, 66(5), $1461-1499$.

Deleersnyder, B., M. G. Dekimpe, J.-B. E. Steenkamp, and P. S. Leeflang, 2009, "The Role of National Culture in Advertising's Sensitivity to Business Cycles: An Investigation Across Continents," Journal of Marketing Research, 46(5), 623-636.

Drake, M. S., D. T. Roulstone, and J. R. Thornock, 2012, "Investor Information Demand: Evidence from Google Searches Around Earnings Announcements," Journal of Accounting Research, 50(4), $1001-1040$. 
— , 2015, "The Determinants and Consequences of Information Acquisition via EDGAR," Contemporary Accounting Research, 32(3), 1128-1161.

Edeling, A., and M. Fischer, 2014, "Marketing's Impact on Firm Value: Generalizations from a Meta-Analysis," Journal of Marketing Research, 53(4), 515-534.

Fama, E. F., and J. D. MacBeth, 1973, "Risk, Return, and Equilibrium: Empirical Tests," The Journal of Political Economy, 81(3), 607-636.

Fang, L., and J. Peress, 2009, "Media Coverage and the Cross-section of Stock Returns," Journal of Finance, 64(5), 2023-2052.

Fehle, F., S. Tsyplakov, and V. Zdorovtsov, 2005, "Can Companies Influence Investor Behaviour through Advertising? Super Bowl Commercials and Stock Returns," European Financial Management, 11(5), 625-647.

Fich, E., L. Starks, and A. Tran, 2016, "Advertising, Attention, and Acquisition Returns," Working Paper.

Focke, F., A. Niessen-Ruenzi, and S. Ruenzi, 2016, "A Friendly Turn: Advertising Bias in the News Media," Working Paper.

Frieder, L., and A. Subrahmanyam, 2005, "Brand perceptions and the market for common stock," Journal of Financial and Quantitative Analysis, 40(1), 57-85.

Gallant, A. R., P. E. Rossi, and G. Tauchen, 1992, "Stock Prices and Volume," Review of Financial Studies, 5, 199-242.

Gervais, S., R. Kaniel, and D. H. Mingelgrin, 2001, "The high-volume return premium," Journal of Finance, 56(3), 877-919.

Graham, J. R., C. R. Harvey, and S. Rajgopal, 2005, "The economic implications of corporate financial reporting," Journal of Accounting and Economics, 40(1-3), 3-73. 
Grullon, G., G. Kanatas, and J. P. Weston, 2004, "Advertising, Breadth of Ownership, and Liquidity," Review of Financial Studies, 17(2), 439-461.

Harford, J., 1999, "Corporate Cash Reserves and Acquisitions," Journal of Finance, 54(6), 19691997.

Harvey, C., and L. Yan, 2018, "False (and Missed) Discoveries in Financial Economics," Working Paper.

Harvey, C. R., 2017, "Presidential Address: The Scientific Outlook in Financial Economics," The Journal of Finance, 72(4), 1399-1440.

Hillert, A., H. Jacobs, and S. Mueller, 2014, "Media Makes Momentum," Review of Financial Studies, 27(12), 3467-3501.

Hillert, A., A. Kunzmann, and S. Ruenzi, 2017, "M \& A(dvertising)," Working Paper.

Hillert, A., E. Maug, and S. Obernberger, 2016, "Stock Repurchases and Liquidity," Journal of Financial Economics, 119(1), 186-209.

Hillert, A., and M. Ungeheuer, 2018, "The Value of Visibility," Working Paper.

Holtz-Eakin, D., W. Newey, and H. Rosen, 1988, "Estimating vector autoregressions with panel data," Econometrica, 56(6), 1371-1395.

Jiang, W., 2017, "Have Instrumental Variables Brought Us Closer to the Truth," Review of Corporate Finance Studies, 6(2), 127-140.

Joo, M., K. C. Wilbur, B. Cowgill, and Y. Zhu, 2013, "Television advertising and online search," Management Science, 60(1), 56-73.

Joseph, K., and V. J. Richardson, 2002, "Free Cash Flow, Agency Costs, and the Affordability Method of Advertising Budgeting," Journal of Marketing, 66, 94-107. 
Karolyi, G. A., and R. C. Liao, 2017, "The Economic Consequences of Investor Relations: A Global Perspective," Working paper.

Keloharju, M., S. Knüpfer, and J. Linnainmaa, 2012, "Do Investors Buy What They Know? Product Market Choices and Investment Decisions," Review of Financial Studies, 25(10), 2921-2958.

Kirk, M. P., and J. D. Vincent, 2014, "Professional Investor Relations within the Firm," The Accounting Review, 89(4), 1421-1452.

Lebedeva, O., 2012, "Measuring and Monitoring Time-Varying Information Asymmetry," Working Paper.

Lee, C., and M. Ready, 1991, "Inferring Trade Direction from Intraday Data," The Journal of Finance, 46(2), 733-746.

Lewis, R. A., and J. M. Rao, 2015, "The Unfavorable Economics of Measuring the Returns to Advertising," Quarterly Journal of Economics, 130(4), 1941-1973.

Lewis, R. A., and D. H. Reiley, 2014a, "Advertising effectively influences older users: How field experiments can improve measurement and targeting," Review of Industrial Organization, 44(2), $147-159$.

—, $2014 \mathrm{~b}$, "Online ads and offline sales: measuring the effect of retail advertising via a controlled experiment on Yahoo!," Quantitative Marketing and Economics, 12(3), 235-266.

Liang, C., 2018, “Advertising Rivalry and Discretionary Disclosure," Working Paper.

Liaukonyte, J., and A. Zaldokas, 2019, "Background Noise? TV Advertising Affects Real Time Investor Behavior," Working paper.

Lintner, J., 1969, "The aggregation of investor's diverse judgments and preferences in purely competitive security markets," Journal of Financial and Quantitative Analysis, 4(4), 347-400. 
Lou, D., 2014, "Attracting Investor Attention through Advertising," Review of Financial Studies, $27(6), 1797-1829$.

Lou, D., C. Polk, and S. Skouras, 2018, "A tug of war: overnight versus intraday expected returns," Journal of Financial Economics, forthcoming.

Love, I., and L. Zicchino, 2006, "Financial development and dynamic investment behavior: Evidence from panel VAR," The Quarterly Review of Economics and Finance, 46(2), 190-210.

Madsen, J., and M. Niessner, 2019, "Is Investor Attention for Sale? The Role of Advertising in Financial Markets," Journal of Accounting Research, forthcoming.

Mayer, E. J., 2019, “Advertising, Investor Attention, and Stock Prices: Evidence from a Natural Experiment," Working Paper.

Mayshar, J., 1983, "On divergence of opinion and imperfections in capital markets," The American Economic Review, 73(1), 114-128.

Mian, M. G., P. Sharma, and F. A. Gul, 2018, "Investor sentiment and advertising expenditure," International Journal of Research in Marketing, 35(4), 611-627.

Miller, E., 1977, "Risk, uncertainty, and divergence of opinion," The Journal of Finance, 32(4), $1151-1168$.

Moat, H. S., C. Curme, A. Avakian, D. Y. Kenett, H. E. Stanley, and T. Preis, 2013, "Quantifying Wikipedia Usage Patterns Before Stock Market Moves," Scientific Reports, 3(1801), 1-5.

Neal, R., and S. M. Wheatley, 1998, "Do measures of investor sentiment predict returns?," Journal of Financial and Quantitative Analysis, 33(4), 523-547.

Newey, W. K., and K. D. West, 1987, "A Simple, Positive Semi-definite, Heteroskedasticity and Autocorrelation Consistent Covariance Matrix," Econometrica, 55(3), 703-708. 
Nickell, S., 1981, "Biases in dynamic models with fixed effects," Econometrica, 49(6), 1417-1426.

Reuter, J., and E. Zitzewitz, 2006, "Do Ads Influence Editors? Advertising and Bias in the Financial Media," Quarterly Journal of Economics, 121, 197-227.

Ryans, J., 2017, "Using the EDGAR log file data set," Working Paper.

Seasholes, M., and G. Wu, 2007, "Predictable Behavior, Profits, and Attention," Journal of Empirical Finance, 14(5), 590-610.

Sethuraman, R., G. J. Tellis, and R. A. Briesch, 2011, "How well does advertising work? Generalizations from meta-analysis of brand advertising elasticities," Journal of Marketing Research, 48(3), 457-471.

Shiller, R. J., 2000, Irrational Exuberance. Princeton University Press, Princeton.

Solomon, D. H., 2012, "Selective publicity and stock prices," The Journal of Finance, 67(2), 599638.

Sridhar, S., F. Germann, C. Kang, and R. Grewal, 2016, "Relating online, regional, and national advertising to firm value," Journal of Marketing, 80(4), 39-55.

Ungeheuer, M., 2018, "Stock Returns and the Cross-Section of Investor Attention," Working Paper. 


\section{Appendix: Variable Description}

The following table briefly defines the main variables used in our empirical analysis. Abbreviations for the data sources are:

(i) Kantar: Kantar Stradegy database

(ii) WIKI: Wikipedia page count database

(iii) GSV: Google search volume data

(iv) SEC: SEC EDGAR log files

(v) BB: Bloomberg

(vi) TAQ: Trade and Quote database

(vii) CRSP: CRSP's Stocks Database

(viii) CS: Compustat

(ix) IBES: I/B/E/S analyst forecasts

(x) OP: The homepages of authors of the respective original papers

EST indicates that the variable is estimated or computed based on original variables from the respective data sources. 
Table A1: Variable definitions

A. Advertising variables

\begin{tabular}{ll}
\hline Variable name & Description \\
\hline TV Ad $\$$ & Daily dollar amount spent on TV advertising in 990 US TV stations, esti- \\
& mated using rate cards that give information on prices for different parts of \\
& the day and/or programs. Available from 1995 to 2012 . For the analysis of \\
& investor attention (Section 2.1), we measure TV advertising for day $t$ from \\
& midnight to midnight Eastern Daylight Time, contemporaneous with our \\
& attention measure. For the analysis of financial markets (Section [3.1), we \\
& measure TV advertising for day $t$ from 4 pm (market close) on day $t-1$ \\
& to 4 pm on day $t$, so that evening TV ads on day $t$ are counted towards \\
& advertising on day $t+1$
\end{tabular}

News TV Ad \$ Daily dollar amount spent on TV advertising in U.S. News TV stations. These stations are CNN, CNBC, Fox News, MSNBC, and CNN headline news. Available from 1995 to 2012. For the analysis of investor attention (Section 2.1, we measure TV advertising for day $t$ from midnight to midnight Eastern Daylight Time, contemporaneous with our attention measure. For the analysis of financial markets (Section 3.1), we measure TV advertising for day $t$ from $4 \mathrm{pm}$ (market close) on day $t-1$ to $4 \mathrm{pm}$ on day $t$, so that evening TV ads on day $t$ are counted toward advertising on day $t+1$

Newspaper Ad $\$ \quad$ Daily dollar amount spent on newspaper advertising in 155 U.S. newspapers, estimated using rate cards that give information on prices based on size, product categories, and days of week or sections. Available from 1995 to 2012

National newspa-

Daily dollar amount spent on newspaper advertising in four national US

Source

Kantar

per Ad $\$$

newspapers: the Wall Street Journal, New York Times, USA Today, and

Washington Post. Includes the Wall Street Journal and the USA Today from 1995 to 2012 and the Wall Street Journal, USA Today, New York Times, and Washington Post from 1999 to 2012

Local newspaper Daily dollar amount spent on newspaper advertising in 151 local U.S. news$\operatorname{Ad} \$$ papers. Available from 1999 to 2012

WSJ Ad $\$$

Daily dollar amount spent on newspaper advertising in the Wall Street Journal. Available from 1995 to 2012

Kantar

Kantar

Kantar

Kantar

Kantar 


\section{A. Advertising variables (continued)}

\begin{tabular}{|c|c|}
\hline Variable name & Description \\
\hline $\begin{array}{l}3 \text { National news- } \\
\text { paper Ad } \$\end{array}$ & $\begin{array}{l}\text { Daily dollar amount spent on newspaper advertising in the three other na- } \\
\text { tional newspapers (New York Times, USA Today, and Washington Post). } \\
\text { Includes the USA Today from } 1995 \text { to } 2012 \text { and the New York Times, USA } \\
\text { Today and Washington Post from } 1999 \text { to } 2012\end{array}$ \\
\hline $\mathrm{Adv}_{\mathrm{TV}, \mathrm{t}}$ & $\begin{array}{l}\text { Abnormal TV advertising on day } t \text {, defined as log-advertising-dollars on day } \\
t \text { relative to log-advertising-dollars } t-1 \text {, with a scalar of } 1 \text { added. Divided } \\
\text { by } 1,000 \text { for better readability of regression output }\end{array}$ \\
\hline AdvTVNWs,t & $\begin{array}{l}\text { Abnormal news TV advertising on day } t \text {, defined as log-advertising-dollars } \\
\text { on day } t \text { relative to log-advertising-dollars } t-1 \text {, with a scalar of } 1 \text { added. } \\
\text { Divided by } 1,000 \text { for better readability of regression output }\end{array}$ \\
\hline AdvTrnonws,t & $\begin{array}{l}\text { Abnormal TV advertising in non-news channels on day } t \text {, defined as log- } \\
\text { advertising-dollars on day } t \text { relative to log-advertising-dollars } t-1 \text {, with a } \\
\text { scalar of } 1 \text { added. Divided by } 1,000 \text { for better readability of regression } \\
\text { output }\end{array}$ \\
\hline $\operatorname{Adv}_{N P, t}$ & $\begin{array}{l}\text { Abnormal newspaper advertising on day } t \text {, defined as log-advertising-dollars } \\
\text { on day } t \text { relative to log-advertising-dollars' median of the same weekday } \\
\text { during the last } 8 \text { weeks, with a scalar of } 1 \text { added. Divided by } 1,000 \text { for } \\
\text { better readability of regression output }\end{array}$ \\
\hline $\mathrm{Adv}_{\mathrm{NPNAT}, \mathrm{t}}$ & $\begin{array}{l}\text { Abnormal national newspaper advertising on day } t \text {, defined as log- } \\
\text { advertising-dollars on day } t \text { relative to log-advertising-dollars' median of the } \\
\text { same weekday during the last } 8 \text { weeks, with a scalar of } 1 \text { added. Divided by } \\
1,000 \text { for better readability of regression output }\end{array}$ \\
\hline $\mathrm{Adv}_{\mathrm{NPLOC}, \mathrm{t}}$ & $\begin{array}{l}\text { Abnormal local newspaper advertising on day } t \text {, defined as log-advertising- } \\
\text { dollars on day } t \text { relative to log-advertising-dollars' median of the same week- } \\
\text { day during the last } 8 \text { weeks, with a scalar of } 1 \text { added. Divided by } 1,000 \text { for } \\
\text { better readability of regression output }\end{array}$ \\
\hline $\mathrm{Adv}_{\mathrm{NPWSJ}, \mathrm{t}}$ & $\begin{array}{l}\text { Abnormal newspaper advertising in the Wall Street Journal on day } t \text {, defined } \\
\text { as log-advertising-dollars on day } t \text { relative to log-advertising-dollars' median } \\
\text { of the same weekday during the last } 8 \text { weeks, with a scalar of } 1 \text { added. } \\
\text { Divided by } 1,000 \text { for better readability of regression output }\end{array}$ \\
\hline $\mathrm{Adv}_{\mathrm{NP} 3 \mathrm{NAT}, \mathrm{t}}$ & $\begin{array}{l}\text { Abnormal newspaper advertising in the three other national newspapers } \\
\text { (New York Times, USA Today and Washington Post) on day } t \text {, defined as } \\
\text { log-advertising-dollars on day } t \text { relative to log-advertising-dollars' median of } \\
\text { the same weekday during the last } 8 \text { weeks, with a scalar of } 1 \text { added. Divided } \\
\text { by } 1,000 \text { for better readability of regression output }\end{array}$ \\
\hline
\end{tabular}

Source

Kantar

Kantar, EST

Kantar, EST

Kantar, EST

Kantar, EST

Kantar, EST

Kantar, EST

Kantar, EST

Kantar, EST 


\section{B. Investor attention variables}

\begin{tabular}{|c|c|c|}
\hline Variable name & Description & Source \\
\hline $\mathrm{Wiki}_{\mathrm{t}}$ & $\begin{array}{l}\text { Number of times the Wikipedia page of a company was visited on day } t \\
\text { (Eastern Daylight Time) }\end{array}$ & WIKI \\
\hline $\mathrm{AWIKI}_{\mathrm{t}}$ & $\begin{array}{l}\text { Abnormal Wikipedia page views on day } t \text {, defined as log-WIKI on day } t \\
\text { relative to the log of the median of the same weekday during the last } 8 \\
\text { weeks. The definition follows that of Da, Engelberg, and Gao (2011), with } \\
\text { the only difference being that we consider daily instead of weekly data }\end{array}$ & WIKI, EST \\
\hline $\mathrm{SVI}_{\mathrm{t}}$ & $\begin{array}{l}\text { Google search volume index of the company ticker on day } t \text { relative to the } \\
\text { search volume at the first time company ticker searches were recorded in } \\
\text { Google Trends. To construct the data set, we downloaded overlapping } 90- \\
\text { day windows series for each ticker and joined the windows by rescaling the } \\
\text { subsequent window s.t. the overlapping observation is equal. We exclude } \\
\text { tickers that appear in the dictionary }\end{array}$ & GSV, OP \\
\hline $\mathrm{ASVI}_{\mathrm{t}}$ & $\begin{array}{l}\text { Abnormal Google search volume index on day } t \text {, defined as log-SVI on day } \\
t \text { relative to the log of the median of the same weekday during the last } 8 \\
\text { weeks. The definition follows Da, Engelberg, and Gao }(2011) \text {, with the only } \\
\text { difference being that we consider daily instead of weekly data, as in Drake, } \\
\text { Roulstone, and Thornock (2015) }\end{array}$ & GSV, EST \\
\hline $\mathrm{RPV}_{\mathrm{t}}$ & $\begin{array}{l}\text { Number of firm's filings downloaded from the SEC's EDGAR website on day } \\
t \text { (Eastern Daylight Time), excluding algorithmic downloads as in Ryans } \\
(2017)\end{array}$ & SEC, EST \\
\hline $\mathrm{ARPV}_{\mathrm{t}}$ & $\begin{array}{l}\text { Abnormal EDGAR downloads on day } t \text {, defined as log-RPV on day } t \text { relative } \\
\text { to the log of the median of the same weekday during the last } 8 \text { weeks. The } \\
\text { definition follows Da, Engelberg, and Gao }(2011) \text {, with the only difference } \\
\text { being that we consider daily instead of weekly data }\end{array}$ & SEC, EST \\
\hline $\mathrm{ARPV}_{\mathrm{t}}$ (Inst.) & $\begin{array}{l}\text { As } \text { ARPV }_{t} \text {, but excluding EDGAR downloads from IP addresses that we } \\
\text { cannot unambiguously link to } 13 \mathrm{f} \text { institutions via the MaxMind IP address } \\
\text { database }\end{array}$ & SEC, EST \\
\hline $\mathrm{AIAC}_{\mathrm{t}}$ & $\begin{array}{l}\text { Abnormal Bloomberg search activity on day } t \text {, defined as the variable AIAC } \\
\text { in Ben-Rephael, Da, and Israelsen (2017) }\end{array}$ & $\mathrm{BB}, \mathrm{EST}$ \\
\hline
\end{tabular}




\section{Financial market variables}

\begin{tabular}{|c|c|c|}
\hline Variable name & Description & Source \\
\hline Turnover $_{\mathrm{t}}$ & Turnover is daily trading volume over shares outstanding on day $t$ & CRSP, EST \\
\hline EffSpr $_{t}$ & $\begin{array}{l}\text { EffSpr is the effective spread, defined as daily transaction-weighted aver- } \\
\text { age of transaction prices relative to prevailing quotes on day } t \text {. Specifically, } \\
\text { EffSpr } r_{t}=2\left|P_{j}-Q_{j}\right| / Q_{j} \text { for each transaction, with } P_{j} \text { being the transac- } \\
\text { tion price, } Q_{j} \text { the quote midpoint price, which is the average of the prevail- } \\
\text { ing bid and ask quotes }\left(Q_{j}=\frac{A_{j}+B_{j}}{2}\right) \text { and } j \text { is the trade. EffSpr } r_{t} \text { is then } \\
\text { averaged over the day for each stock }\end{array}$ & $\begin{array}{l}\text { TAQ, EST, } \\
\text { OP }\end{array}$ \\
\hline $\operatorname{RelSpr}_{\mathrm{t}}$ & $\begin{array}{l}\text { RelSpr is the relative spread, defined as daily transaction-weighted average } \\
\text { of bid and ask quotes relative to prevailing quotes on day } t \text {. Specifically, } \\
\operatorname{RelSpr} r_{t}=\left(A_{j}-B_{j}\right) / Q_{j} \text { for each transaction, with } A_{j} \text { being the prevailing } \\
\text { ask quote, } B_{j} \text { the prevailing bid quote, } Q_{j} \text { the quote midpoint price, which } \\
\text { is the average of the prevailing bid and ask quotes }\left(Q_{j}=\frac{A_{j}+B_{j}}{2}\right) \text {, and } j \text { is } \\
\text { the trade. RelSpr } r_{t} \text { is then averaged over the day for each stock }\end{array}$ & $\begin{array}{l}\text { TAQ, EST, } \\
\text { OP }\end{array}$ \\
\hline PrcImpt & $\begin{array}{l}\text { PrcImp is the price impact, defined as transaction-weighted average of } 5 \text { - } \\
\text { minute impacts on quote midpoints on day } t \text {. Specifically, PrcImpt }= \\
2\left|Q_{j+5}-Q_{j}\right| / Q_{j} \text { for each transaction, where } Q_{j+5} \text { represents the quote } \\
\text { midpoint price of the stock after } 5 \text { minutes ( } 300 \text { seconds), } Q_{j} \text { is defined as } \\
\text { above, and } j \text { is the trade. PrcImp } p_{t} \text { is then averaged over the day for each } \\
\text { stock }\end{array}$ & $\begin{array}{l}\text { TAQ, EST, } \\
\text { OP }\end{array}$ \\
\hline IntAmi & $\begin{array}{l}\text { IntAmi is the intraday Amihud measure, defined as the daily transaction- } \\
\text { weighted average of the } 5 \text {-minute price impact scaled by trade size on day } \\
t \text {. Specifically, Int Ami } i_{t}=2\left|Q_{j+5}-Q_{j}\right| /\left(Q_{j} * w_{j}\right) \text { for each transaction, } \\
\text { with } Q_{t+5} \text { being the quote midpoint price of the stock after } 5 \text { minutes ( } 300 \\
\text { seconds), } Q_{j} \text { is defined as above, } w_{j} \text { the transaction volume in shares, and } \\
j \text { is the trade. IntAmit is then averaged over the day for each stock }\end{array}$ & $\begin{array}{l}\text { TAQ, EST, } \\
\text { OP }\end{array}$ \\
\hline $\operatorname{Abs}\left(\operatorname{Return}_{\mathrm{t}}\right)$ & The absolute value of the raw return of a stock on day $t$ & CRSP, EST \\
\hline Buys $_{t}$ & $\begin{array}{l}\text { The total traded value (in } \$ \text { ) of buy transactions over a day, where buy } \\
\text { transactions are defined using the algorithm in Lee and Ready (1991) }\end{array}$ & $\begin{array}{l}\text { TAQ, EST, } \\
\text { OP }\end{array}$ \\
\hline Sells $_{\mathrm{t}}$ & $\begin{array}{l}\text { The total traded value (in } \$ \text { ) of sell transactions over a day, where sell } \\
\text { transactions are defined using the algorithm in Lee and Ready (1991) }\end{array}$ & $\begin{array}{l}\text { TAQ, EST, } \\
\text { OP }\end{array}$ \\
\hline $\mathrm{OIB}_{\mathrm{t}}$ & $\begin{array}{l}\text { The signed difference between value of buys and sells on } 1 \text { day relative to } \\
\text { the total transaction value. Specifically, OIB } B_{t}=\left(\text { Buys }_{t}-\text { Sells }_{t}\right) /\left(\text { Buys }_{t}+\right. \\
\left.\text { Sell } s_{t}\right) \text {, where Buys and Sells are defined as above }\end{array}$ & $\begin{array}{l}\text { TAQ, EST, } \\
\text { OP }\end{array}$ \\
\hline
\end{tabular}


C. Financial market variables (continued)

\begin{tabular}{|c|c|c|}
\hline Variable name & Description & Source \\
\hline $\operatorname{Return}_{t}^{\text {excess }}$ & $\begin{array}{l}\text { Raw excess return of a stock over the market return taken from Kenneth } \\
\text { French's Web page on day } t\end{array}$ & CRSP, EST \\
\hline Turnover $_{\mathrm{t}-7, \mathrm{t}-36}$ & $\begin{array}{l}\text { Turnover }{ }_{t-7, t-36} \text { is the trading volume over the } 4 \text { weeks up to } t-7 \text {, divided by } \\
\text { average shares outstanding }\end{array}$ & CRSP, EST \\
\hline $\operatorname{Return}_{t-7, t-36}$ & Return $_{\mathrm{t}-7, \mathrm{t}-36}$ is the holding period return over the 4 weeks up to $\mathrm{t}-7$ & CRSP, EST \\
\hline ReaVolat $-7, t-36$ & $\begin{array}{l}\text { ReaVolat-7,t-36 is realized volatility, defined as average absolute return dur- } \\
\text { ing the } 4 \text { weeks up to t- } 7\end{array}$ & CRSP, EST \\
\hline MarketCap $_{t}$ & MarketCap is the firm's market capitalization in million USD on day $t$ & CRSP, EST \\
\hline \multicolumn{3}{|c|}{ D. Other variables } \\
\hline Variable name & Description & Source \\
\hline News $_{t}$ & $\begin{array}{l}\text { Dummy variable equal to one if the firm is covered in at least one of four } \\
\text { national newspapers (Wall Street Journal, New York Times, USA Today, } \\
\text { Washington Post) on day t. The data comes from Hillert, Jacobs, and } \\
\text { Mueller (2014) }\end{array}$ & OP \\
\hline $\begin{array}{l}\text { Earnings } \\
\text { Announcement } t_{t}\end{array}$ & $\begin{array}{l}\text { Dummy variable equal to one if the firm has an earnings announcement on } \\
\text { day } t\end{array}$ & IBES \\
\hline $\mathrm{SUE}_{\mathrm{t}}$ & $\begin{array}{l}\text { Earnings Surprise based on analyst consensus forecast and month } t \text { 's earn- } \\
\text { ings announcement }\end{array}$ & IBES \\
\hline
\end{tabular}


Figure 1: Impulse response functions: Stock returns and total advertising

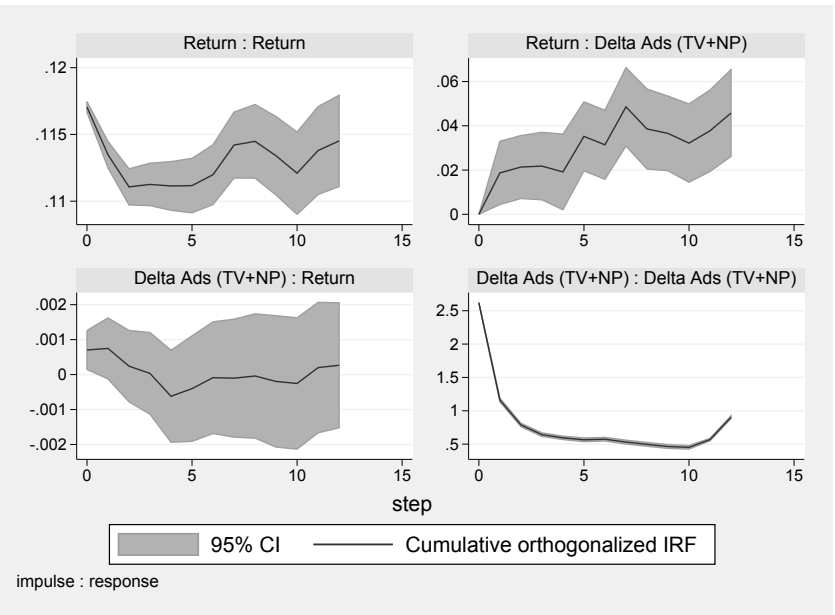

This figure displays impulse response functions from a panel VAR model with monthly stock returns and the sum of TV and newspaper advertising as the components. For the underlying estimates, see Table 5, Columns 1 and 2. The impulse response functions are cumulative and orthogonalized in the order advertising - stock returns. They give the effect on the response variable for a 1-standard-deviation shock to the impulse variable. Ninety-five percent confidence intervals based on Monte Carlo simulations with 200 draws are represented by the gray area around the point estimates. Delta Ads (TV+NP) are monthly log differences in the sum of TV and newspaper advertising dollars. 
Table 1: Summary statistics: Advertising and investor attention

\begin{tabular}{|c|c|c|c|c|c|c|}
\hline & Mean & Median & $\mathrm{SD}$ & $10 \%$ ile & $90 \%$ ile & $\mathrm{N}$ \\
\hline \multicolumn{7}{|c|}{ A. Public firms with Wikipedia articles and Kantar ads } \\
\hline Market cap (million $\$$ ) & $7,491.42$ & $1,557.88$ & $22,746.40$ & 142.65 & $16,746.38$ & 1,730 \\
\hline Firm age & 22.81 & 16.86 & 19.56 & 3.61 & 48.62 & 1,730 \\
\hline Return on assets (\%) & 11.84 & 11.95 & 13.13 & 1.14 & 24.84 & 1,684 \\
\hline Advertising-to-sales (\%) & 3.49 & 1.11 & 11.88 & 0.01 & 6.91 & 1,290 \\
\hline Turnovert-7,t-36 (\%) & 289.67 & 252.13 & 192.25 & 89.20 & 535.07 & 1,729 \\
\hline ReaVolat-7,t-36 $(\%)$ & 49.84 & 45.96 & 21.63 & 27.10 & 76.46 & 1,729 \\
\hline Return $_{\mathrm{t}-7, \mathrm{t}-36}(\%)$ & 0.40 & 0.72 & 3.00 & -1.92 & 2.91 & 1,729 \\
\hline News $(\%)$ & 1.81 & 0.09 & 6.89 & 0.00 & 3.60 & 1,730 \\
\hline Wiki page count & 326.80 & 45.98 & $2,450.97$ & 1.74 & 554.59 & 1,730 \\
\hline TV adv (daily $\$$ ) & $79,846.13$ & 56.97 & $405,088.47$ & 0.00 & $94,766.99$ & 1,730 \\
\hline News TV adv (daily $\$$ ) & $6,022.32$ & 0.00 & $38,056.40$ & 0.00 & $3,354.48$ & 1,730 \\
\hline Newspaper adv (daily $\$$ ) & $14,108.04$ & 81.81 & $106,206.52$ & 0.29 & $11,473.72$ & 1,730 \\
\hline WSJ adv (daily \$) & 780.10 & 0.00 & $6,698.93$ & 0.00 & 507.23 & 1,730 \\
\hline 3 national newspaper adv (daily $\$$ ) & $1,671.44$ & 0.00 & $10,910.57$ & 0.00 & $1,180.74$ & 1,730 \\
\hline Local newspaper adv (daily $\$)$ & $11,656.50$ & 43.12 & $93,485.94$ & 0.00 & $6,977.19$ & 1,730 \\
\hline \multicolumn{7}{|c|}{ B. Public firms with TAQ data and Kantar ads } \\
\hline Market cap (million $\$$ ) & $3,547.02$ & 597.81 & $13,697.86$ & 62.66 & $6,542.52$ & 4,139 \\
\hline Firm age & 15.08 & 8.58 & 16.01 & 2.60 & 34.69 & 4,139 \\
\hline Return on assets (\%) & 9.16 & 12.20 & 18.44 & -7.47 & 25.71 & 3,998 \\
\hline Advertising-to-sales (\%) & 5.65 & 1.53 & 15.80 & 0.06 & 10.58 & 2,593 \\
\hline Turnover $_{\mathrm{t}}(\%)$ & 202.44 & 167.19 & 153.96 & 44.81 & 410.73 & 4,139 \\
\hline $\operatorname{Return}_{\mathrm{t}}(\%)$ & 0.01 & 0.05 & 0.28 & -0.17 & 0.13 & 4,139 \\
\hline Rea.Volat-7,t-36 (\%) & 52.43 & 46.51 & 24.23 & 28.50 & 86.01 & 4,139 \\
\hline News $(\%)$ & 1.90 & 0.32 & 6.18 & 0.00 & 3.84 & 4,139 \\
\hline Effective spread (\%) & 3.46 & 2.65 & 2.93 & 0.77 & 7.03 & 4,136 \\
\hline TV adv (daily $\$$ ) & $32,359.20$ & 3.00 & $239,409.36$ & 0.00 & $19,802.44$ & 4,139 \\
\hline News TV adv (daily $\$$ ) & $1,612.65$ & 0.00 & $12,634.24$ & 0.00 & 489.57 & 4,139 \\
\hline No-news TV adv (daily $\$$ ) & $30,746.55$ & 2.44 & $228,540.29$ & 0.00 & $18,702.14$ & 4,139 \\
\hline Newspaper adv (daily \$) & $5,393.29$ & 30.72 & $51,720.75$ & 0.00 & $4,200.63$ & 3,852 \\
\hline WSJ newspaper adv (daily $\$$ ) & 681.19 & 0.00 & $5,584.95$ & 0.00 & 641.37 & 3,852 \\
\hline 3 national newspaper adv (daily $\$$ ) & 883.48 & 0.00 & $6,837.88$ & 0.00 & 505.56 & 3,852 \\
\hline Local newspaper adv (daily \$) & $3,828.63$ & 7.04 & $43,875.06$ & 0.00 & $1,863.94$ & 3,852 \\
\hline
\end{tabular}

This table gives cross-sectional summary statistics on financial market data, Wikipedia page views, and Kantar advertising expenditures. The summary statistics are based on within-firm time-series averages. In panel A, we present summary statistics on all firms for which Wikipedia and Kantar data are available. The time period is from 2007 to 2012. In panel B, we present summary statistics on all firms for which TAQ and Kantar data are available. The time period is from 1995 until 2012. Wiki page views and the advertising variables are per day. Marketcap is the firm's market capitalization. Return on assets and advertising-to-sales ratios are based on Compustat data. Turnover $_{\mathrm{t}-7, \mathrm{t}-36}$ is the trading volume over the 4 weeks up to t-7, divided by average shares outstanding. Return t-7,t-36 is the holding period return over the 4 weeks up to t-7. ReaVolat $7, t-36$ is realized volatility, defined as average absolute return during the 4 weeks up to t-7. News is a national newspaper article dummy. EffSpr is the effective spread, defined as the daily transaction-weighted average of transaction prices relative to prevailing quotes. 
Table 2: Advertising and investor attention: Main results

\begin{tabular}{|c|c|c|c|c|c|c|}
\hline \multicolumn{7}{|c|}{ A. TV advertising } \\
\hline & $\begin{array}{c}(1) \\
\text { AWIKI }\end{array}$ & $\begin{array}{c}(2) \\
\text { AWIKI }\end{array}$ & $\begin{array}{c}(3) \\
\text { ASVI }\end{array}$ & $\begin{array}{c}(4) \\
\text { ASVI }\end{array}$ & $\begin{array}{c}(5) \\
\text { ARPV }\end{array}$ & $\begin{array}{c}(6) \\
\text { AIAC }\end{array}$ \\
\hline $\mathrm{Adv}_{\mathrm{TV}, \mathrm{t}}$ & $\begin{array}{c}0.8348^{* * *} \\
(0.1699)\end{array}$ & $\begin{array}{c}0.8533^{* * *} \\
(0.1697)\end{array}$ & $\begin{array}{l}-0.0140 \\
(0.1436)\end{array}$ & $\begin{array}{l}-0.0266 \\
(0.1445)\end{array}$ & $\begin{array}{l}-0.3640 \\
(0.3733)\end{array}$ & $\begin{array}{c}0.3159 \\
(0.6848)\end{array}$ \\
\hline $\mathrm{Adv}_{\mathrm{TV}, \mathrm{t}-1}$ & $\begin{array}{c}1.4564^{* * *} \\
(0.2133)\end{array}$ & $\begin{array}{c}1.4833^{* * *} \\
(0.2123)\end{array}$ & $\begin{array}{l}-0.0259 \\
(0.1656)\end{array}$ & $\begin{array}{l}-0.0525 \\
(0.1656)\end{array}$ & $\begin{array}{l}-0.2334 \\
(0.4063)\end{array}$ & $\begin{array}{l}1.6676^{* *} \\
(0.7543)\end{array}$ \\
\hline $\mathrm{Adv}_{\mathrm{TV}, \mathrm{t}-2}$ & $\begin{array}{c}1.4985^{* * *} \\
(0.2085)\end{array}$ & $\begin{array}{c}1.5160^{* * *} \\
(0.2069)\end{array}$ & $\begin{array}{c}0.1332 \\
(0.1595)\end{array}$ & $\begin{array}{c}0.1040 \\
(0.1582)\end{array}$ & $\begin{array}{l}-0.0110 \\
(0.3602)\end{array}$ & $\begin{array}{c}0.2424 \\
(0.6702)\end{array}$ \\
\hline $\operatorname{Adv}_{T V, t-3}$ & $\begin{array}{c}1.1729^{* * *} \\
(0.1900)\end{array}$ & $\begin{array}{c}1.1933^{* * *} \\
(0.1897)\end{array}$ & $\begin{array}{c}0.0396 \\
(0.1344)\end{array}$ & $\begin{array}{c}0.0254 \\
(0.1343)\end{array}$ & $\begin{array}{l}-0.2511 \\
(0.3312)\end{array}$ & $\begin{array}{c}0.4636 \\
(0.5932)\end{array}$ \\
\hline $\mathrm{EA}_{\mathrm{t}}$ & & $\begin{array}{c}0.1006^{* * *} \\
(0.0048)\end{array}$ & & $\begin{array}{c}0.0983^{* * *} \\
(0.0080)\end{array}$ & $\begin{array}{c}0.6970 * * * \\
(0.0113)\end{array}$ & $\begin{array}{c}1.3024^{* * *} \\
(0.0209)\end{array}$ \\
\hline Newst & & $\begin{array}{c}0.0861^{* * *} \\
(0.0056)\end{array}$ & & $\begin{array}{c}0.0550^{* * *} \\
(0.0062)\end{array}$ & $\begin{array}{c}0.1582^{* * *} \\
(0.0079)\end{array}$ & $\begin{array}{c}0.1969 * * * \\
(0.0144)\end{array}$ \\
\hline $\ln \left(\right.$ Turnover $\left._{\mathrm{t}-7, \mathrm{t}-36}\right)$ & & $\begin{array}{c}-0.0115^{* * *} \\
(0.0020)\end{array}$ & & $\begin{array}{l}-0.0010 \\
(0.0017)\end{array}$ & $\begin{array}{c}-0.0396 * * * \\
(0.0028)\end{array}$ & $\begin{array}{l}-0.0179 \\
(0.0147)\end{array}$ \\
\hline Return $_{\mathrm{t}-7, \mathrm{t}-36}$ & & $\begin{array}{l}-0.0004 \\
(0.0078)\end{array}$ & & $\begin{array}{l}-0.0041 \\
(0.0054)\end{array}$ & $\begin{array}{c}-0.0532^{* * *} \\
(0.0104)\end{array}$ & $\begin{array}{l}0.0546^{*} \\
(0.0303)\end{array}$ \\
\hline $\ln \left(\right.$ ReaVolat $\left._{\mathrm{t}-\mathrm{t}-36}\right)$ & & $\begin{array}{l}-0.0044 \\
(0.0027)\end{array}$ & & $\begin{array}{l}-0.0031 \\
(0.0020)\end{array}$ & $\begin{array}{c}0.0246^{* * *} \\
(0.0038)\end{array}$ & $\begin{array}{c}-0.1814^{* * *} \\
(0.0136)\end{array}$ \\
\hline $\ln ($ MarketCapt-7 $)$ & & $\begin{array}{c}0.0017 \\
(0.0024)\end{array}$ & & $\begin{array}{l}-0.0018 \\
(0.0019)\end{array}$ & $\begin{array}{c}0.0096 * * * \\
(0.0026)\end{array}$ & $\begin{array}{c}0.0142 \\
(0.0253)\end{array}$ \\
\hline $\mathrm{AWIKI}_{\mathrm{t}-7}$ & $\begin{array}{c}0.2111^{* * *} \\
(0.0074)\end{array}$ & $\begin{array}{c}0.2102^{* * *} \\
(0.0073)\end{array}$ & & & & \\
\hline $\mathrm{ASVI}_{\mathrm{t}-7}$ & & & $\begin{array}{c}0.1917^{* * *} \\
(0.0063)\end{array}$ & $\begin{array}{c}0.1907 * * * \\
(0.0063)\end{array}$ & & \\
\hline $\mathrm{ARPV}_{\mathrm{t}-7}$ & & & & & $\begin{array}{c}0.1370^{* * *} \\
(0.0015)\end{array}$ & \\
\hline $\mathrm{AIAC}_{\mathrm{t}-7}$ & & & & & & $\begin{array}{c}0.1661^{* * *} \\
(0.0074)\end{array}$ \\
\hline Firm FEs & YES & YES & YES & YES & YES & YES \\
\hline Week FEs & YES & YES & YES & YES & YES & YES \\
\hline Day-of-week FEs & YES & YES & YES & YES & YES & YES \\
\hline$R_{2}$ & .185 & .188 & .062 & .063 & .158 & .361 \\
\hline No. obs. & 947,982 & 945,457 & $1,199,587$ & $1,194,997$ & $1,531,248$ & 353,500 \\
\hline
\end{tabular}




\begin{tabular}{|c|c|c|c|c|c|c|}
\hline \multicolumn{7}{|c|}{ B. Newspaper advertising } \\
\hline & $\begin{array}{c}(1) \\
\text { AWIKI }\end{array}$ & $\begin{array}{c}(2) \\
\text { AWIKI }\end{array}$ & $\begin{array}{c}(3) \\
\text { ASVI }\end{array}$ & $\begin{array}{c}(4) \\
\text { ASVI }\end{array}$ & $\begin{array}{c}(5) \\
\text { ARPV }\end{array}$ & $\begin{array}{c}(6) \\
\text { AIAC }\end{array}$ \\
\hline $\operatorname{Adv}_{N P, t}$ & $\begin{array}{c}1.2523 * * * \\
(0.1261)\end{array}$ & $\begin{array}{c}1.2556^{* * *} \\
(0.1259)\end{array}$ & $\begin{array}{c}0.3687^{* * *} \\
(0.1109)\end{array}$ & $\begin{array}{c}0.3259 * * * \\
(0.1016)\end{array}$ & $\begin{array}{c}0.5517^{* * *} \\
(0.2137)\end{array}$ & $\begin{array}{c}0.9888^{* *} \\
(0.4773)\end{array}$ \\
\hline $\operatorname{Adv}_{N P, t-1}$ & $\begin{array}{c}1.1463^{* * *} \\
(0.1199)\end{array}$ & $\begin{array}{c}1.1376^{* * *} \\
(0.1190)\end{array}$ & $\begin{array}{c}0.3697^{* * *} \\
(0.1174)\end{array}$ & $\begin{array}{c}0.3251^{* * *} \\
(0.1087)\end{array}$ & $\begin{array}{c}0.7080 * * * \\
(0.1980)\end{array}$ & $\begin{array}{l}0.7066^{*} \\
(0.4005)\end{array}$ \\
\hline $\mathrm{Adv}_{\mathrm{NP}, \mathrm{t}-2}$ & $\begin{array}{c}0.9810^{* * *} \\
(0.1225)\end{array}$ & $\begin{array}{c}0.9761^{* * *} \\
(0.1214)\end{array}$ & $\begin{array}{c}0.2885^{* * *} \\
(0.1034)\end{array}$ & $\begin{array}{c}0.2565^{* * *} \\
(0.0959)\end{array}$ & $\begin{array}{c}0.2319 \\
(0.2015)\end{array}$ & $\begin{array}{c}0.1853 \\
(0.4202)\end{array}$ \\
\hline $\operatorname{AdvNP,t-3}$ & $\begin{array}{c}0.8493^{* * *} \\
(0.1200)\end{array}$ & $\begin{array}{c}0.8540^{* * *} \\
(0.1201)\end{array}$ & $\begin{array}{c}0.1624 \\
(0.1161)\end{array}$ & $\begin{array}{c}0.1211 \\
(0.1047)\end{array}$ & $\begin{array}{c}0.1258 \\
(0.2132)\end{array}$ & $\begin{array}{c}0.3965 \\
(0.4217)\end{array}$ \\
\hline $\mathrm{EA}_{\mathrm{t}}$ & & $\begin{array}{c}0.1018^{* * *} \\
(0.0050)\end{array}$ & & $\begin{array}{c}0.0905^{* * *} \\
(0.0075)\end{array}$ & $\begin{array}{c}0.6727^{* * *} \\
(0.0107)\end{array}$ & $\begin{array}{c}1.2718^{* * *} \\
(0.0192)\end{array}$ \\
\hline Newst & & $\begin{array}{c}0.0803^{* * *} \\
(0.0050)\end{array}$ & & $\begin{array}{c}0.0524^{* * *} \\
(0.0059)\end{array}$ & $\begin{array}{c}0.1521 * * * \\
(0.0072)\end{array}$ & $\begin{array}{c}0.1939 * * * \\
(0.0139)\end{array}$ \\
\hline $\ln \left(\right.$ Turnover $\left._{\mathrm{t}-7, \mathrm{t}-36}\right)$ & & $\begin{array}{c}-0.0088^{* * *} \\
(0.0020)\end{array}$ & & $\begin{array}{c}0.0010 \\
(0.0015)\end{array}$ & $\begin{array}{c}-0.0414^{* * *} \\
(0.0027)\end{array}$ & $\begin{array}{c}-0.0372^{* * *} \\
(0.0143)\end{array}$ \\
\hline Return $_{\mathrm{t}-7, \mathrm{t}-36}$ & & $\begin{array}{c}-0.0071 \\
(0.0070)\end{array}$ & & $\begin{array}{c}0.0001 \\
(0.0057)\end{array}$ & $\begin{array}{c}-0.0484^{* * *} \\
(0.0099)\end{array}$ & $\begin{array}{l}0.0615^{*} \\
(0.0324)\end{array}$ \\
\hline $\ln \left(\right.$ ReaVolat $\left._{\mathrm{t}-\mathrm{t}, \mathrm{t}-36}\right)$ & & $\begin{array}{l}-0.0028 \\
(0.0027)\end{array}$ & & $\begin{array}{l}-0.0023 \\
(0.0020)\end{array}$ & $\begin{array}{c}0.0255^{* * * *} \\
(0.0039)\end{array}$ & $\begin{array}{c}-0.1746^{* * *} \\
(0.0134)\end{array}$ \\
\hline $\ln ($ MarketCap t-7 $)$ & & $\begin{array}{c}0.0013 \\
(0.0020)\end{array}$ & & $\begin{array}{l}-0.0001 \\
(0.0018)\end{array}$ & $\begin{array}{c}0.0105 * * * \\
(0.0027)\end{array}$ & $\begin{array}{c}0.0048 \\
(0.0280)\end{array}$ \\
\hline $\mathrm{AWIKI}_{\mathrm{t}-7}$ & $\begin{array}{c}0.2070^{* * *} \\
(0.0070)\end{array}$ & $\begin{array}{c}0.2059^{* * *} \\
(0.0069)\end{array}$ & & & & \\
\hline $\mathrm{ASVI}_{\mathrm{t}-7}$ & & & $\begin{array}{c}0.1923^{* * *} \\
(0.0057)\end{array}$ & $\begin{array}{c}0.1907 * * * \\
(0.0057)\end{array}$ & & \\
\hline $\mathrm{ARPV}_{\mathrm{t}-7}$ & & & & & $\begin{array}{c}0.1364^{* * *} \\
(0.0014)\end{array}$ & \\
\hline $\mathrm{AIAC}_{\mathrm{t}-7}$ & & & & & & $\begin{array}{c}0.1689^{* * * *} \\
(0.0074)\end{array}$ \\
\hline Firm FEs & YES & YES & YES & YES & YES & YES \\
\hline Week FEs & YES & YES & YES & YES & YES & YES \\
\hline Day-of-week FEs & YES & YES & YES & YES & YES & YES \\
\hline$R_{2}$ & .187 & .189 & .068 & .069 & .154 & .365 \\
\hline No. obs. & 930,230 & 927,759 & $1,289,179$ & $1,284,128$ & $1,657,757$ & 351,125 \\
\hline
\end{tabular}

This table shows regressions of abnormal Wikipedia page visits (AWIKI), Google search volume (ASVI), SEC EDGAR downloads (ARPV), and Bloomberg search volume (AIAC) on abnormal TV advertising $\left(A d v_{T V}\right.$, in panel A) and newspaper advertising $\left(A d v_{N P}\right.$, in panel B). For Wikipedia, the sample covers all publicly listed companies with Wikipedia page visits and positive advertising in the previous 8 weeks from 2007 to 2012. For (EDGAR) Google, the sample period is (2003) 2004 to 2012. For Bloomberg, the sample period is 2010 to 2012. For ASVI, tickers corresponding to words in a dictionary have been excluded. For ARPV, downloads from IP addresses that are identified as "robots" have been excluded. EA $\mathrm{t}_{\mathrm{t}}$ is an earnings announcement dummy. News is a national newspaper article dummy. Turnover ${ }_{t-7, t-36}$ is the trading volume over the 4 weeks up to t-7, divided by average shares outstanding. Return $_{\mathrm{t}-7, \mathrm{t}-36}$ is the holding period return over the 4 weeks up to t-7. ReaVolat-7,t-36 is realized volatility, defined as average absolute return during the 4 weeks up to t-7. MarketCapt-7 is the firm's market capitalization. Standard errors are clustered by firm and shown in parentheses. ${ }^{*} p<.1 ;{ }^{* *} p<.05 ;{ }^{* * *} p<.01$. 
Table 3: Impact on financial markets: Main results

\begin{tabular}{|c|c|c|c|}
\hline \multicolumn{4}{|c|}{ A. TV advertising } \\
\hline & $\begin{array}{c}(1) \\
\ln \left(\text { Turnover }_{\mathrm{t}}\right)\end{array}$ & $\begin{array}{c}(2) \\
\ln \left(\text { EffSpr }_{\mathrm{t}}\right)\end{array}$ & Return $_{\mathrm{t}}^{(3)}{ }^{\text {excess }}$ \\
\hline $\mathrm{Adv}_{\mathrm{TV}, \mathrm{t}}$ & $\begin{array}{c}0.4422^{* *} \\
(0.1926)\end{array}$ & $\begin{array}{l}-0.4657 \\
(0.4633)\end{array}$ & $\begin{array}{l}-0.0082 \\
(0.0065)\end{array}$ \\
\hline $\operatorname{Adv}_{T V, t-1}$ & $\begin{array}{c}0.5119 * * \\
(0.2077)\end{array}$ & $\begin{array}{l}-0.6551 \\
(0.4272)\end{array}$ & $\begin{array}{l}-0.0003 \\
(0.0065)\end{array}$ \\
\hline $\mathrm{Adv}_{\mathrm{TV}, \mathrm{t}-2}$ & $\begin{array}{c}0.0029 \\
(0.1877)\end{array}$ & $\begin{array}{c}-0.6077^{*} \\
(0.3616)\end{array}$ & $\begin{array}{l}0.0129 * * \\
(0.0058)\end{array}$ \\
\hline $\mathrm{Adv}_{\mathrm{TV}, \mathrm{t}-3}$ & $\begin{array}{l}0.3071^{*} \\
(0.1579)\end{array}$ & $\begin{array}{c}-0.5281^{*} \\
(0.3129)\end{array}$ & $\begin{array}{c}0.0009 \\
(0.0057)\end{array}$ \\
\hline $\mathrm{EA}_{\mathrm{t}}$ & $\begin{array}{c}0.4972^{* * *} \\
(0.0083)\end{array}$ & $\begin{array}{c}0.1730 * * * \\
(0.0068)\end{array}$ & $\begin{array}{c}0.0016^{* * *} \\
(0.0002)\end{array}$ \\
\hline Newst & $\begin{array}{c}0.1595^{* * *} \\
(0.0062)\end{array}$ & $\begin{array}{c}0.0624^{* * *} \\
(0.0088)\end{array}$ & $\begin{array}{c}0.0002^{* * *} \\
(0.0001)\end{array}$ \\
\hline $\ln \left(\right.$ Turnover $\left._{\mathrm{t}-7, \mathrm{t}-36}\right)$ & $\begin{array}{c}0.6165^{* * *} \\
(0.0052)\end{array}$ & $\begin{array}{c}-0.0711^{* * *} \\
(0.0102)\end{array}$ & $\begin{array}{c}0.0001^{* *} \\
(0.0000)\end{array}$ \\
\hline Return $_{\mathrm{t}-7, \mathrm{t}-36}$ & $\begin{array}{c}-0.1620^{* * *} \\
(0.0085)\end{array}$ & $\begin{array}{c}0.0209 \\
(0.0131)\end{array}$ & $\begin{array}{c}-0.0009^{* * *} \\
(0.0002)\end{array}$ \\
\hline $\ln ($ ReaVolat $-7, t-36)$ & $\begin{array}{c}-0.0509^{* * *} \\
(0.0047)\end{array}$ & $\begin{array}{c}0.1677^{* * * *} \\
(0.0109)\end{array}$ & $\begin{array}{c}-0.0001^{* * *} \\
(0.0000)\end{array}$ \\
\hline $\ln ($ MarketCapt-7 $)$ & $\begin{array}{c}0.0302^{* * *} \\
(0.0059)\end{array}$ & $\begin{array}{c}-0.1190^{* * *} \\
(0.0133)\end{array}$ & $\begin{array}{c}-0.0009 * * * \\
(0.0000)\end{array}$ \\
\hline $\ln \left(\right.$ Turnover $\left._{\mathrm{t}-7}\right)$ & $\begin{array}{c}0.1654^{* * * *} \\
(0.0016)\end{array}$ & & \\
\hline $\ln \left(\mathrm{EffSpr}_{\mathrm{t}-7}\right)$ & & $\begin{array}{c}0.3437^{* * *} \\
(0.0051)\end{array}$ & \\
\hline Firm FEs & YES & YES & YES \\
\hline Week FEs & YES & YES & YES \\
\hline Day-of-Week FEs & YES & YES & YES \\
\hline$R_{2}$ & .70 & .58 & .01 \\
\hline No. obs. & $2,871,633$ & $2,287,395$ & $3,009,588$ \\
\hline
\end{tabular}




\begin{tabular}{|c|c|c|c|}
\hline \multicolumn{4}{|c|}{ B. Newspaper advertising } \\
\hline & $\begin{array}{c}(1) \\
\ln \left(\text { Turnover }_{\mathrm{t}}\right)\end{array}$ & $\begin{array}{c}(2) \\
\ln \left(\text { EffSpr }_{\mathrm{t}}\right)\end{array}$ & $\begin{array}{c}(3) \\
\operatorname{Return}_{\mathrm{t}} \\
\text { excess }\end{array}$ \\
\hline $\operatorname{Adv}_{N P, t}$ & $\begin{array}{c}0.3158^{* * * *} \\
(0.1153)\end{array}$ & $\begin{array}{c}0.1189 \\
(0.2350)\end{array}$ & $\begin{array}{c}0.0042 \\
(0.0042)\end{array}$ \\
\hline $\operatorname{Adv}_{N P, t-1}$ & $\begin{array}{c}0.4601^{* * * *} \\
(0.1125)\end{array}$ & $\begin{array}{l}-0.1164 \\
(0.2104)\end{array}$ & $\begin{array}{c}0.0038 \\
(0.0041)\end{array}$ \\
\hline $\mathrm{Adv}_{\mathrm{NP}, \mathrm{t}-2}$ & $\begin{array}{c}0.4990^{* * * *} \\
(0.1166)\end{array}$ & $\begin{array}{c}-0.3935^{*} \\
(0.2127)\end{array}$ & $\begin{array}{l}-0.0034 \\
(0.0043)\end{array}$ \\
\hline $\operatorname{Adv}_{N P, t-3}$ & $\begin{array}{c}0.0776 \\
(0.1201)\end{array}$ & $\begin{array}{l}-0.0020 \\
(0.2180)\end{array}$ & $\begin{array}{c}0.0009 \\
(0.0044)\end{array}$ \\
\hline $\mathrm{EA}_{\mathrm{t}}$ & $\begin{array}{c}0.4712^{* * *} \\
(0.0081)\end{array}$ & $\begin{array}{c}0.1725^{* * *} \\
(0.0061)\end{array}$ & $\begin{array}{c}0.0019 * * * \\
(0.0002)\end{array}$ \\
\hline Newst & $\begin{array}{c}0.1512^{* * *} \\
(0.0060)\end{array}$ & $\begin{array}{c}0.0672^{* * *} \\
(0.0092)\end{array}$ & $\begin{array}{l}0.0002^{*} \\
(0.0001)\end{array}$ \\
\hline $\ln \left(\right.$ Turnover $\left._{\mathrm{t}-7, \mathrm{t}-36}\right)$ & $\begin{array}{c}0.6088^{* * * *} \\
(0.0048)\end{array}$ & $\begin{array}{c}-0.0930 * * * \\
(0.0085)\end{array}$ & $\begin{array}{c}0.0001^{* * *} \\
(0.0000)\end{array}$ \\
\hline Return $_{\mathrm{t}-7, \mathrm{t}-36}$ & $\begin{array}{c}-0.1389^{* * *} \\
(0.0079)\end{array}$ & $\begin{array}{c}0.0145 \\
(0.0109)\end{array}$ & $\begin{array}{c}-0.0006^{* * *} \\
(0.0002)\end{array}$ \\
\hline $\ln ($ ReaVolat-7,t-36) & $\begin{array}{c}-0.0385^{* * *} \\
(0.0042)\end{array}$ & $\begin{array}{c}0.1712^{* * *} \\
(0.0095)\end{array}$ & $\begin{array}{c}-0.0002^{* * *} \\
(0.0000)\end{array}$ \\
\hline $\ln \left(\right.$ MarketCap $\left.{ }_{\mathrm{t}-7}\right)$ & $\begin{array}{c}0.0367^{* * *} \\
(0.0051)\end{array}$ & $\begin{array}{c}-0.1066^{* * *} \\
(0.0111)\end{array}$ & $\begin{array}{c}-0.0011^{* * *} \\
(0.0001)\end{array}$ \\
\hline $\ln \left(\right.$ Turnover $\left._{\mathrm{t}-7}\right)$ & $\begin{array}{c}0.1701^{* * *} \\
(0.0016)\end{array}$ & & \\
\hline $\ln \left(\right.$ EffSpr $\left._{\mathrm{t}-7}\right)$ & & $\begin{array}{c}0.3528^{* * *} \\
(0.0048)\end{array}$ & \\
\hline Firm FEs & YES & YES & YES \\
\hline Week FEs & YES & YES & YES \\
\hline Day-of-week FEs & YES & YES & YES \\
\hline $\begin{array}{l}R_{2} \\
\text { No. obs. }\end{array}$ & $\begin{array}{c}.72 \\
3,051,008\end{array}$ & $\begin{array}{c}.59 \\
2,575,174\end{array}$ & $\begin{array}{c}.01 \\
3,218,136\end{array}$ \\
\hline
\end{tabular}

This table shows regressions of the logarithm of turnover, the logarithm of the effective spread (EffSpr), and the excess return of a firm on abnormal TV advertising $\left(A d v_{T V}\right.$, in panel A) and newspaper advertising $\left(A d v_{N P}\right.$, in panel B). Turnover is daily trading volume over shares outstanding. EffSpr is the effective spread, defined as daily transactionweighted average of transaction prices relative to prevailing quotes. Return ${ }^{\text {excess }}$ is the return of a stock over Kenneth French's market return measure. EA $A_{t}$ is an earnings announcement dummy. News $s_{t}$ is a national newspaper article dummy. Turnover ${ }_{t-7, t-36}$ is the trading volume over the 4 weeks up to t-7, divided by average shares outstanding. Return $_{\mathrm{t}-7, \mathrm{t}-36}$ is the holding period return over the 4 weeks up to t-7. ReaVola $\mathrm{t}_{\mathrm{t}-\mathrm{t} \text { - } 36}$ is realized volatility, defined as average absolute return during the 4 weeks up to t-7. MarketCapt-7 is the firm's market capitalization. The analysis is performed for 1995-2012 (1996-2010) common stocks from NYSE, AMEX, and NASDAQ for Turnover and Returns (TAQ-based data), excluding stocks with last-week prices below 5 USD. Standard errors are shown in parentheses and clustered by firm. ${ }^{*} p<.1 ;{ }^{* *} p<.05 ;{ }^{* * *} p<.01$. 
Table 4: Impact on financial markets: Advertising sensitivity

\begin{tabular}{|c|c|c|}
\hline & TV advertising & Newspaper advertising \\
\hline & $\begin{array}{c}(1) \\
\text { Return }_{\mathrm{t}} \\
\text { excess }\end{array}$ & $\begin{array}{c}(2) \\
\text { Return }_{t} \\
\text { excess }\end{array}$ \\
\hline \multicolumn{3}{|c|}{ A. Low advertising sensitivity } \\
\hline $\mathrm{Adv}_{\mathrm{t}}$ & $\begin{array}{l}-0.0076 \\
(0.0104)\end{array}$ & $\begin{array}{c}0.0076 \\
(0.0066)\end{array}$ \\
\hline $\operatorname{Adv}_{\mathrm{t}-1}$ & $\begin{array}{c}0.0039 \\
(0.0112)\end{array}$ & $\begin{array}{c}0.0002 \\
(0.0063)\end{array}$ \\
\hline $\mathrm{Adv}_{\mathrm{t}-2}$ & $\begin{array}{c}0.0151 \\
(0.0096)\end{array}$ & $\begin{array}{l}-0.0023 \\
(0.0067)\end{array}$ \\
\hline $\mathrm{Adv}_{\mathrm{t}-3}$ & $\begin{array}{c}0.0004 \\
(0.0091)\end{array}$ & $\begin{array}{c}0.0067 \\
(0.0069)\end{array}$ \\
\hline \multicolumn{3}{|c|}{ B. High advertising sensitivity } \\
\hline $\mathrm{Adv}_{\mathrm{t}}$ & $\begin{array}{l}-0.0169 \\
(0.0120)\end{array}$ & $\begin{array}{l}-0.0070 \\
(0.0073)\end{array}$ \\
\hline $\mathrm{Adv}_{\mathrm{t}-1}$ & $\begin{array}{c}0.0090 \\
(0.0113)\end{array}$ & $\begin{array}{c}0.0111 \\
(0.0071)\end{array}$ \\
\hline $\mathrm{Adv}_{\mathrm{t}-2}$ & $\begin{array}{l}0.0188^{*} \\
(0.0107)\end{array}$ & $\begin{array}{c}0.0006 \\
(0.0071)\end{array}$ \\
\hline $\mathrm{Adv}_{\mathrm{t}-3}$ & $\begin{array}{c}0.0079 \\
(0.0103)\end{array}$ & $\begin{array}{c}0.0016 \\
(0.0074)\end{array}$ \\
\hline Firm FEs & YES & YES \\
\hline Week FEs & YES & YES \\
\hline Day-of-week FEs & YES & YES \\
\hline Controls & YES & YES \\
\hline
\end{tabular}

This table shows regressions of the excess return of a firm on abnormal TV advertising $\left(A d v_{T V}\right)$ and newspaper advertising $\left(A d v_{N P}\right)$ for high and low advertising sensitivity firms. Advertising sensitivity is the firm's average coefficient for the 4 advertising-regressors in a firm-by-firm regression of $\mathrm{AWIKI}_{\mathrm{t}}$ on $\mathrm{Adv}_{\mathrm{t}}$ through $\mathrm{Adv}_{\mathrm{t}-3}$, day-ofweek dummies, AWIKI $\mathrm{t}_{-7}$ and the usual control variables. Panel A (B) reports results based on a sample of firms with advertising sensitivities below (above) the cross-sectional median. Return ${ }^{\text {excess }}$ is the return of a stock over Kenneth French's market return measure. $E A_{t}$ is an earnings announcement dummy. News is a national newspaper article dummy. Turnover ${ }_{t-7, t-36}$ is the trading volume over the 4 weeks up to t-7, divided by average shares outstanding. Return $_{\mathrm{t}-7, \mathrm{t}-36}$ is the holding period return over the 4 weeks up to t-7. ReaVolat-7,t-36 is realized volatility, defined as average absolute return during the 4 weeks up to t-7. MarketCapt-7 is the firm's market capitalization. For ease of presentation, only the advertising coefficients are reported. The analysis is performed for 1995-2012 common stocks from NYSE, AMEX, and NASDAQ, excluding stocks with last-week prices below 5 USD. Standard errors are shown in parentheses and clustered by firm. ${ }^{*} p<.1 ;{ }^{* *} p<.05 ;{ }^{* * *} p<.01$. 
Table 5: Panel VAR with stock returns and advertising

\begin{tabular}{|c|c|c|}
\hline & $\begin{array}{l}(1) \\
\text { Return }_{\mathrm{t}}\end{array}$ & $\Delta \operatorname{Ads}(\mathrm{TV}+\mathrm{NP})_{\mathrm{t}}$ \\
\hline \multicolumn{3}{|l|}{ Return } \\
\hline Lag 1 & $-0.0305^{* * *}$ & $0.1599^{* * *}$ \\
\hline Lag 2 & $-0.0215^{* * *}$ & $0.1165^{*}$ \\
\hline Lag 3 & 0.0003 & $0.0954^{*}$ \\
\hline Lag 4 & -0.0013 & 0.0567 \\
\hline Lag 5 & 0.0003 & $0.1913^{* * *}$ \\
\hline Lag 6 & $0.0070^{*}$ & $0.0949 *$ \\
\hline Lag 7 & $0.0194^{* * *}$ & $0.2329 * * *$ \\
\hline Lag 8 & 0.0039 & 0.0732 \\
\hline Lag 9 & $-0.0082^{* *}$ & 0.0695 \\
\hline Lag 10 & $-0.0115^{* * *}$ & 0.0322 \\
\hline Lag 11 & $0.0135^{* * *}$ & 0.0888 \\
\hline Lag 12 & $0.0065^{* *}$ & $0.1245^{* *}$ \\
\hline \multicolumn{3}{|l|}{$\Delta$ Ads } \\
\hline Lag 1 & 0.0000 & $-0.5561^{* * *}$ \\
\hline Lag 2 & -0.0002 & $-0.4519^{* * *}$ \\
\hline Lag 3 & -0.0002 & $-0.3864^{* * *}$ \\
\hline Lag 4 & $-0.0004^{* * *}$ & $-0.3286^{* * *}$ \\
\hline Lag 5 & -0.0002 & $-0.2844^{* * *}$ \\
\hline Lag 6 & -0.0000 & $-0.2376^{* * *}$ \\
\hline Lag 7 & -0.0001 & $-0.2178^{* * *}$ \\
\hline Lag 8 & -0.0000 & $-0.2019 * * *$ \\
\hline Lag 9 & -0.0001 & $-0.1912^{* * *}$ \\
\hline Lag 10 & -0.0001 & $-0.1774^{* * *}$ \\
\hline Lag 11 & 0.0001 & $-0.1171^{* * *}$ \\
\hline Lag 12 & 0.0000 & $0.0305^{* * *}$ \\
\hline$\chi^{2}$-stat $($ Return $=0)$ & - & 40.83 \\
\hline$p$-value $($ Return $=0)$ & - & .00 \\
\hline$\chi^{2}$-stat $(\Delta \mathrm{Ads}=0)$ & 13.59 & - \\
\hline$p$-value $(\Delta \operatorname{Ads}=0)$ & .33 & - \\
\hline $\mathrm{N}$ & 183,003 & 183,003 \\
\hline
\end{tabular}

This table reports the results of panel VAR models with monthly stock returns and advertising (TV and newspaper). The measure of advertising is $\Delta$ Ads $(\mathrm{TV}+\mathrm{NP})$, which is the log difference of the sum of monthly TV and newspaper advertising. The analysis is performed for 1995-2012 common stocks from NYSE, AMEX, and NASDAQ, excluding stocks with prices below 5 USD in the month before the estimation period and those with no advertising in the 2 months before the estimation period. The model is estimated following the extension of standard vector autoregression to the panel context by Holtz-Eakin, Newey, and Rosen (1988) and using the program developed by Love and Zicchino (2006) and Abrigo and Love (2016). It takes firm fixed effects into account by forward orthogonal deviations and month fixed effects by monthly demeaning of the variables. The $\chi^{2}$ statistics and associated $p$-values are for the Granger causality test that all lags of a variable are jointly zero. The tests have 12 degrees of freedom. Standard errors are clustered by firm and shown in parentheses. ${ }^{*} p<.1 ;{ }^{* *} p<.05 ;{ }^{* * *} p<.01$. 
Table 6: Positive news and advertising growth

\begin{tabular}{|c|c|c|c|c|}
\hline & (1) & $(2)$ & (3) & (4) \\
\hline & \multicolumn{2}{|c|}{$\Delta \ln (\operatorname{Adv})_{t+1, t+12}$} & \multicolumn{2}{|c|}{ Return $_{\mathrm{t}}$} \\
\hline $\mathrm{SUE}_{\mathrm{t}}$ & $\begin{array}{c}0.2453^{* * *} \\
(4.53)\end{array}$ & $\begin{array}{c}0.1630^{* * *} \\
(2.89)\end{array}$ & $\begin{array}{c}0.1162^{* * *} \\
(31.25)\end{array}$ & $\begin{array}{c}0.1189^{* * *} \\
(30.56)\end{array}$ \\
\hline$\Delta \ln (\mathrm{Adv})_{\mathrm{t}-12, \mathrm{t}-1}$ & & $\begin{array}{c}-0.3943^{* * *} \\
(-34.41)\end{array}$ & & $\begin{array}{c}-0.0002 \\
(-0.89)\end{array}$ \\
\hline Return $_{\mathrm{t}-12, \mathrm{t}-1}$ & & $\begin{array}{c}0.3725^{* * *} \\
\quad(5.61)\end{array}$ & & $\begin{array}{c}-0.0237^{* * *} \\
(-3.98)\end{array}$ \\
\hline Return $_{\mathrm{t}-36, \mathrm{t}-13}$ & & $\begin{array}{c}-0.0286 \\
(-0.61)\end{array}$ & & $\begin{array}{c}-0.0059^{* *} \\
(-2.10)\end{array}$ \\
\hline Firm FEs & YES & YES & YES & YES \\
\hline Month FEs & YES & YES & YES & YES \\
\hline$R_{2}$ & .07 & .21 & .23 & .25 \\
\hline No. obs. & 73,635 & 59,256 & 73,633 & 59,256 \\
\hline
\end{tabular}

This table shows regressions of changes in advertising and returns on earnings surprises. The analysis is performed for 1996-2012 common stocks from NYSE, AMEX, and NASDAQ with an earnings announcement in month $t$, excluding stocks with last-month prices below 5 USD. $\Delta \ln (\mathrm{Adv})_{t+1, t+12}\left(\Delta \ln (\mathrm{Adv})_{\mathrm{t}-12, \mathrm{t}+1}\right)$ is the year-to-year growth of the $\log$ of advertising expenditures from the 12 months up to the earnings announcement month $t$ to the 12 months after month $t$ (from months -24 to -13 prior to the announcement to the 12 months prior the announcement). SUE $\mathrm{t}_{\mathrm{t}}$ the rank of the firm's earnings surprise (SUE) within month $t$. Return $\mathrm{t}_{\mathrm{t}}$ is the return in the earnings announcement month $t$. Return $n_{\mathrm{t}-12, \mathrm{t}-1}$ is the return over the year right before the earnings announcement month $t$. Return $\mathrm{t}_{\mathrm{t}-36, \mathrm{t}-13}$ is the return over the 2 years ending 12 months before the earnings announcement month $t$. $t$-statistics are shown in parentheses. Standard errors are clustered by firm and month. ${ }^{*} p<.1 ;{ }^{* *} p<.05 ;{ }^{* * *} p<.01$. 


\title{
Internet Appendix for "Advertising, Attention, and Financial Markets"
}

\author{
Florens Focke \\ University of Mannheim \\ Stefan Ruenzi \\ University of Mannheim \\ Michael Ungeheuer \\ Aalto University
}

\begin{abstract}
The Internet Appendix consists of three sections. In Internet Appendix A, we describe the Wikipedia data and discuss several additional stability tests of our analysis from Sections 2 and 3 of the main paper. Internet Appendices $\mathrm{B}$ and $\mathrm{C}$ contain additional figures and tables, respectively.
\end{abstract}




\section{A Appendix: Additional Information}

\section{A.1 Wikipedia Page View Data}

This section briefly describes the procedure we use to extract Wikipedia page view counts on the firm-day level.

1. Download of full set of page count data from December 2007 to December 2012, as provided by Wikipedia. The data can be accessed from https://dumps.wikimedia.org/other/ pagecountsraw/. This data shows the unscaled, hourly number of page views for each redirect (URL) that was used at least once in this hour to access a Wikipedia page. We have checked the precision of this data set by calling an infrequently visited Wikipedia page 10 (20) times shortly before (after) the full hour. This led to a count of 10 (20) for the Wikipedia page we called in the correct hour.

2. Construction of a set of firms (permco-level) that are of interest in the context of our analysis: We use all firms available in CRSP any time between December 2007 and December 2012 (variables used for link: name, ticker, headquarter state, time period of availability in CRSP).

3. Identification of firms' Wikipedia pages by searching English-language Wikipedia for the company name. If a page is found, information on ticker and headquarter state are used to make sure this actually is the Wikipedia page of the firm from CRSP. If there are separate pages for product and firm ('Coca-Cola' and 'The Coca-Cola Company'), only the firm page is used.

4. Manual selection of redirects that directly relate to firm name. For instance, 'Apple Computer', 'Option-Shift-K' and 'Jobs and Wozniak' all redirect to 'Apple Inc.'. We only classify the first redirect as 'directly related to firm name'.

5. For each hour, page counts for all redirects of each permco are added up. Then a dataset on the firm-day level is constructed by adding up hourly counts for Eastern Time (NYC) days.

IA. 1 


\section{A.2 Advertising and Attention: Stability Tests}

This section describes the robustness tests we conduct for our analysis of the impact of advertising on investor attention in detail. First, we examine whether the impact of advertising on attention differs across advertising channels. Then, we test the robustness of our findings from Section 2.1 by looking at longer lags of advertising, cross-sectional sample splits, assessing the temporal stability of the relationships, using alternative attention proxies, alternative advertising definitions, and using firm as well as day fixed effects and clustering.

\section{Advertising Channels}

In the main paper, we show that advertising generally has a significant impact on attention. We now present results of an analysis where we examine different advertising channels in more detail.

We start by splitting up TV advertising into advertising on CNN, CNBC, Fox News, MSNBC and CNN Headline News and advertising on all other TV channels. The first channels are news or business channels, while the other channels mainly include pure entertainment channels. It is plausible that potential investors are more likely to watch news and business channels than other channels. However, the amount of advertising dollars spent on spots in news and business channels is much lower (see Table 1, Panel A as well as Tables C6, C7, C8). Thus, still finding an impact of advertising on our attention proxies even in this case would strongly reinforce our prior evidence that advertising also creates attention among potential investors. The results are presented in Tables C11 and C12, for TV and newspaper advertising, respectively.

In Column (1) of Table C11 we present results for the TV advertising effect on Wikipedia page views. Both $A d v_{T V N W S}$ and $A d v_{T V N O N W S}$ have a significant impact on abnormal Wikipedia attention. The coefficient sizes are of comparable magnitude, meaning that doubling advertising in news TV channels has a similar effect compared to other TV channels. However, firms spend on average 6,022 USD per day on advertising in news channels and 73.824 USD per day on advertising in all other channels (see Table 1. Panel A, from the main paper). Assuming that the true relationship was linear, these patterns suggest that the impact of an increase in abnormal advertising 
on a per dollar basis is more than 12 times as large for news channels than for other channels. This finding shows that firms trying to attract investor attention should focus their advertising on news channels.

In Column (2) we use abnormal Google Search Volume as our proxy for investor attention. We do not find any significant effects of either news or other TV channels. While this is consistent with the insignificant coefficient estimates on combined TV advertising in Table 2 in the main paper, it also implies that even for news TV channels, there is no significant effect of advertising on abnormal Google search volume.

In the final two columns, we look at EDGAR downloads and Bloomberg search activity as our proxies for attention. For both, we only find significant effects for advertising in news channels, not other channels. Given that advertising in other channels again represents much larger dollar expenses, this result indicates that attracting attention on EDGAR and Bloomberg is mostly effective through advertising in news channels. This result is in line with the prior that sophisticated, institutional investors who use the SEC's EDGAR platform or Bloomberg are particularly likely to watch news channels.

Looking at newspapers, we find a similar pattern. Here, we split up newspapers into local newspapers, the Wall Street Journal (WSJ) and three other national newspapers, which comprise the New York Times, USA Today, and the Washington Post. Results with Wikipedia page views as the attention proxy are presented in Column (1) of Table C12, We again find that the coefficients on local and national newspapers as well as the WSJ are of a similar magnitude and statistically significant (except for the third lag of WSJ advertising). However, the average firm invests more than six times as much into local newspaper advertising compared to national newspaper advertising, excluding the WSJ. It also invests more than 14 times as much into local newspaper advertising than advertising in the WSJ. Therefore, the effects on a per-dollar basis are again much stronger for advertising in the WSJ and other national newspapers compared to local newspapers.

In Column (2), we again use Google Search Volume as our attention proxy. Overall, the sta- 
tistical significance is lower than in the regression with Wikipedia page views. Specifically, the contemporaneous effect of local newspaper advertising is significant only at the $10 \%$ level, while the first and second lag are significant at the $1 \%$ and $5 \%$ level, respectively. For advertising in the WSJ, only the contemporaneous effect is significant at the $10 \%$ level, while for the other national newspapers, the contemporaneous effect and the first lag are significant at least at the $5 \%$ level. However, for Google Search Volume we find that already the coefficient estimates are larger for WSJ and national newspaper advertising compared to local advertising. For instance, the contemporaneous effect is 0.5389 for WSJ advertising and 0.7399 for other national newspaper advertising, but only 0.1913 for local newspaper advertising. Combined with the much larger dollar magnitudes of advertising in the WSJ and the other national newspapers, we can conclude that also for Google Search Volume, the per-dollar impact is much larger in these media channels.

In Column (3) we focus on EDGAR downloads and again find much larger effects for advertising in the WSJ and the other national newspapers. As for SVI, the effects are larger both in terms of coefficient estimates as well as on a per-dollar basis. Similar to our news-TV advertising results, this finding is in line with the prior that sophisticated, institutional investors who use the SEC's EDGAR platform or Bloomberg are particularly likely to read the WSJ.

Finally, in Column (4) we consider Bloomberg search activity as our attention proxy. In this case, we only find the first lag of local newspaper advertising and the contemporaneous effect of WSJ advertising to be positive and significant. For the other national newspapers, we do not find any significant effects. The coefficient estimate on WSJ advertising (2.9508) is again much larger than for local newspaper advertising (insignificant -0.2169 for the contemporaneous effect and significant at the $5 \%$ level 0.9897 for the first lag). Therefore, we can conclude that Bloomberg search activity is most strongly affected by advertising in the WSJ.

Overall, the above results show that advertising in media channels more likely to be consumed by investors (i.e., TV news channels and national newspapers, especially the WSJ) is associated with stronger effects on investor attention. With the exception being TV advertising for Google Search

\section{IA.4}


Volume, for which we do not find an effect for either TV news channels or all other channels, this is generally true for all four attention proxies we analyze. Therefore, we conclude that these attention proxies all capture investor attention and are more strongly affected by advertising targeted at investors. In addition, the differences in effects by channel are especially pronounced for EDGAR downloads and Bloomberg search volume. This indicates that these attention proxies are more focused on sophisticated, institutional investor attention, whereas SVI and especially WIKI capture retail investor attention to a greater extent.

\section{Longer Lags for Advertising}

In Figure B1, we show results on TV advertising from a regression as in Table 2, Column (2), from the main paper with two weeks of advertising (i.e., 14 coefficients). The results show that the effect of TV advertising on Wikipedia page drops off quickly after lag 1. In Figure B2, we present the results on newspaper advertising from the same regression. While newspaper effects seem to last a bit longer, their economic significance is virtually zero from lag 9 and the effect on lag 7 is already $70 \%$ smaller than on day $t=0$. We therefore conclude that the effects of TV and newspaper advertising on investor attention are most pronounced in the first few days after an advertisement.

\section{Cross-Sectional Sample Splits}

In Panel A.1 of Table C13 we present results based on TV advertising. In the upper left part of the panel we split the sample into firms that belong to consumer industries and firms that belong to other industries and run the same regression as in Column (3) of Table2, While we only show the impact of $A d v_{T V, t}$ and $A d v_{T V, t-1}$, lags 2 and 3 as well as the same controls as before are included in the regression. We find highly significant coefficient estimates for both subsamples. The effect is somewhat stronger for firms from the consumer industry whose name might be more familiar to the viewers, but it is still substantial in non-consumer industries. In the following two columns, we split the sample according to the firms' media coverage. The low (high) media coverage sample 
contains all firms with a below (above) median number of national newspaper articles mentioning the firm over the previous 12 months. We now find a stronger effect among firms with low media coverage. In this case, the coefficient for contemporaneous as well as lagged abnormal advertising is positive and highly statistically significant, while it is insignificant for contemporaneous $A d v$ among firms with high media coverage. The coefficient estimates are also much larger in the first case. Thus, creating attention through advertising is particularly effective for firms that are not already well-known due to their high press coverage.

\section{Temporal Stability}

In Panel A.2 we split our sample period into the earlier years 2007 to 2009 and the later years 2010 to 2012. Despite the relatively short subsample periods, we still find highly significant coefficients which are of similar magnitude to those in the overall sample, confirming that our results are robust over time. In addition, we estimate our main specification with firm as well as day fixed effects and cluster our standard errors on the firm and day level. Our results are robust to this change as well.

\section{Alternative Abnormal Advertising Measures}

In Panel A.3 we use variations of our proxy for abnormal advertising. In the first and second column we replace the scaling constant, which is one in our base case, with 0.1 and 0.5 . The scaling constant makes sure that we do not need to drop observations with zero advertising on the current day or the median observation during the last eight weeks. A scaling constant of one is in line with a $\$ 1$ advertising expenditure, which is clearly arbitrary. Varying this scaling constant does not strongly affect results. In the third column we vary the computation of normal advertising during the last eight weeks, that is, the denominator of our abnormal advertising ratio. We switch from using the median level of advertising expenditures on the same weekday during the last 8 weeks to the mean. Again, results remain statistically significant and economically relatively weak.

In the bottom right part of the panel we replace our $A d v$ variables by more coarse and endogeneityprone advertising measures (without differencing / normalization). In the fourth column we define 
advertising as the natural logarithm of 1 plus the dollar amount spent on TV advertising by the respective firm, $\log (1+A d \$)$. In the fifth column, we replace $A d v$ by a dummy variable that takes on the value one, if the firm spent at least one USD on advertising on TV on the respective day, and zero otherwise, $\mathrm{I}_{A d \$>0}$. In both cases, we still find positive coefficients of advertising on attention and the impact of contemporaneous as well lagged advertising is significant at the 1\%level. For readability, both log-advertising and the dummy are divided by 1000, so that a TV ad is associated with $0.97 \%(0.65 \%)$ abnormal advertising on the day of (the day after) the advertisement is broadcast.

Panel B of Table C13 presents the respective results for newspaper advertising. We find highly significant effects for firms in consumer as well as in non-consumer industries, with the coefficient estimates in consumer industries being slightly larger. Similarly, while newspaper advertising is significantly related to AWIKI for low as well as high media coverage firms, the effect is somewhat stronger for firms with low media coverage. When we split the sample into the earlier and later time period, we find significant effects in both. The same is true if we look at the result from the other stability tests described above.

\section{A.3 Advertising and Financial Markets: Stability Tests}

This section describes in more detail the tests we only shortly present in Sections 3.2 and 3.3 . We test the stability of our main findings from Section 3.1 and use the same regression specifications as there, except when otherwise mentioned. To keep the presentation of results short, we only report the contemporaneous and first-lag effects of advertising, that is, the lags with the largest attention effects.

\section{Advertising Channels}

We begin our analysis by regressing our financial market variables on measures of abnormal news and business channel advertising, $A d v_{T V N W S}$, and abnormal advertising in all other channels, $A d v_{T V N O N W S}$. The set of control variables and fixed effects is the same as in Section 3.1. Table

\section{IA.7}


C22 presents the results. Column (1) shows that the effect of advertising on turnover is consistently insignificant for news and business channel advertising. In contrast, for non-news TV advertising the contemporaneous effect and the first lag of $A d v_{T V N O N W S}$ are significant. This result is consistent with a particularly large effect of advertising-induced attention via non-news TV stations due to the large audience reached. It is also possible that the insignificant results on $A d v_{T V N W S}$ are caused by insufficient power to measure such a small effect or noise in the variable due to the low overall dollar level. E.g., when we consider the dollar impact associated with the coefficient estimates, the effect of contemporaneous advertising on turnover is of similar magnitude for both types of channels.

For illiquidity, we find a substantially stronger effect both in statistical and economic terms for $A d v_{T V N W S}$ than for $A d v_{T V N O N W S}$. As can be seen in Column (2), the coefficients on lags one to three of $A d v_{T V N W S}$ are significant at least at the $5 \%$ level. Except for lag two, which is significant at the $10 \%$ level, $A d v_{T V N O N W S}$ is insignificant. The economic significance of all coefficients on $A d v_{T V N W S}$ is substantially higher in absolute terms than for $A d v_{T V N O N W S}$. For instance, the coefficients on the first lag in Column (2) suggest that a campaign starting on day $t-1$, and that is associated with an increase of abnormal advertising in news and business (other) TV channels of one standard deviation leads to a decrease in Eff Spr $r_{t}$ by $-0.29 \%$ (-0.12\%). Considering an equally large increase in dollar terms, e.g., by 100,000 USD, in both news and business (other) TV channels is associated with a decrease in EffSpr $r_{t}$ by $-0.89 \%$ (-0.029\%). This pattern suggests a substantially stronger effect of news and business TV advertising on illiquidity. Although it is plausible that the effect for advertising in news and business channels is stronger than that of advertising in the other channels, it should be noted that the economic significance is still small in both cases since 100,000 USD in news and business channel advertising is far above its mean (2,300 USD).

When we investigate the effect on returns, we find no significant positive effect of either $A d v_{T V N W S}$ or $A d v_{T V N O N W S}$ (see Column (3)), consistent with our earlier result that return effects are negligible. That is, even advertising via channels that are more likely to be seen by potential

\section{IA. 8}


investors (and that we show in Section 2 to trigger more investor attention) does not lead to a measurable return effect.

Next, we study the effect of advertising in specific newspapers by computing abnormal advertising separately for the Wall Street Journal, $A d v_{N P W S J}$, the other three national newspapers (New York Times, USA Today, Washington Post), $A d v_{N P 3 N A T}$, and for all local newspapers $A d v_{N P L O C}$. Advertising in the Wall Street Journal (the other three national newspapers) is about 8 (5) times smaller than aggregate advertising in the 151 local newspapers, so that the coefficients should again be interpreted in dollar terms. Results are presented in Table C23

Column (1) shows that the effect on turnover is strongest for $A d v_{N P W S J}$. For lags one to three, the coefficients on $A d v_{N P W S J}$ and $A d v_{N P L O C}$ are significant at least at the $5 \%$ level, while they are insignificant for the other three national newspapers. Except for the contemporaneous effect, the coefficients on all lags of advertising are largest for $A d v_{N P W S J}$. For instance, the coefficients on the first lag imply that doubling the amount of advertising spent in the Wall Street Journal (local) newspapers is associated with an increase in turnover by $0.05 \%(0.03 \%)$. Since seven times less advertising dollars are spent in the Wall Street Journal alone compared to all local newspapers, this effect is strongly reinforced and clearly shows that the impact on turnover is strongest for $A d v_{N P W S J}$.

We find no significant impact of $A d v_{N P 3 N A T}$ or $A d v_{N P L O C}$ on illiquidity (see Column (2)). For the third lag of $A d v_{N P W S J}$, the coefficients are negative, but not significant, for the contemporaneous effect and the first two lags. In the third lag, we observe a positive coefficient that is significant at the $5 \%$ level. This suggests that illiquidity increases following an increase in advertising in $t$-3. Given that the other coefficients are consistently negative, we conclude that there is also no strong effect of $A d v_{N P W S J}$ on illiquidity.

Results for the impact of newspaper advertising on returns are presented in Column (3). We observe no statistically significant impact of abnormal advertising in the three national newspapers on returns, a positive impact (at the $5 \%$ level) of yesterday's advertising in local newspapers on 
today's returns and a counter-intuitive negative impact of yesterday's advertising in the Wall Street Journal. However, even for these cases the economic magnitude of the effect is always negligible.

\section{Advertising Sensitivity}

In Tables C24 and C25, we report our results for the advertising sensitivity split including turnover and liquidity as dependent variables, analogous to our main Table 4, where we report only results with returns as the dependent variable. Thus, results in Column (3) of Tables C24 and C25 are the same as those in Table 4.

In Table C24, we present results from this sample split for TV advertising. Panel A shows that there is no significant impact of advertising on turnover or illiquidity in the low sensitivity group. Panel B presents the results for the high sensitivity group. For turnover, Column (1) shows that the coefficients are slightly larger than for low sensitivity firms for lags two and three and significant at the $5 \%$ level for lag 3. For illiquidity, Column (2) shows that the coefficients on advertising are always larger (in absolute terms) in the high sensitivity group. For lags one to three, they are significant at least at the $10 \%$ level. For turnover and illiquidity, our results therefore appear somewhat stronger for high advertising sensitivity firms compared to low sensitivity firms. However, the confidence intervals are quite wide and often overlapping 35 Thus, we conclude that the advertising effect appears to be somewhat stronger for high sensitivity firms, but even in the high sensitivity group, where we would expect the strongest effect, the impact of advertising on financial market outcomes remains small with respect to turnover and liquidity.

Next, we conduct the same sample split for newspaper advertising. The results are presented in Table C25. Panel A shows that we find virtually no effect of advertising on our dependent variables in the low sensitivity group. In the high sensitivity sample (Panel B), we find strong effects for contemporaneous advertising as well as for the first and second lag on turnover (see Column (1)).

\footnotetext{
${ }^{35}$ For instance, the $90 \%$ confidence interval for the first lag of $A d v_{T V}$ on $E f f S p r$, where the difference is strongest, is [-1.2415, 0.8201] in the low sensitivity sample (see Panel A, Column (2)) and [-2.6632, -0.1268] in the high sensitivity sample (see Panel B, Column (2)). Moreover, even the largest effects accommodated by our results are still economically small. The lower bound of the interval in the high sensitivity sample, -2.6632 , implies that a campaign starting yesterday with a one standard deviation increase in $A d v_{T V}$ is associated with a decrease in EffSpr by $\frac{2.28}{1000} \cdot(-2.6632)=-0.61 \%$.
} 
All four advertising coefficient estimates are larger than in the low sensitivity sample. Column (2) shows that we do not find larger effects on illiquidity for high advertising sensitivity firms.

\section{TV Advertising: Looking for Firms and Times with Larger Effects}

We first report results for TV advertising for subsamples of firms where we might expect the effects of advertising on financial markets to be heterogeneous (Table C26) ${ }^{36}$ In the first robustness check we split our sample at the median of firm size. One could expect small firms to be less liquid and less heavily traded, so that advertising-induced attention is more likely to have an impact on trading activity, liquidity and returns. We indeed find a statistically significant effect of advertising on turnover only among small firms (Panels A and B). However, there is essentially no effect on liquidity or returns among small or large firms 37

In a second stability test, we split the sample into firm with below and above, respectively, median values of analyst coverage (Panels $\mathrm{C}$ and $\mathrm{D}$ ). One could expect low analyst coverage firms to be less visible to investors, so that advertising should have a particularly large effect on these firms. Indeed, the impact of TV advertising on turnover is larger for low coverage firms. It is statistically significant at the 5\% (1\%) level contemporaneously (at the first lag). Economic significance remains small. Again, the impact on illiquidity is consistently negative, but there are no clear differences between low and high coverage firms. For returns, there are no statistically significant coefficients in either group.

In the third split, we analyze low and high media coverage firms separately (Panels E and F) ${ }^{38}$ One could expect low media coverage firms to be less visible to investors and thus more susceptible to the impact of advertising. Turnover in fact seems to react more strongly to TV advertising for low coverage firms, while liquidity is impacted more for high coverage firms and returns are unaffected for both. In any case, effects remain economically small.

In a fourth split, we separately examine consumer industry firms and other firms (Panels G and

\footnotetext{
${ }^{36}$ Results for newspaper advertisements are discussed separately later in this section.

${ }^{37}$ When we consider the smallest quintile of firms, we find qualitatively similar results (untabulated).

${ }^{38}$ We use the number of national newspaper articles during the last 12 months in order to measure media coverage. We split at the cross-sectional median.
} 
H). Consumer industry firms should be known to more retail investors, so that stronger effects of advertising could be expected for the remaining, less-known firms. Although the only statistically significant coefficients are indeed in the non-consumer industry subgroup, coefficient sizes do not systematically vary over the two groups. Signs are consistent with our previous results, that is, TV advertising positively impacts turnover and liquidity. More importantly, the economic significance of coefficients is small for both subsamples.

In a fifth split, we estimate our results separately for low- and high-concentration industries (Panels I and J) ${ }^{39}$ There is marketing literature showing larger advertising-valuation elasticities for less concentrated industries (Edeling and Fischer, 2014), so that one could argue that investor attention might also be more strongly affected in these industries. Although turnover coefficients are indeed stronger in the low-concentration subsample, effects remain economically weak, in particular for returns.

In a further test on the heterogeneity of advertising effects, we examine the impact of extreme advertising shocks using a dummy indicating that abnormal TV advertising was in its highest decile (Panel K) or even percentile (Panel L) on that day. On days with extreme abnormal advertising in its highest decile, the effect on turnover is limited to a meager $0.27 \%(0.52 \%)$ increase on the contemporaneous (subsequent) day. The impact on liquidity and returns remains insignificant (and coefficient estimates small). Focusing on even more extreme advertising in its highest percentile, we find no significant effects at all (except a counter-intuitive significant negative impact on returns for lagged advertising).

Next, we focus on first time advertisers and abnormal advertising after low versus high advertising periods, measured by the log of advertising expenditures in the last eight weeks relative to the log of advertising in the previous eight weeks. We find that - in addition to the usual effect of abnormal advertising - effects for first time advertisers are not significant (Panel M). Abnormal advertising after low advertising periods is followed by significantly more turnover at similar economic magni-

\footnotetext{
${ }^{39}$ We use the Herfindahl-Hirschman Index with respect to sales within 3-digit NAICS-industries to estimate industry concentration and split at the last financial year's cross-sectional median.
}

IA.12 
tudes as previous results, whereas turnover effects are statistically insignificant and economically smaller after high advertising periods (Panels $\mathrm{N}$ and $\mathrm{O}$ ). Effects on liquidity and returns remain insignificant independent of the level of advertising in the previous eight weeks.

In our next test about the heterogeneity of TV advertising's effects on financial markets, we look at overnight (close-to-open) and intraday (open-to-close) returns separately. This analysis is motivated by the higher overnight retail trading activity and associated return patterns documented in Lou, Polk, and Skouras (2018). We use CRSP's open and close prices to compute overnight and intraday returns, respectively, and we assume dividends and splits to occur after markets close. We do not find that return effects become significant, even when focusing on the nights directly after advertising, that is, the nights with the plausibly highest advertising-induced retail buying pressure (Panel P).

In Panels $\mathrm{R}$ through $\mathrm{W}$ we focus on high vs. low advertising expenditure times, specifically Mondays vs. other weekdays, December vs. other months, and NBER recession months vs. nonrecession months. Weekends, the holidays, and non-recession months are times with particularly high advertising expenditures, so that one could expect stronger effects. Indeed, turnover is more strongly affected by advertising during high advertising times (see Panels R and T). Importantly, coefficients in the return regression do not increase enough to be economically significant.

Last, In Panel X, we specifically look at days including an earnings announcement or national newspaper coverage in the three previous or next days, that is, the days we exclude in Panel A of Table C21 due to potential endogeneity concerns. Coefficients remain economically insignificant, in particular for returns.

\section{TV Advertising: Further Robustness Tests}

In Table C27 we present results of some further robustness tests of our results on TV advertising and financial markets. In the first test, we jointly estimate the effects of TV and newspaper advertising ${ }^{40}$ If firms increase advertising across different channels (TV and newspapers) simulta-

\footnotetext{
${ }^{40}$ For inclusion in this panel we require a firm to have advertised at least once on either channel during the last 8
} 
neously, any effect measured for TV advertising might actually be due to the impact of newspaper advertising, and vice versa. Correlations between $A d v_{T V}$ and $A d v_{N P}$ are close to zero (0.0012), so that we do not expect results to be significantly affected by this potential omitted variable bias. This is confirmed by results from Panel A, where we show the impact of TV advertising while controlling for the impact of newspaper advertising: coefficients remain similar to those from Panel A of Table 3 in the main paper. TV advertising still has a positive effect on turnover, significant at the $1 \%$ level. TV ads seem to increase liquidity (statistically insignificant). We also observe a counterintuitive negative but economically very small impact on contemporaneous returns.

To analyze the temporal stability of results, we then split our sample into the nine year subperiods of 1995 to 2003 and 2004 to 2012 (Panels B and C). The coefficient of TV advertising on turnover is higher in the earlier period. This could be because during the later period algorithmic trading and the associated increase in trading activity may mask the relatively small impact of advertising on turnover. Liquidity on the other hand seems to be more strongly impacted by TV advertising during the post-2003 period in terms of statistical significance. Possibly, high frequency trading strengthens the effect through a quicker, more efficient detection of uninformed trading due to advertising. In both periods, short-term returns do not react to TV advertising.

Next, we split the sample by trading venue (Panels D and E). NYSE/AMEX are limit order markets, whereas NASDAQ is a dealer market. This leads to differences in trading volumes ${ }^{41}$ and possibly in the response of financial markets to advertising-induced trading. On both types of exchanges, TV advertising impacts turnover and liquidity positively. The positive effect on liquidity seems to be stronger on NASDAQ (maybe because NASDAQ firms tend to be less well-known), while the negative effect on stock returns is stronger on NYSE/AMEX. For both types of exchanges, the economic magnitude of effects remains small.

In further robustness checks we change the definition of our advertising measure. We first report

weeks.

${ }^{41}$ Interdealer trades on NASDAQ increase trading volumes by a factor that varies over stocks and over time, see Atkins and Dyl (1997) and Anderson and Dyl (2007).

IA.14 
results for variations of our abnormal advertising measure, where we use 0.1 (Panel F) or 0.5 (Panel G) instead of 1.0 as the scaling constant, and the mean instead of the median advertising from the previous eight weeks in the denominator (Panel H). We believe that analyzing abnormal advertisingdollars as in the main paper is important for a clean identification: it alleviates the problem that persistent firm-specific advertising might drive our estimates. However, we find similar results when we use the log of TV advertising dollars or a dummy that indicates whether TV ads were broadcast on that day or not, respectively (Panels I and J). TV advertising significantly increases turnover contemporaneously. The economic impact implied by the coefficients is comparable to our earlier results: For $\ln ($ advertising) the coefficients can be directly compared (and interpreted as elasticities), while for dummies the $0.30 \%$ increase in turnover on days with TV ads is similar in magnitude to a two to three standard deviation impact for our results based on abnormal advertising from Section 3.1 in the main paper. The effect of the alternative measures of advertising on liquidity is mostly positive and statistically insignificant, while the effect on returns always remains economically insignificant. Hence, the normalization of advertising does not drive our results.

In the next four panels ( $\mathrm{K}$ to $\mathrm{N}$ ), we report variations of our regression specification. We first use firm and day fixed effects with firm and day clustered standard-errors. This specification is slightly more rigorous than our usual panel regression with week and day-of-week fixed effects and firm clustered standard-errors. Still, results are very similar to before. Second, we use a specification, where we control for firm-specific seasonality by normalizing the dependent variables with the lagged dependent variable on the same day last week, instead of including this lagged dependent variable directly in the regression. This leads to economically and statistically slightly stronger effects of advertising on illiquidity, but does not qualitatively change turnover and return effects. Third, we aggregate our data to the weekly frequency and regress on weekly log-differences of TV advertising expenditures. This aggregation seems to blur the daily effects, consistent with the short-lasting impact of attention: Coefficients are mostly statistically insignificant with the exception of the contemporaneous effect of advertising on turnover, which is negative and significant 
at the $10 \%$-level, contrary to expectations. The disappearance of the daily turnover effects on the weekly level is in line with economically small and short-lasting attention-effects of advertising. Last, we use a daily Fama-MacBeth regression instead of the panel regression for returns, to more rigorously control for cross-sectional correlation and to be consistent with the bulk of the asset pricing literature. In all specifications, results remain qualitatively unchanged.

\section{Newspaper Advertising: Looking for Firms and Times with Larger Effects}

Tables $\mathrm{C} 28$ and $\mathrm{C} 29$ present the results of analogous stability checks for newspaper advertising that we conducted for TV advertising above. First, in Table C28, we again focus on firms and times, for which we expect the effects of newspaper advertising on financial markets to be heterogeneous. In contrast to our results for TV advertising, we do not find that small firms or low coverage firms are more strongly impacted by newspaper advertising. For turnover, the coefficients of newspaper advertising are actually statistically significant only in the large firms and high coverage sub groups. However, overall, coefficient sizes are not systematically larger for the large firms and high coverage subgroups, particularly for liquidity and returns. Importantly, economic significance does not change markedly 22

Results for the impact of newspaper advertising in media coverage subgroups are likewise mixed (Panels E and F). It seems that turnover for the low media coverage group reacts more strongly contemporaneously, but more weakly a day after the ad. The liquidity results indicate a higher (more positive) impact of newspaper advertising on liquidity of low media coverage firms, relative to high media coverage firms. However, coefficient sizes are economically near zero and mostly statistically insignificant. Return effects are essentially zero and always insignificant.

In the consumer industry split (Panels $\mathrm{G}$ and $\mathrm{H}$ ), we find that turnover effects are larger in the non-consumer industry subgroup. Liquidity however increases in the non-consumer industry subgroup and decreases in the consumer industry subgroup, but coefficients are insignificant. For returns we find one marginally significant positive coefficient for the impact of contemporaneous

\footnotetext{
${ }^{42}$ We find qualitatively similar results when considering only firms in the lowest size quintile.
} 
(but not lagged) newspaper advertising in the non-consumer industry subgroup. In any case, confidence intervals are very close to zero or include zero, that is, effects remain economically small.

When we split by industry concentration (Panels I and J), turnover effects seem to be stronger in the low-concentration industries. However, liquidity effects remain insignificant throughout and return effects remain economically small, even for the one statistically significant positive effect in the low-concentration subsample.

We then split firms by investor attention's sensitivity to Wall Street Journal advertising (rather than overall advertisement sensitivities as in Section 3.2 of the main paper). We regress on abnormal advertising in the Wall Street Journal on our dependent variables to find out whether the large proportion of investors in the Wall Street Journal's readership, together with a focus on firms with a high attention-sensitivity to Wall Street Journal advertising, might lead to a larger effect on financial markets (Panels $\mathrm{K}$ and L). Turnover and return effects are not stronger in the high sensitivity subsample. Effects on illiquidity are statistically stronger, but economically at a similarly small magnitude as previous results.

Next, in Panels M to Q, we replace our abnormal advertising measure with a dummy that indicates whether abnormal TV advertising was in its highest decile or percentile, respectively, on that day and focus on first time advertisers as well as abnormal advertising after low versus high advertising periods, measured as in Table C26. In all cases, the patterns documented above are generally confirmed. Most importantly, we never find any statistically significant coefficient estimates for the impact of newspaper advertising on returns.

In our next robustness check, we look at the effect of newspaper advertising on overnight and intraday returns separately (Panels R and S). As for TV advertising, we do not find significant return effects, even overnight, when retail investors are supposedly particularly active.

In Panels T through Y we focus on high vs. low advertising expenditure times, specifically Mondays (after high advertising weekends), Decembers (around high advertising holidays), and NBER 
non-recession months. Results are mixed. Importantly, coefficients in the return regression never increase enough to be economically significant. As our economically most significant coefficient, we even find a counterintuitive significantly negative coefficient for Monday newspaper advertising. However, this coefficient also is not economically significant.

Last, In Panel Z, we specifically look at days including an earnings announcement or national newspaper coverage in the three previous or next days, that is, the days we exclude in Panel B of Table C21 due to potential endogeneity concerns. Coefficients remain economically insignificant, in particular for returns.

\section{Newspaper Advertising: Further Robustness Tests}

In Table C29 we report the remaining stability checks for newspaper advertising (analogous to Table C27). Again, jointly estimating the impact of advertising on turnover for TV and newspaper advertising does not change our results compared to Panel B of Table 3 from the main paper 43 If anything, the positive effect of newspaper advertising on turnover becomes a bit stronger when we control for TV advertising (Panel A). However, it still remains economically insignificant. A one standard deviation increase of newspaper advertising increases tomorrow's turnover by around $0.16 \%$. Liquidity and returns are not significantly impacted by newspaper advertising.

Splitting our sample into the subperiods 1995 to 2003 and 2004 to 2012, we also find a stronger impact of newspaper advertising on turnover for the earlier subperiod (Panels B and C). The insignificance of newspaper advertising's effect on liquidity and returns is temporally stable.

In the trading venue split (Panels D and E), we find that newspaper advertising has a slightly stronger impact on NYSE/AMEX firms' turnover. Although the statistical significance is stronger for this sub group, coefficient sizes are similar, that is, standard errors are larger for NASDAQcoefficients. Effects on liquidity on the other hand are stronger for the NASDAQ subgroup. In particular, the positive reaction of liquidity to newspaper advertising yesterday is strong and significant only for NASDAQ firms. Return effects are mostly insignificant, with the exception of a

\footnotetext{
${ }^{43}$ For inclusion in this panel we require a firm to have advertised at least once on either channel during the last 8 weeks.
} 
small positive contemporary impact in the NASDAQ sample. However, even this effect- despite being statistically significant at the $10 \%$-level - is tiny in terms of economic significance.

In a further robustness check we use alternative measures of advertising. As we do in Table C27 for TV advertising, we first report results for variations of out abnormal advertising measure, where we use 0.1 (Panel F) or 0.5 (Panel G) instead of one as the scaling constant, and the mean instead of the median advertising from the previous eight weeks in the denominator (Panel H). We then use the log of advertising and a dummy indicating any newspaper advertising, respectively in Panels I and J. Importantly, confidence intervals never include economically significant values. For the dummy specification, the effect of an ad today on tomorrow's turnover is statistically significant (10\% level) and positive at $0.25 \%$, which is in the range of the 1-2 standard deviations effect for our default abnormal advertising specification in Panel B of Table 3 from the main paper.

In the next four panels ( $\mathrm{K}$ to $\mathrm{N}$ ), we again report variations of our regression specification. Firm and day fixed effects with firm and day clustered standard-errors do not lead to qualitatively different results. Controlling for firm-specific seasonality by normalizing the dependent variables with the lagged dependent variable on the same day last week does not change our findings either. Effects of newspaper advertising on turnover remain positive and return effects are economically small. Next, we aggregate our data to the weekly frequency and regress on log-differences of weekly newspaper advertising expenditures relative to the median week amongst the last eight weeks. As for TV advertising, this aggregation seems to blur the daily effects, consistent with the short-lasting impact of attention: Coefficients are all statistically insignificant. Going to high-frequency daily data is necessary to capture the causal effect of advertising on financial markets via attention. Last, we also again use a daily Fama-MacBeth regression instead of the panel regression for returns. In all specifications, results remain qualitatively unchanged.

\section{Monthly Return Regressions}

In Table C30, we run regressions of monthly stock returns on contemporaneous and lagged logchanges in TV and newspaper advertising expenditures, as well as conventional control variables 
from the asset pricing literature. Specifications (1) to (3) are Fama-MacBeth regressions and Specifications (4) to (6) are analogous panel regressions with firm and month fixed effects and double-clustered standard errors. These monthly regressions might be exposed to similar endogeneity problems that regressions using yearly advertising data face, since firms might have already enough time to adjust their advertising in response to high returns (or whatever else causes them) within a month. However, monthly regressions are more common in (and thus comparable to) the conventional asset pricing literature. For our sample period, we can for instance see a significant positive effect of the past year's returns on this month's return, that is, momentum. More importantly, the coefficients for contemporaneous and lagged monthly log-changes in advertising are statistically insignificant in Specifications (1) and (4) with TV advertising, Specifications (2) and (5) with newspaper advertising, and Specifications (3) and (6), where TV and newspaper advertising are both included. Upper bounds for $99 \%$ confidence intervals of a one-standard-deviation increase in advertising are all below 15bp per month, so that economically large effects of advertising on returns can again be rejected. Hence, monthly return regressions are in line with our higher-frequency results: We can reject an economically (of statistically) significant short-term effect of advertising on stock returns.

\section{Alternative Liquidity Proxies}

In our main analysis we use effective spreads as our default liquidity proxy. To test for the stability of our results, we instead use relative spreads, price impact, or an intraday version of the Amihud illiquidity measure. Results are reported in Tables C31 and C32 for TV and newspaper advertising, respectively. Our conclusions remain unchanged: Product market advertising tends to have a positive impact on liquidity, decreasing spreads, price impact, and the intraday Amihud measure. However, coefficients tend to be statistically insignificant, and we can reject economically large effects.

\section{Buys, Sells, Order Imbalances, and Volatility}


In a last set of additional tests, we analyze further financial market variables that might be affected by product market advertising. We test the effect of advertising on order imbalances, buy- and sell-volume, as well as volatility measured by absolute daily returns. Results are reported in Tables C33 and C34 for TV and newspaper advertising, respectively. Whereas advertising significantly increases trading activity both for buys and sells, we do not find significant order imbalances as a reaction to advertising. This is in line with the missing effect of advertising on returns. Attentioninduced return effects should be driven by buying pressure, which we do not observe. Also consistent with a negligible effect of advertising on returns, we can reject economically significant increases in volatility when advertising increases (Column (4) in Tables C33 and C34).

\section{PVAR model by advertising channel}

In the main paper we present results based on a PVAR model using advertising in TV and newspapers jointly. We also rerun the PVAR model with TV and newspaper advertising separately. Results are reported in Table C35. The estimates become more noisy, but we still find a highly significant positive impact of returns on advertising. The effect from advertising on stock returns is statistically insignificant for newspapers and economically insignificant and even negative for TV advertising (less than -20bp after twelve months). Impulse response functions for TV and newspaper advertising are shown in Figures B3 and B4 in the Internet Appendix. 


\section{B Appendix: Additional Figures}

Figure B1: Advertising and investor attention -2 weeks TV advertising

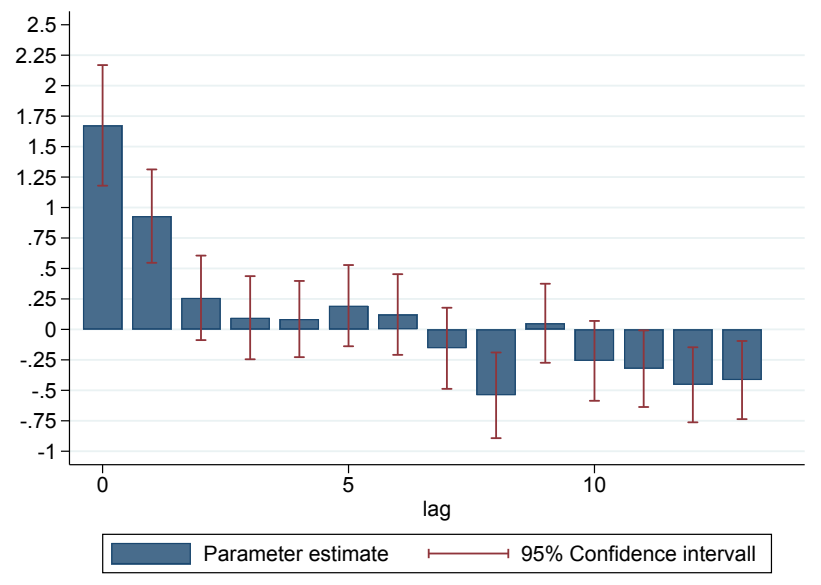

This figure effects of TV advertising from a regression as in Table 2. Column (2) with two weeks of advertising (i.e., 14 coefficients). To identify effects of one-day spikes for lags larger than 0 , first differences of the coefficients are displayed. This is because a one-day spike in advertising on day $\mathrm{t}$ will cause an increase in AdvTV on day $\mathrm{t}$ and an equally large decrease in $\mathrm{Adv}_{\mathrm{TV}}$ on day $\mathrm{t}+1$. The error lines give $95 \%$ confidence intervals based on standard errors clustered by firm. 
Figure B2: Advertising and investor attention - 2 weeks NP advertising

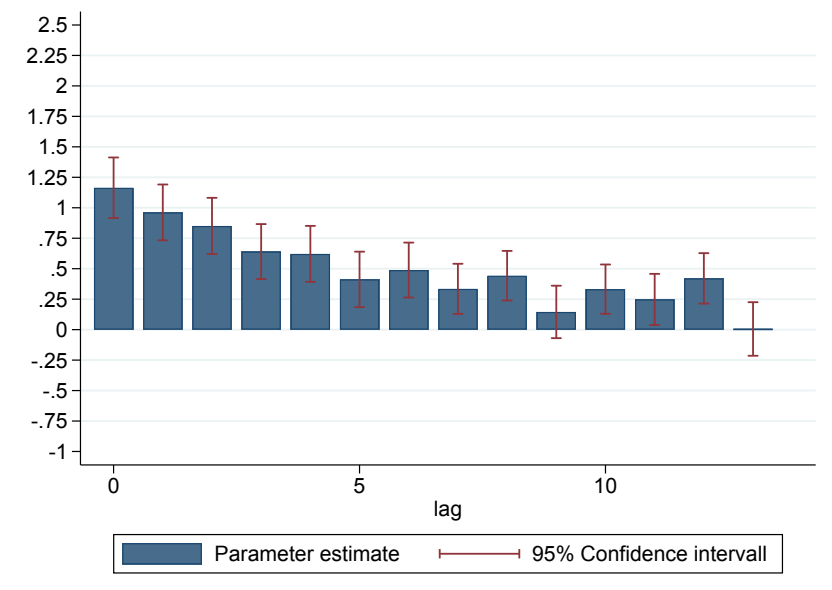

This figure coefficients on TV advertising from a regression as in Table 2, Column (2) with two weeks of advertising (i.e., 14 coefficients). The error lines give $95 \%$ confidence intervals based on standard errors clustered by firm.

IA. 23 
Figure B3: Impulse Response Functions: Stock Returns and TV Advertising

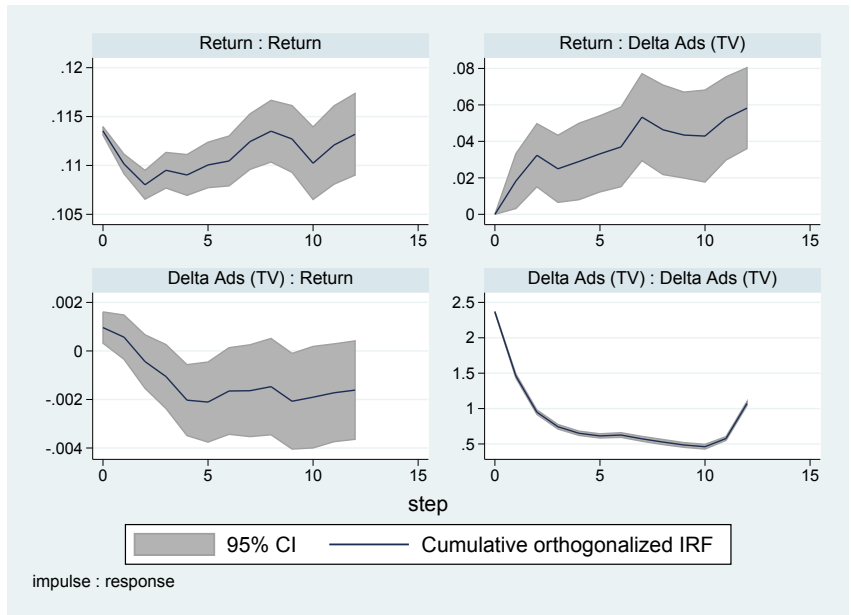

This figure displays impulse response functions from a panel VAR model with monthly stock returns and TV advertising as the components. For the underlying estimates see Table 5 columns (3) and (4). The impulse response functions are cumulative and orthogonalized in the order advertising - stock returns. They give the effect on the response variable for a one standard deviation shock to the impulse variable. 95 percent confidence intervals based on monte carlo simulations with 200 draws are given by the grey area around the point estimates. Delta Ads (TV) are monthly log differences in TV advertising dollars.

IA.24 
Figure B4: Impulse Response Functions: Stock Returns and Newspaper Advertising

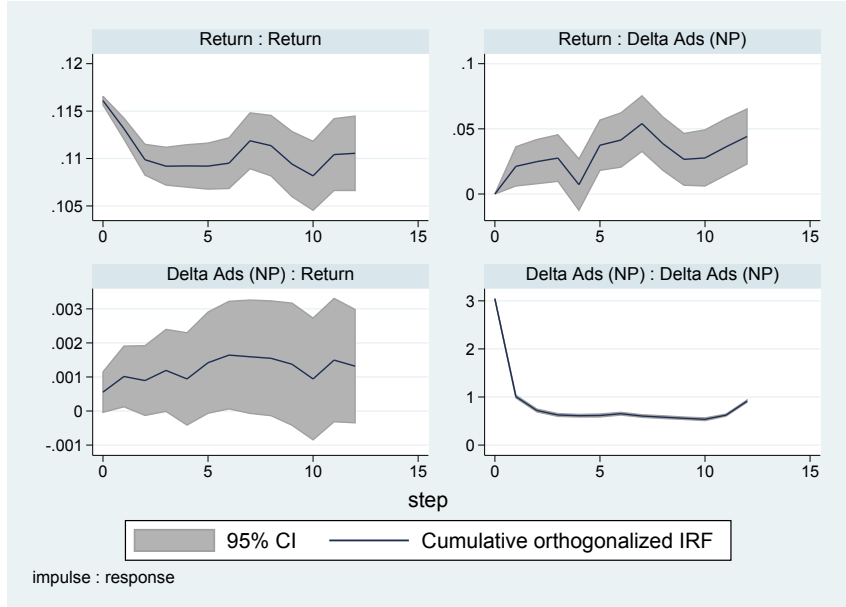

This figure displays impulse response functions from a panel VAR model with monthly stock returns and newspaper advertising as the components. For the underlying estimates see Table 5 columns (5) and (6). The impulse response functions are cumulative and orthogonalized in the order advertising - stock returns. They give the effect on the response variable for a one standard deviation shock to the impulse variable. 95 percent confidence intervals based on monte carlo simulations with 200 draws are given by the grey area around the point estimates. Delta Ads (NP) are monthly log differences in newspaper advertising dollars.

IA. 25 


\section{Appendix: Additional Tables}

Table C1: Summary Statistics - Advertising and Wikipedia page views

This table gives summary statistics on Wikipedia page visits and Kantar advertising expenditure. The sample goes from 2007 to 2012. Wiki page visits and the advertising variables are per day. $\mathrm{Adv}_{\mathrm{i}, \mathrm{t}}$ is abnormal newspaper advertising, $\mathrm{i}=\{\mathrm{TV}, \mathrm{TVNWS}, \mathrm{TVNONWS}, \mathrm{NP}, \mathrm{NPLOC}, \mathrm{NPNAT}$, NPWSJ, NP3NAT $\}$. TV refers to all TV channels, TVNWS to news channels (CNN, CNBC, Fox News, MSNBC, CNN headline news), TVNONWS to all non-news TV channels, NP to all newspapers, NPLOC to local newspapers, NPNAT to national newspapers (Wall Street Journal, New York Times, USA Today and Washington Post), NPWSJ to the Wall Street Journaland NP3NAT to the other three national newspapers. News is a national newspaper article dummy. Turnovert-7,t-36 is the trading volume over the 4 weeks up to t-7, divided by average shares outstanding. Return $\mathrm{t}_{\mathrm{t}, \mathrm{t}-\mathrm{t} 36}$ is the holding period return over the 4 weeks up to t-7. ReaVolat-7,t-36 is realized volatility, defined as average absolute return during the 4 weeks up to t-7. MarketCap is the firm's market capitalization. Panel A and B report statistics at the firm-day level on the regression samples for our TV and newspaper analyses, respectively.

\begin{tabular}{|c|c|c|c|c|c|c|}
\hline & Mean & Median & $\mathrm{SD}$ & $10 \%$ ile & $90 \%$ ile & $\mathrm{N}$ \\
\hline \multicolumn{7}{|c|}{ Panel A: TV regression sample } \\
\hline Market Cap (Million \$) & $14,608.23$ & $3,108.25$ & $35,826.63$ & 217.58 & $34,022.50$ & 946,215 \\
\hline Advertising-to-sales (\%) & 0.03 & 0.02 & 0.04 & 0.00 & 0.08 & 780,702 \\
\hline ReaVolat-7,t-36 (\%) & 46.05 & 35.46 & 35.67 & 16.77 & 86.53 & 945,457 \\
\hline Turnover $_{\mathrm{t}-7, \mathrm{t}-36}(\%)$ & 308.02 & 240.54 & 235.68 & 93.78 & 609.51 & 945,499 \\
\hline Return $_{\mathrm{t}-7, \mathrm{t}-36}(\%)$ & 0.91 & 0.93 & 14.40 & -14.50 & 15.13 & 945,457 \\
\hline News $_{t}(\%)$ & 3.44 & 0.00 & 18.23 & 0.00 & 0.00 & 947,982 \\
\hline Wiki page count & 540.89 & 116.00 & $2,572.65$ & 17.00 & $1,135.00$ & 947,982 \\
\hline TV Ad (daily $\$$ ) & $206,163.55$ & $1,757.00$ & $775,621.24$ & 0.00 & $430,238.00$ & 947,982 \\
\hline News TV Ad (daily $\$$ ) & $16,065.27$ & 0.00 & $141,040.80$ & 0.00 & $5,583.00$ & 947,982 \\
\hline $\mathrm{Adv}_{\mathrm{TV}, \mathrm{t}} * 1000$ & -0.02 & 0.00 & 2.16 & -1.48 & 1.44 & 947,982 \\
\hline $\operatorname{Adv}_{\text {TVNWS }, \mathrm{t}} * 1000$ & -0.00 & 0.00 & 1.89 & 0.00 & 0.00 & 947,982 \\
\hline $\operatorname{Adv}_{\text {TVNONWS }, \mathrm{t}} * 1000$ & -0.00 & 0.00 & 2.14 & -1.49 & 1.46 & 947,982 \\
\hline \multicolumn{7}{|c|}{ Panel B: Newspaper regression sample } \\
\hline Market Cap (Million \$) & $14,926.38$ & $3,261.33$ & $35,464.06$ & 229.40 & $34,855.18$ & 928,416 \\
\hline Advertising-to-sales (\%) & 0.03 & 0.01 & 0.04 & 0.00 & 0.06 & 760,751 \\
\hline ReaVolat-7,t-36 (\%) & 46.49 & 35.76 & 35.88 & 17.07 & 87.44 & 927,759 \\
\hline Turnover $_{\mathrm{t}-7, \mathrm{t}-36}(\%)$ & 310.24 & 243.80 & 234.06 & 96.28 & 614.21 & 927,799 \\
\hline Return $_{\mathrm{t}-7, \mathrm{t}-36}(\%)$ & 0.90 & 0.90 & 14.46 & -14.58 & 15.27 & 927,759 \\
\hline Newst $(\%)$ & 3.67 & 0.00 & 18.79 & 0.00 & 0.00 & 930,230 \\
\hline Wiki page count & 543.21 & 107.00 & $2,637.73$ & 16.00 & $1,157.00$ & 930,230 \\
\hline Newspaper Ad (daily \$) & $30,667.02$ & 0.00 & $265,019.90$ & 0.00 & $22,407.00$ & 930,230 \\
\hline National Newspaper Ad (daily $\$$ ) & $6,183.43$ & 0.00 & $46,386.81$ & 0.00 & 0.00 & 930,230 \\
\hline Local Newspaper Ad (daily \$) & $24,483.59$ & 0.00 & $237,697.16$ & 0.00 & $13,443.50$ & 930,230 \\
\hline 3 national newspaper Ad (daily $\$$ ) & $3,984.24$ & 0.00 & $35,541.67$ & 0.00 & 0.00 & 930,230 \\
\hline WSJ Ad (daily $\$)$ & $2,199.19$ & 0.00 & $24,778.52$ & 0.00 & 0.00 & 930,230 \\
\hline $\operatorname{Adv}_{N P, t} * 1000$ & 0.18 & 0.00 & 3.18 & -0.30 & 1.22 & 930,230 \\
\hline $\operatorname{Adv}_{N P L O C, t} * 1000$ & 0.16 & 0.00 & 2.96 & -0.16 & 0.90 & 930,230 \\
\hline $\mathrm{Adv}_{\mathrm{NPNAT}, \mathrm{t}} * 1000$ & 0.10 & 0.00 & 1.99 & 0.00 & 0.00 & 930,230 \\
\hline $\operatorname{Adv}_{\text {NPWSJ,t }} * 1000$ & 0.06 & 0.00 & 1.26 & 0.00 & 0.00 & 930,230 \\
\hline $\mathrm{Adv}_{\mathrm{NP} 3 \mathrm{NAT}, \mathrm{t}} * 1000$ & 0.07 & 0.00 & 1.74 & 0.00 & 0.00 & 930,230 \\
\hline
\end{tabular}


Table C2: Summary Statistics - Advertising and Google SVI

This table gives summary statistics on Google SVI and Kantar advertising expenditure. The sample goes from 2004 to 2012. Google SVI and the advertising variables are per day. $A_{d v} \mathrm{i,t}$ is abnormal newspaper advertising, $\mathrm{i}$ $=\{\mathrm{TV}, \mathrm{TVNWS}, \mathrm{TVNONWS}, \mathrm{NP}, \mathrm{NPLOC}, \mathrm{NPNAT}, \mathrm{NPWSJ}, \mathrm{NP} 3 \mathrm{NAT}\}$. TV refers to all TV channels, TVNWS to news channels (CNN, CNBC, Fox News, MSNBC, CNN headline news), TVNONWS to all non-news TV channels, NP to all newspapers, NPLOC to local newspapers, NPNAT to national newspapers (Wall Street Journal, New York Times, USA Today and Washington Post), NPWSJ to the Wall Street Journal and NP3NAT to the other three national newspapers. News is a national newspaper article dummy. Turnover $\mathrm{t}_{\mathrm{t}-\mathrm{t}, \mathrm{t}-36}$ is the trading volume over the 4 weeks up to t-7, divided by average shares outstanding. Return ${ }_{t-7, t-36}$ is the holding period return over the 4 weeks up to t-7. ReaVolat-7,t-36 is realized volatility, defined as average absolute return during the 4 weeks up to t-7. MarketCap is the firm's market capitalization. Panel A and B report statistics at the firm-day level on the regression samples for our TV and newspaper analyses, respectively.

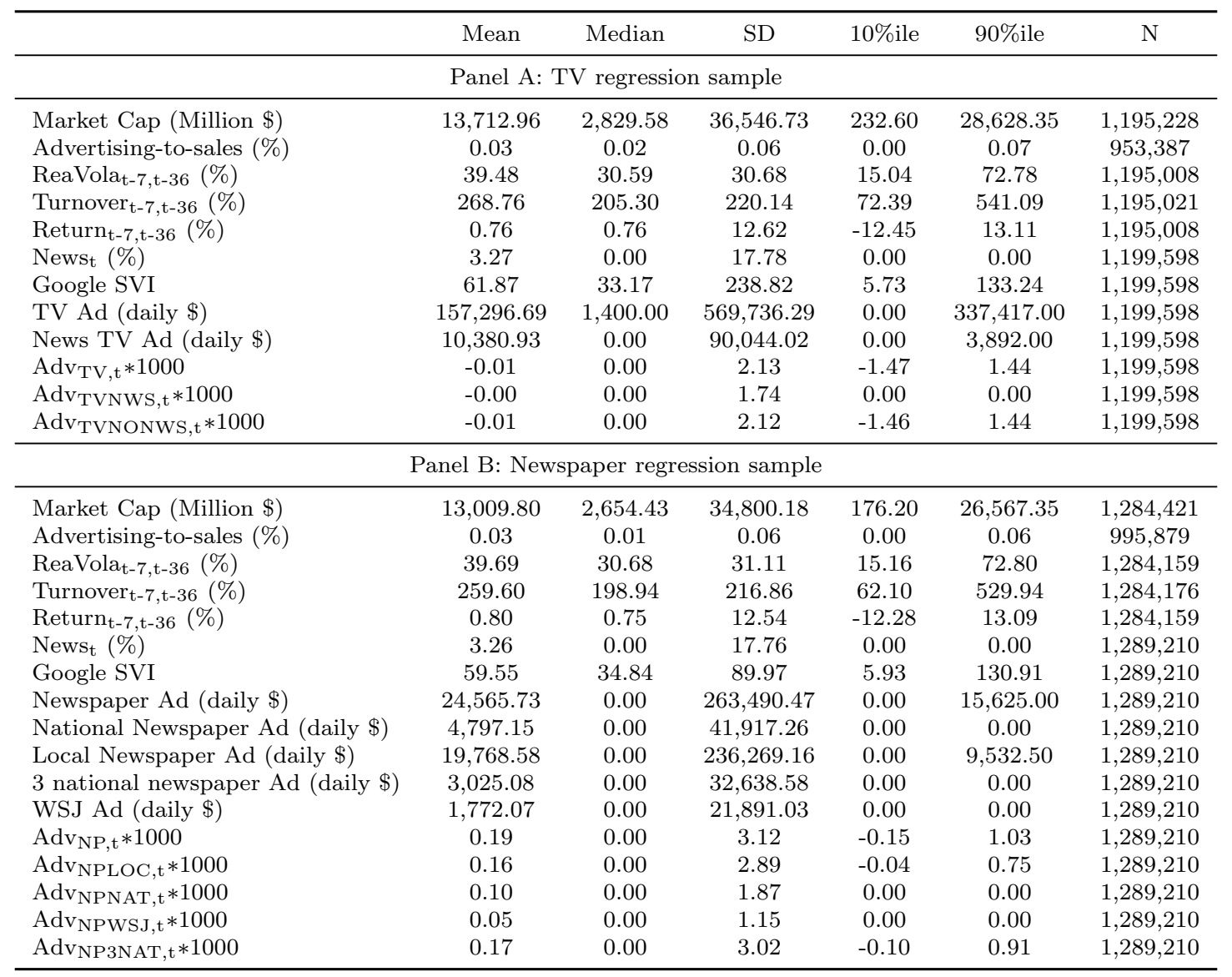


Table C3: Summary Statistics - Advertising and Edgar RPV

This table gives summary statistics on Edgar RPV and Kantar advertising expenditure. The sample goes from 2003 to 2012. Edgar RPV and the advertising variables are per day. $\mathrm{Adv}_{\mathrm{i}, \mathrm{t}}$ is abnormal newspaper advertising, $\mathrm{i}$ $=\{T V, T V N W S, T V N O N W S, N P, N P L O C$, NPNAT, NPWSJ, NP3NAT $\}$. TV refers to all TV channels, TVNWS to news channels (CNN, CNBC, Fox News, MSNBC, CNN headline news), TVNONWS to all non-news TV channels, NP to all newspapers, NPLOC to local newspapers, NPNAT to national newspapers (Wall Street Journal, New York Times, USA Today and Washington Post), NPWSJ to the Wall Street Journal and NP3NAT to the other three national newspapers. News is a national newspaper article dummy. Turnover $\mathrm{t}_{-7, \mathrm{t}-36}$ is the trading volume over the 4 weeks up to t-7, divided by average shares outstanding. Return $\mathrm{t}_{\mathrm{t}, \mathrm{t}-36}$ is the holding period return over the 4 weeks up to t-7. ReaVolat-7,t-36 is realized volatility, defined as average absolute return during the 4 weeks up to t-7. MarketCap is the firm's market capitalization. Panel A and B report statistics at the firm-day level on the regression samples for our TV and newspaper analyses, respectively.

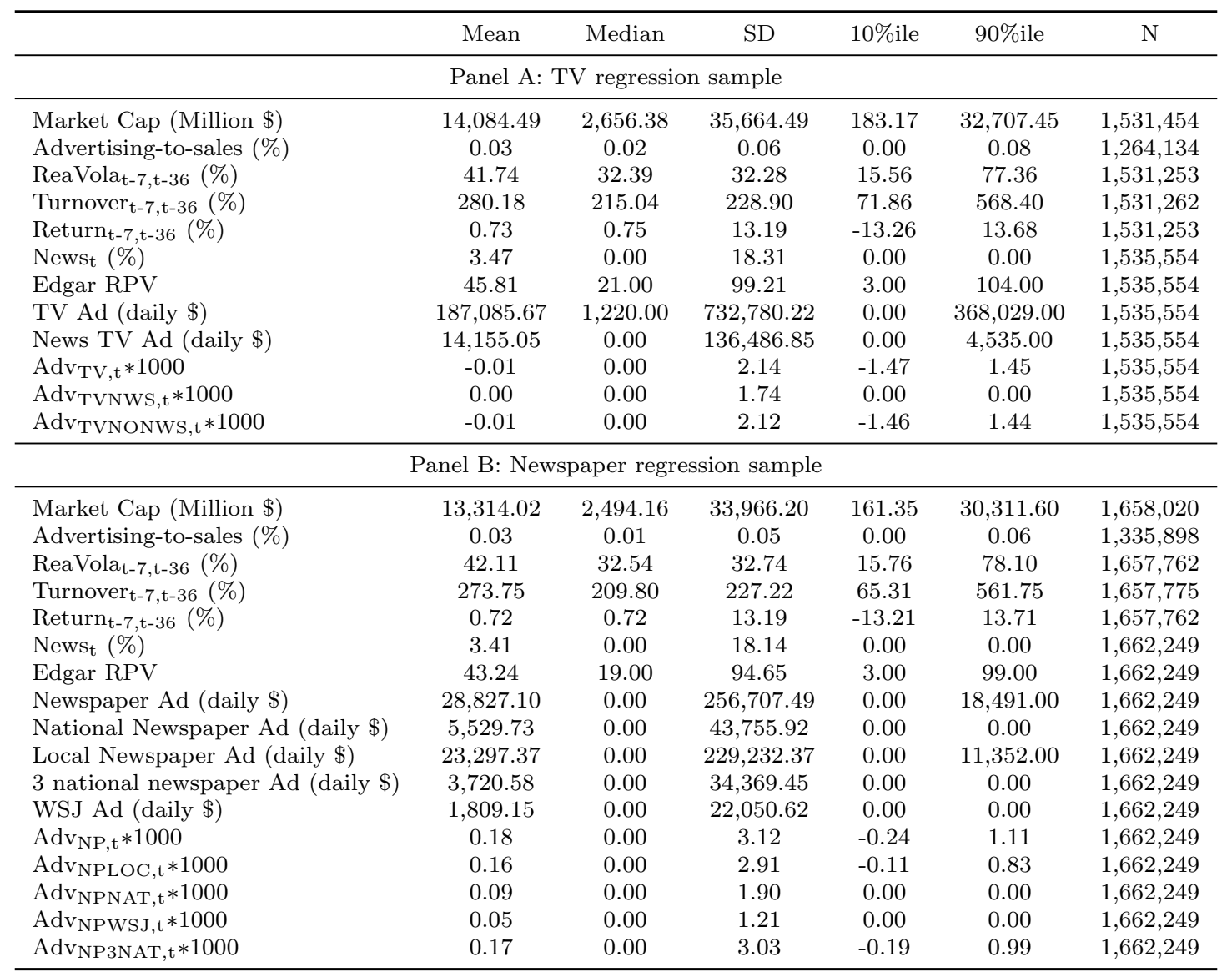


Table C4: Summary Statistics - Advertising and Bloomberg AIAC

This table gives summary statistics on Bloomberg AIACand Kantar advertising expenditure. The sample goes from March 2010 to 2012. Bloomberg AIAC and the advertising variables are per day. Advi,t is abnormal newspaper advertising, $\mathrm{i}=\{\mathrm{TV}, \mathrm{TVNWS}, \mathrm{TVNONWS}, \mathrm{NP}, \mathrm{NPLOC}$, NPNAT, NPWSJ, NP3NAT $\}$. TV refers to all TV channels, TVNWS to news channels (CNN, CNBC, Fox News, MSNBC, CNN headline news), TVNONWS to all non-news TV channels, NP to all newspapers, NPLOC to local newspapers, NPNAT to national newspapers (Wall Street Journal, New York Times, USA Today and Washington Post), NPWSJ to the Wall Street Journal and NP3NAT to the other three national newspapers. News is a national newspaper article dummy. Turnover $\mathrm{t}_{\mathrm{t}, \mathrm{t}-36}$ is the trading volume over the 4 weeks up to t-7, divided by average shares outstanding. Return $\mathrm{t}_{\mathrm{t}, \mathrm{t}-36}$ is the holding period return over the 4 weeks up to t-7. ReaVolat-7,t-36 is realized volatility, defined as average absolute return during the 4 weeks up to t-7. MarketCap is the firm's market capitalization. Panel A and B report statistics at the firm-day level on the regression samples for our TV and newspaper analyses, respectively.

\begin{tabular}{|c|c|c|c|c|c|c|}
\hline & Mean & Median & $\mathrm{SD}$ & $10 \%$ ile & $90 \%$ ile & $\mathrm{N}$ \\
\hline \multicolumn{7}{|c|}{ Panel A: TV regression sample } \\
\hline Market Cap (Million $\$$ ) & $14,800.56$ & $3,412.41$ & $34,518.00$ & 309.69 & $36,353.59$ & 353,520 \\
\hline Advertising-to-sales (\%) & 0.03 & 0.01 & 0.05 & 0.00 & 0.08 & 295,936 \\
\hline ReaVolat-7,t-36 $(\%)$ & 33.19 & 28.64 & 19.34 & 15.01 & 56.18 & 353,500 \\
\hline Turnover $_{\mathrm{t}-7, \mathrm{t}-36}(\%)$ & 274.55 & 217.14 & 204.40 & 95.22 & 514.44 & 353,502 \\
\hline Return $_{\mathrm{t}-7, \mathrm{t}-36}(\%)$ & 1.57 & 1.48 & 10.38 & -9.98 & 12.72 & 353,500 \\
\hline News $_{t}(\%)$ & 3.36 & 0.00 & 18.02 & 0.00 & 0.00 & 353,687 \\
\hline Bloomberg AIAC & 0.40 & -0.35 & 0.92 & -0.35 & 1.65 & 353,687 \\
\hline TV Ad (daily $\$)$ & $191,239.23$ & $1,818.00$ & $674,319.86$ & 0.00 & $408,459.00$ & 353,687 \\
\hline News TV Ad (daily $\$$ ) & $13,069.26$ & 0.00 & $106,262.35$ & 0.00 & $6,566.00$ & 353,687 \\
\hline $\mathrm{Adv}_{\mathrm{TV}, \mathrm{t}} * 1000$ & -0.04 & 0.00 & 2.06 & -1.27 & 1.18 & 353,687 \\
\hline $\operatorname{Adv}_{T V N W S, t} * 1000$ & -0.00 & 0.00 & 1.75 & 0.00 & 0.00 & 353,687 \\
\hline AdvTVNONWS, $t * 1000$ & -0.05 & 0.00 & 2.04 & -1.27 & 1.17 & 353,648 \\
\hline \multicolumn{7}{|c|}{ Panel B: Newspaper regression sample } \\
\hline Market Cap (Million $\$$ ) & $14,943.39$ & $3,485.57$ & $33,159.96$ & 313.48 & $37,218.32$ & 351,128 \\
\hline Advertising-to-sales (\%) & 0.02 & 0.01 & 0.05 & 0.00 & 0.06 & 290,193 \\
\hline ReaVolat-7,t-36 $(\%)$ & 33.06 & 28.68 & 19.03 & 15.28 & 55.43 & 351,126 \\
\hline Turnover $_{\mathrm{t}-7, \mathrm{t}-36}(\%)$ & 271.28 & 216.63 & 200.47 & 93.22 & 509.81 & 351,126 \\
\hline Return $_{\mathrm{t}-7, \mathrm{t}-36}(\%)$ & 1.65 & 1.47 & 10.27 & -9.69 & 12.78 & 351,126 \\
\hline Newst $(\%)$ & 3.53 & 0.00 & 18.46 & 0.00 & 0.00 & 351,255 \\
\hline Bloomberg AIAC & 0.41 & -0.35 & 0.93 & -0.35 & 1.65 & 351,255 \\
\hline Newspaper Ad (daily $\$$ ) & $17,401.32$ & 0.00 & $132,177.58$ & 0.00 & $13,289.00$ & 351,255 \\
\hline National Newspaper Ad (daily $\$$ ) & $5,423.96$ & 0.00 & $39,659.74$ & 0.00 & 0.00 & 351,255 \\
\hline Local Newspaper Ad (daily $\$$ ) & $11,977.36$ & 0.00 & $114,076.85$ & 0.00 & $6,876.00$ & 351,255 \\
\hline 3 national newspaper Ad (daily $\$$ ) & $2,717.80$ & 0.00 & $23,791.69$ & 0.00 & 0.00 & 351,255 \\
\hline WSJ Ad (daily \$) & $2,706.16$ & 0.00 & $27,251.11$ & 0.00 & 0.00 & 351,255 \\
\hline $\operatorname{Adv}_{N P, t} * 1000$ & 0.21 & 0.00 & 3.15 & -0.03 & 0.97 & 351,255 \\
\hline $\mathrm{Adv}_{\mathrm{NPLOC}, \mathrm{t}} * 1000$ & 0.18 & 0.00 & 2.84 & 0.00 & 0.68 & 351,255 \\
\hline $\mathrm{Adv}_{\mathrm{NPNAT}, \mathrm{t}} * 1000$ & 0.12 & 0.00 & 2.01 & 0.00 & 0.00 & 351,255 \\
\hline $\operatorname{Adv}_{\text {NPWSJ }, t} * 1000$ & 0.07 & 0.00 & 1.38 & 0.00 & 0.00 & 351,255 \\
\hline 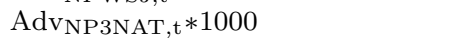 & 0.20 & 0.00 & 3.02 & 0.00 & 0.79 & 351,255 \\
\hline
\end{tabular}


Table C5: Summary Statistics - Advertising and Wikipedia Page Views

This table gives summary statistics on financial market data, Wikipedia page views and Kantar advertising expenditures. The sample goes from 2007 until 2012. Wiki page views and the advertising variables are per day. MarketCap is the firm's market capitalization. Return on assets and advertising-to-sales ratios are based on Compustat data. Turnover $_{\mathrm{t}-7, \mathrm{t}-36}$ is the trading volume over the 4 weeks up to t-7, divided by average shares outstanding. Return $\mathrm{t}_{\mathrm{t}-7, \mathrm{t}-36}$ is the holding period return over the 4 weeks up to t-7. ReaVola $a_{t-7, t-36}$ is realized volatility, defined as average absolute return during the 4 weeks up to t-7. News is a national newspaper article dummy. Panel A to C report cross-sectional summary statistics that are based on within-firm time series averages.

\begin{tabular}{|c|c|c|c|c|c|c|}
\hline & Mean & Median & $\mathrm{SD}$ & $10 \%$ ile & $90 \%$ ile & $\mathrm{N}$ \\
\hline \multicolumn{7}{|c|}{ Panel A: All public firms } \\
\hline Market Cap (Million \$) & $2,823.46$ & 281.87 & $13,542.11$ & 27.23 & $4,422.01$ & 5,308 \\
\hline Firm age & 16.63 & 12.93 & 15.41 & 2.32 & 38.20 & 5,308 \\
\hline Return on assets (\%) & 3.73 & 7.79 & 22.62 & -18.47 & 22.73 & 5,021 \\
\hline Advertising-to-sales (\%) & 5.58 & 0.98 & 19.75 & 0.02 & 8.37 & 3,385 \\
\hline Turnover $_{\mathrm{t}-7, \mathrm{t}-36}(\%)$ & 205.62 & 162.69 & 177.32 & 32.16 & 431.95 & 5,299 \\
\hline ReaVolat-7,t-36 (\%) & 61.84 & 55.22 & 31.18 & 30.79 & 101.48 & 5,299 \\
\hline Return $_{\mathrm{t}-7, \mathrm{t}-36}(\%)$ & -0.45 & 0.33 & 4.97 & -5.04 & 3.19 & 5,299 \\
\hline News $(\%)$ & 0.63 & 0.00 & 4.03 & 0.00 & 0.60 & 5,308 \\
\hline \multicolumn{7}{|c|}{ Panel B: Public firms with Wikipedia articles } \\
\hline Market Cap (Million $\$$ ) & $4,720.18$ & 789.44 & $17,598.72$ & 68.55 & $8,912.83$ & 3,058 \\
\hline Firm age & 19.08 & 14.52 & 17.40 & 2.80 & 40.95 & 3,058 \\
\hline Return on assets (\%) & 7.46 & 10.50 & 19.79 & -8.55 & 24.27 & 2,935 \\
\hline Advertising-to-sales (\%) & 5.16 & 1.00 & 18.23 & 0.01 & 8.40 & 2,093 \\
\hline Turnover $_{\mathrm{t}-7, \mathrm{t}-36}(\%)$ & 261.90 & 220.80 & 188.44 & 64.15 & 506.48 & 3,054 \\
\hline ReaVolat-7,t-36 (\%) & 55.55 & 50.91 & 25.23 & 29.37 & 85.64 & 3,054 \\
\hline Return $_{\mathrm{t}-7, \mathrm{t}-36}(\%)$ & 0.16 & 0.64 & 4.13 & -3.22 & 3.19 & 3,054 \\
\hline News $(\%)$ & 1.08 & 0.00 & 5.27 & 0.00 & 1.62 & 3,058 \\
\hline Wiki page count & 205.06 & 25.30 & $1,850.88$ & 0.22 & 313.84 & 3,058 \\
\hline \multicolumn{7}{|c|}{ Panel C: Public firms with Wikipedia articles and Kantar ads } \\
\hline Market Cap (Million $\$$ ) & $7,491.42$ & $1,557.88$ & $22,746.40$ & 142.65 & $16,746.38$ & 1,730 \\
\hline Firm age & 22.81 & 16.86 & 19.56 & 3.61 & 48.62 & 1,730 \\
\hline Return on assets (\%) & 11.84 & 11.95 & 13.13 & 1.14 & 24.84 & 1,684 \\
\hline Advertising-to-sales (\%) & 3.49 & 1.11 & 11.88 & 0.01 & 6.91 & 1,290 \\
\hline Turnover $_{\mathrm{t}-7, \mathrm{t}-36}(\%)$ & 289.67 & 252.13 & 192.25 & 89.20 & 535.07 & 1,729 \\
\hline ReaVolat-7,t-36 $(\%)^{\prime}$ & 49.84 & 45.96 & 21.63 & 27.10 & 76.46 & 1,729 \\
\hline Return $_{\mathrm{t}-7, \mathrm{t}-36}(\%)$ & 0.40 & 0.72 & 3.00 & -1.92 & 2.91 & 1,729 \\
\hline News $(\%)$ & 1.81 & 0.09 & 6.89 & 0.00 & 3.60 & 1,730 \\
\hline Wiki page count & 326.80 & 45.98 & $2,450.97$ & 1.74 & 554.59 & 1,730 \\
\hline TV Ad (daily $\$$ ) & $79,846.13$ & 56.97 & $405,088.47$ & 0.00 & $94,766.99$ & 1,730 \\
\hline News TV Ad Daily (\$) & $6,020.04$ & 0.00 & $38,112.84$ & 0.00 & $3,276.58$ & 1,730 \\
\hline Newspaper (daily $\$$ ) & $14,108.04$ & 81.81 & $106,206.52$ & 0.29 & $11,473.72$ & 1,730 \\
\hline WSJ Ad (daily \$) & 780.10 & 0.00 & $6,698.93$ & 0.00 & 507.23 & 1,730 \\
\hline 3 National newspaper Ad (daily $\$$ ) & $1,671.44$ & 0.00 & $10,910.57$ & 0.00 & $1,180.74$ & 1,730 \\
\hline Local Newspaper Ad (daily \$) & $11,656.50$ & 43.12 & $93,485.94$ & 0.00 & $6,977.19$ & 1,730 \\
\hline
\end{tabular}


Table C6: Summary Statistics - Advertising and Google SVI

This table gives summary statistics on Google SVI and Kantar advertising expenditure. The sample goes from 2004 to 2012. Google search volume (SVI) and the advertising variables are per day. News is a national newspaper article dummy. Turnover $r_{t-7,36}$ is the trading volume over the 4 weeks up to t-7, divided by average shares outstanding. Return $_{\mathrm{t}-7, \mathrm{t}-36}$ is the holding period return over the 4 weeks up to t-7. ReaVolat-7,t-36 is realized volatility, defined as average absolute return during the 4 weeks up to t-7. MarketCap is the firm's market capitalization. Panels A to C report cross-sectional summary statistics that are based on within-firm time series averages.

\begin{tabular}{|c|c|c|c|c|c|c|}
\hline & Mean & Median & $\mathrm{SD}$ & $10 \%$ ile & $90 \%$ ile & $\mathrm{N}$ \\
\hline \multicolumn{7}{|c|}{ Panel A: All public firms } \\
\hline Market Cap (Million $\$$ ) & $2,526.89$ & 282.85 & $12,196.05$ & 31.86 & $3,905.66$ & 6,459 \\
\hline Firm age & 15.24 & 11.26 & 14.63 & 2.32 & 36.68 & 6,459 \\
\hline Return on assets (\%) & 3.85 & 7.93 & 22.22 & -18.29 & 22.63 & 6,117 \\
\hline Advertising-to-sales (\%) & 5.30 & 1.07 & 18.05 & 0.04 & 8.27 & 4,023 \\
\hline Turnover $_{\mathrm{t}-7, \mathrm{t}-36}(\%)$ & 194.70 & 158.64 & 159.78 & 32.00 & 406.29 & 6,450 \\
\hline ReaVolat-7,t-36 (\%) & 52.79 & 47.97 & 25.94 & 25.52 & 86.09 & 6,450 \\
\hline Return $_{\mathrm{t}-7, \mathrm{t}-36}(\%)$ & 1.21 & 1.27 & 4.08 & -2.54 & 4.46 & 6,450 \\
\hline News $_{t}(\%)$ & 0.65 & 0.00 & 3.90 & 0.00 & 0.72 & 6,459 \\
\hline \multicolumn{7}{|c|}{ Panel B: Public firms with Google SVI data } \\
\hline Market Cap (Million \$) & $2,239.60$ & 295.14 & $11,324.87$ & 35.46 & $3,609.33$ & 4,848 \\
\hline Firm age & 14.92 & 11.30 & 13.92 & 2.32 & 36.59 & 4,848 \\
\hline Return on assets (\%) & 3.68 & 7.99 & 22.78 & -20.30 & 22.95 & 4,607 \\
\hline Advertising-to-sales (\%) & 5.44 & 1.05 & 18.84 & 0.03 & 7.91 & 3,038 \\
\hline Turnover $_{\mathrm{t}-7, \mathrm{t}-36}(\%)$ & 196.20 & 162.60 & 157.62 & 33.41 & 406.92 & 4,848 \\
\hline ReaVolat-7,t-36 (\%) & 53.24 & 48.52 & 25.24 & 26.55 & 86.22 & 4,848 \\
\hline Return $_{\mathrm{t}-7, \mathrm{t}-36}(\%)$ & 1.04 & 1.22 & 3.66 & -2.66 & 4.16 & 4,848 \\
\hline News $_{t}(\%)$ & 0.52 & 0.00 & 3.34 & 0.00 & 0.61 & 4,848 \\
\hline Google SVI & 38.07 & 15.24 & 317.99 & 2.54 & 83.34 & 4,848 \\
\hline \multicolumn{7}{|c|}{ Panel C: Public firms with Google SVI data and Kantar ads } \\
\hline Market Cap (Million \$) & $4,098.72$ & 749.79 & $15,983.81$ & 69.01 & $7,864.81$ & 2,296 \\
\hline Firm age & 17.99 & 13.25 & 16.04 & 3.34 & 37.91 & 2,296 \\
\hline Return on assets (\%) & 9.41 & 10.82 & 15.94 & -0.53 & 24.39 & 2,233 \\
\hline Advertising-to-sales (\%) & 3.64 & 1.15 & 11.85 & 0.03 & 6.71 & 1,625 \\
\hline Turnover $_{\mathrm{t}-7, \mathrm{t}-36}(\%)$ & 223.17 & 196.20 & 158.99 & 44.68 & 432.32 & 2,296 \\
\hline ReaVolat-7,t-36 $(\%)$ & 46.00 & 42.75 & 19.40 & 24.97 & 70.64 & 2,296 \\
\hline Return $_{\mathrm{t}-7, \mathrm{t}-36}(\%)$ & 1.26 & 1.34 & 2.86 & -1.11 & 3.75 & 2,296 \\
\hline Newst $(\%)$ & 1.03 & 0.06 & 4.71 & 0.00 & 1.76 & 2,296 \\
\hline Google SVI & 46.23 & 17.06 & 457.47 & 3.36 & 91.11 & 2,296 \\
\hline TV Ad Daily $(\$)$ & $30,824.65$ & 0.16 & $188,193.46$ & 0.00 & $22,889.55$ & 2,296 \\
\hline News TV Ad Daily $(\$)$ & $1,943.10$ & 0.00 & $14,018.09$ & 0.00 & 422.35 & 2,296 \\
\hline Newspaper Daily $(\$)$ & $5,800.78$ & 28.53 & $55,008.00$ & 0.00 & $4,310.86$ & 2,296 \\
\hline WSJ Ad Daily $(\$)$ & 360.82 & 0.00 & $4,464.74$ & 0.00 & 92.54 & 2,296 \\
\hline 3 national newspaper Ad Daily $(\$)$ & 691.19 & 0.00 & $6,145.43$ & 0.00 & 368.81 & 2,296 \\
\hline Local Newspaper Ad Daily $(\$)$ & $4,748.77$ & 16.05 & $46,190.81$ & 0.00 & $2,792.29$ & 2,296 \\
\hline
\end{tabular}


Table C7: Summary Statistics - Advertising and EDGAR downloads

This table gives summary statistics on EDGAR downloads and Kantar advertising expenditure. The sample goes from 2003 to 2012. EDGAR downloads (RPV) and the advertising variables are per day. News is a national newspaper article dummy. Turnover $\mathrm{t}-7, \mathrm{t}-36$ is the trading volume over the 4 weeks up to t-7, divided by average shares outstanding. Return $_{\mathrm{t}-7, \mathrm{t}-36}$ is the holding period return over the 4 weeks up to t-7. ReaVolat-7,t-36 is realized volatility, defined as average absolute return during the 4 weeks up to t-7. MarketCap is the firm's market capitalization. Panels A to C report cross-sectional summary statistics that are based on within-firm time series averages.

\begin{tabular}{|c|c|c|c|c|c|c|}
\hline & Mean & Median & $\mathrm{SD}$ & $10 \%$ ile & $90 \%$ ile & $\mathrm{N}$ \\
\hline \multicolumn{7}{|c|}{ Panel A: All public firms } \\
\hline Market Cap (Million $\$$ ) & $2,526.89$ & 282.85 & $12,196.05$ & 31.86 & $3,905.66$ & 6,459 \\
\hline Firm age & 15.24 & 11.26 & 14.63 & 2.32 & 36.68 & 6,459 \\
\hline Return on assets (\%) & 3.85 & 7.93 & 22.22 & -18.29 & 22.63 & 6,117 \\
\hline Advertising-to-sales (\%) & 5.30 & 1.07 & 18.05 & 0.04 & 8.27 & 4,023 \\
\hline Turnover $_{\mathrm{t}-7, \mathrm{t}-36}(\%)$ & 194.70 & 158.64 & 159.78 & 32.00 & 406.29 & 6,450 \\
\hline ReaVolat-7,t-36 (\%) & 52.79 & 47.97 & 25.94 & 25.52 & 86.09 & 6,450 \\
\hline Return $_{\mathrm{t}-7, \mathrm{t}-36}(\%)$ & 1.21 & 1.27 & 4.08 & -2.54 & 4.46 & 6,450 \\
\hline Newst $_{t}(\%)$ & 0.65 & 0.00 & 3.90 & 0.00 & 0.72 & 6,459 \\
\hline \multicolumn{7}{|c|}{ Panel B: Public firms with EDGAR RPV data } \\
\hline Market Cap (Million $\$$ ) & $2,527.84$ & 287.34 & $12,324.53$ & 32.53 & $3,858.58$ & 6,184 \\
\hline Firm age & 15.38 & 11.39 & 14.59 & 2.37 & 36.68 & 6,184 \\
\hline Return on assets (\%) & 3.99 & 7.96 & 21.99 & -17.81 & 22.54 & 5,893 \\
\hline Advertising-to-sales (\%) & 5.17 & 1.06 & 17.60 & 0.03 & 8.27 & 3,873 \\
\hline Turnover $_{\mathrm{t}-7, \mathrm{t}-36}(\%)$ & 194.45 & 158.28 & 159.56 & 32.47 & 404.60 & 6,184 \\
\hline ReaVolat-7,t-36 (\%) & 52.63 & 47.88 & 25.68 & 25.65 & 85.61 & 6,184 \\
\hline Return $_{\mathrm{t}-7, \mathrm{t}-36}(\%)$ & 1.24 & 1.29 & 3.93 & -2.45 & 4.46 & 6,184 \\
\hline News $_{t}(\%)$ & 0.63 & 0.00 & 3.73 & 0.00 & 0.70 & 6,184 \\
\hline EDGAR RPV & 14.62 & 9.51 & 22.82 & 2.89 & 28.80 & 6,184 \\
\hline \multicolumn{7}{|c|}{ Panel C: Public firms with EDGAR RPV data and Kantar ads } \\
\hline Market Cap (Million \$) & $4,660.60$ & 759.88 & $17,221.99$ & 66.04 & $9,325.05$ & 2,968 \\
\hline Firm age & 18.70 & 13.51 & 16.97 & 3.41 & 39.70 & 2,968 \\
\hline Return on assets (\%) & 9.35 & 10.64 & 15.68 & -0.49 & 23.78 & 2,896 \\
\hline Advertising-to-sales (\%) & 3.83 & 1.15 & 12.25 & 0.02 & 7.06 & 2,097 \\
\hline Turnover $_{\mathrm{t}-7, \mathrm{t}-36}(\%)$ & 224.72 & 194.90 & 162.96 & 45.32 & 435.50 & 2,968 \\
\hline ReaVolat-7,t-36 $(\%)$ & 45.81 & 42.28 & 19.96 & 24.68 & 70.64 & 2,968 \\
\hline Return $_{\mathrm{t}-7, \mathrm{t}-36}(\%)$ & 1.39 & 1.38 & 3.13 & -1.00 & 3.89 & 2,968 \\
\hline Newst $(\%)$ & 1.25 & 0.06 & 5.25 & 0.00 & 2.33 & 2,968 \\
\hline EDGAR RPV & 19.89 & 12.90 & 30.39 & 4.18 & 38.02 & 2,968 \\
\hline TV Ad Daily $(\$)$ & $43,602.99$ & 0.31 & $285,148.85$ & 0.00 & $27,821.90$ & 2,968 \\
\hline News TV Ad Daily $(\$)$ & $3,238.51$ & 0.00 & $26,236.07$ & 0.00 & 601.27 & 2,968 \\
\hline Newspaper Daily $(\$)$ & $8,341.91$ & 24.51 & $74,128.54$ & 0.00 & $5,425.17$ & 2,968 \\
\hline WSJ Ad Daily (\$) & 422.03 & 0.00 & $4,279.67$ & 0.00 & 126.98 & 2,968 \\
\hline 3 national newspaper Ad Daily $(\$)$ & 997.87 & 0.00 & $8,292.99$ & 0.00 & 496.13 & 2,968 \\
\hline Local Newspaper Ad Daily $(\$)$ & $6,922.01$ & 14.10 & $64,548.23$ & 0.00 & $3,436.23$ & 2,968 \\
\hline
\end{tabular}


Table C8: Summary Statistics - Advertising and Bloomberg searches

This table gives summary statistics on Bloomberg searches and Kantar advertising expenditure. The sample goes from March 2010 to 2012. Abnormal Bloomberg searches (AIAC) and the advertising variables are per day. The search activity proxy provided by Bloomberg is already normalized relative to the last month's searches, so that we cannot provide an unnormalized variable, as compared to Wikipedia or EDGAR. News is a national newspaper article dummy. Turnover $\mathrm{t}_{-7, \mathrm{t}-36}$ is the trading volume over the 4 weeks up to t-7, divided by average shares outstanding. Return $_{\mathrm{t}-7, \mathrm{t}-36}$ is the holding period return over the 4 weeks up to t- 7 . ReaVolat-7,t-36 is realized volatility, defined as average absolute return during the 4 weeks up to t-7. MarketCap is the firm's market capitalization. Panels A to C report cross-sectional summary statistics that are based on within-firm time series averages.

\begin{tabular}{|c|c|c|c|c|c|c|}
\hline & Mean & Median & $\mathrm{SD}$ & $10 \%$ ile & $90 \%$ ile & $\mathrm{N}$ \\
\hline \multicolumn{7}{|c|}{ Panel A: All public firms } \\
\hline Market Cap (Million \$) & $3,280.11$ & 354.70 & $15,038.74$ & 27.71 & $5,405.84$ & 4,489 \\
\hline Firm age & 18.38 & 14.73 & 16.04 & 2.48 & 39.64 & 4,489 \\
\hline Return on assets (\%) & 5.20 & 8.50 & 20.65 & -11.22 & 22.30 & 4,250 \\
\hline Advertising-to-sales (\%) & 5.39 & 0.87 & 19.80 & 0.02 & 7.38 & 2,961 \\
\hline Turnover $_{\mathrm{t}-7, \mathrm{t}-36}(\%)$ & 208.23 & 160.63 & 184.00 & 31.97 & 448.04 & 4,480 \\
\hline ReaVolat-7,t-36 (\%) & 49.12 & 43.69 & 24.57 & 25.48 & 78.81 & 4,480 \\
\hline Return $_{\mathrm{t}-7, \mathrm{t}-36}(\%)$ & 0.95 & 1.24 & 4.12 & -2.75 & 4.17 & 4,480 \\
\hline Newst $(\%)$ & 0.59 & 0.00 & 3.98 & 0.00 & 0.51 & 4,489 \\
\hline \multicolumn{7}{|c|}{ Panel B: Public firms with Bloomberg AIAC data } \\
\hline Market Cap (Million \$) & $4,193.72$ & 608.51 & $16,101.21$ & 70.81 & $7,790.90$ & 2,973 \\
\hline Firm age & 19.76 & 15.73 & 16.85 & 3.14 & 40.39 & 2,973 \\
\hline Return on assets (\%) & 6.53 & 10.02 & 20.98 & -10.14 & 24.03 & 2,924 \\
\hline Advertising-to-sales (\%) & 5.74 & 0.80 & 20.63 & 0.01 & 8.63 & 2,091 \\
\hline Turnover $_{\mathrm{t}-7, \mathrm{t}-36}(\%)$ & 226.42 & 182.73 & 173.15 & 59.07 & 450.07 & 2,973 \\
\hline ReaVolat-7,t-36 (\%) & 45.39 & 41.87 & 19.20 & 25.23 & 70.49 & 2,973 \\
\hline Return $_{\mathrm{t}-7, \mathrm{t}-36}(\%)$ & 0.99 & 1.27 & 2.73 & -1.92 & 3.55 & 2,973 \\
\hline News $_{\mathrm{t}}(\%)$ & 0.73 & 0.00 & 4.57 & 0.00 & 0.67 & 2,973 \\
\hline Bloomberg AIAC & 0.10 & -0.06 & 0.42 & -0.30 & 0.76 & 2,973 \\
\hline \multicolumn{7}{|c|}{ Panel C: Public firms with Bloomberg AIAC data and Kantar ads } \\
\hline Market Cap (Million \$) & $7,795.93$ & $1,562.74$ & $22,584.86$ & 163.33 & $17,044.02$ & 1,402 \\
\hline Firm age & 24.11 & 18.35 & 19.76 & 4.98 & 50.06 & 1,402 \\
\hline Return on assets (\%) & 11.50 & 11.42 & 13.97 & 0.71 & 25.19 & 1,385 \\
\hline Advertising-to-sales (\%) & 3.39 & 1.00 & 11.42 & 0.00 & 6.89 & 1,087 \\
\hline Turnover $_{\mathrm{t}-7, \mathrm{t}-36}(\%)$ & 255.73 & 215.87 & 180.63 & 73.61 & 491.12 & 1,402 \\
\hline ReaVolat-7,t-36 $(\%)$ & 38.67 & 36.10 & 15.35 & 21.97 & 58.24 & 1,402 \\
\hline Return $_{\mathrm{t}-7, \mathrm{t}-36}(\%)$ & 1.26 & 1.31 & 2.16 & -0.75 & 3.43 & 1,402 \\
\hline Newst $(\%)$ & 1.49 & 0.00 & 6.56 & 0.00 & 2.66 & 1,402 \\
\hline Bloomberg AIAC & 0.25 & 0.12 & 0.46 & -0.27 & 0.92 & 1,402 \\
\hline TV Ad Daily $(\$)$ & $77,550.46$ & 55.45 & $382,344.18$ & 0.00 & $100,676.24$ & 1,402 \\
\hline News TV Ad Daily $(\$)$ & $5,936.29$ & 0.00 & $38,356.40$ & 0.00 & $3,804.38$ & 1,402 \\
\hline Newspaper Daily $(\$)$ & $10,170.67$ & 92.36 & $78,840.00$ & 0.18 & $9,049.21$ & 1,402 \\
\hline WSJ Ad Daily $(\$)$ & 818.29 & 0.00 & $8,027.72$ & 0.00 & 418.10 & 1,402 \\
\hline 3 national newspaper Ad Daily (\$) & $1,280.92$ & 0.00 & $8,221.17$ & 0.00 & 947.99 & 1,402 \\
\hline Local Newspaper Ad Daily $(\$)$ & $8,071.46$ & 48.95 & $67,110.42$ & 0.00 & $5,130.23$ & 1,402 \\
\hline
\end{tabular}




\section{Table C9: Correlations - Attention Proxies}

This table gives correlations between our three attention proxies. Wikipedia page views (WIKI) are available from 2008 to 2012. Google search volume (SVI) is available from 2004 to 2012. SEC EDGAR download volumes (RPV) are available from 2003 to 2012. Bloomberg search activity (AIAC) is abnormal attention as the variable AIAC in Ben-Rephael, Da, and Israelsen (2017). The search activity proxy provided by Bloomberg is already normalized relative to the last month's searches, so that we cannot provide an unnormalized variable, as compared to Wikipedia (WIKI) or EDGAR (RPV). For the correlation matrix we only use the overlapping 2008-2012 period, except for AIAC, which is only available March 2010 to 2012. Our attention proxies (WIKI, SVI, RPV) are logarithmic levels. Abnormal attention proxies (AWIKI, ASVI, and ARPV) are the the log-differences between today's attention and the median attention over the last 8 weeks' same weekdays, except for AIAC, which is defined as in Ben-Rephael, Da, and Israelsen (2017). 1/2/3 stars denote significance at the 10/5/1\%-level.

\begin{tabular}{lccccccc}
\hline & AWIKI & WIKI & ASVI & SVI & ARPV & RPV & AIAC \\
\hline AWIKI & 1.0000 & & & & & & \\
WIKI & $0.0624^{* * *}$ & 1.0000 & & & & & \\
ASVI & $0.0498^{* * *}$ & $0.0082^{* * *}$ & 1.0000 & & & & \\
SVI & $0.0082^{* * *}$ & $0.3496^{* * *}$ & $0.0646^{* * *}$ & 1.0000 & & & \\
ARPV & $0.0948^{* * *}$ & $0.0025^{* *}$ & $0.0326^{* * *}$ & -0.0013 & 1.0000 & & \\
RPV & $0.0583^{* * *}$ & $0.3772^{* * *}$ & $0.0127^{* * *}$ & $0.1460^{* * *}$ & $0.1698^{* * *}$ & 1.0000 & \\
AIAC & $0.0961^{* * *}$ & $0.0891^{* * *}$ & $0.0359^{* * *}$ & $0.0640^{* * *}$ & $0.1186^{* * *}$ & $0.2558^{* * *}$ & 1.0000 \\
\hline
\end{tabular}

IA.34 
Table C10: AR-Model Advertising

The analysis is done for 1995-2012 firm-day observations for firms with common stocks on NYSE, AMEX and NASDAQ. Advertising is daily advertising expenditure in dollars. Nontrading days are excluded, but results are stable when all days are used. Standard errors are clustered by firm. Controls are as in Table 3 and include $\mathrm{EA}_{\mathrm{t}}, \mathrm{News}_{\mathrm{t}}$, Turnover ${ }_{\mathrm{t}-7, \mathrm{t}-36}$, Return $_{\mathrm{t}-7, \mathrm{t}-36}$, ReaVolat-7,t-36 and MarketCapt-7. 1/2/3 stars denote significance at the $10 / 5 / 1 \%$-level.

\begin{tabular}{|c|c|c|}
\hline & $\ln \left(1+\operatorname{Adv}(\mathrm{TV})_{\mathrm{t}}\right)$ & $\ln \left(1+\operatorname{Adv}(\mathrm{NP})_{\mathrm{t}}\right)$ \\
\hline $\ln \left(1+\operatorname{Adv}(T V)_{t-1}\right)$ & $\begin{array}{c}0.534^{* * *} \\
(0.006)\end{array}$ & \\
\hline $\ln \left(1+\operatorname{Adv}(T V)_{t-2}\right)$ & $\begin{array}{c}0.128^{* * *} \\
(0.003)\end{array}$ & \\
\hline $\ln \left(1+\operatorname{Adv}(T V)_{t-3}\right)$ & $\begin{array}{c}0.055^{* * *} \\
(0.002)\end{array}$ & \\
\hline $\ln \left(1+\operatorname{Adv}(T V)_{t-4}\right)$ & $\begin{array}{c}0.030^{* * *} \\
(0.002)\end{array}$ & \\
\hline $\ln \left(1+\operatorname{Adv}(T V)_{t-5}\right)$ & $\begin{array}{c}0.010^{* * *} \\
(0.003)\end{array}$ & \\
\hline $\ln \left(1+\operatorname{Adv}(T V)_{t-6}\right)$ & $\begin{array}{c}0.024^{* * *} \\
(0.003)\end{array}$ & \\
\hline $\ln \left(1+\operatorname{Adv}(T V)_{t-7}\right)$ & $\begin{array}{c}0.124^{* * *} \\
(0.005)\end{array}$ & \\
\hline $\ln \left(1+\operatorname{Adv}(\mathrm{NP})_{\mathrm{t}-1}\right)$ & & $\begin{array}{c}0.099^{* * *} \\
(0.003)\end{array}$ \\
\hline $\ln \left(1+\operatorname{Adv}(\mathrm{NP})_{\mathrm{t}-2}\right)$ & & $\begin{array}{c}0.063^{* * *} \\
(0.003)\end{array}$ \\
\hline $\ln \left(1+\operatorname{Adv}(\mathrm{NP})_{\mathrm{t}-3}\right)$ & & $\begin{array}{c}0.039^{* * *} \\
(0.003)\end{array}$ \\
\hline $\ln \left(1+\operatorname{Adv}(N P)_{t-4}\right)$ & & $\begin{array}{c}0.028^{* * *} \\
(0.002)\end{array}$ \\
\hline $\ln \left(1+\operatorname{Adv}(N P)_{t-5}\right)$ & & $\begin{array}{c}0.045^{* * *} \\
(0.003)\end{array}$ \\
\hline $\ln \left(1+\operatorname{Adv}(\mathrm{NP})_{\mathrm{t}-6}\right)$ & & $\begin{array}{c}0.072^{* * *} \\
(0.003)\end{array}$ \\
\hline $\ln \left(1+\operatorname{Adv}(\mathrm{NP})_{\mathrm{t}-7}\right)$ & & $\begin{array}{c}0.374^{* * *} \\
(0.006)\end{array}$ \\
\hline Controls & YES & YES \\
\hline Firm-FEs & YES & YES \\
\hline Week-FEs & YES & YES \\
\hline Day-of-Week-FEs & YES & YES \\
\hline $\mathrm{R}^{2}$ & 0.83 & 0.52 \\
\hline No. obs. & $3,007,878$ & $3,218,153$ \\
\hline
\end{tabular}

IA.35 
Table C11: Advertising and Investor Attention - TV Channel Subsets

This table shows regressions of abnormal Wikipedia page visits (AWIKI), Google search volume (ASVI), SEC EDGAR downloads (ARPV) and Bloomberg search volume (AIAC) on abnormal advertising (Adv), measured by TV channel subsets. For Wikipedia, the sample covers all publicly listed companies with Wikipedia page visits and positive advertising in the previous 8 weeks from 2007 to 2012. For (EDGAR) Google, the sample period is (2003) 2004 to 2012. For Bloomberg, the sample period is 2010 to 2012. For ASVI, tickers corresponding to words in a dictionary have been excluded. For ARPV, downloads from IP addresses that are identified as 'robots' have been excluded. $\mathrm{Adv}_{\mathrm{i}, \mathrm{t}}$ is abnormal advertising, with $\mathrm{i}=\{$ TVNWS,TVNONWS $\}$. TVNWS to news channels $(\mathrm{CNN}, \mathrm{CNBC}$, Fox News, MSNBC, CNN headline news), TVNONWS to all non-news TV channels All regressions include the same set of controls as in Table 2 column 5. Hence, they include Turnover $_{\mathrm{t}-7, \mathrm{t}-36}$, Return $_{\mathrm{t}-7, \mathrm{t}-36}, \operatorname{ReaVola}_{\mathrm{t}-7, \mathrm{t}-36}, \mathrm{Market}$ Cap $_{\mathrm{t}-7}$, $\mathrm{AWIKI}_{\mathrm{t}-7}$ (or $\mathrm{ASVI}_{\mathrm{t}-7}, \mathrm{ARPV}_{\mathrm{t}-7}$ or $\mathrm{AIAC}_{\mathrm{t}-7}$, respectively). Standard errors are clustered by firm and shown in parentheses. $1 / 2 / 3$ stars denote significance at the $10 / 5 / 1 \%$-level.

\begin{tabular}{lcccc}
\hline & $(1)$ & $(2)$ & $(3)$ & $(4)$ \\
& AWIKI & ASVI & ARPV & AIAC \\
\hline Adv $_{\text {TVNWS,t }}$ & $1.0042^{* * *}$ & -0.1811 & 0.3772 & 1.2054 \\
& $(0.1799)$ & $(0.1795)$ & $(0.4336)$ & $(0.8949)$ \\
$\mathrm{Adv}_{\text {TVNWS,t-1 }}$ & $1.1313^{* * *}$ & 0.0139 & $0.8436^{*}$ & $2.3118^{* *}$ \\
& $(0.2474)$ & $(0.2002)$ & $(0.4796)$ & $(0.9926)$ \\
$\mathrm{Adv}_{\text {TVNWS,t-2 }}$ & $0.9356^{* * *}$ & 0.2300 & $1.0499^{* *}$ & 0.6292 \\
& $(0.2602)$ & $(0.1994)$ & $(0.4200)$ & $(0.7989)$ \\
$\mathrm{Adv}_{\text {TVNWS,t-3 }}$ & $0.9199^{* * *}$ & -0.0715 & $0.7472^{* *}$ & $1.3071^{*}$ \\
& $(0.2087)$ & $(0.1499)$ & $(0.3224)$ & $(0.6773)$ \\
$\mathrm{Adv}_{\text {TVNONWS,t }}$ & $0.6106^{* * *}$ & -0.0421 & -0.5392 & -0.2021 \\
& $(0.1650)$ & $(0.1455)$ & $(0.3726)$ & $(0.7037)$ \\
$\mathrm{Adv}_{\text {TVNONWS,t-1 }}$ & $1.2481^{* * *}$ & -0.0654 & -0.3869 & 1.1999 \\
& $(0.2061)$ & $(0.1681)$ & $(0.4062)$ & $(0.7775)$ \\
$\mathrm{Adv}_{\text {TVNONWS,t-2 }}$ & $1.3765^{* * *}$ & 0.0859 & -0.1426 & 0.0348 \\
& $(0.1998)$ & $(0.1589)$ & $(0.3655)$ & $(0.6812)$ \\
Adv $_{\text {TVNONWS,t-3 }}$ & $1.0790^{* * *}$ & 0.0293 & -0.3390 & 0.2382 \\
& $(0.1827)$ & $(0.1335)$ & $(0.3349)$ & $(0.6034)$ \\
\hline Firm FEs & YES & YES & YES & YES \\
Week FEs $_{\text {Day-of-week FEs }}$ & YES & YES & YES & YES \\
Controls & YES & YES & YES & YES \\
\hline $\mathrm{R}^{2}$ & 0.188 & 0.064 & YES & YES \\
No. obs. & 945,457 & $1,188,741$ & $1,527,599$ & 352,867 \\
\hline
\end{tabular}


Table C12: Advertising and Investor Attention - Newspaper Subsets

This table shows regressions of abnormal Wikipedia page visits (AWIKI), Google search volume (ASVI), SEC EDGAR downloads (ARPV) and Bloomberg search volume (AIAC) on abnormal advertising (Adv), measured by newspaper channel subsets. For Wikipedia, the sample covers all publicly listed companies with Wikipedia page visits and positive advertising in the previous 8 weeks from 2007 to 2012. For (EDGAR) Google, the sample period is (2003) 2004 to 2012. For Bloomberg, the sample period is 2010 to 2012. For ASVI, tickers corresponding to words in a dictionary have been excluded. For ARPV, downloads from IP addresses that are identified as 'robots' have been excluded. $A d v_{i, t}$ is abnormal newspaper advertising, $\mathrm{i}=\{\mathrm{NPLOC}, \mathrm{NPNAT}, \mathrm{NPWSJ}, \mathrm{NP} 3 \mathrm{NAT}\}$. NPLOC refers to local newspapers, NPNAT to national newspapers (Wall Street Journal, New York Times, USA Today and Washington Post), NPWSJ to the Wall Street Journal and NP3NAT to the other three national newspapers. All regressions include the same set of controls as in Table 2 Column 5. Standard errors are clustered by firm and shown in parentheses. $1 / 2 / 3$ stars denote significance at the $10 / 5 / 1 \%$-level.

\begin{tabular}{|c|c|c|c|c|}
\hline & $\begin{array}{c}(1) \\
\text { AWIKI }\end{array}$ & $\begin{array}{c}(2) \\
\text { ASVI }\end{array}$ & $\begin{array}{c}(3) \\
\text { ARPV }\end{array}$ & $\begin{array}{c}(4) \\
\text { AIAC }\end{array}$ \\
\hline $\mathrm{Adv}_{\mathrm{NPLOC}, \mathrm{t}}$ & $\begin{array}{c}0.9794 * * * \\
(0.1369)\end{array}$ & $\begin{array}{c}0.1913^{*} \\
(0.1078)\end{array}$ & $\begin{array}{c}0.1100 \\
(0.2328)\end{array}$ & $\begin{array}{l}-0.2169 \\
(0.5300)\end{array}$ \\
\hline $\mathrm{Adv}_{\mathrm{NPLOC}, \mathrm{t}-1}$ & $\begin{array}{c}1.0433^{* * *} * \\
(0.1260)\end{array}$ & $\begin{array}{c}0.3204^{* * *} \\
(0.1137)\end{array}$ & $\begin{array}{c}0.7297 * * * \\
(0.2122)\end{array}$ & $\begin{array}{c}0.9897^{* *} * \\
(0.4431)\end{array}$ \\
\hline $\mathrm{Adv}_{\mathrm{NPLOC}, \mathrm{t}-2}$ & $\begin{array}{c}0.8390 * * * \\
(0.1315)\end{array}$ & $\begin{array}{c}0.2163^{* *} \\
(0.0994)\end{array}$ & $\begin{array}{c}0.1596 \\
(0.2113)\end{array}$ & $\begin{array}{c}0.5983 \\
(0.4485)\end{array}$ \\
\hline $\mathrm{Adv}_{\mathrm{NPLOC}, \mathrm{t}-3}$ & $\begin{array}{c}0.7610^{* * *} \\
(0.1344)\end{array}$ & $\begin{array}{c}0.0975 \\
(0.1134)\end{array}$ & $\begin{array}{c}0.1588 \\
(0.2335)\end{array}$ & $\begin{array}{c}0.3776 \\
(0.4568)\end{array}$ \\
\hline $\mathrm{Adv}_{\mathrm{NPWSJ}, \mathrm{t}}$ & $\begin{array}{c}0.9586^{* * * *} \\
(0.2530)\end{array}$ & $\begin{array}{l}0.5389^{*} \\
(0.2842)\end{array}$ & $\begin{array}{c}2.7194^{* * * *} \\
(0.5623)\end{array}$ & $\begin{array}{c}2.9508^{* * *} \\
(1.1178)\end{array}$ \\
\hline $\mathrm{Adv}_{\mathrm{NPWSJ}, \mathrm{t}-1}$ & $\begin{array}{c}0.4845^{*} \\
(0.2522)\end{array}$ & $\begin{array}{c}0.4007 \\
(0.2696)\end{array}$ & $\begin{array}{l}-0.3479 \\
(0.4702)\end{array}$ & $\begin{array}{l}-0.6802 \\
(0.9260)\end{array}$ \\
\hline $\mathrm{Adv}_{\mathrm{NPWSJ}, \mathrm{t}-2}$ & $\begin{array}{c}0.6802^{* * *} \\
(0.2540)\end{array}$ & $\begin{array}{c}0.2767 \\
(0.2667)\end{array}$ & $\begin{array}{c}1.0781^{* *} \\
(0.5057)\end{array}$ & $\begin{array}{l}-0.3215 \\
(1.2078)\end{array}$ \\
\hline $\operatorname{Adv}_{\text {NPWSJ,t-3 }}$ & $\begin{array}{c}0.2920 \\
(0.2858)\end{array}$ & $\begin{array}{l}-0.0409 \\
(0.2584)\end{array}$ & $\begin{array}{l}-0.1570 \\
(0.5239)\end{array}$ & $\begin{array}{l}-0.5999 \\
(1.1309)\end{array}$ \\
\hline $\mathrm{Adv}_{\mathrm{NPNAT}, \mathrm{t}}$ & $\begin{array}{c}1.2365^{* * *} \\
(0.2189)\end{array}$ & $\begin{array}{c}0.7399 * * * \\
(0.1948)\end{array}$ & $\begin{array}{c}1.1143^{* * *} \\
(0.3736)\end{array}$ & $\begin{array}{c}0.4962 \\
(0.8250)\end{array}$ \\
\hline $\mathrm{Adv}_{\mathrm{NPNAT}, \mathrm{t}-1}$ & $\begin{array}{c}1.0043^{* * *} * \\
(0.2207)\end{array}$ & $\begin{array}{c}0.5117^{* *} \\
(0.2042)\end{array}$ & $\begin{array}{c}0.8609 * * \\
(0.3696)\end{array}$ & $\begin{array}{l}-0.0106 \\
(0.7165)\end{array}$ \\
\hline $\mathrm{Adv}_{\mathrm{NPNAT}, \mathrm{t}-2}$ & $\begin{array}{c}0.8777^{* * *} \\
(0.2050)\end{array}$ & $\begin{array}{c}0.0639 \\
(0.2010)\end{array}$ & $\begin{array}{c}0.2476 \\
(0.3576)\end{array}$ & $\begin{array}{l}-0.1310 \\
(0.7911)\end{array}$ \\
\hline $\mathrm{Adv}_{\mathrm{NPNAT}, \mathrm{t}-3}$ & $\begin{array}{c}0.8001^{* * *} * \\
(0.2184)\end{array}$ & $\begin{array}{c}0.2517 \\
(0.1731)\end{array}$ & $\begin{array}{l}-0.0959 \\
(0.3805)\end{array}$ & $\begin{array}{c}0.0126 \\
(0.8384)\end{array}$ \\
\hline Firm FEs & YES & YES & YES & YES \\
\hline Week FEs & YES & YES & YES & YES \\
\hline Day-of-week FEs & YES & YES & YES & YES \\
\hline Controls & YES & YES & YES & YES \\
\hline $\mathrm{R}^{2}$ & 0.189 & 0.069 & 0.154 & 0.365 \\
\hline No. obs. & 927,759 & $1,284,128$ & $1,657,757$ & 351,125 \\
\hline
\end{tabular}


Table C13: Advertising and Investor Attention - Stability

This table shows regressions of abnormal Wikipedia page visits (AWIKI) on abnormal advertising (Adv). The sample covers all publicly listed companies with Wikipedia page visits and positive advertising in the previous 8 weeks from 2007 to 2012. AWIKI is abnormal Wikipedia page visits. Adv $\mathrm{AdV}_{\mathrm{t}, \mathrm{t}}$ and $\mathrm{Adv}_{\mathrm{NP}, \mathrm{t}}$ are abnormal advertising. All regressions include the same set of fixed effects and controls as in Table 2 Column 5 unless indicated otherwise. Splits are done at the cross-sectional median except for the consumer industry split. Consumer industry is defined according to the Fama-French five industry classification as in Lou (2014). Media coverage is the number of national newspaper articles on the firm in the previous 12 months. Panel A (B) displays results using television (newspaper) advertising. Standard errors are clustered by firm and shown in parentheses. $1 / 2 / 3$ stars denote significance at the 10/5/1\%-level.

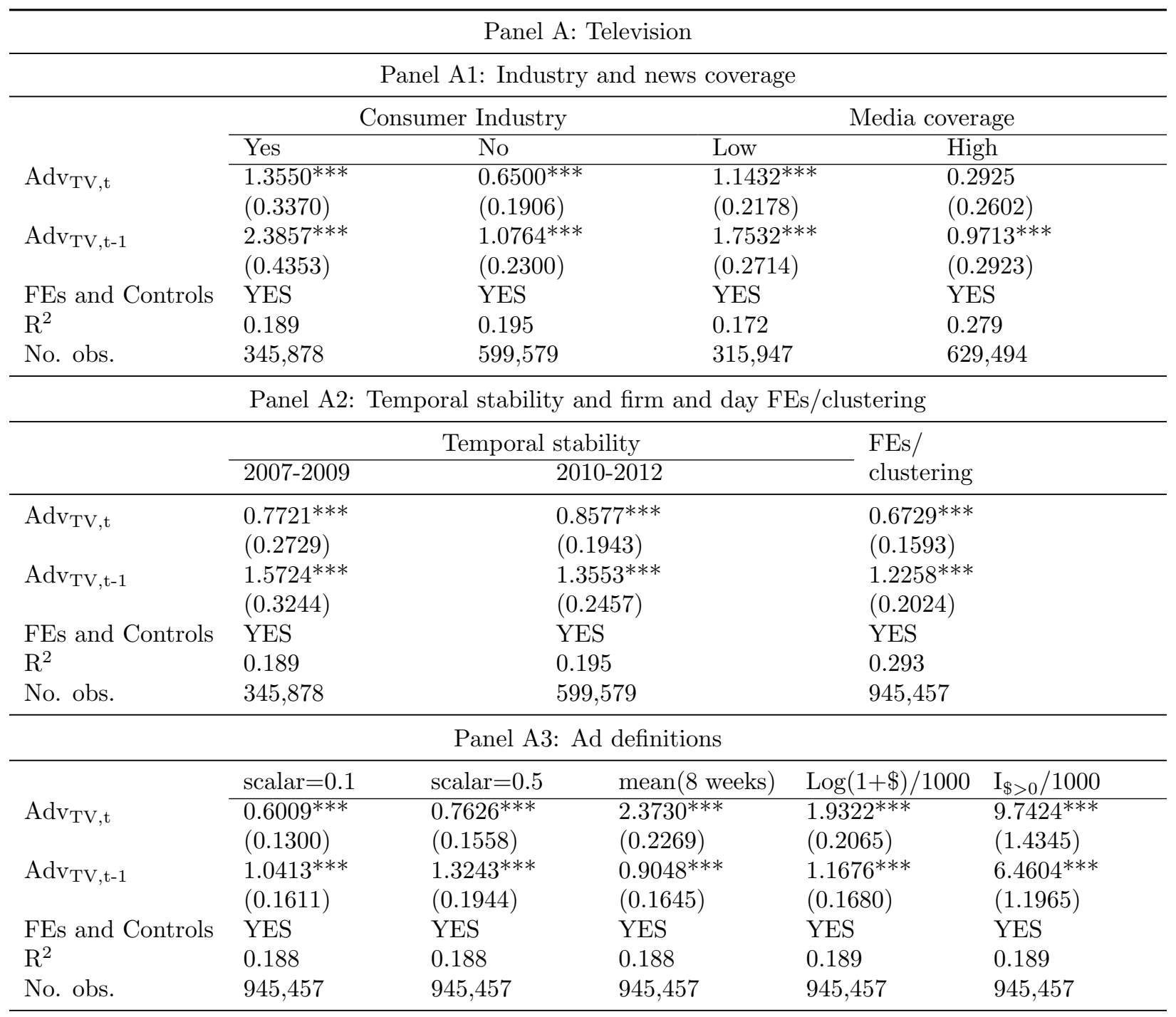




\begin{tabular}{|c|c|c|c|c|c|c|}
\hline \multicolumn{7}{|c|}{ Panel B: Newspaper } \\
\hline \multicolumn{7}{|c|}{ Panel B1: Industry and news coverage } \\
\hline \multirow{4}{*}{$\operatorname{Adv}_{\mathrm{NP}, \mathrm{t}}$} & \multicolumn{3}{|c|}{ Consumer Industry } & \multicolumn{3}{|c|}{ Media coverage } \\
\hline & Yes & No & \multirow{2}{*}{\multicolumn{2}{|c|}{$\begin{array}{l}\text { Low } \\
1.5714^{* * *}\end{array}$}} & \multicolumn{2}{|c|}{ High } \\
\hline & $1.2851^{* * *}$ & \multirow{2}{*}{$\begin{array}{l}1.1080^{* *} \\
(0.1535)\end{array}$} & $1.5714^{*}$ & & \multicolumn{2}{|c|}{$0.7740^{* * *}$} \\
\hline & $(0.2071)$ & & & $(0.1742)$ & $(0.1$ & $565)$ \\
\hline \multirow{2}{*}{$\operatorname{Adv}_{\mathrm{NP}, \mathrm{t}-1}$} & $1.2434^{* * *}$ & $0.9436^{* *}$ & & $1.5500^{* * *}$ & \multicolumn{2}{|c|}{$0.6201 * * *$} \\
\hline & $(0.1917)$ & $(0.1441)$ & \multicolumn{2}{|c|}{$(0.1756)$} & \multicolumn{2}{|c|}{$(0.1312)$} \\
\hline FEs and Controls & YES & YES & \multicolumn{2}{|c|}{ YES } & \multicolumn{2}{|c|}{ YES } \\
\hline & 0.227 & 0.179 & & 0.174 & \multicolumn{2}{|c|}{0.276} \\
\hline No. obs. & 306,015 & 621,741 & \multicolumn{2}{|c|}{600,437} & \multicolumn{2}{|c|}{327,322} \\
\hline \multicolumn{7}{|c|}{ Panel B2: Temporal stability and firm and day FEs/clustering } \\
\hline & \multicolumn{4}{|c|}{ Temporal stability } & \multirow{2}{*}{\multicolumn{2}{|c|}{$\begin{array}{l}\text { FEs/ } \\
\text { clustering }\end{array}$}} \\
\hline & $2007-2009$ & \multicolumn{2}{|c|}{$2010-2012$} & clustering & & \\
\hline $\operatorname{Adv}_{\mathrm{NP}, \mathrm{t}}$ & $\begin{array}{l}1.6147^{* * * *} \\
(0.1979)\end{array}$ & \multicolumn{2}{|c|}{$\begin{array}{l}1.0416^{* * *} \\
(0.1466)\end{array}$} & & & \\
\hline $\mathrm{Adv}_{\mathrm{NP}, \mathrm{t}-1}$ & $\begin{array}{l}1.2378^{* * *} \\
(0.1976)\end{array}$ & & $\begin{array}{l}43^{* * *} \\
36)\end{array}$ & & $\begin{array}{l}7^{* * *} \\
33)\end{array}$ & \\
\hline FEs and Controls & YES & & & & & \\
\hline & 0.195 & & & & & \\
\hline No. obs. & 352,263 & & & & & \\
\hline & & Panel B3: & definitions & & & \\
\hline & scalar $=0.1$ & scalar $=0.5$ & mean $(8$ weeks $)$ & & 1000 & $\mathrm{I}_{\$>0} / 1000$ \\
\hline $\operatorname{Adv}_{\mathrm{NP}, \mathrm{t}}$ & $\begin{array}{l}0.9742^{* * *} \\
(0.0982)\end{array}$ & $\begin{array}{l}1.3136^{* * *} \\
(0.1295)\end{array}$ & $\begin{array}{l}0.9973^{* * *} \\
(0.0979)\end{array}$ & & & $\begin{array}{l}7.5526^{* * *} \\
(1.0761)\end{array}$ \\
\hline $\operatorname{Adv}_{\mathrm{NP}, \mathrm{t}-1} *$ & $\begin{array}{l}0.8101^{* * *} \\
(0.0989)\end{array}$ & $\begin{array}{l}1.0922^{* * *} \\
(0.1295)\end{array}$ & $\begin{array}{l}0.7516^{* * *} \\
(0.0969)\end{array}$ & & & $\begin{array}{l}7.0202^{* * *} \\
(1.0017)\end{array}$ \\
\hline FEs and Controls & YES & YES & YES & $\mathrm{YE}$ & & YES \\
\hline $\mathrm{R}^{2}$ & 0.189 & 0.189 & 0.187 & 0.1 & & 0.189 \\
\hline No. obs. & 927,759 & 927,759 & 927,759 & & & 927,759 \\
\hline
\end{tabular}


Table C14: Advertising and Investor Attention - Excluding EA and Coverage Windows

This table shows regressions of abnormal Wikipedia page visits (AWIKI), abnormal Google search volume, abnormal EDGAR search volume (ARPV) and abnormal Bloomberg search volume (AIAC) on abnormal TV advertising $\left(A d v_{T V}\right.$, in Panel A) and newspaper advertising $\left(A d v_{N P}\right.$, in Panel B). The sample for WIKI covers all publicly listed companies with Wikipedia page visits and positive advertising in the previous 8 weeks from 2007 to 2012 . For (Edgar) and Google, corresponding filters have been included and the sample period is (2003) 2004 to 2012. For Bloomberg, the filters have also been included and the sample period is 2010 to 2012 . We exclude days with an earnings announcement or national media coverage in the window from $t-3$ to $t+3$. AWIKI is abnormal Wikipedia page views. ASVI is abnormal Google search volume. ARPV is abnormal EDGAR search volume. AIAC is abnormal Bloomberg search volume. Adv $v_{\mathrm{TV}, \mathrm{t}}$ is abnormal TV advertising. Adv $\mathrm{NP}_{\mathrm{t}}$ is abnormal Newspaper advertising. Turnover ${ }_{\mathrm{t}-7, \mathrm{t}-36}$ is the trading volume over the 4 weeks up to t-7, divided by average shares outstanding. Return $n_{\mathrm{t}-7, \mathrm{t}-36}$ is the holding period return over the 4 weeks up to t-7. ReaVolat-7,t-36 is realized volatility, defined as average absolute return during the 4 weeks up to t-7. MarketCap is the firm's market capitalization. Standard errors are clustered by firm and shown in parentheses. $1 / 2 / 3$ stars denote significance at the $10 / 5 / 1 \%$-level.

\begin{tabular}{|c|c|c|c|c|}
\hline \multicolumn{5}{|c|}{ Panel A: TV Advertising } \\
\hline & (1) & $(2)$ & $(3)$ & $(4)$ \\
\hline & AWIKI & ASVI & ARPV & AIAC \\
\hline \multirow[t]{2}{*}{$\mathrm{Adv}_{\mathrm{TV}, \mathrm{t}}$} & $0.9807^{* * *}$ & -0.0239 & -0.1664 & 0.5535 \\
\hline & $(0.1843)$ & $(0.1541)$ & $(0.4124)$ & $(0.7277)$ \\
\hline \multirow[t]{2}{*}{$\mathrm{Adv}_{\mathrm{TV}, \mathrm{t}-1}$} & $1.6057^{* * *}$ & -0.1328 & -0.2968 & $1.4045^{*}$ \\
\hline & $(0.2372)$ & $(0.1765)$ & $(0.4491)$ & $(0.7996)$ \\
\hline \multirow[t]{2}{*}{$\mathrm{Adv}_{\mathrm{TV}, \mathrm{t}-2}$} & $1.5742^{* * *}$ & 0.1323 & -0.0325 & -0.1480 \\
\hline & $(0.2282)$ & $(0.1717)$ & $(0.4040)$ & $(0.7264)$ \\
\hline \multirow{2}{*}{$\mathrm{Adv}_{\mathrm{TV}, \mathrm{t}-3}$} & $1.2100^{* * *}$ & 0.0704 & -0.2963 & 0.3730 \\
\hline & $(0.2093)$ & $(0.1449)$ & $(0.3636)$ & $(0.6304)$ \\
\hline \multirow[t]{2}{*}{$\ln \left(\right.$ Turnover $\left._{\mathrm{t}-7, \mathrm{t}-36}\right)$} & $-0.0108^{* * *}$ & -0.0009 & $-0.0371^{* * *}$ & -0.0082 \\
\hline & $(0.0022)$ & $(0.0017)$ & $(0.0030)$ & $(0.0130)$ \\
\hline \multirow[t]{2}{*}{ Return $_{t-7, t-36}$} & -0.0012 & -0.0048 & $-0.0505^{* * *}$ & 0.0141 \\
\hline & $(0.0080)$ & $(0.0055)$ & $(0.0109)$ & $(0.0266)$ \\
\hline \multirow[t]{2}{*}{$\ln ($ ReaVolat-7,t-36 $)$} & -0.0020 & -0.0027 & $0.0307^{* * *}$ & $-0.1663^{* * *}$ \\
\hline & $(0.0027)$ & $(0.0020)$ & $(0.0040)$ & $(0.0132)$ \\
\hline \multirow[t]{2}{*}{$\ln ($ MarketCapt-7 $)$} & 0.0018 & -0.0017 & $0.0128^{* * *}$ & 0.0322 \\
\hline & $(0.0026)$ & $(0.0021)$ & $(0.0028)$ & $(0.0206)$ \\
\hline \multirow[t]{2}{*}{$\mathrm{AWIKI}_{\mathrm{t}-7}$} & $0.1944^{* * *}$ & & & \\
\hline & $(0.0069)$ & & & \\
\hline \multirow{2}{*}{\multicolumn{2}{|c|}{$\mathrm{ASVI}_{\mathrm{t}-7}$}} & $0.1914^{* * *}$ & & \\
\hline & & $(0.0066)$ & & \\
\hline \multirow{2}{*}{\multicolumn{2}{|c|}{$\mathrm{ARPV}_{\mathrm{t}-7}$}} & & $0.1366^{* * *}$ & \\
\hline & & & $(0.0016)$ & \\
\hline \multirow[t]{2}{*}{$\mathrm{AIAC}_{\mathrm{t}-7}$} & & & & $0.1559 * * *$ \\
\hline & & & & $(0.0059)$ \\
\hline Firm FEs & YES & YES & YES & YES \\
\hline Week FEs & YES & YES & YES & YES \\
\hline Day-of-week FEs & YES & YES & YES & YES \\
\hline $\mathrm{R}^{2}$ & 0.177 & 0.064 & 0.143 & 0.322 \\
\hline No. obs. & 772,839 & 978,088 & $1,242,442$ & 294,508 \\
\hline
\end{tabular}

IA. 40 


\begin{tabular}{|c|c|c|c|c|}
\hline \multicolumn{5}{|c|}{ Panel B: Newspaper Advertising } \\
\hline & $\begin{array}{c}(1) \\
\text { AWIKI }\end{array}$ & $\begin{array}{c}(2) \\
\text { ASVI }\end{array}$ & $\begin{array}{c}(3) \\
\text { ARPV }\end{array}$ & $\begin{array}{c}(4) \\
\text { AIAC }\end{array}$ \\
\hline $\operatorname{Adv}_{\mathrm{NP}, \mathrm{t}}$ & $\begin{array}{c}1.3071^{* * *} \\
(0.1385)\end{array}$ & $\begin{array}{c}0.2766^{* *} \\
(0.1150)\end{array}$ & $\begin{array}{c}0.4669^{*} \\
(0.2526)\end{array}$ & $\begin{array}{c}1.1000^{* *} \\
(0.5254)\end{array}$ \\
\hline $\operatorname{Adv}_{\mathrm{NP}, \mathrm{t}-1}$ & $\begin{array}{c}1.3217^{* * * *} \\
(0.1345)\end{array}$ & $\begin{array}{c}0.3420^{* * * *} \\
(0.1143)\end{array}$ & $\begin{array}{c}0.6765^{* * * *} \\
(0.2312)\end{array}$ & $\begin{array}{c}0.5830 \\
(0.4520)\end{array}$ \\
\hline $\operatorname{Adv}_{\mathrm{NP}, \mathrm{t}-2}$ & $\begin{array}{c}1.0234^{* * * *} \\
(0.1357)\end{array}$ & $\begin{array}{c}0.3003^{* * *} \\
(0.1078)\end{array}$ & $\begin{array}{c}0.1202 \\
(0.2371)\end{array}$ & $\begin{array}{c}0.1078 \\
(0.4752)\end{array}$ \\
\hline $\operatorname{Adv}_{N P, t-3}$ & $\begin{array}{c}0.9362^{* * *} \\
(0.1332)\end{array}$ & $\begin{array}{c}0.1393 \\
(0.1105)\end{array}$ & $\begin{array}{c}0.1554 \\
(0.2410)\end{array}$ & $\begin{array}{l}0.7819^{*} \\
(0.4686)\end{array}$ \\
\hline $\ln \left(\right.$ Turnover $\left._{\mathrm{t}-7, \mathrm{t}-36}\right)$ & $\begin{array}{c}-0.0077^{* * *} \\
(0.0021)\end{array}$ & $\begin{array}{c}0.0015 \\
(0.0016)\end{array}$ & $\begin{array}{c}-0.0390^{* * *} \\
(0.0029)\end{array}$ & $\begin{array}{c}-0.0272^{* *} \\
(0.0122)\end{array}$ \\
\hline Return $_{\mathrm{t}-7, \mathrm{t}-36}$ & $\begin{array}{l}-0.0055 \\
(0.0070)\end{array}$ & $\begin{array}{l}-0.0006 \\
(0.0060)\end{array}$ & $\begin{array}{c}-0.0430^{* * * *} \\
(0.0104)\end{array}$ & $\begin{array}{c}0.0115 \\
(0.0277)\end{array}$ \\
\hline $\ln ($ ReaVolat-7,t-36 $)$ & $\begin{array}{l}-0.0003 \\
(0.0027)\end{array}$ & $\begin{array}{l}-0.0016 \\
(0.0021)\end{array}$ & $\begin{array}{c}0.0310^{* * * *} \\
(0.0041)\end{array}$ & $\begin{array}{c}-0.1650 * * * \\
(0.0128)\end{array}$ \\
\hline $\ln ($ MarketCapt-7 $)$ & $\begin{array}{c}0.0014 \\
(0.0021)\end{array}$ & $\begin{array}{c}0.0004 \\
(0.0019)\end{array}$ & $\begin{array}{c}0.0150^{* * * *} \\
(0.0029)\end{array}$ & $\begin{array}{c}0.0331 \\
(0.0224)\end{array}$ \\
\hline $\mathrm{AWIKI}_{\mathrm{t}-7}$ & $\begin{array}{c}0.1892^{* * * *} \\
(0.0064)\end{array}$ & & & \\
\hline $\mathrm{ASVI}_{\mathrm{t}-7}$ & & $\begin{array}{c}0.1923^{* * * *} \\
(0.0058)\end{array}$ & & \\
\hline $\mathrm{ARPV}_{\mathrm{t}-7}$ & & & $\begin{array}{c}0.1353^{* * *} \\
(0.0014)\end{array}$ & \\
\hline $\mathrm{AIAC}_{\mathrm{t}-7}$ & & & & $\begin{array}{c}0.1578^{* * *} \\
(0.0058)\end{array}$ \\
\hline Firm FEs & YES & YES & YES & YES \\
\hline Week FEs & YES & YES & YES & YES \\
\hline Day-of-week FEs & YES & YES & YES & YES \\
\hline $\mathrm{R}^{2}$ & 0.178 & 0.071 & 0.140 & 0.328 \\
\hline No. obs. & 752,756 & $1,053,861$ & $1,348,268$ & 291,089 \\
\hline
\end{tabular}

IA. 41 
Table C15: Advertising and Investor Attention - Results with Wikipedia Page Views

This table shows regressions of abnormal Wikipedia page visits (AWIKI) on abnormal advertising (Adv). The sample covers all publicly listed companies with Wikipedia page visits and positive advertising in the previous 8 weeks from 2007 to 2012. AdvNP,t and AdvTV,t are abnormal advertising. EA is an earnings announcement dummy. News is a national newspaper article dummy. Turnover $\mathrm{r}_{\mathrm{t}-\mathrm{t}, \mathrm{t}-36}$ is the trading volume over the 4 weeks up to t- 7 , divided by average shares outstanding. Return $\mathrm{t}_{-7, \mathrm{t}-36}$ is the holding period return over the 4 weeks up to t-7. ReaVolat-7,t-36 is realized volatility, defined as average absolute return during the 4 weeks up to t-7. MarketCap is the firm's market capitalization. Standard errors are clustered by firm and shown in parentheses. $1 / 2 / 3$ stars denote significance at the $10 / 5 / 1 \%$-level.

\begin{tabular}{|c|c|c|c|c|c|}
\hline & $\begin{array}{c}(1) \\
\text { AWIKI }\end{array}$ & $\begin{array}{c}(2) \\
\text { AWIKI }\end{array}$ & $\begin{array}{c}(3) \\
\text { AWIKI }\end{array}$ & $\begin{array}{c}(4) \\
\text { AWIKI }\end{array}$ & $\begin{array}{c}(5) \\
\text { AWIKI }\end{array}$ \\
\hline $\mathrm{Adv}_{\mathrm{TV}, \mathrm{t}}$ & $\begin{array}{c}0.8348 * * * \\
(0.1699)\end{array}$ & & $\begin{array}{c}0.8533^{* * * *} \\
(0.1697)\end{array}$ & & $\begin{array}{c}0.8601 * * * \\
(0.1676)\end{array}$ \\
\hline $\operatorname{Adv}_{T V}, t-1$ & $\begin{array}{c}1.4564 * * * \\
(0.2133)\end{array}$ & & $\begin{array}{c}1.4833^{* * *} \\
(0.2123)\end{array}$ & & $\begin{array}{c}1.4586 * * * \\
(0.2107)\end{array}$ \\
\hline $\operatorname{Adv}_{T V, t-2}$ & $\begin{array}{c}1.4985 * * * \\
(0.2085)\end{array}$ & & $\begin{array}{c}1.5160 * * * \\
(0.2069)\end{array}$ & & $\begin{array}{c}1.4861 * * * \\
(0.2054)\end{array}$ \\
\hline $\mathrm{Adv}_{\mathrm{TV}, \mathrm{t}-3}$ & $\begin{array}{c}1.1729 * * * \\
(0.1900)\end{array}$ & & $\begin{array}{c}1.1933^{* * *} \\
(0.1897)\end{array}$ & & $\begin{array}{c}1.1617 * * * \\
(0.1879)\end{array}$ \\
\hline $\mathrm{Adv}_{\mathrm{NP}, \mathrm{t}}$ & & $\begin{array}{c}1.2523 * * * \\
(0.1261)\end{array}$ & & $\begin{array}{l}1.2556^{* * *} \\
(0.1259)\end{array}$ & $\begin{array}{c}1.2806 * * * \\
(0.1258)\end{array}$ \\
\hline $\operatorname{Adv}_{N P, t-1}$ & & $\begin{array}{c}1.1463 * * * \\
(0.1199)\end{array}$ & & $\begin{array}{c}1.1376^{* * *} \\
(0.1190)\end{array}$ & $\begin{array}{c}1.1483^{* * *} \\
(0.1187)\end{array}$ \\
\hline $\mathrm{Adv}_{\mathrm{NP}, \mathrm{t}-2}$ & & $\begin{array}{c}0.9810^{* * *} \\
(0.1225)\end{array}$ & & $\begin{array}{c}0.9761 * * * \\
(0.1214)\end{array}$ & $\begin{array}{c}0.9896 * * * \\
(0.1213)\end{array}$ \\
\hline $\mathrm{Adv}_{\mathrm{NP}, \mathrm{t}-3}$ & & $\begin{array}{c}0.8493^{* * *} \\
(0.1200)\end{array}$ & & $\begin{array}{l}0.8540 * * * \\
(0.1201)\end{array}$ & $\begin{array}{c}0.8748^{* * *} \\
(0.1207)\end{array}$ \\
\hline $\mathrm{EA}_{\mathrm{t}}$ & & & $\begin{array}{c}0.1006^{* * *} \\
(0.0048)\end{array}$ & $\begin{array}{l}0.1018^{* * *} \\
(0.0050)\end{array}$ & $\begin{array}{c}0.0974 * * * \\
(0.0045)\end{array}$ \\
\hline News $_{t}$ & & & $\begin{array}{c}0.0861 * * * \\
(0.0056)\end{array}$ & $\begin{array}{c}0.0803^{* * * *} \\
(0.0050)\end{array}$ & $\begin{array}{c}0.0868 * * * \\
(0.0052)\end{array}$ \\
\hline $\ln \left(\right.$ Turnover $\left._{\mathrm{t}-7, \mathrm{t}-36}\right)$ & & & $\begin{array}{c}-0.0115^{* * *} \\
(0.0020)\end{array}$ & $\begin{array}{c}-0.0088^{* * * *} \\
(0.0020)\end{array}$ & $\begin{array}{c}-0.0097^{* * *} \\
(0.0017)\end{array}$ \\
\hline $\operatorname{Return}_{\mathrm{t}-7, \mathrm{t}-36}$ & & & $\begin{array}{l}-0.0004 \\
(0.0078)\end{array}$ & $\begin{array}{l}-0.0071 \\
(0.0070)\end{array}$ & $\begin{array}{l}-0.0040 \\
(0.0064)\end{array}$ \\
\hline $\ln ($ ReaVolat $-7, t-36)$ & & & $\begin{array}{l}-0.0044 \\
(0.0027)\end{array}$ & $\begin{array}{l}-0.0028 \\
(0.0027)\end{array}$ & $\begin{array}{l}-0.0025 \\
(0.0024)\end{array}$ \\
\hline $\ln ($ MarketCapt-7 $)$ & & & $\begin{array}{l}0.0017 \\
(0.0024)\end{array}$ & $\begin{array}{c}0.0013 \\
(0.0020)\end{array}$ & $\begin{array}{c}0.0021 \\
(0.0020)\end{array}$ \\
\hline $\mathrm{AWIKI}_{\mathrm{t}-7}$ & $\begin{array}{l}0.2111^{* * *} \\
(0.0074)\end{array}$ & $\begin{array}{c}0.2070 * * * \\
(0.0070)\end{array}$ & $\begin{array}{c}0.2102^{* * * *} \\
(0.0073)\end{array}$ & $\begin{array}{c}0.2059^{* * *} * \\
(0.0069)\end{array}$ & $\begin{array}{c}0.1993^{* * *} \\
(0.0061)\end{array}$ \\
\hline Firm FEs & YES & YES & YES & YES & YES \\
\hline Week FEs & YES & YES & YES & YES & YES \\
\hline Day-of-week FEs & YES & YES & YES & YES & YES \\
\hline $\mathrm{R}^{2}$ & 0.185 & 0.187 & 0.188 & 0.189 & 0.177 \\
\hline No. obs. & 947,982 & 930,230 & 945,457 & 927,759 & $1,209,864$ \\
\hline
\end{tabular}

IA. 42 
Table C16: Advertising and Investor Attention - Results with Google Search Volume

This table shows regressions of abnormal Google search volume for tickers (ASVI) on abnormal advertising (Adv). Tickers corresponding to words in a dictionary have been excluded and the sample period is 2004 to 2012. AdvNP,t and $A d v_{T V, t}$ are abnormal advertising. EA is an earnings announcement dummy. News is a national newspaper article dummy. Turnovert-7,t-36 is the trading volume over the 4 weeks up to t-7, divided by average shares outstanding. Return $_{\mathrm{t}-7, \mathrm{t}-36}$ is the holding period return over the 4 weeks up to t-7. ReaVolat-7,t-36 is realized volatility, defined as average absolute return during the 4 weeks up to t-7. MarketCap is the firm's market capitalization. Standard errors are clustered by firm and shown in parentheses. $1 / 2 / 3$ stars denote significance at the $10 / 5 / 1 \%$-level.

\begin{tabular}{|c|c|c|c|c|c|}
\hline & $\begin{array}{c}(1) \\
\text { ASVI }\end{array}$ & $\begin{array}{c}(2) \\
\text { ASVI }\end{array}$ & $\begin{array}{c}(3) \\
\text { ASVI }\end{array}$ & $\begin{array}{c}(4) \\
\text { ASVI }\end{array}$ & $\begin{array}{c}(5) \\
\text { ASVI }\end{array}$ \\
\hline $\operatorname{Adv}_{T V, t}$ & $\begin{array}{c}-0.0140 \\
(0.1436)\end{array}$ & & $\begin{array}{c}-0.0266 \\
(0.1445)\end{array}$ & & $\begin{array}{c}-0.0705 \\
(0.1441)\end{array}$ \\
\hline $\operatorname{Adv}_{T V, t-1}$ & $\begin{array}{l}-0.0259 \\
(0.1656)\end{array}$ & & $\begin{array}{c}-0.0525 \\
(0.1656)\end{array}$ & & $\begin{array}{c}-0.0795 \\
(0.1648)\end{array}$ \\
\hline $\mathrm{Adv}_{\mathrm{TV}, \mathrm{t}-2}$ & $\begin{array}{c}0.1332 \\
(0.1595)\end{array}$ & & $\begin{array}{c}0.1040 \\
(0.1582)\end{array}$ & & $\begin{array}{c}0.0821 \\
(0.1582)\end{array}$ \\
\hline $\operatorname{Adv}_{T V, t-3}$ & $\begin{array}{c}0.0396 \\
(0.1344)\end{array}$ & & $\begin{array}{c}0.0254 \\
(0.1343)\end{array}$ & & $\begin{array}{c}0.0057 \\
(0.1342)\end{array}$ \\
\hline $\operatorname{Adv}_{N P, t}$ & & $\begin{array}{c}0.3687^{* * *} * \\
(0.1109)\end{array}$ & & $\begin{array}{c}0.3259^{* * *} \\
(0.1016)\end{array}$ & $\begin{array}{c}0.3520 * * * \\
(0.1006)\end{array}$ \\
\hline $\operatorname{Adv}_{N P, t-1}$ & & $\begin{array}{c}0.3697 \text { *** } \\
(0.1174)\end{array}$ & & $\begin{array}{c}0.3251^{* * *} \\
(0.1087)\end{array}$ & $\begin{array}{c}0.3311^{* * *} \\
(0.1083)\end{array}$ \\
\hline $\operatorname{Adv}_{N P, t-2}$ & & $\begin{array}{c}0.2885^{* * *} \\
(0.1034)\end{array}$ & & $\begin{array}{c}0.2565^{* * * *} \\
(0.0959)\end{array}$ & $\begin{array}{c}0.2651^{* * *} * \\
(0.0960)\end{array}$ \\
\hline $\operatorname{Adv}_{N P, t-3}$ & & $\begin{array}{c}0.1624 \\
(0.1161)\end{array}$ & & $\begin{array}{c}0.1211 \\
(0.1047)\end{array}$ & $\begin{array}{c}0.1295 \\
(0.1044)\end{array}$ \\
\hline $\mathrm{EA}_{\mathrm{t}}$ & & & $\begin{array}{c}0.0983^{* * *} \\
(0.0080)\end{array}$ & $\begin{array}{c}0.0905^{* * * *} \\
(0.0075)\end{array}$ & $\begin{array}{c}0.0866^{* * *} * \\
(0.0065)\end{array}$ \\
\hline News $_{t}$ & & & $\begin{array}{c}0.0550 * * * \\
(0.0062)\end{array}$ & $\begin{array}{c}0.0524 * * * \\
(0.0059)\end{array}$ & $\begin{array}{c}0.0534 * * * \\
(0.0057)\end{array}$ \\
\hline $\ln \left(\right.$ Turnover $\left._{\mathrm{t}-7, \mathrm{t}-36}\right)$ & & & $\begin{array}{l}-0.0010 \\
(0.0017)\end{array}$ & $\begin{array}{c}0.0010 \\
(0.0015)\end{array}$ & $\begin{array}{c}0.0000 \\
(0.0014)\end{array}$ \\
\hline Return $_{\mathrm{t}-7, \mathrm{t}-36}$ & & & $\begin{array}{c}-0.0041 \\
(0.0054)\end{array}$ & $\begin{array}{c}0.0001 \\
(0.0057)\end{array}$ & $\begin{array}{c}0.0029 \\
(0.0047)\end{array}$ \\
\hline $\ln \left(\right.$ ReaVola $\left._{\mathrm{t}-7, \mathrm{t}-36}\right)$ & & & $\begin{array}{c}-0.0031 \\
(0.0020)\end{array}$ & $\begin{array}{c}-0.0023 \\
(0.0020)\end{array}$ & $\begin{array}{l}-0.0025 \\
(0.0017)\end{array}$ \\
\hline $\ln ($ MarketCapt-7) & & & $\begin{array}{c}-0.0018 \\
(0.0019)\end{array}$ & $\begin{array}{l}-0.0001 \\
(0.0018)\end{array}$ & $\begin{array}{l}-0.0007 \\
(0.0016)\end{array}$ \\
\hline $\mathrm{ASVI}_{\mathrm{t}-7}$ & $\begin{array}{c}0.1917^{* * *} \\
(0.0063)\end{array}$ & $\begin{array}{c}0.1923^{* * *} \\
(0.0057)\end{array}$ & $\begin{array}{c}0.1907 * * * \\
(0.0063)\end{array}$ & $\begin{array}{c}0.1907^{* * *} \\
(0.0057)\end{array}$ & $\begin{array}{c}0.1921 * * * \\
(0.0051)\end{array}$ \\
\hline Firm FEs & YES & YES & YES & YES & YES \\
\hline Week FEs & YES & YES & YES & YES & YES \\
\hline Day-of-week FEs & YES & YES & YES & YES & YES \\
\hline $\mathrm{R}^{2}$ & 0.062 & 0.068 & 0.063 & 0.069 & 0.068 \\
\hline No. obs. & $1,199,587$ & $1,289,179$ & $1,194,997$ & $1,284,128$ & $1,661,941$ \\
\hline
\end{tabular}

IA. 43 
Table C17: Advertising and Investor Attention - Results with EDGAR Downloads

This table shows regressions of abnormal EDGAR downloads of a firm's filings (ARPV) on abnormal advertising (Adv). Downloads from IP addresses that are identified as 'robots' have been excluded and the sample covers 2003 to 2012. $\operatorname{Adv}_{\mathrm{NP}, \mathrm{t}}$ and $\mathrm{Adv}_{\mathrm{TV}, \mathrm{t}}$ are abnormal advertising. EA is an earnings announcement dummy. News is a national newspaper article dummy. Turnover $\mathrm{r}_{\mathrm{t}-\mathrm{t}, \mathrm{t}-36}$ is the trading volume over the 4 weeks up to $\mathrm{t}-7$, divided by average shares outstanding. Return $\mathrm{t}-7, \mathrm{t}-36$ is the holding period return over the 4 weeks up to t-7. ReaVolat $-7, \mathrm{t}-36$ is realized volatility, defined as average absolute return during the 4 weeks up to t-7. MarketCap is the firm's market capitalization. Standard errors are clustered by firm and shown in parentheses. $1 / 2 / 3$ stars denote significance at the $10 / 5 / 1 \%$-level.

\begin{tabular}{|c|c|c|c|c|c|c|}
\hline & $\begin{array}{c}(1) \\
\text { ARPV }\end{array}$ & $\begin{array}{c}(2) \\
\text { ARPV }\end{array}$ & $\begin{array}{l}(3) \\
\text { ARPV }\end{array}$ & $\begin{array}{c}(4) \\
\text { ARPV }\end{array}$ & $\begin{array}{l}(5) \\
\text { ARPV }\end{array}$ & $\begin{array}{c}(6) \\
\text { ARPV(Inst.) }\end{array}$ \\
\hline $\mathrm{Adv}_{\mathrm{TV}, \mathrm{t}}$ & $\begin{array}{l}-0.3389 \\
(0.3741)\end{array}$ & & $\begin{array}{l}-0.3640 \\
(0.3733)\end{array}$ & & $\begin{array}{l}-0.4401 \\
(0.3779)\end{array}$ & $\begin{array}{c}0.3875 \\
(1.0175)\end{array}$ \\
\hline $\mathrm{Adv}_{\mathrm{TV}, \mathrm{t}-1}$ & $\begin{array}{l}-0.2257 \\
(0.4115)\end{array}$ & & $\begin{array}{l}-0.2334 \\
(0.4063)\end{array}$ & & $\begin{array}{l}-0.1941 \\
(0.4101)\end{array}$ & $\begin{array}{l}-0.8238 \\
(0.9796)\end{array}$ \\
\hline $\mathrm{Adv}_{\mathrm{TV}, \mathrm{t}-2}$ & $\begin{array}{l}-0.0139 \\
(0.3674)\end{array}$ & & $\begin{array}{l}-0.0110 \\
(0.3602)\end{array}$ & & $\begin{array}{c}0.0323 \\
(0.3608)\end{array}$ & $\begin{array}{l}-0.9906 \\
(0.9018)\end{array}$ \\
\hline $\mathrm{Adv}_{\mathrm{TV}, \mathrm{t}-3}$ & $\begin{array}{l}-0.2649 \\
(0.3323)\end{array}$ & & $\begin{array}{l}-0.2511 \\
(0.3312)\end{array}$ & & $\begin{array}{l}-0.2241 \\
(0.3308)\end{array}$ & $\begin{array}{l}-0.9516 \\
(0.7570)\end{array}$ \\
\hline $\operatorname{Adv}_{N P, t}$ & & $\begin{array}{c}0.5643^{* * *} \\
(0.2156)\end{array}$ & & $\begin{array}{c}0.5517^{* * *} \\
(0.2137)\end{array}$ & $\begin{array}{c}0.5661^{* * *} \\
(0.2134)\end{array}$ & $\begin{array}{c}1.8064^{* * *} \\
(0.5069)\end{array}$ \\
\hline $\operatorname{Adv}_{N P, t-1}$ & & $\begin{array}{c}0.7315^{* * * *} \\
(0.1986)\end{array}$ & & $\begin{array}{c}0.7080^{* * *} \\
(0.1980)\end{array}$ & $\begin{array}{c}0.7655^{* * *} \\
(0.1981)\end{array}$ & $\begin{array}{c}0.5465 \\
(0.4817)\end{array}$ \\
\hline $\mathrm{Adv}_{\mathrm{NP}, \mathrm{t}-2}$ & & $\begin{array}{c}0.1917 \\
(0.2026)\end{array}$ & & $\begin{array}{c}0.2319 \\
(0.2015)\end{array}$ & $\begin{array}{c}0.2799 \\
(0.2020)\end{array}$ & $\begin{array}{c}0.2573 \\
(0.4942)\end{array}$ \\
\hline $\operatorname{Adv}_{\mathrm{NP}, \mathrm{t}-3}$ & & $\begin{array}{c}0.1182 \\
(0.2142)\end{array}$ & & $\begin{array}{c}0.1258 \\
(0.2132)\end{array}$ & $\begin{array}{c}0.1656 \\
(0.2139)\end{array}$ & $\begin{array}{l}0.8118^{*} \\
(0.4843)\end{array}$ \\
\hline $\mathrm{EA}_{\mathrm{t}}$ & & & $\begin{array}{c}0.6970^{* * * *} \\
(0.0113)\end{array}$ & $\begin{array}{c}0.6727^{* * * *} \\
(0.0107)\end{array}$ & $\begin{array}{c}0.6812^{* * * *} \\
(0.0095)\end{array}$ & $\begin{array}{c}0.6461^{* * * *} \\
(0.0192)\end{array}$ \\
\hline Newst & & & $\begin{array}{c}0.1582^{* * *} \\
(0.0079)\end{array}$ & $\begin{array}{c}0.1521^{* * *} \\
(0.0072)\end{array}$ & $\begin{array}{c}0.1619^{* * *} \\
(0.0073)\end{array}$ & $\begin{array}{c}0.1544^{* * * *} \\
(0.0108)\end{array}$ \\
\hline $\ln$ (Turnover $\left._{\mathrm{t}-7, \mathrm{t}-36}\right)$ & & & $\begin{array}{c}-0.0396 * * * \\
(0.0028)\end{array}$ & $\begin{array}{c}-0.0414^{* * *} \\
(0.0027)\end{array}$ & $\begin{array}{c}-0.0415^{* * *} \\
(0.0024)\end{array}$ & $\begin{array}{c}-0.1009^{* * * *} \\
(0.0075)\end{array}$ \\
\hline Return $_{\mathrm{t}-7, \mathrm{t}-36}$ & & & $\begin{array}{c}-0.0532^{* * *} \\
(0.0104)\end{array}$ & $\begin{array}{c}-0.0484^{* * *} \\
(0.0099)\end{array}$ & $\begin{array}{c}-0.0533^{* * *} \\
(0.0088)\end{array}$ & $\begin{array}{l}-0.0282 \\
(0.0201)\end{array}$ \\
\hline $\ln ($ ReaVolat-7,t-36) & & & $\begin{array}{c}0.0246^{* * *} \\
(0.0038)\end{array}$ & $\begin{array}{c}0.0255^{* * * *} \\
(0.0039)\end{array}$ & $\begin{array}{c}0.0256^{* * *} \\
(0.0034)\end{array}$ & $\begin{array}{c}0.0579 * * * \\
(0.0090)\end{array}$ \\
\hline $\ln ($ MarketCapt-7) & & & $\begin{array}{c}0.0096^{* * * *} \\
(0.0026)\end{array}$ & $\begin{array}{c}0.0105^{* * * *} \\
(0.0027)\end{array}$ & $\begin{array}{c}0.0115^{* * *} \\
(0.0024)\end{array}$ & $\begin{array}{l}-0.0091 \\
(0.0068)\end{array}$ \\
\hline $\mathrm{ARPV}_{\mathrm{t}-7}$ & $\begin{array}{c}0.1366^{* * *} \\
(0.0016)\end{array}$ & $\begin{array}{c}0.1363^{* * *} \\
(0.0014)\end{array}$ & $\begin{array}{c}0.1370^{* * *} \\
(0.0015)\end{array}$ & $\begin{array}{c}0.1364^{* * *} \\
(0.0014)\end{array}$ & $\begin{array}{c}0.1366^{* * *} \\
(0.0013)\end{array}$ & $\begin{array}{c}0.1500^{* * *} \\
(0.0021)\end{array}$ \\
\hline Firm FEs & YES & YES & YES & YES & YES & YES \\
\hline Week FEs & YES & YES & YES & YES & YES & YES \\
\hline Day-of-week FEs & YES & YES & YES & YES & YES & YES \\
\hline $\mathrm{R}^{2}$ & 0.149 & 0.146 & 0.158 & 0.154 & 0.149 & 0.103 \\
\hline No. obs. & $1,535,549$ & $1,662,244$ & $1,531,248$ & $1,657,757$ & $2,126,378$ & 431,791 \\
\hline
\end{tabular}

IA. 44 
Table C18: Advertising and Investor Attention - Results with Bloomberg search

This table shows regressions of abnormal Bloomberg search volume (AIAC) on abnormal advertising (Adv). The sample covers March 2010 to 2012. Adv NP,t $_{\text {and }}$ AdvTV,t are abnormal advertising. EA is an earnings announcement dummy. News is a national newspaper article dummy. Turnover $\mathrm{t}_{\mathrm{t}, \mathrm{t}-36}$ is the trading volume over the 4 weeks up to t-7, divided by average shares outstanding. Return ${ }_{t-7, t-36}$ is the holding period return over the 4 weeks up to t-7. ReaVolat-7,t-36 is realized volatility, defined as average absolute return during the 4 weeks up to t-7. MarketCap is the firm's market capitalization. Standard errors are clustered by firm and shown in parentheses. 1/2/3 stars denote significance at the $10 / 5 / 1 \%$-level.

\begin{tabular}{|c|c|c|c|c|c|}
\hline & $\begin{array}{c}(1) \\
\text { AIAC }\end{array}$ & $\begin{array}{c}(2) \\
\text { AIAC }\end{array}$ & $\begin{array}{c}(3) \\
\text { AIAC }\end{array}$ & $\begin{array}{c}(4) \\
\text { AIAC }\end{array}$ & $\begin{array}{c}(5) \\
\text { AIAC }\end{array}$ \\
\hline $\mathrm{Adv}_{\mathrm{TV}, \mathrm{t}}$ & $\begin{array}{c}0.3921 \\
(0.6973)\end{array}$ & & $\begin{array}{c}0.3159 \\
(0.6848)\end{array}$ & & $\begin{array}{c}0.4793 \\
(0.6799)\end{array}$ \\
\hline $\mathrm{Adv}_{\mathrm{TV}, \mathrm{t}-1}$ & $\begin{array}{c}1.7711^{* *} \\
(0.7820)\end{array}$ & & $\begin{array}{l}1.6676^{* *} \\
(0.7543)\end{array}$ & & $\begin{array}{c}1.7454^{* *} \\
(0.7543)\end{array}$ \\
\hline $\mathrm{Adv}_{\mathrm{TV}, \mathrm{t}-2}$ & $\begin{array}{c}0.2315 \\
(0.6995)\end{array}$ & & $\begin{array}{c}0.2424 \\
(0.6702)\end{array}$ & & $\begin{array}{c}0.2598 \\
(0.6713)\end{array}$ \\
\hline $\mathrm{Adv}_{\mathrm{TV}, \mathrm{t}-3}$ & $\begin{array}{c}0.3825 \\
(0.6143)\end{array}$ & & $\begin{array}{c}0.4636 \\
(0.5932)\end{array}$ & & $\begin{array}{c}0.4797 \\
(0.5927)\end{array}$ \\
\hline $\operatorname{Adv}_{N P, t}$ & & $\begin{array}{l}0.9547^{*} \\
(0.4943)\end{array}$ & & $\begin{array}{c}0.9888^{* *} \\
(0.4773)\end{array}$ & $\begin{array}{l}1.0791^{* *} \\
(0.4742)\end{array}$ \\
\hline $\operatorname{Adv}_{N P, t-1}$ & & $\begin{array}{c}0.8040^{* *} \\
(0.4093)\end{array}$ & & $\begin{array}{l}0.7066^{*} \\
(0.4005)\end{array}$ & $\begin{array}{l}0.7534^{*} \\
(0.4009)\end{array}$ \\
\hline $\operatorname{Adv}_{\mathrm{NP}, \mathrm{t}-2}$ & & $\begin{array}{c}0.1893 \\
(0.4241)\end{array}$ & & $\begin{array}{c}0.1853 \\
(0.4202)\end{array}$ & $\begin{array}{c}0.2250 \\
(0.4216)\end{array}$ \\
\hline $\operatorname{Adv}_{N P, t-3}$ & & $\begin{array}{c}0.3732 \\
(0.4319)\end{array}$ & & $\begin{array}{c}0.3965 \\
(0.4217)\end{array}$ & $\begin{array}{c}0.4584 \\
(0.4237)\end{array}$ \\
\hline $\mathrm{EA}_{\mathrm{t}}$ & & & $\begin{array}{c}1.3024^{* * *} \\
(0.0209)\end{array}$ & $\begin{array}{c}1.2718^{* * *} \\
(0.0192)\end{array}$ & $\begin{array}{c}1.3032^{* * *} \\
(0.0179)\end{array}$ \\
\hline News $_{t}$ & & & $\begin{array}{c}0.1969 * * * \\
(0.0144)\end{array}$ & $\begin{array}{c}0.1939 * * * \\
(0.0139)\end{array}$ & $\begin{array}{c}0.2012^{* * *} * \\
(0.0134)\end{array}$ \\
\hline $\ln \left(\right.$ Turnover $\left._{\mathrm{t}-7, \mathrm{t}-36}\right)$ & & & $\begin{array}{l}-0.0179 \\
(0.0147)\end{array}$ & $\begin{array}{c}-0.0372^{* * *} \\
(0.0143)\end{array}$ & $\begin{array}{l}-0.0185 \\
(0.0118)\end{array}$ \\
\hline Return $_{\mathrm{t}-7, \mathrm{t}-36}$ & & & $\begin{array}{l}0.0546^{*} \\
(0.0303)\end{array}$ & $\begin{array}{l}0.0615^{*} \\
(0.0324)\end{array}$ & $\begin{array}{c}0.0398 \\
(0.0257)\end{array}$ \\
\hline $\ln \left(\right.$ ReaVola $\left._{\mathrm{t}-7, \mathrm{t}-36}\right)$ & & & $\begin{array}{c}-0.1814^{* * *} \\
(0.0136)\end{array}$ & $\begin{array}{c}-0.1746^{* * *} \\
(0.0134)\end{array}$ & $\begin{array}{c}-0.1672^{* * *} \\
(0.0114)\end{array}$ \\
\hline $\ln ($ MarketCapt-7 $)$ & & & $\begin{array}{c}0.0142 \\
(0.0253)\end{array}$ & $\begin{array}{c}0.0048 \\
(0.0280)\end{array}$ & $\begin{array}{c}0.0297 \\
(0.0215)\end{array}$ \\
\hline $\mathrm{AIAC}_{\mathrm{t}-7}$ & $\begin{array}{c}0.1674^{* * *} \\
(0.0074)\end{array}$ & $\begin{array}{c}0.1702^{* * *} \\
(0.0073)\end{array}$ & $\begin{array}{c}0.1661^{* * *} \\
(0.0074)\end{array}$ & $\begin{array}{c}0.1689^{* * *} \\
(0.0074)\end{array}$ & $\begin{array}{c}0.1643^{* * *} \\
(0.0063)\end{array}$ \\
\hline Firm FEs & YES & YES & YES & YES & YES \\
\hline Week FEs & YES & YES & YES & YES & YES \\
\hline Day-of-week FEs & YES & YES & YES & YES & YES \\
\hline $\mathrm{R}^{2}$ & 0.328 & 0.334 & 0.361 & 0.365 & 0.360 \\
\hline No. obs. & 353,687 & 351,254 & 353,500 & 351,125 & 464,211 \\
\hline
\end{tabular}


Table C19: Summary Statistics - Advertising and Financial Markets

This table reports summary statistics on financial market data and Kantar-advertising on the firm-day level. The observations are restricted to NYSE/AMEX/NASDAQ stocks, to those days when a firm's price was $\geq 5$ last week and when it advertised at least once during the last 8 weeks, i.e., when the main data requirements for the panel regressions are fulfilled. In order to keep TAQ-based variables (available 1996-2010 only) and other variables comparable, the sample includes observations from 1996 to 2010 only. Statistics for newspaper subcategories (local papers, Wall Street Journal and the other national papers) are further restricted to the $\geq 1999$ period, as local paper ads are available only after 1998 .

\begin{tabular}{|c|c|c|c|c|c|c|}
\hline & Mean & Median & $\mathrm{SD}$ & $10 \%$ ile & $90 \%$ ile & $\mathrm{N}$ \\
\hline \multicolumn{7}{|c|}{ Panel A: TV Regression sample } \\
\hline Market Cap (Million \$) & $11,320.41$ & $2,184.80$ & $28,057.57$ & 244.11 & $27,337.38$ & $2,576,578$ \\
\hline Advertising-to-sales (\%) & 4.10 & 1.89 & 7.82 & 0.02 & 9.25 & $2,094,648$ \\
\hline Turnover $_{\mathrm{t}}(\%)$ & 196.52 & 118.24 & 240.00 & 26.03 & 442.11 & $2,562,647$ \\
\hline $\operatorname{Return}_{\mathrm{t}}(\%)$ & 0.05 & 0.00 & 2.63 & -2.72 & 2.83 & $2,562,323$ \\
\hline Rea.Vola ${ }_{\mathrm{t}-7, \mathrm{t}-36}(\%)$ & 39.43 & 32.79 & 24.98 & 16.54 & 69.97 & $2,555,867$ \\
\hline News $_{t}(\%)$ & 5.19 & 0.00 & 22.17 & 0.00 & 0.00 & $2,576,578$ \\
\hline Effective Spread $_{t}(\%)$ & 2.58 & 2.23 & 1.80 & 0.78 & 4.71 & $2,576,546$ \\
\hline TV Ad (daily $\$$ ) & $147,807.43$ & $1,133.00$ & $597,339.53$ & 0.00 & $255,458.00$ & $2,576,578$ \\
\hline News TV Ad (daily \$) & $7,253.34$ & 0.00 & $65,385.82$ & 0.00 & $2,999.00$ & $2,576,578$ \\
\hline No-News TV Ad (daily \$) & $140,554.09$ & 993.00 & $566,471.99$ & 0.00 & $246,875.00$ & $2,576,578$ \\
\hline $\mathrm{Adv}_{\mathrm{TV}, \mathrm{t}} * 1000$ & 0.02 & 0.00 & 2.28 & -1.70 & 1.76 & $2,576,578$ \\
\hline $\operatorname{Adv}_{\text {TVNWS }, \mathrm{t}} * 1000$ & -0.02 & 0.00 & 1.86 & 0.00 & 0.00 & $2,576,188$ \\
\hline Advtvnonws,t $* 1000$ & -0.04 & 0.00 & 2.20 & -1.36 & 1.25 & $2,576,188$ \\
\hline \multicolumn{7}{|c|}{ Panel B: Newspaper Regression sample } \\
\hline Market Cap (Million \$) & $10,191.61$ & $1,875.77$ & $26,597.27$ & 177.24 & $22,816.52$ & $2,879,703$ \\
\hline Advertising-to-sales (\%) & 3.45 & 1.50 & 7.64 & 0.01 & 7.51 & $2,280,072$ \\
\hline Turnover $_{\mathrm{t}}(\%)$ & 204.04 & 123.59 & 247.70 & 23.33 & 462.80 & $2,864,976$ \\
\hline $\operatorname{Return}_{\mathrm{t}}(\%)$ & 0.04 & 0.00 & 2.78 & -2.88 & 2.98 & $2,864,557$ \\
\hline Rea.Volat-7,t-36 (\%) & 41.82 & 34.18 & 27.55 & 16.87 & 76.08 & $2,855,942$ \\
\hline Newst $(\%)$ & 4.86 & 0.00 & 21.50 & 0.00 & 0.00 & $2,879,703$ \\
\hline Effective Spread $_{\mathrm{t}}(\%)$ & 2.52 & 2.23 & 1.64 & 0.80 & 4.48 & $2,879,703$ \\
\hline Newspaper Ad (daily \$) & $20,991.65$ & 0.00 & $168,195.85$ & 0.00 & $14,714.00$ & $2,675,054$ \\
\hline WSJ Newspaper Ad (daily \$) & $2,066.51$ & 0.00 & $22,955.88$ & 0.00 & 0.00 & $2,675,054$ \\
\hline 3 National Newspaper Ad (daily $\$$ ) & $3,224.47$ & 0.00 & $27,801.07$ & 0.00 & 0.00 & $2,675,054$ \\
\hline Local Newspaper Ad (daily $\$$ ) & $15,700.66$ & 0.00 & $145,939.92$ & 0.00 & $8,168.00$ & $2,675,054$ \\
\hline $\operatorname{Adv}_{\mathrm{NP}, \mathrm{t}} * 1000$ & 0.21 & 0.00 & 3.01 & -0.12 & 1.06 & $2,879,703$ \\
\hline $\operatorname{Adv}_{\text {NPWSJ,t }} * 1000$ & 0.06 & 0.00 & 1.34 & 0.00 & 0.00 & $2,675,054$ \\
\hline $\operatorname{Adv}_{\text {NP3NAT, },} * 1000$ & 0.07 & 0.00 & 1.63 & 0.00 & 0.00 & $2,675,054$ \\
\hline $\mathrm{Adv}_{\mathrm{NPLOC}, \mathrm{t}} * 1000$ & 0.17 & 0.00 & 2.70 & -0.03 & 0.74 & $2,675,054$ \\
\hline
\end{tabular}

IA. 46 
Table C20: Summary Statistics - Advertising and Financial Markets Appendix

This table reports summary statistics on financial market data used in the appendix at the firm-day level. The observations are restricted to NYSE/AMEX/NASDAQ stocks, to those days when a firm's price was $\geq 5$ last week and when it advertised at least once during the last 8 weeks, i.e., when the main data requirements for the panel regressions are fulfilled. In order to keep TAQ-based variables (available 1996-2010 only) and other variables comparable, the sample includes observations from 1996 to 2010 only.

\begin{tabular}{|c|c|c|c|c|c|c|}
\hline & Mean & Median & $\mathrm{SD}$ & $10 \%$ ile & $90 \%$ ile & $\mathrm{N}$ \\
\hline \multicolumn{7}{|c|}{ Panel A: TV Regression sample } \\
\hline Relative Spread $_{t}(\%)$ & 0.96 & 0.57 & 1.36 & 0.15 & 2.06 & $2,576,546$ \\
\hline Price Impact I $_{\mathrm{t}}(\%)$ & 3.98 & 0.64 & 11.81 & 0.23 & 7.09 & $2,576,546$ \\
\hline Intraday Amihud $\left(* 10^{4}\right)$ & 0.12 & 0.02 & 0.54 & 0.00 & 0.17 & $2,576,546$ \\
\hline Absolute Returnst $(\%)$ & 1.90 & 1.25 & 2.15 & 0.25 & 4.21 & $2,562,323$ \\
\hline Order Imbalance $_{t}(\%)$ & 3.42 & 2.80 & 27.07 & -26.06 & 33.46 & $2,576,546$ \\
\hline Buys $_{\mathrm{t}}($ Thousand $\$$ ) & $35,189.65$ & $6,211.77$ & $114,381.91$ & 202.40 & $80,814.61$ & $2,576,546$ \\
\hline Sells $_{\mathrm{t}}($ Thousand \$) & $33,132.45$ & $5,666.11$ & $112,045.68$ & 206.88 & $74,305.20$ & $2,576,546$ \\
\hline \multicolumn{7}{|c|}{ Panel B: Newspaper Regression sample } \\
\hline Relati & 1.00 & 0.56 & 1.50 & 0.15 & 2.14 & $2,879,703$ \\
\hline Price Impact $_{t}(\%)$ & 3.64 & 0.68 & 10.93 & 0.24 & 6.25 & $2,879,703$ \\
\hline Intraday Amihud $_{\mathrm{t}}\left(* 10^{4}\right)$ & 0.11 & 0.02 & 0.50 & 0.00 & 0.17 & $2,879,703$ \\
\hline Absolute Returns ${ }_{\mathrm{t}}(\%)$ & 2.01 & 1.29 & 2.32 & 0.25 & 4.49 & $2,864,976$ \\
\hline Order Imbalance $(\%)$ & 3.20 & 2.71 & 26.43 & -25.45 & 32.36 & $2,879,703$ \\
\hline Buyst $_{t}($ Thousand $\$)$ & $34,871.32$ & $5,975.34$ & $113,238.29$ & 149.96 & $80,234.81$ & $2,879,703$ \\
\hline Sells $_{\mathrm{t}}$ (Thousand \$) & $32,794.27$ & $5,454.56$ & $110,660.79$ & 158.72 & $73,770.14$ & $2,879,703$ \\
\hline
\end{tabular}


Table C21: Impact on Financial Markets - Excluding EA and Coverage Windows

The analysis is done for 1995-2012 (1996-2010) common stocks from NYSE, AMEX and NASDAQ for Turnover and Returns (TAQ-based data), excluding stocks with last-week prices below 5 USD. We exclude days with an earnings announcement or national media coverage in the window from $t-3$ to $t+3$. Turnover is daily trading volume over shares outstanding. EffSpr is the effective spread, defined as daily transaction-weighted average of transaction prices relative to prevailing quotes. Return ${ }^{\text {excess }}$ is the return of a stock over Kenneth French's market return. Adv is abnormal advertising. Turnover $r_{t-7, t-36}$ is the trading volume over the 4 weeks up to $t-7$, divided by average shares outstanding. Return $_{\mathrm{t}-7, \mathrm{t}-36}$ is the holding period return over the 4 weeks up to $\mathrm{t}-7$. ReaVolat $-7, \mathrm{t}-36$ is realized volatility, defined as average absolute return during the 4 weeks up to t-7. MarketCap is the firm's market capitalization. Standard errors are shown in parentheses and clustered by firm for the panel-regressions. $1 / 2 / 3$ stars denote significance at the $10 / 5 / 1 \%$-level.

\begin{tabular}{|c|c|c|c|}
\hline \multicolumn{4}{|c|}{ Panel A: TV Advertising } \\
\hline & $\begin{array}{c}(1) \\
\ln \left(\text { Turnover }_{\mathrm{t}}\right)\end{array}$ & $\begin{array}{c}(2) \\
\ln \left(\text { EffSpr }_{\mathrm{t}}\right)\end{array}$ & Return $_{\mathrm{t}}^{(3)}$ \\
\hline $\mathrm{Adv}_{\mathrm{TV}, \mathrm{t}}$ & $\begin{array}{c}0.5390^{* *} \\
(0.2311)\end{array}$ & $\begin{array}{l}-0.9070^{*} \\
(0.4782)\end{array}$ & $\begin{array}{l}-0.0026 \\
(0.0081)\end{array}$ \\
\hline $\operatorname{Adv}_{T V, t-1}$ & $\begin{array}{l}0.4615^{*} \\
(0.2399)\end{array}$ & $\begin{array}{l}-0.6762 \\
(0.4390)\end{array}$ & $\begin{array}{l}-0.0078 \\
(0.0078)\end{array}$ \\
\hline $\operatorname{Adv}_{T V, t-2}$ & $\begin{array}{c}0.0554 \\
(0.2177)\end{array}$ & $\begin{array}{l}-0.6313 \\
(0.3957)\end{array}$ & $\begin{array}{c}0.0093 \\
(0.0073)\end{array}$ \\
\hline $\operatorname{Adv}_{\mathrm{TV}, \mathrm{t}-3}$ & $\begin{array}{c}0.3992^{* *} \\
(0.1783)\end{array}$ & $\begin{array}{l}-0.2811 \\
(0.3449)\end{array}$ & $\begin{array}{c}0.0092 \\
(0.0073)\end{array}$ \\
\hline $\ln \left(\right.$ Turnover $\left._{\mathrm{t}-7, \mathrm{t}-36}\right)$ & $\begin{array}{c}0.6142^{* * * *} \\
(0.0052)\end{array}$ & $\begin{array}{c}-0.0702^{* * *} \\
(0.0010)\end{array}$ & $\begin{array}{c}0.0001^{* * *} \\
(0.0000)\end{array}$ \\
\hline Return $_{\mathrm{t}-7, \mathrm{t}-36}$ & $\begin{array}{c}-0.1624^{* * *} \\
(0.0090)\end{array}$ & $\begin{array}{c}0.0315^{* *} \\
(0.0132)\end{array}$ & $\begin{array}{c}-0.0012^{* * *} \\
(0.0002)\end{array}$ \\
\hline $\ln ($ ReaVolat-7,t-36) & $\begin{array}{c}-0.0408^{* * *} \\
(0.0050)\end{array}$ & $\begin{array}{c}0.1618^{* * *} \\
(0.0104)\end{array}$ & $\begin{array}{c}-0.0000 \\
(0.0001)\end{array}$ \\
\hline $\ln ($ MarketCapt-7) & $\begin{array}{c}0.0470^{* * *} \\
(0.0061)\end{array}$ & $\begin{array}{c}-0.1352^{* * *} \\
(0.0135)\end{array}$ & $\begin{array}{c}-0.0009^{* * *} \\
(0.0001)\end{array}$ \\
\hline $\ln \left(\right.$ Turnover $\left._{\mathrm{t}-7}\right)$ & $\begin{array}{c}0.1617^{* * *} \\
(0.0017)\end{array}$ & & \\
\hline $\ln \left(\mathrm{EffSpr}_{\mathrm{t}-7}\right)$ & & $\begin{array}{c}0.3467^{* * *} \\
(0.0055)\end{array}$ & \\
\hline Firm-FEs & YES & YES & YES \\
\hline Week-FEs & YES & YES & YES \\
\hline Day-of-Week-FEs & YES & YES & YES \\
\hline $\mathrm{R}^{2}$ & 0.70 & 0.59 & 0.01 \\
\hline No. obs. & $2,129,030$ & $1,682,003$ & $2,129,030$ \\
\hline
\end{tabular}




\begin{tabular}{|c|c|c|c|}
\hline \multicolumn{4}{|c|}{ Panel B: Newspaper Advertising } \\
\hline & $\begin{array}{c}(1) \\
\ln \left(\text { Turnover }_{\mathrm{t}}\right)\end{array}$ & $\begin{array}{c}(2) \\
\ln \left(\text { EffSpr }_{\mathrm{t}}\right)\end{array}$ & $\operatorname{Return}_{\mathrm{t}}{ }^{\text {excess }}$ \\
\hline $\operatorname{Adv}_{N P, t}$ & $\begin{array}{c}0.3900^{* * *} \\
(0.1433)\end{array}$ & $\begin{array}{c}0.1489 \\
(0.2605)\end{array}$ & $\begin{array}{l}-0.0057 \\
(0.0053)\end{array}$ \\
\hline $\operatorname{Adv}_{N P, t-1}$ & $\begin{array}{c}0.4894^{* * *} \\
(0.1370)\end{array}$ & $\begin{array}{l}-0.1179 \\
(0.2387)\end{array}$ & $\begin{array}{c}0.0075 \\
(0.0053)\end{array}$ \\
\hline $\mathrm{Adv}_{\mathrm{NP}, \mathrm{t}-2}$ & $\begin{array}{c}0.4700^{* * * *} \\
(0.1384)\end{array}$ & $\begin{array}{l}-0.2687 \\
(0.2359)\end{array}$ & $\begin{array}{l}-0.0045 \\
(0.0053)\end{array}$ \\
\hline $\mathrm{Adv}_{\mathrm{NP}, \mathrm{t}-3}$ & $\begin{array}{c}0.0059 \\
(0.1459)\end{array}$ & $\begin{array}{c}0.3382 \\
(0.2454)\end{array}$ & $\begin{array}{l}-0.0009 \\
(0.0057)\end{array}$ \\
\hline $\ln \left(\right.$ Turnover $\left._{\mathrm{t}-7, \mathrm{t}-36}\right)$ & $\begin{array}{c}0.6063^{* * *} \\
(0.0047)\end{array}$ & $\begin{array}{c}-0.0936^{* * *} \\
(0.0081)\end{array}$ & $\begin{array}{c}0.0001^{* * *} \\
(0.0000)\end{array}$ \\
\hline $\operatorname{Return}_{\mathrm{t}-7, \mathrm{t}-36}$ & $\begin{array}{c}-0.1405^{* * *} \\
(0.0084)\end{array}$ & $\begin{array}{c}0.0259^{* *} \\
(0.0108)\end{array}$ & $\begin{array}{c}-0.0006^{* * *} \\
(0.0002)\end{array}$ \\
\hline $\ln \left(\right.$ ReaVolat$\left._{\mathrm{t}-7, \mathrm{t}-36}\right)$ & $\begin{array}{c}-0.0265^{* * *} \\
(0.0045)\end{array}$ & $\begin{array}{c}0.1662^{* * *} \\
(0.0090)\end{array}$ & $\begin{array}{l}-0.0001 \\
(0.0001)\end{array}$ \\
\hline $\ln ($ MarketCapt-7 $)$ & $\begin{array}{c}0.0562^{* * * *} \\
(0.0051)\end{array}$ & $\begin{array}{c}-0.1204^{* * *} \\
(0.0112)\end{array}$ & $\begin{array}{c}-0.0012^{* * *} \\
(0.0001)\end{array}$ \\
\hline $\ln \left(\right.$ Turnover $\left._{\mathrm{t}-7}\right)$ & $\begin{array}{c}0.1658^{* * *} \\
(0.0017)\end{array}$ & & \\
\hline $\ln \left(\mathrm{EffSpr}_{\mathrm{t}-7}\right)$ & & $\begin{array}{c}0.3535^{* * *} \\
(0.0050)\end{array}$ & \\
\hline Firm-FEs & YES & YES & YES \\
\hline Week-FEs & YES & YES & YES \\
\hline Day-of-Week-FEs & YES & YES & YES \\
\hline $\mathrm{R}^{2}$ & 0.72 & 0.60 & 0.01 \\
\hline No. obs. & $2,291,956$ & $1,928,619$ & $2,291,956$ \\
\hline
\end{tabular}

IA. 49 
Table C22: Impact on Financial Markets - TV Advertising Channels

This table shows regressions of the logarithm of turnover, the logarithm of the effective spread (EffSpr), and the excess return of a firm on abnormal TV advertising $\left(A d v_{T V}\right)$. Turnover is daily trading volume over shares outstanding. EffSpr is the effective spread, defined as daily transaction-weighted average of transaction prices relative to prevailing quotes. Return ${ }^{\text {excess }}$ is the return of a stock over Kenneth French's market return. Adv is abnormal advertising. Controls are included in the regressions (same as in the main regressions), but not reported. The analysis is done for 1995-2012 (1996-2010) common stocks from NYSE, AMEX and NASDAQ for Turnover and Returns (TAQ-based data), excluding stocks with last-week prices below 5 USD. Standard errors are shown in parentheses and clustered by firm. $1 / 2 / 3$ stars denote significance at the $10 / 5 / 1 \%$-level.

\begin{tabular}{|c|c|c|c|}
\hline & $\begin{array}{c}(1) \\
\ln \left(\text { Turnover }_{t}\right)\end{array}$ & $\begin{array}{c}(2) \\
\ln \left(\text { EffSpr }_{t}\right)\end{array}$ & $\begin{array}{c}(3) \\
\text { Return }_{\mathrm{t}} \\
\text { excess }\end{array}$ \\
\hline $\mathrm{Adv}_{\mathrm{TVNWS}, \mathrm{t}}$ & $\begin{array}{c}0.0050 \\
(0.2270)\end{array}$ & $\begin{array}{l}-0.8478 \\
(0.7288)\end{array}$ & $\begin{array}{c}-0.0210^{* *} \\
(0.0085)\end{array}$ \\
\hline AdvTVNWS,t-1 & $\begin{array}{l}-0.3122 \\
(0.2700)\end{array}$ & $\begin{array}{c}-2.8275^{* * *} \\
(0.7749)\end{array}$ & $\begin{array}{l}-0.0077 \\
(0.0089)\end{array}$ \\
\hline $\operatorname{Adv}_{\text {TVNWS,t-2 }}$ & $\begin{array}{l}-0.1981 \\
(0.2269)\end{array}$ & $\begin{array}{c}-1.9020^{* * *} \\
(0.5957)\end{array}$ & $\begin{array}{c}0.0067 \\
(0.0085)\end{array}$ \\
\hline $\operatorname{Adv}_{\text {TVNWS }, \mathrm{t}-3}$ & $\begin{array}{l}-0.0102 \\
(0.1601)\end{array}$ & $\begin{array}{c}-0.9850^{* *} \\
(0.4212)\end{array}$ & $\begin{array}{l}-0.0020 \\
(0.0079)\end{array}$ \\
\hline $\mathrm{Adv}_{\text {TVNONWS }, \mathrm{t}}$ & $\begin{array}{c}0.5774^{* * * *} \\
(0.2144)\end{array}$ & $\begin{array}{l}-0.1041 \\
(0.4666)\end{array}$ & $\begin{array}{l}-0.0120 \\
(0.0080)\end{array}$ \\
\hline $\mathrm{Adv}_{\text {TVNONWS,t-1 }}$ & $\begin{array}{c}0.4938^{* *} \\
(0.2286)\end{array}$ & $\begin{array}{l}-0.2330 \\
(0.4869)\end{array}$ & $\begin{array}{l}-0.0078 \\
(0.0079)\end{array}$ \\
\hline $\mathrm{Adv}_{\text {TVNONWS,t-2 }}$ & $\begin{array}{c}0.3309 \\
(0.2027)\end{array}$ & $\begin{array}{l}-0.6447^{*} \\
(0.3855)\end{array}$ & $\begin{array}{c}0.0035 \\
(0.0070)\end{array}$ \\
\hline AdvTVNONWS,t-3 & $\begin{array}{c}0.2444 \\
(0.1672)\end{array}$ & $\begin{array}{l}-0.4961 \\
(0.3088)\end{array}$ & $\begin{array}{l}-0.0085 \\
(0.0067)\end{array}$ \\
\hline Firm-FEs & YES & YES & YES \\
\hline Week-FEs & YES & YES & YES \\
\hline Day-of-Week-FEs & YES & YES & YES \\
\hline Controls & YES & YES & YES \\
\hline $\mathrm{R}^{2}$ & 0.70 & 0.58 & 0.01 \\
\hline No. obs. & $2,870,033$ & $2,286,073$ & $2,870,033$ \\
\hline
\end{tabular}


Table C23: Impact on Financial Markets - Newspapers Advertising Channels

This table shows regressions of the logarithm of turnover, the logarithm of the effective spread (EffSpr), and the excess return of a firm on abnormal newspaper advertising $\left(A d v_{N P}\right)$. Turnover is daily trading volume over shares outstanding. EffSpr is the effective spread, defined as daily transaction-weighted average of transaction prices relative to prevailing quotes. Return ${ }^{\text {excess }}$ is the return of a stock over Kenneth French's market return. Adv is abnormal advertising. Controls are included in the regressions (same as in the main regressions), but not reported. The analysis is done for 1999-2012 (1999-2010) common stocks from NYSE, AMEX and NASDAQ for Turnover and Returns (TAQ-based data), excluding stocks with last-week prices below 5 USD. Standard errors are shown in parentheses and clustered by firm. $1 / 2 / 3$ stars denote significance at the $10 / 5 / 1 \%$-level.

\begin{tabular}{|c|c|c|c|}
\hline & $\begin{array}{c}(1) \\
\ln \left(\text { Turnover }_{\mathrm{t}}\right)\end{array}$ & $\begin{array}{c}(2) \\
\ln \left(\text { EffSpr }_{\mathrm{t}}\right)\end{array}$ & Return $_{\mathrm{t}}{ }^{\text {excess }}$ \\
\hline $\operatorname{Adv}_{\mathrm{NPWSJ}, \mathrm{t}}$ & $\begin{array}{c}0.0562 \\
(0.2129)\end{array}$ & $\begin{array}{c}-0.7472 \\
(0.5669)\end{array}$ & $\begin{array}{c}0.0034 \\
(0.0115)\end{array}$ \\
\hline $\operatorname{Adv}_{\text {NPWSJ,t-1 }}$ & $\begin{array}{c}0.7019^{* * *} \\
(0.2273)\end{array}$ & $\begin{array}{c}-0.3458 \\
(0.6376)\end{array}$ & $\begin{array}{c}-0.0216^{* *} \\
(0.0109)\end{array}$ \\
\hline $\mathrm{Adv}_{\mathrm{NPWSJ}, \mathrm{t}-2}$ & $\begin{array}{c}0.6916^{* * *} \\
(0.2663)\end{array}$ & $\begin{array}{l}-0.8218 \\
(0.6594)\end{array}$ & $\begin{array}{l}-0.0112 \\
(0.0127)\end{array}$ \\
\hline AdvNPWSJ,t-3 & $\begin{array}{c}0.6538^{* *} \\
(0.2843)\end{array}$ & $\begin{array}{l}1.4963^{* *} \\
(0.6426)\end{array}$ & $\begin{array}{c}0.0120 \\
(0.0147)\end{array}$ \\
\hline AdvNP3NAT,t & $\begin{array}{c}0.2766 \\
(0.1876)\end{array}$ & $\begin{array}{c}0.0718 \\
(0.4710)\end{array}$ & $\begin{array}{c}-0.0044 \\
(0.0089)\end{array}$ \\
\hline $\mathrm{Adv}_{\mathrm{NP}} 3 \mathrm{NAT}, \mathrm{t}-1$ & $\begin{array}{c}-0.0266 \\
(0.1962)\end{array}$ & $\begin{array}{c}0.1591 \\
(0.4066)\end{array}$ & $\begin{array}{c}-0.0043 \\
(0.0088)\end{array}$ \\
\hline $\mathrm{Adv}_{\mathrm{NP}} 3 \mathrm{NAT}, \mathrm{t}-2$ & $\begin{array}{c}0.1873 \\
(0.2010)\end{array}$ & $\begin{array}{c}-0.2512 \\
(0.3659)\end{array}$ & $\begin{array}{c}0.0061 \\
(0.0088)\end{array}$ \\
\hline $\mathrm{Adv}_{\mathrm{NP}} 3 \mathrm{NAT}, \mathrm{t}-3$ & $\begin{array}{c}0.2542 \\
(0.1975)\end{array}$ & $\begin{array}{c}0.0752 \\
(0.4213)\end{array}$ & $\begin{array}{c}0.0051 \\
(0.0093)\end{array}$ \\
\hline $\operatorname{Adv}_{\text {NPLOC }, \mathrm{t}}$ & $\begin{array}{c}0.2966^{* *} \\
(0.1375)\end{array}$ & $\begin{array}{c}-0.0944 \\
(0.2477)\end{array}$ & $\begin{array}{c}0.0047 \\
(0.0053)\end{array}$ \\
\hline $\operatorname{Adv}_{\text {NPLOC,t-1 }}$ & $\begin{array}{c}0.3748^{* * *} \\
(0.1296)\end{array}$ & $\begin{array}{l}-0.0548 \\
(0.2227)\end{array}$ & $\begin{array}{c}0.0115^{* *} \\
(0.0049)\end{array}$ \\
\hline $\mathrm{Adv}_{\mathrm{NPLOC}, \mathrm{t}-2}$ & $\begin{array}{c}0.4292^{* * *} \\
(0.1296)\end{array}$ & $\begin{array}{c}-0.3366 \\
(0.2190)\end{array}$ & $\begin{array}{c}-0.0046 \\
(0.0053)\end{array}$ \\
\hline $\mathrm{Adv}_{\mathrm{NPLOC}, \mathrm{t}-3}$ & $\begin{array}{l}-0.0229 \\
(0.1306)\end{array}$ & $\begin{array}{c}0.0098 \\
(0.2296)\end{array}$ & $\begin{array}{l}-0.0000 \\
(0.0052)\end{array}$ \\
\hline Firm-FEs & YES & YES & YES \\
\hline Week-FEs & YES & YES & YES \\
\hline Day-of-Week-FEs & YES & YES & YES \\
\hline Controls & YES & YES & YES \\
\hline $\mathrm{R}^{2}$ & 0.72 & 0.62 & 0.01 \\
\hline No. obs. & $2,801,776$ & $2,404,404$ & $2,801,776$ \\
\hline
\end{tabular}


Table C24: Impact on Financial Markets - TV Advertising Sensitivity

This table shows regressions of the logarithm of turnover, the logarithm of the effective spread (EffSpr), and the excess return of a firm on abnormal TV advertising $\left(A d v_{T V}\right)$ for high and low advertising sensitivity firms. Advertising sensitivity is the firm's average coefficient for the 4 advertising-regressors in a firm-by-firm regression of $\mathrm{AWIKI}_{\mathrm{t}}$ on $\mathrm{Adv}_{\mathrm{t}}$ through $\mathrm{Adv}_{\mathrm{t}-3}$, day-of-week dummies, $\mathrm{AWIKI}_{\mathrm{t}-7}$ and the usual control variables. Panel $\mathrm{A}$ (B) reports results based on a sample of firms with advertising sensitivities below (above) the cross-sectional median. Turnover is daily trading volume over shares outstanding. EffSpr is the effective spread, defined as daily transaction-weighted average of transaction prices relative to prevailing quotes. Return ${ }^{\text {excess }}$ is the return of a stock over Kenneth French's market return. Adv is abnormal advertising. EA is an earnings announcement dummy. News is a national newspaper article dummy. Turnover $\mathrm{t}_{-7, \mathrm{t}-36}$ is the trading volume over the 4 weeks up to t-7, divided by average shares outstanding. Return $_{\mathrm{t}-7, \mathrm{t}-36}$ is the holding period return over the 4 weeks up to t-7. ReaVola $\mathrm{t}_{\mathrm{t}-7, \mathrm{t}-36}$ is realized volatility, defined as average absolute return during the 4 weeks up to t-7. MarketCap is the firm's market capitalization. For ease of presentation, only the advertising coefficients are reported. The analysis is done for 1995-2012 (1996-2010) common stocks from NYSE, AMEX and NASDAQ for Turnover and Returns (TAQ-based data), excluding stocks with lastweek prices below 5 USD. Standard errors are shown in parentheses and clustered by firm. 1/2/3 stars denote significance at the $10 / 5 / 1 \%$-level.

\begin{tabular}{|c|c|c|c|}
\hline & $\begin{array}{c}(1) \\
\ln \left(\text { Turnover }_{\mathrm{t}}\right)\end{array}$ & $\begin{array}{c}(2) \\
\ln \left(\text { EffSpr }_{\mathrm{t}}\right)\end{array}$ & $\begin{array}{c}(3) \\
\text { Return }_{\mathrm{t}} \\
\text { excess }\end{array}$ \\
\hline \multicolumn{4}{|c|}{ Panel A: Low Advertising Sensitivity } \\
\hline $\mathrm{Adv}_{\mathrm{TV}, \mathrm{t}}$ & $\begin{array}{c}0.3033 \\
(0.2592)\end{array}$ & $\begin{array}{l}-0.6381 \\
(0.6859)\end{array}$ & $\begin{array}{l}-0.0076 \\
(0.0104)\end{array}$ \\
\hline $\mathrm{Adv}_{\mathrm{TV}, \mathrm{t}-1}$ & $\begin{array}{c}0.4581 \\
(0.2892)\end{array}$ & $\begin{array}{l}-0.2107 \\
(0.6247)\end{array}$ & $\begin{array}{c}0.0039 \\
(0.0112)\end{array}$ \\
\hline $\mathrm{Adv}_{\mathrm{TV}, \mathrm{t}-2}$ & $\begin{array}{c}0.1018 \\
(0.2765)\end{array}$ & $\begin{array}{l}-0.3063 \\
(0.5130)\end{array}$ & $\begin{array}{c}0.0151 \\
(0.0096)\end{array}$ \\
\hline $\mathrm{Adv}_{\mathrm{TV}, \mathrm{t}-3}$ & $\begin{array}{c}0.3601 \\
(0.2265)\end{array}$ & $\begin{array}{c}0.4561 \\
(0.4389)\end{array}$ & $\begin{array}{c}0.0004 \\
(0.0091)\end{array}$ \\
\hline \multicolumn{4}{|c|}{ Panel B: High Advertising Sensitivity } \\
\hline $\operatorname{Adv}_{\mathrm{TV}, \mathrm{t}}$ & $\begin{array}{c}0.1912 \\
(0.3124)\end{array}$ & $\begin{array}{l}-1.1069 \\
(0.8235)\end{array}$ & $\begin{array}{l}-0.0169 \\
(0.0120)\end{array}$ \\
\hline $\mathrm{Adv}_{\mathrm{TV}, \mathrm{t}-1}$ & $\begin{array}{c}0.4584 \\
(0.3278)\end{array}$ & $\begin{array}{l}-1.3950^{*} \\
(0.7686)\end{array}$ & $\begin{array}{c}0.0090 \\
(0.0113)\end{array}$ \\
\hline $\mathrm{Adv}_{\mathrm{TV}, \mathrm{t}-2}$ & $\begin{array}{c}0.3122 \\
(0.2823)\end{array}$ & $\begin{array}{l}-1.1713^{*} \\
(0.6367)\end{array}$ & $\begin{array}{l}0.0188^{*} \\
(0.0107)\end{array}$ \\
\hline $\mathrm{Adv}_{\mathrm{TV}, \mathrm{t}-3}$ & $\begin{array}{c}0.4954^{* *} \\
(0.2345)\end{array}$ & $\begin{array}{c}-1.1019^{* *} \\
(0.5204)\end{array}$ & $\begin{array}{c}0.0079 \\
(0.0103)\end{array}$ \\
\hline Firm-FEs & YES & YES & YES \\
\hline Week-FEs & YES & YES & YES \\
\hline Day-of-Week-FEs & YES & YES & YES \\
\hline Controls & YES & YES & YES \\
\hline
\end{tabular}


Table C25: Impact on Financial Markets - Newspaper Advertising Sensitivity

This table shows regressions of the logarithm of turnover, the logarithm of the effective spread (EffSpr), and the excess return of a firm on abnormal newspaper advertising $\left(A d v_{N P}\right)$ for high and low advertising sensitivity firms. Advertising sensitivity is the firm's average coefficient for the 4 advertising-regressors in a firm-by-firm regression of $\mathrm{AWIKI}_{\mathrm{t}}$ on $\mathrm{Adv}_{\mathrm{t}}$ through $\mathrm{Adv}_{\mathrm{t}-3}$, day-of-week dummies, $\mathrm{AWIKI}_{\mathrm{t}-7}$ and the usual control variables. Panel A (B) reports results based on a sample of firms with advertising sensitivities below (above) the cross-sectional median. Turnover is daily trading volume over shares outstanding. EffSpr is the effective spread, defined as daily transactionweighted average of transaction prices relative to prevailing quotes. Return ${ }^{\text {excess }}$ is the return of a stock over Kenneth French's market return. Adv is abnormal advertising. EA is an earnings announcement dummy. News is a national newspaper article dummy. Turnover $\mathrm{t}_{\mathrm{t}-\mathrm{t} \text { - } 36}$ is the trading volume over the 4 weeks up to t-7, divided by average shares outstanding. Return $\mathrm{t}_{\mathrm{t}-\mathrm{t}-\mathrm{t}-36}$ is the holding period return over the 4 weeks up to t-7. ReaVolat-7,t-36 is realized volatility, defined as average absolute return during the 4 weeks up to t-7. MarketCap is the firm's market capitalization. For ease of presentation, only the advertising coefficients are reported. The analysis is done for 1995-2012 (1996-2010) common stocks from NYSE, AMEX and NASDAQ for Turnover and Returns (TAQ-based data), excluding stocks with last-week prices below 5 USD. Standard errors are shown in parentheses and clustered by firm. 1/2/3 stars denote significance at the $10 / 5 / 1 \%$-level.

\begin{tabular}{|c|c|c|c|}
\hline & $\begin{array}{c}(1) \\
\ln \left(\text { Turnover }_{t}\right)\end{array}$ & $\begin{array}{c}(2) \\
\ln \left(\text { EffSpr }_{t}\right)\end{array}$ & $\begin{array}{c}(3) \\
\text { Return }_{\mathrm{t}} \text { excess }^{-}\end{array}$ \\
\hline \multicolumn{4}{|c|}{ Panel A: Low Advertising Sensitivity } \\
\hline $\operatorname{Adv}_{\mathrm{NP}, \mathrm{t}}$ & $\begin{array}{l}-0.0097 \\
(0.1604)\end{array}$ & $\begin{array}{c}0.2082 \\
(0.3599)\end{array}$ & $\begin{array}{c}0.0076 \\
(0.0066)\end{array}$ \\
\hline $\operatorname{Adv}_{\mathrm{NP}, \mathrm{t}-1}$ & $\begin{array}{c}0.1579 \\
(0.1548)\end{array}$ & $\begin{array}{l}-0.1537 \\
(0.3088)\end{array}$ & $\begin{array}{c}0.0002 \\
(0.0063)\end{array}$ \\
\hline $\mathrm{Adv}_{\mathrm{NP}, \mathrm{t}-2}$ & $\begin{array}{l}0.2907^{*} \\
(0.1640)\end{array}$ & $\begin{array}{l}-0.3052 \\
(0.3246)\end{array}$ & $\begin{array}{l}-0.0023 \\
(0.0067)\end{array}$ \\
\hline $\operatorname{Adv}_{N P, t-3}$ & $\begin{array}{l}-0.0973 \\
(0.1721)\end{array}$ & $\begin{array}{l}-0.2027 \\
(0.3344)\end{array}$ & $\begin{array}{c}0.0067 \\
(0.0069)\end{array}$ \\
\hline \multicolumn{4}{|c|}{ Panel B: High Advertising Sensitivity } \\
\hline $\operatorname{Adv}_{\mathrm{NP}, \mathrm{t}}$ & $\begin{array}{c}0.6956^{* * * *} \\
(0.1634)\end{array}$ & $\begin{array}{c}0.0080 \\
(0.3704)\end{array}$ & $\begin{array}{l}-0.0070 \\
(0.0073)\end{array}$ \\
\hline $\operatorname{Adv}_{N P, t-1}$ & $\begin{array}{c}0.5672^{* * * *} \\
(0.1714)\end{array}$ & $\begin{array}{c}0.0723 \\
(0.3701)\end{array}$ & $\begin{array}{c}0.0111 \\
(0.0071)\end{array}$ \\
\hline $\operatorname{Adv}_{\mathrm{NP}, \mathrm{t}-2}$ & $\begin{array}{l}0.3301^{*} \\
(0.1691)\end{array}$ & $\begin{array}{c}-0.3583 \\
(0.3462)\end{array}$ & $\begin{array}{c}0.0006 \\
(0.0071)\end{array}$ \\
\hline $\operatorname{Adv}_{N P, t-3}$ & $\begin{array}{c}0.2583 \\
(0.1787)\end{array}$ & $\begin{array}{c}0.1170 \\
(0.3727)\end{array}$ & $\begin{array}{c}0.0016 \\
(0.0074)\end{array}$ \\
\hline Firm-FEs & YES & YES & YES \\
\hline Week-FEs & YES & YES & YES \\
\hline Day-of-Week-FEs & YES & YES & YES \\
\hline Controls & YES & YES & YES \\
\hline
\end{tabular}


Table C26: Impact on Financial Markets - TV Advertising: Heterogeneity of Effects?

The data requirements and regression specifications are equivalent to those in the main analysis. Turnover is daily trading volume over shares outstanding. EffSpr is the effective spread, defined as daily transaction-weighted average of transaction prices relative to prevailing quotes. Return ${ }^{\text {excess }}$ is the return of a stock over Kenneth French's market return. For ease of presentation, only the contemporary and first lag effects of advertising expenditures are reported. Splits are done at the cross-sectional median except for the consumer industry split. Consumer industry is defined according to the Fama-French five industry classification as in Lou (2014). Media coverage is the number of national newspaper articles on the firm in the previous 12 months. Standard errors are clustered by firm for the panelregressions. $1 / 2 / 3$ stars denote significance at the $10 / 5 / 1 \%$-level.

\begin{tabular}{|c|c|c|c|}
\hline & $\begin{array}{c}(1) \\
\ln \left(\text { Turnover }_{\mathrm{t}}\right)\end{array}$ & $\begin{array}{c}(2) \\
\ln \left(\text { EffSpr }_{\mathrm{t}}\right)\end{array}$ & $\begin{array}{c}(3) \\
\text { Return }_{t}\end{array}$ \\
\hline \multicolumn{4}{|c|}{ Panel A: Small firms } \\
\hline $\mathrm{Adv}_{\mathrm{TV}, \mathrm{t}}$ & $\begin{array}{c}0.5854^{*} \\
(0.3113)\end{array}$ & $\begin{array}{l}-0.3353 \\
(0.5154)\end{array}$ & $\begin{array}{l}-0.0019 \\
(0.0105)\end{array}$ \\
\hline $\mathrm{Adv}_{\mathrm{TV}, \mathrm{t}-1}$ & $\begin{array}{c}0.7302^{* *} \\
(0.3200)\end{array}$ & $\begin{array}{l}-0.4322 \\
(0.4650)\end{array}$ & $\begin{array}{l}-0.0012 \\
(0.0104)\end{array}$ \\
\hline \multicolumn{4}{|c|}{ Panel B: Large firms } \\
\hline $\mathrm{Adv}_{\mathrm{TV}, \mathrm{t}}$ & $\begin{array}{c}0.0705 \\
(0.2028)\end{array}$ & $\begin{array}{l}-0.7697 \\
(0.7257)\end{array}$ & $\begin{array}{c}-0.0139 \\
(0.0088)\end{array}$ \\
\hline $\operatorname{Adv}_{T V}, \mathrm{t}-1$ & $\begin{array}{c}0.3401 \\
(0.2316)\end{array}$ & $\begin{array}{l}-0.8483 \\
(0.6969)\end{array}$ & $\begin{array}{l}-0.0019 \\
(0.0088)\end{array}$ \\
\hline \multicolumn{4}{|c|}{ Panel C: Low Analyst Coverage } \\
\hline $\mathrm{Adv}_{\mathrm{TV}, \mathrm{t}}$ & $\begin{array}{c}0.6025^{* *} \\
(0.3019)\end{array}$ & $\begin{array}{l}-0.7184 \\
(0.5344)\end{array}$ & $\begin{array}{l}-0.0077 \\
(0.0092)\end{array}$ \\
\hline $\mathrm{Adv}_{\mathrm{TV}, \mathrm{t}-1}$ & $\begin{array}{c}0.8748^{* * * *} \\
(0.3151)\end{array}$ & $\begin{array}{l}-0.5945 \\
(0.4944)\end{array}$ & $\begin{array}{l}-0.0058 \\
(0.0090)\end{array}$ \\
\hline \multicolumn{4}{|c|}{ Panel D: High Analyst Coverage } \\
\hline $\mathrm{Adv}_{\mathrm{TV}, \mathrm{t}}$ & $\begin{array}{c}0.0074 \\
(0.2202)\end{array}$ & $\begin{array}{l}-0.3869 \\
(0.6977)\end{array}$ & $\begin{array}{l}-0.0071 \\
(0.0091)\end{array}$ \\
\hline $\mathrm{Adv}_{\mathrm{TV}, \mathrm{t}-1}$ & $\begin{array}{c}0.1250 \\
(0.2387)\end{array}$ & $\begin{array}{l}-0.6190 \\
(0.6670)\end{array}$ & $\begin{array}{c}0.0047 \\
(0.0090)\end{array}$ \\
\hline \multicolumn{4}{|c|}{ Panel E: Low Media Coverage } \\
\hline $\mathrm{Adv}_{\mathrm{TV}, \mathrm{t}}$ & $\begin{array}{c}0.6806^{* *} \\
(0.2843)\end{array}$ & $\begin{array}{l}-0.2441 \\
(0.5448)\end{array}$ & $\begin{array}{l}-0.0034 \\
(0.0097)\end{array}$ \\
\hline $\mathrm{Adv}_{\mathrm{TV}, \mathrm{t}-1}$ & $\begin{array}{l}0.5113^{*} \\
(0.2992)\end{array}$ & $\begin{array}{l}-0.1144 \\
(0.5010)\end{array}$ & $\begin{array}{l}-0.0063 \\
(0.0096)\end{array}$ \\
\hline \multicolumn{4}{|c|}{ Panel F: High Media Coverage } \\
\hline $\mathrm{Adv}_{\mathrm{TV}, \mathrm{t}}$ & $\begin{array}{l}-0.0978 \\
(0.2292)\end{array}$ & $\begin{array}{l}-0.7041 \\
(0.6966)\end{array}$ & $\begin{array}{l}-0.0129 \\
(0.0102)\end{array}$ \\
\hline $\mathrm{Adv}_{\mathrm{TV}, \mathrm{t}-1}$ & $\begin{array}{c}0.3982 \\
(0.2597)\end{array}$ & $\begin{array}{l}-1.2892^{*} \\
(0.6670)\end{array}$ & $\begin{array}{c}0.0071 \\
(0.0103)\end{array}$ \\
\hline
\end{tabular}

IA. 54 


\begin{tabular}{|c|c|c|c|}
\hline & $\begin{array}{c}(1) \\
\ln \left(\text { Turnover }_{\mathrm{t}}\right)\end{array}$ & $\begin{array}{c}(2) \\
\ln \left(\text { EffSpr }_{\mathrm{t}}\right)\end{array}$ & Return $_{\mathrm{t}}^{(3)}$ excess \\
\hline \multicolumn{4}{|c|}{ Panel G: Consumer Industry } \\
\hline AdvTV,t & $\begin{array}{c}0.4507 \\
(0.3582)\end{array}$ & $\begin{array}{l}-0.1680 \\
(0.7499)\end{array}$ & $\begin{array}{l}-0.0067 \\
(0.0120)\end{array}$ \\
\hline $\operatorname{Adv}_{T V, t-1}$ & $\begin{array}{c}0.5929 \\
(0.3757)\end{array}$ & $\begin{array}{l}-0.7222 \\
(0.6875)\end{array}$ & $\begin{array}{c}0.0122 \\
(0.0110)\end{array}$ \\
\hline \multicolumn{4}{|c|}{ Panel H: Non-Consumer Industry } \\
\hline \multirow{2}{*}{$\begin{array}{l}\operatorname{Adv}_{T V, t} \\
\operatorname{Adv}_{T V, t-1}\end{array}$} & $\begin{array}{l}0.4136^{*} \\
(0.2259)\end{array}$ & $\begin{array}{l}-0.5748 \\
(0.5798)\end{array}$ & $\begin{array}{l}-0.0085 \\
(0.0078)\end{array}$ \\
\hline & $\begin{array}{l}0.4797^{*} \\
(0.2477)\end{array}$ & $\begin{array}{l}-0.6026 \\
(0.5432)\end{array}$ & $\begin{array}{l}-0.0054 \\
(0.0079)\end{array}$ \\
\hline \multicolumn{4}{|c|}{ Panel I: Low Industry Concentration } \\
\hline \multirow{2}{*}{$\begin{array}{l}\operatorname{Adv}_{\mathrm{TV}, \mathrm{t}} \\
\mathrm{Adv}_{\mathrm{TV}, \mathrm{t}-1}\end{array}$} & $\begin{array}{c}0.2192 \\
(0.2642)\end{array}$ & $\begin{array}{c}-0.2746 \\
(0.6809)\end{array}$ & $\begin{array}{l}-0.0088 \\
(0.0099)\end{array}$ \\
\hline & $\begin{array}{c}0.3311 \\
(0.2892)\end{array}$ & $\begin{array}{l}-0.5406 \\
(0.6147)\end{array}$ & $\begin{array}{l}-0.0034 \\
(0.0102)\end{array}$ \\
\hline \multicolumn{4}{|c|}{ Panel J: High Industry Concentration } \\
\hline$A d v_{T V}, \mathrm{t}$ & $\begin{array}{l}0.4933^{*} \\
(0.2890)\end{array}$ & $\begin{array}{l}-0.6923 \\
(0.6226)\end{array}$ & $\begin{array}{l}-0.0060 \\
(0.0117)\end{array}$ \\
\hline $\mathrm{Adv}_{\mathrm{TV}, \mathrm{t}-1}$ & $\begin{array}{c}0.3851 \\
(0.3043)\end{array}$ & $\begin{array}{l}-0.7172 \\
(0.5829)\end{array}$ & $\begin{array}{c}0.0056 \\
(0.0114)\end{array}$ \\
\hline
\end{tabular}

IA. 55 


\begin{tabular}{|c|c|c|c|}
\hline & $\begin{array}{c}(1) \\
\ln \left(\text { Turnover }_{\mathrm{t}}\right)\end{array}$ & $\begin{array}{c}(2) \\
\ln \left(\text { EffSpr }_{t}\right)\end{array}$ & $\begin{array}{c}(3) \\
\text { Return }_{\mathrm{t}} \\
\text { excess }\end{array}$ \\
\hline \multicolumn{4}{|c|}{ Panel K: Highest Decile Advertising Shock } \\
\hline $\mathrm{I}_{\mathrm{Ad}(\mathrm{TV}), \mathrm{t}}$ & $\begin{array}{l}2.6937^{*} \\
(1.5108)\end{array}$ & $\begin{array}{l}-2.0934 \\
(3.2999)\end{array}$ & $\begin{array}{l}-0.0347 \\
(0.0490)\end{array}$ \\
\hline $\mathrm{I}_{\mathrm{Ad}(\mathrm{TV}), \mathrm{t}-1}$ & $\begin{array}{c}5.1943^{* * *} \\
(1.5278)\end{array}$ & $\begin{array}{l}-0.5054 \\
(3.2890)\end{array}$ & $\begin{array}{l}-0.0337 \\
(0.0488)\end{array}$ \\
\hline \multicolumn{4}{|c|}{ Panel L: Highest Percentile Advertising Shock } \\
\hline $\mathrm{I}_{\mathrm{Ad}(\mathrm{TV}), \mathrm{t}}$ & $\begin{array}{c}0.8751 \\
(3.9408)\end{array}$ & $\begin{array}{c}3.5637 \\
(8.4944)\end{array}$ & $\begin{array}{l}-0.1742 \\
(0.1639)\end{array}$ \\
\hline $\mathrm{I}_{\mathrm{Ad}(\mathrm{TV}), \mathrm{t}-1}$ & $\begin{array}{l}-0.7360 \\
(3.8470)\end{array}$ & $\begin{array}{l}11.0411 \\
(9.3521)\end{array}$ & $\begin{array}{c}-0.4285^{* * *} \\
(0.1510)\end{array}$ \\
\hline \multicolumn{4}{|c|}{ Panel M: First Time Advertiser } \\
\hline $\mathrm{I}_{\mathrm{Ad}(\mathrm{TV}), \mathrm{t}}$ & $\begin{array}{c}0.0115 \\
(0.0166)\end{array}$ & $\begin{array}{l}-0.0319 \\
(0.0239)\end{array}$ & $\begin{array}{l}-0.0001 \\
(0.0006)\end{array}$ \\
\hline $\mathrm{I}_{\mathrm{Ad}(\mathrm{TV}), \mathrm{t}-1}$ & $\begin{array}{l}-0.0039 \\
(0.0157)\end{array}$ & $\begin{array}{c}0.0137 \\
(0.0244)\end{array}$ & $\begin{array}{l}-0.0001 \\
(0.0007)\end{array}$ \\
\hline \multicolumn{4}{|c|}{ Panel N: After 8-week Low } \\
\hline $\operatorname{Adv}_{T V, t}$ & $\begin{array}{c}0.5846^{* *} \\
(0.2827)\end{array}$ & $\begin{array}{l}-0.2326 \\
(0.5847)\end{array}$ & $\begin{array}{l}-0.0069 \\
(0.0105)\end{array}$ \\
\hline $\mathrm{Adv}_{\mathrm{TV}, \mathrm{t}-1}$ & $\begin{array}{c}1.1019^{* * *} \\
(0.2947)\end{array}$ & $\begin{array}{l}-0.6124 \\
(0.5612)\end{array}$ & $\begin{array}{l}-0.0093 \\
(0.0106)\end{array}$ \\
\hline \multicolumn{4}{|c|}{ Panel O: After 8-week High } \\
\hline $\operatorname{Adv}_{T V, t}$ & $\begin{array}{c}0.3569 \\
(0.2722)\end{array}$ & $\begin{array}{l}-0.7404 \\
(0.5527)\end{array}$ & $\begin{array}{l}-0.0088 \\
(0.0103)\end{array}$ \\
\hline $\mathrm{Adv}_{\mathrm{TV}, \mathrm{t}-1}$ & $\begin{array}{l}-0.0240 \\
(0.2831)\end{array}$ & $\begin{array}{l}-0.7214 \\
(0.5268)\end{array}$ & $\begin{array}{c}0.0099 \\
(0.0104)\end{array}$ \\
\hline \multicolumn{4}{|c|}{ Panel P: Overnight Returns } \\
\hline $\operatorname{Adv}_{\mathrm{TV}, \mathrm{t}}$ & & & $\begin{array}{l}-0.0031 \\
(0.0042)\end{array}$ \\
\hline $\mathrm{Adv}_{\mathrm{TV}, \mathrm{t}-1}$ & & & $\begin{array}{c}0.0003 \\
(0.0042)\end{array}$ \\
\hline \multicolumn{4}{|c|}{ Panel Q: Intraday Returns } \\
\hline $\operatorname{Adv}_{\mathrm{TV}, \mathrm{t}}$ & & & $\begin{array}{c}0.0096 \\
(0.0079)\end{array}$ \\
\hline $\mathrm{Adv}_{\mathrm{TV}, \mathrm{t}-1}$ & & & $\begin{array}{l}-0.0059 \\
(0.0077)\end{array}$ \\
\hline
\end{tabular}

IA. 56 


\begin{tabular}{|c|c|c|c|}
\hline & $\begin{array}{c}(1) \\
\ln \left(\text { Turnover }_{\mathrm{t}}\right)\end{array}$ & $\begin{array}{c}(2) \\
\ln \left(\text { EffSpr }_{\mathrm{t}}\right)\end{array}$ & Return $_{\mathrm{t}}^{(3)}$ excess \\
\hline \multicolumn{4}{|c|}{ Panel R: Monday } \\
\hline $\mathrm{Adv}_{\mathrm{TV}, \mathrm{t}}$ & $\begin{array}{c}0.8494^{* *} \\
(0.3782)\end{array}$ & $\begin{array}{l}-0.0290 \\
(0.8540)\end{array}$ & $\begin{array}{c}0.0227 \\
(0.0143)\end{array}$ \\
\hline $\mathrm{Adv}_{\mathrm{TV}, \mathrm{t}-1}$ & $\begin{array}{c}0.4775 \\
(0.5256)\end{array}$ & $\begin{array}{c}0.1859 \\
(1.1764)\end{array}$ & $\begin{array}{l}0.0313^{*} \\
(0.0184)\end{array}$ \\
\hline \multicolumn{4}{|c|}{ Panel S: Tuesday to Friday } \\
\hline $\mathrm{Adv}_{\mathrm{TV}, \mathrm{t}}$ & $\begin{array}{c}0.0560 \\
(0.2293)\end{array}$ & $\begin{array}{l}-0.6266 \\
(0.5287)\end{array}$ & $\begin{array}{l}-0.0087 \\
(0.0090)\end{array}$ \\
\hline $\mathrm{Adv}_{\mathrm{TV}, \mathrm{t}-1}$ & $\begin{array}{c}0.3665 \\
(0.2511)\end{array}$ & $\begin{array}{l}-0.5131 \\
(0.5581)\end{array}$ & $\begin{array}{l}-0.0023 \\
(0.0084)\end{array}$ \\
\hline \multicolumn{4}{|c|}{ Panel T: December } \\
\hline $\mathrm{Adv} T \mathrm{~T}, \mathrm{t}$ & $\begin{array}{c}1.5058^{* *} \\
(0.6226)\end{array}$ & $\begin{array}{c}-0.4637 \\
(1.1499)\end{array}$ & $\begin{array}{c}0.0240 \\
(0.0241)\end{array}$ \\
\hline$A d v_{T V}, t-1$ & $\begin{array}{c}2.4451^{* * * *} \\
(0.6906)\end{array}$ & $\begin{array}{l}-0.3391 \\
(1.1530)\end{array}$ & $\begin{array}{l}0.0450^{*} \\
(0.0246)\end{array}$ \\
\hline \multicolumn{4}{|c|}{ Panel U: January to November } \\
\hline $\mathrm{Adv}_{\mathrm{TV}, \mathrm{t}}$ & $\begin{array}{c}0.3325 \\
(0.2032)\end{array}$ & $\begin{array}{l}-0.4541 \\
(0.4840)\end{array}$ & $\begin{array}{l}-0.0118 \\
(0.0077)\end{array}$ \\
\hline$A d v_{T V, t-1}$ & $\begin{array}{c}0.2647 \\
(0.2145)\end{array}$ & $\begin{array}{l}-0.6691 \\
(0.4389)\end{array}$ & $\begin{array}{l}-0.0032 \\
(0.0076)\end{array}$ \\
\hline \multicolumn{4}{|c|}{ Panel V: Recession Months } \\
\hline $\mathrm{Adv}_{\mathrm{TV}, \mathrm{t}}$ & $\begin{array}{c}0.2845 \\
0.2771)\end{array}$ & $\begin{array}{c}-1.1722^{* *} \\
(0.5794)\end{array}$ & $\begin{array}{c}0.0033 \\
(0.0143)\end{array}$ \\
\hline$A d v_{T V, t-1}$ & $\begin{array}{l}0.5974^{*} \\
0.3106)\end{array}$ & $\begin{array}{l}-0.1229 \\
(0.5863)\end{array}$ & $\begin{array}{l}-0.0108 \\
(0.0139)\end{array}$ \\
\hline \multicolumn{4}{|c|}{ Panel W: Non-Recession Months } \\
\hline$A d v_{T V}, \mathrm{t}$ & $\begin{array}{l}0.3756^{*} \\
0.2087)\end{array}$ & $\begin{array}{c}-0.3716 \\
(0.4831)\end{array}$ & $\begin{array}{l}-0.0107 \\
(0.0075)\end{array}$ \\
\hline $\mathrm{Adv}_{\mathrm{TV}, \mathrm{t}-1}$ & $\begin{array}{l}0.4279^{*} \\
0.2236)\end{array}$ & $\begin{array}{l}-0.7229 \\
(0.4514)\end{array}$ & $\begin{array}{c}0.0041 \\
(0.0075)\end{array}$ \\
\hline \multicolumn{4}{|c|}{ Panel X: Only EA and Coverage Windows } \\
\hline$A d v_{T V}, t$ & $\begin{array}{l}-0.2068 \\
(0.3771)\end{array}$ & $\begin{array}{c}0.7771 \\
(0.9421)\end{array}$ & $\begin{array}{l}-0.0184 \\
(0.0163)\end{array}$ \\
\hline $\mathrm{Adv}_{\mathrm{TV}, \mathrm{t}-1}$ & $\begin{array}{c}0.3050 \\
(0.4121)\end{array}$ & $\begin{array}{l}-0.5083 \\
(0.9354)\end{array}$ & $\begin{array}{l}0.0293^{*} \\
(0.0163)\end{array}$ \\
\hline
\end{tabular}

IA. 57 
Table C27: Impact on Financial Markets - TV Advertising: Stability of Effects?

The data requirements and regression specifications are equivalent to those in the main analysis. Turnover is daily trading volume over shares outstanding. EffSpr is the effective spread, defined as daily transaction-weighted average of transaction prices relative to prevailing quotes. Return ${ }^{\text {excess }}$ is the return of a stock over Kenneth French's market return. For ease of presentation, only the contemporary and first lag effects of advertising expenditures are reported. Standard errors are clustered by firm for the panel-regressions. 1/2/3 stars denote significance at the $10 / 5 / 1 \%$-level.

\begin{tabular}{|c|c|c|c|}
\hline & $\begin{array}{c}(1) \\
\ln \left(\text { Turnover }_{\mathrm{t}}\right)\end{array}$ & $\begin{array}{c}(2) \\
\ln \left(\text { EffSpr }_{\mathrm{t}}\right)\end{array}$ & $\begin{array}{c}(3) \\
\text { Return }_{\mathrm{t}} \\
\text { excess }\end{array}$ \\
\hline \multicolumn{4}{|c|}{ Panel A: Controlling for Newspaper Advertising } \\
\hline $\mathrm{Adv}_{\mathrm{TV}, \mathrm{t}}$ & $\begin{array}{c}0.5092^{* * *} \\
(0.1929)\end{array}$ & $\begin{array}{l}-0.2841 \\
(0.4722)\end{array}$ & $\begin{array}{c}-0.0142^{* *} \\
(0.0069)\end{array}$ \\
\hline $\mathrm{Adv}_{\mathrm{TV}, \mathrm{t}-1}$ & $\begin{array}{c}0.5371^{* * *} \\
(0.2077)\end{array}$ & $\begin{array}{l}-0.4490 \\
(0.4310)\end{array}$ & $\begin{array}{l}-0.0035 \\
(0.0070)\end{array}$ \\
\hline \multicolumn{4}{|c|}{ Panel B: 1995-2003 } \\
\hline $\mathrm{Adv}_{\mathrm{TV}, \mathrm{t}}$ & $\begin{array}{c}0.7763^{* * * *} \\
(0.2913)\end{array}$ & $\begin{array}{l}-0.4431 \\
(0.6859)\end{array}$ & $\begin{array}{l}-0.0157 \\
(0.0095)\end{array}$ \\
\hline $\mathrm{Adv}_{\mathrm{TV}, \mathrm{t}-1}$ & $\begin{array}{c}0.9734^{* * *} \\
(0.3166) \\
\end{array}$ & $\begin{array}{r}-1.1218^{*} \\
(0.6460) \\
\end{array}$ & $\begin{array}{c}0.0046 \\
(0.0096) \\
\end{array}$ \\
\hline \multicolumn{4}{|c|}{ Panel C: 2004-2012 } \\
\hline $\mathrm{Adv}_{\mathrm{TV}, \mathrm{t}}$ & $\begin{array}{l}-0.0934 \\
(0.2271)\end{array}$ & $\begin{array}{c}-0.8814^{* * *} \\
(0.3175)\end{array}$ & $\begin{array}{c}0.0012 \\
(0.0087)\end{array}$ \\
\hline $\mathrm{Adv}_{\mathrm{TV}, \mathrm{t}-1}$ & $\begin{array}{l}-0.1116 \\
(0.2365)\end{array}$ & $\begin{array}{l}-0.4868 \\
(0.3213)\end{array}$ & $\begin{array}{l}-0.0053 \\
(0.0084) \\
\end{array}$ \\
\hline \multicolumn{4}{|c|}{ Panel D: NYSE/AMEX } \\
\hline $\mathrm{Adv}_{\mathrm{TV}, \mathrm{t}}$ & $\begin{array}{c}0.2913 \\
(0.2058)\end{array}$ & $\begin{array}{l}-0.3916 \\
(0.5797)\end{array}$ & $\begin{array}{c}-0.0186^{* *} \\
(0.0075)\end{array}$ \\
\hline $\mathrm{Adv}_{\mathrm{TV}, \mathrm{t}-1}$ & $\begin{array}{c}0.5525^{* *} \\
(0.2319) \\
\end{array}$ & $\begin{array}{l}-0.4835 \\
(0.5449) \\
\end{array}$ & $\begin{array}{l}-0.0020 \\
(0.0071)\end{array}$ \\
\hline \multicolumn{4}{|c|}{ Panel E: NASDAQ } \\
\hline $\mathrm{Adv}_{\mathrm{TV}, \mathrm{t}}$ & $\begin{array}{c}0.6363 \\
(0.3933)\end{array}$ & $\begin{array}{l}-0.8592 \\
(0.5798)\end{array}$ & $\begin{array}{c}0.0168 \\
(0.0124)\end{array}$ \\
\hline $\mathrm{Adv}_{\mathrm{TV}, \mathrm{t}-1}$ & $\begin{array}{c}0.4233 \\
(0.4036)\end{array}$ & $\begin{array}{c}-1.2480 * * \\
(0.5642)\end{array}$ & $\begin{array}{c}0.0045 \\
(0.0127)\end{array}$ \\
\hline
\end{tabular}




\begin{tabular}{|c|c|c|c|}
\hline & $\begin{array}{c}(1) \\
\ln \left(\text { Turnover }_{\mathrm{t}}\right)\end{array}$ & $\begin{array}{c}(2) \\
\ln \left(\text { EffSpr }_{\mathrm{t}}\right)\end{array}$ & $\begin{array}{c}(3) \\
\text { Return }_{\mathrm{t}} \\
\text { excess }\end{array}$ \\
\hline \multicolumn{4}{|c|}{ Panel F: Adv with scalar $=0.1$} \\
\hline $\mathrm{Adv}_{\mathrm{TV}, \mathrm{t}}$ & $\begin{array}{c}0.4364^{* * * *} \\
(0.1305)\end{array}$ & $\begin{array}{l}-0.2974 \\
(0.2319)\end{array}$ & $\begin{array}{l}-0.0026 \\
(0.0049)\end{array}$ \\
\hline $\operatorname{Adv}_{T V, t-1}$ & $\begin{array}{c}0.0392 \\
(0.1192)\end{array}$ & $\begin{array}{l}-0.1699 \\
(0.2487)\end{array}$ & $\begin{array}{c}0.0119^{* *} \\
(0.0053)\end{array}$ \\
\hline \multicolumn{4}{|c|}{ Panel G: Adv with scalar $=0.5$} \\
\hline $\mathrm{Adv}_{\mathrm{TV}, \mathrm{t}}$ & $\begin{array}{c}0.5512^{* * * *} \\
(0.1745)\end{array}$ & $\begin{array}{l}-0.5014 \\
(0.3233)\end{array}$ & $\begin{array}{l}-0.0037 \\
(0.0066)\end{array}$ \\
\hline $\mathrm{Adv}_{\mathrm{TV}, \mathrm{t}-1}$ & $\begin{array}{c}0.1302 \\
(0.1584)\end{array}$ & $\begin{array}{l}-0.1200 \\
(0.3460)\end{array}$ & $\begin{array}{c}0.0162^{* *} \\
(0.0072)\end{array}$ \\
\hline \multicolumn{4}{|c|}{ Panel H: Adv with mean instead of median } \\
\hline $\operatorname{Adv}_{T V, t}$ & $\begin{array}{c}0.2692 \\
(0.1737)\end{array}$ & $\begin{array}{l}-0.5918 \\
(0.3824)\end{array}$ & $\begin{array}{c}0.0034 \\
(0.0068)\end{array}$ \\
\hline $\mathrm{Adv}_{T V, t-1}$ & $\begin{array}{c}0.2384 \\
(0.1622)\end{array}$ & $\begin{array}{c}0.0138 \\
(0.3241)\end{array}$ & $\begin{array}{c}0.0058 \\
(0.0073)\end{array}$ \\
\hline \multicolumn{4}{|c|}{ Panel I: $\operatorname{Ln}(1+\$$ Advertising $) / 1000$} \\
\hline $\operatorname{Adv}_{T V, t}$ & $\begin{array}{c}0.4527^{* *} \\
(0.2167)\end{array}$ & $\begin{array}{l}-0.3864 \\
(0.5193)\end{array}$ & $\begin{array}{l}-0.0101 \\
(0.0069)\end{array}$ \\
\hline $\mathrm{Adv}_{\mathrm{TV}, \mathrm{t}-1}$ & $\begin{array}{l}-0.1909 \\
(0.1795)\end{array}$ & $\begin{array}{l}-0.6778^{*} \\
(0.3741)\end{array}$ & $\begin{array}{c}0.0064 \\
(0.0076)\end{array}$ \\
\hline \multicolumn{4}{|c|}{ Panel J: $\mathrm{I}_{\$ \mathrm{Ad}_{i} 0} / 1000$} \\
\hline $\mathrm{Adv}_{T V, \mathrm{t}}$ & $\begin{array}{l}2.9867^{*} \\
(1.6943)\end{array}$ & $\begin{array}{l}-1.2966 \\
(4.0437)\end{array}$ & $\begin{array}{l}-0.0321 \\
(0.0524)\end{array}$ \\
\hline $\mathrm{Adv}_{\mathrm{TV}, \mathrm{t}-1}$ & $\begin{array}{l}-0.6776 \\
(1.4308)\end{array}$ & $\begin{array}{l}-2.6719 \\
(2.8231)\end{array}$ & $\begin{array}{l}-0.0118 \\
(0.0551)\end{array}$ \\
\hline
\end{tabular}

IA. 59 


\begin{tabular}{|c|c|c|c|}
\hline & $\begin{array}{c}(1) \\
\ln \left(\text { Turnover }_{t}\right)\end{array}$ & $\begin{array}{c}(2) \\
\ln \left(\text { EffSpr }_{t}\right)\end{array}$ & $\begin{array}{l}(3) \\
\text { Return }_{t} \\
\text { excess }\end{array}$ \\
\hline \multicolumn{4}{|c|}{$\begin{array}{l}\text { Panel K: Permco and Day Fixed Effects, } \\
\text { Permco and Day Clustered Standard-Errors }\end{array}$} \\
\hline $\mathrm{Adv}_{\mathrm{TV}, \mathrm{t}}$ & $\begin{array}{c}0.6021^{* * *} \\
(0.1971)\end{array}$ & $\begin{array}{l}-0.2198 \\
(0.4748)\end{array}$ & $\begin{array}{l}-0.0073 \\
(0.0078)\end{array}$ \\
\hline $\mathrm{Adv}_{\mathrm{TV}, \mathrm{t}-1}$ & $\begin{array}{c}0.4625^{* *} \\
(0.2140)\end{array}$ & $\begin{array}{l}-0.5590 \\
(0.4424)\end{array}$ & $\begin{array}{c}0.0052 \\
(0.0077)\end{array}$ \\
\hline \multicolumn{4}{|c|}{ Panel L: Dependent Variables Normalized with Lag 7} \\
\hline $\operatorname{Adv}_{\mathrm{TV}, \mathrm{t}}$ & $\begin{array}{c}0.2023 \\
(0.2278)\end{array}$ & $\begin{array}{c}-0.9209 * * \\
(0.4180)\end{array}$ & $\begin{array}{l}-0.0051 \\
(0.0097)\end{array}$ \\
\hline $\mathrm{Adv}_{\mathrm{TV}, \mathrm{t}-1}$ & $\begin{array}{c}0.7364^{* * *} \\
(0.2370)\end{array}$ & $\begin{array}{c}-0.8518^{* *} \\
(0.3991)\end{array}$ & $\begin{array}{l}-0.0034 \\
(0.0096)\end{array}$ \\
\hline \multicolumn{4}{|c|}{ Panel M: Weekly Instead of Daily } \\
\hline $\mathrm{Adv}_{\mathrm{TV}, \mathrm{t}}$ & $\begin{array}{c}-0.5293^{*} \\
(0.2809)\end{array}$ & $\begin{array}{l}-0.1732 \\
(0.4546)\end{array}$ & $\begin{array}{c}0.0355 \\
(0.0317)\end{array}$ \\
\hline $\operatorname{Adv}_{T V, t-1}$ & $\begin{array}{c}0.0107 \\
(0.2797)\end{array}$ & $\begin{array}{l}-0.1148 \\
(0.3909)\end{array}$ & $\begin{array}{l}-0.0065 \\
(0.0288)\end{array}$ \\
\hline $\mathrm{Adv}_{\mathrm{TV}, \mathrm{t}-2}$ & $\begin{array}{c}0.0956 \\
(0.2629)\end{array}$ & $\begin{array}{l}-0.2151 \\
(0.3936)\end{array}$ & $\begin{array}{c}0.0002 \\
(0.0286)\end{array}$ \\
\hline \multicolumn{4}{|c|}{ Panel N: Daily Fama-MacBeth instead of Panel Regressions } \\
\hline $\mathrm{Adv}_{\mathrm{TV}, \mathrm{t}}$ & & & $\begin{array}{l}-0.0129 \\
(0.0080)\end{array}$ \\
\hline $\mathrm{Adv}_{\mathrm{TV}, \mathrm{t}-1}$ & & & $\begin{array}{c}0.0036 \\
(0.0081)\end{array}$ \\
\hline
\end{tabular}

IA. 60 
Table C28: Impact on Financial Markets - Newspaper Advertising: Heterogeneity of Effects?

The data requirements and regression specifications are equivalent to those in the main analysis. Turnover is daily trading volume over shares outstanding. EffSpr is the effective spread, defined as daily transaction-weighted average of transaction prices relative to prevailing quotes. Return ${ }^{\text {excess }}$ is the return of a stock over Kenneth French's market return. For ease of presentation, only the contemporary and first lag effects of advertising expenditures are reported. Splits are done at the cross-sectional median except for the consumer industry split. Consumer industry is defined according to the Fama-French five industry classification as in Lou (2014). Media coverage is the number of national newspaper articles on the firm in the previous 12 months. Standard errors are clustered by firm for the panelregressions. $1 / 2 / 3$ stars denote significance at the $10 / 5 / 1 \%$-level.

\begin{tabular}{|c|c|c|c|}
\hline & $\begin{array}{c}(1) \\
\ln \left(\text { Turnover }_{\mathrm{t}}\right)\end{array}$ & $\begin{array}{c}(2) \\
\ln \left(\text { EffSpr }_{\mathrm{t}}\right)\end{array}$ & $\begin{array}{c}(3) \\
\text { Return }_{\mathrm{t}} \\
\text { excess }\end{array}$ \\
\hline \multicolumn{4}{|c|}{ Panel A: Small firms } \\
\hline $\operatorname{Adv}_{\mathrm{NP}, \mathrm{t}}$ & $\begin{array}{c}0.2856 \\
(0.2357)\end{array}$ & $\begin{array}{c}0.2056 \\
(0.3240)\end{array}$ & $\begin{array}{l}-0.0009 \\
(0.0081)\end{array}$ \\
\hline $\operatorname{Adv}_{N P, t-1}$ & $\begin{array}{c}0.2931 \\
(0.2175)\end{array}$ & $\begin{array}{l}-0.5691^{*} \\
(0.2920)\end{array}$ & $\begin{array}{c}0.0022 \\
(0.0079)\end{array}$ \\
\hline \multicolumn{4}{|c|}{ Panel B: Large firms } \\
\hline $\operatorname{Adv}_{\mathrm{NP}, \mathrm{t}}$ & $\begin{array}{c}0.2567^{* *} \\
(0.1143)\end{array}$ & $\begin{array}{c}0.0529 \\
(0.3073)\end{array}$ & $\begin{array}{c}0.0071 \\
(0.0052)\end{array}$ \\
\hline $\operatorname{Adv}_{\mathrm{NP}, \mathrm{t}-1}$ & $\begin{array}{c}0.4731^{* * *} \\
(0.1073)\end{array}$ & $\begin{array}{c}0.2490 \\
(0.2772)\end{array}$ & $\begin{array}{c}0.0066 \\
(0.0048)\end{array}$ \\
\hline \multicolumn{4}{|c|}{ Panel C: Low Analyst Coverage } \\
\hline $\operatorname{Adv}_{\mathrm{NP}, \mathrm{t}}$ & $\begin{array}{c}0.2977 \\
(0.2236)\end{array}$ & $\begin{array}{c}0.4022 \\
(0.3085)\end{array}$ & $\begin{array}{c}0.0012 \\
(0.0072)\end{array}$ \\
\hline $\operatorname{Adv}_{N P, t-1}$ & $\begin{array}{c}0.1863 \\
(0.2056)\end{array}$ & $\begin{array}{l}-0.3321 \\
(0.2820)\end{array}$ & $\begin{array}{c}0.0086 \\
(0.0068)\end{array}$ \\
\hline \multicolumn{4}{|c|}{ Panel D: High Analyst Coverage } \\
\hline $\operatorname{Adv}_{\mathrm{NP}, \mathrm{t}}$ & $\begin{array}{c}0.3079^{* * *} \\
(0.1112)\end{array}$ & $\begin{array}{c}0.0833 \\
(0.3172)\end{array}$ & $\begin{array}{c}0.0065 \\
(0.0050)\end{array}$ \\
\hline $\operatorname{Adv}_{N P, t-1}$ & $\begin{array}{c}0.5770^{* * * *} \\
(0.1098)\end{array}$ & $\begin{array}{c}0.1431 \\
(0.2834)\end{array}$ & $\begin{array}{c}0.0006 \\
(0.0050)\end{array}$ \\
\hline \multicolumn{4}{|c|}{ Panel E: Low Media Coverage } \\
\hline $\operatorname{Adv}_{\mathrm{NP}, \mathrm{t}}$ & $\begin{array}{l}0.3813^{*} \\
(0.2111)\end{array}$ & $\begin{array}{l}-0.0768 \\
(0.3222)\end{array}$ & $\begin{array}{c}0.0026 \\
(0.0069)\end{array}$ \\
\hline $\operatorname{Adv}_{N P, t-1}$ & $\begin{array}{c}0.2914 \\
(0.1966)\end{array}$ & $\begin{array}{l}-0.4948^{*} \\
(0.2915)\end{array}$ & $\begin{array}{c}0.0093 \\
(0.0069)\end{array}$ \\
\hline \multicolumn{4}{|c|}{ Panel F: High Media Coverage } \\
\hline $\operatorname{Adv}_{\mathrm{NP}, \mathrm{t}}$ & $\begin{array}{l}0.2107^{*} \\
(0.1246)\end{array}$ & $\begin{array}{c}0.2054 \\
(0.3006)\end{array}$ & $\begin{array}{c}0.0048 \\
(0.0059)\end{array}$ \\
\hline $\mathrm{Adv}_{\mathrm{NP}, \mathrm{t}-1}$ & $\begin{array}{c}0.5368^{* * *} \\
(0.1212)\end{array}$ & $\begin{array}{c}0.1310 \\
(0.2802)\end{array}$ & $\begin{array}{c}0.0008 \\
(0.0054)\end{array}$ \\
\hline
\end{tabular}




\begin{tabular}{|c|c|c|c|}
\hline & $\begin{array}{c}(1) \\
\ln \left(\text { Turnover }_{\mathrm{t}}\right)\end{array}$ & $\begin{array}{c}(2) \\
\ln \left(\text { EffSpr }_{\mathrm{t}}\right)\end{array}$ & $\begin{array}{c}(3) \\
\text { Return }_{\mathrm{t}}{ }^{\text {excess }}\end{array}$ \\
\hline \multicolumn{4}{|c|}{ Panel G: Consumer Industry } \\
\hline $\operatorname{Adv}_{N P, t}$ & $\begin{array}{c}0.2980 \\
(0.2161)\end{array}$ & $\begin{array}{c}0.3707 \\
(0.3798)\end{array}$ & $\begin{array}{l}-0.0044 \\
(0.0079)\end{array}$ \\
\hline $\operatorname{Adv}_{N P, t-1}$ & $\begin{array}{c}0.1333 \\
(0.2059)\end{array}$ & $\begin{array}{c}0.4956 \\
(0.3679)\end{array}$ & $\begin{array}{l}-0.0031 \\
(0.0078)\end{array}$ \\
\hline \multicolumn{4}{|c|}{ Panel H: Non-Consumer Industry } \\
\hline $\operatorname{Adv}_{N P, t}$ & $\begin{array}{c}0.2802^{* *} \\
(0.1360)\end{array}$ & $\begin{array}{c}-0.0263 \\
(0.2892)\end{array}$ & $\begin{array}{l}0.0087^{*} \\
(0.0049)\end{array}$ \\
\hline $\operatorname{Adv}_{\mathrm{NP}, \mathrm{t}-1}$ & $\begin{array}{c}0.5237^{* * *} \\
(0.1335)\end{array}$ & $\begin{array}{l}-0.3775 \\
(0.2543)\end{array}$ & $\begin{array}{c}0.0075 \\
(0.0048)\end{array}$ \\
\hline \multicolumn{4}{|c|}{ Panel I: Low Industry Concentration } \\
\hline $\mathrm{Adv}_{\mathrm{NP}, \mathrm{t}}$ & $\begin{array}{c}0.3803^{* *} \\
(0.1663)\end{array}$ & $\begin{array}{c}0.1378 \\
(0.3636)\end{array}$ & $\begin{array}{l}0.0119^{*} \\
(0.0062)\end{array}$ \\
\hline $\operatorname{Adv}_{N P, t-1}$ & $\begin{array}{c}0.6762^{* * *} \\
(0.1633)\end{array}$ & $\begin{array}{l}-0.0085 \\
(0.2980)\end{array}$ & $\begin{array}{c}0.0022 \\
(0.0062)\end{array}$ \\
\hline \multicolumn{4}{|c|}{ Panel J: High Industry Concentration } \\
\hline $\mathrm{Adv}_{\mathrm{NP}, \mathrm{t}}$ & $\begin{array}{c}0.2299 \\
(0.1591)\end{array}$ & $\begin{array}{c}0.0157 \\
(0.3124)\end{array}$ & $\begin{array}{l}-0.0060 \\
(0.0071)\end{array}$ \\
\hline $\mathrm{Adv}_{\mathrm{NP}, \mathrm{t}-1}$ & $\begin{array}{c}0.2002 \\
(0.1547)\end{array}$ & $\begin{array}{l}-0.1224 \\
(0.3064)\end{array}$ & $\begin{array}{c}0.0102 \\
(0.0069)\end{array}$ \\
\hline \multicolumn{4}{|c|}{ Panel K: Low WSJ-Ad Sensitivity } \\
\hline $\operatorname{Adv} w s J, t$ & $\begin{array}{c}0.1151 \\
(0.2475)\end{array}$ & $\begin{array}{c}0.0500 \\
(0.6672)\end{array}$ & $\begin{array}{c}0.0231 \\
(0.0146)\end{array}$ \\
\hline $\mathrm{Adv}_{\mathrm{WSJ}, \mathrm{t}-1}$ & $\begin{array}{c}0.2590 \\
(0.2824)\end{array}$ & $\begin{array}{c}0.4893 \\
(0.8718)\end{array}$ & $\begin{array}{l}-0.0144 \\
(0.0118)\end{array}$ \\
\hline \multicolumn{4}{|c|}{ Panel L: High WSJ-Ad Sensitivity } \\
\hline $\operatorname{Adv}_{W S J, t}$ & $\begin{array}{c}0.0105 \\
(0.2594)\end{array}$ & $\begin{array}{c}-1.6145^{* *} \\
(0.8139)\end{array}$ & $\begin{array}{c}0.0016 \\
(0.0128)\end{array}$ \\
\hline AdvWSJ,t-1 & $\begin{array}{c}0.4369 \\
(0.3160)\end{array}$ & $\begin{array}{l}-1.0063 \\
(1.2105)\end{array}$ & $\begin{array}{l}-0.0124 \\
(0.0136)\end{array}$ \\
\hline
\end{tabular}

IA. 62 


\begin{tabular}{|c|c|c|c|}
\hline & $\begin{array}{c}(1) \\
\ln \left(\text { Turnover }_{\mathrm{t}}\right)\end{array}$ & $\begin{array}{c}(2) \\
\ln \left(\text { EffSpr }_{t}\right)\end{array}$ & $\begin{array}{c}(3) \\
\text { Return }_{\mathrm{t}} \\
\text { excess }\end{array}$ \\
\hline \multicolumn{4}{|c|}{ Panel M: Highest Decile Advertising Shock } \\
\hline $\mathrm{I}_{\mathrm{Ad}(\mathrm{NP}), \mathrm{t}}$ & $\begin{array}{c}2.8456^{* *} \\
(1.3547)\end{array}$ & $\begin{array}{c}3.0236 \\
(2.7837)\end{array}$ & $\begin{array}{c}0.0239 \\
(0.0510)\end{array}$ \\
\hline $\mathrm{I}_{\mathrm{Ad}(\mathrm{NP}), \mathrm{t}-1}$ & $\begin{array}{c}3.5487^{* * *} \\
(1.2870)\end{array}$ & $\begin{array}{l}-0.0269 \\
(2.5115)\end{array}$ & $\begin{array}{c}0.0376 \\
(0.0501)\end{array}$ \\
\hline \multicolumn{4}{|c|}{ Panel N: Highest Percentile Advertising Shock } \\
\hline $\mathrm{I}_{\mathrm{Ad}(\mathrm{NP}), \mathrm{t}}$ & $\begin{array}{l}6.9743^{*} \\
(3.6437)\end{array}$ & $\begin{array}{c}1.9818 \\
(8.9562)\end{array}$ & $\begin{array}{l}-0.0187 \\
(0.1504)\end{array}$ \\
\hline $\mathrm{I}_{\mathrm{Ad}(\mathrm{NP}), \mathrm{t}-1}$ & $\begin{array}{l}7.8064^{* *} \\
(3.6108)\end{array}$ & $\begin{array}{l}-0.1802 \\
(8.7209)\end{array}$ & $\begin{array}{l}-0.0639 \\
(0.1564)\end{array}$ \\
\hline \multicolumn{4}{|c|}{ Panel O: First Time Advertiser } \\
\hline $\mathrm{I}_{\mathrm{Ad}(\mathrm{NP}), \mathrm{t}}$ & $\begin{array}{c}0.0107 \\
(0.0086)\end{array}$ & $\begin{array}{l}-0.0187 \\
(0.0163)\end{array}$ & $\begin{array}{l}-0.0001 \\
(0.0003)\end{array}$ \\
\hline $\mathrm{I}_{\mathrm{Ad}(\mathrm{NP}), \mathrm{t}-1}$ & $\begin{array}{c}0.0033 \\
(0.0085)\end{array}$ & $\begin{array}{c}0.0221 \\
(0.0160)\end{array}$ & $\begin{array}{c}0.0001 \\
(0.0004)\end{array}$ \\
\hline \multicolumn{4}{|c|}{ Panel P: After 8-week Low } \\
\hline $\operatorname{Adv}_{\mathrm{NP}, \mathrm{t}}$ & $\begin{array}{c}0.4003 * * * \\
(0.1497)\end{array}$ & $\begin{array}{l}-0.0454 \\
(0.3019)\end{array}$ & $\begin{array}{c}-0.0016 \\
(0.0061)\end{array}$ \\
\hline $\operatorname{Adv}_{\mathrm{NP}, \mathrm{t}-1}$ & $\begin{array}{c}0.6003^{* * *} \\
(0.1509)\end{array}$ & $\begin{array}{l}-0.0165 \\
(0.2911)\end{array}$ & $\begin{array}{c}0.0058 \\
(0.0063)\end{array}$ \\
\hline \multicolumn{4}{|c|}{ Panel Q: After 8-week High } \\
\hline $\operatorname{Adv}_{\mathrm{NP}, \mathrm{t}}$ & $\begin{array}{c}0.2185 \\
(0.1782)\end{array}$ & $\begin{array}{c}0.3127 \\
(0.3488)\end{array}$ & $\begin{array}{c}0.0077 \\
(0.0075)\end{array}$ \\
\hline $\operatorname{Adv}_{N P, t-1}$ & $\begin{array}{c}0.3164^{* *} \\
(0.1604)\end{array}$ & $\begin{array}{l}-0.2411 \\
(0.2976)\end{array}$ & $\begin{array}{c}0.0044 \\
(0.0067)\end{array}$ \\
\hline \multicolumn{4}{|c|}{ Panel R: Overnight Returns } \\
\hline $\operatorname{Adv}_{N P, t}$ & & & $\begin{array}{c}0.0018 \\
(0.0028)\end{array}$ \\
\hline $\operatorname{Adv}_{N P, t-1}$ & & & $\begin{array}{c}0.0036 \\
(0.0027)\end{array}$ \\
\hline \multicolumn{4}{|c|}{ Panel S: Intraday Returns } \\
\hline $\operatorname{Adv}_{N P, t}$ & & & $\begin{array}{l}-0.0031 \\
(0.0051)\end{array}$ \\
\hline $\operatorname{Adv}_{\mathrm{NP}, \mathrm{t}-1}$ & & & $\begin{array}{c}0.0080 \\
(0.0049)\end{array}$ \\
\hline
\end{tabular}

\section{IA. 63}




\begin{tabular}{|c|c|c|c|}
\hline & $\begin{array}{c}(1) \\
\ln \left(\text { Turnover }_{t}\right)\end{array}$ & $\begin{array}{c}(2) \\
\ln \left(\text { EffSpr }_{t}\right)\end{array}$ & $\begin{array}{c}(3) \\
\text { Return }_{\mathrm{t}} \text { excess }\end{array}$ \\
\hline \multicolumn{4}{|c|}{ Panel T: Monday } \\
\hline $\mathrm{Adv}_{\mathrm{NP}, \mathrm{t}}$ & $\begin{array}{l}0.4259^{*} \\
(0.2416)\end{array}$ & $\begin{array}{c}0.3678 \\
(0.5299)\end{array}$ & $\begin{array}{c}-0.0276^{* *} \\
(0.0119)\end{array}$ \\
\hline $\mathrm{Adv}_{\mathrm{NP}, \mathrm{t}-1}$ & $\begin{array}{l}-0.0265 \\
(0.2384)\end{array}$ & $\begin{array}{l}-0.0567 \\
(0.4403)\end{array}$ & $\begin{array}{c}0.0117 \\
(0.0103)\end{array}$ \\
\hline \multicolumn{4}{|c|}{ Panel U: Tuesday to Friday } \\
\hline $\mathrm{Adv}_{\mathrm{NP}, \mathrm{t}}$ & $\begin{array}{c}0.2701^{* *} \\
(0.1300)\end{array}$ & $\begin{array}{c}0.0930 \\
(0.2583)\end{array}$ & $\begin{array}{c}0.0104^{* *} \\
(0.0052)\end{array}$ \\
\hline $\operatorname{Adv}_{N P, t-1}$ & $\begin{array}{c}0.4233^{* * *} \\
(0.1272)\end{array}$ & $\begin{array}{l}-0.1324 \\
(0.2372)\end{array}$ & $\begin{array}{c}0.0034 \\
(0.0051)\end{array}$ \\
\hline \multicolumn{4}{|c|}{ Panel V: December } \\
\hline $\operatorname{Adv}_{N P, t}$ & $\begin{array}{c}0.8302^{* *} \\
(0.3945)\end{array}$ & $\begin{array}{l}1.1878 \\
(0.7676)\end{array}$ & $\begin{array}{c}0.0090 \\
(0.0165)\end{array}$ \\
\hline $\mathrm{Adv}_{\mathrm{NP}, \mathrm{t}-1}$ & $\begin{array}{c}0.2622 \\
(0.3613)\end{array}$ & $\begin{array}{c}0.6387 \\
(0.6815)\end{array}$ & $\begin{array}{l}-0.0200 \\
(0.0162)\end{array}$ \\
\hline \multicolumn{4}{|c|}{ Panel W: January to November } \\
\hline $\operatorname{Adv}_{\mathrm{NP}, \mathrm{t}}$ & $\begin{array}{l}0.1965^{*} \\
(0.1186)\end{array}$ & $\begin{array}{c}0.0042 \\
(0.2404)\end{array}$ & $\begin{array}{c}0.0023 \\
(0.0050)\end{array}$ \\
\hline $\mathrm{Adv}_{\mathrm{NP}, \mathrm{t}-1}$ & $\begin{array}{c}0.4238^{* * *} \\
(0.1177)\end{array}$ & $\begin{array}{l}-0.2184 \\
(0.2199)\end{array}$ & $\begin{array}{l}0.0080^{*} \\
(0.0047)\end{array}$ \\
\hline \multicolumn{4}{|c|}{ Panel X: Recession Months } \\
\hline $\operatorname{Adv}_{N P, t}$ & $\begin{array}{l}0.3744^{*} \\
(0.1912)\end{array}$ & $\begin{array}{c}0.4113 \\
(0.3342)\end{array}$ & $\begin{array}{c}0.0030 \\
(0.0090)\end{array}$ \\
\hline $\mathrm{Adv}_{\mathrm{NP}, \mathrm{t}-1}$ & $\begin{array}{c}0.0382 \\
(0.1733)\end{array}$ & $\begin{array}{l}-0.3598 \\
(0.3011)\end{array}$ & $\begin{array}{c}0.0036 \\
(0.0087) \\
\end{array}$ \\
\hline \multicolumn{4}{|c|}{ Panel Y: Non-Recession Months } \\
\hline $\operatorname{Adv}_{N P, t}$ & $\begin{array}{c}0.2868^{* *} \\
(0.1234)\end{array}$ & $\begin{array}{c}0.0155 \\
(0.2559)\end{array}$ & $\begin{array}{c}0.0027 \\
(0.0048)\end{array}$ \\
\hline $\mathrm{Adv}_{\mathrm{NP}, \mathrm{t}-1}$ & $\begin{array}{c}0.5419 * * * \\
(0.1223)\end{array}$ & $\begin{array}{c}-0.0714 \\
(0.2343) \\
\end{array}$ & $\begin{array}{c}0.0035 \\
(0.0048) \\
\end{array}$ \\
\hline \multicolumn{4}{|c|}{ Panel Z: Only EA and Coverage Windows } \\
\hline $\operatorname{Adv}_{\mathrm{NP}, \mathrm{t}}$ & $\begin{array}{c}0.0517 \\
(0.1867)\end{array}$ & $\begin{array}{c}0.0231 \\
(0.4386)\end{array}$ & $\begin{array}{c}0.0215^{* *} \\
(0.0096)\end{array}$ \\
\hline $\mathrm{Adv}_{\mathrm{NP}, \mathrm{t}-1}$ & $\begin{array}{c}0.1510 \\
(0.1839)\end{array}$ & $\begin{array}{l}-0.1497 \\
(0.4207)\end{array}$ & $\begin{array}{l}-0.0007 \\
(0.0090)\end{array}$ \\
\hline
\end{tabular}

IA. 64 
Table C29: Impact on Financial Markets - Newspaper Advertising: Stability of Effects?

The data requirements and regression specifications are equivalent to those in the main analysis. Turnover is daily trading volume over shares outstanding. EffSpr is the effective spread, defined as daily transaction-weighted average of transaction prices relative to prevailing quotes. Return ${ }^{\text {excess }}$ is the return of a stock over Kenneth French's market return. For ease of presentation, only the contemporary and first lag effects of advertising expenditures are reported. Standard errors are clustered by firm for the panel-regressions. 1/2/3 stars denote significance at the $10 / 5 / 1 \%$-level.

\begin{tabular}{|c|c|c|c|}
\hline & $\begin{array}{c}(1) \\
\ln \left(\text { Turnover }_{\mathrm{t}}\right)\end{array}$ & $\begin{array}{c}(2) \\
\ln \left(\text { EffSpr }_{t}\right)\end{array}$ & $\begin{array}{c}(3) \\
\text { Return }_{t}{ }^{\text {excess }}\end{array}$ \\
\hline \multicolumn{4}{|c|}{ Panel A: Controlling for TV Advertising } \\
\hline $\operatorname{Adv}_{N P, t}$ & $\begin{array}{c}0.3956^{* * *} \\
(0.1175)\end{array}$ & $\begin{array}{c}0.1717 \\
(0.2417)\end{array}$ & $\begin{array}{c}0.0047 \\
(0.0045)\end{array}$ \\
\hline $\mathrm{Adv}_{\mathrm{NP}, \mathrm{t}-1}$ & $\begin{array}{c}0.5351^{* * * *} \\
(0.1143)\end{array}$ & $\begin{array}{l}-0.0496 \\
(0.2170)\end{array}$ & $\begin{array}{c}0.0051 \\
(0.0043)\end{array}$ \\
\hline \multicolumn{4}{|c|}{ Panel B: 1995-2003 } \\
\hline $\operatorname{Adv}_{\mathrm{NP}, \mathrm{t}-1}$ & $\begin{array}{c}0.4763^{* * *} \\
(0.1796)\end{array}$ & $\begin{array}{c}0.4606 \\
(0.3891)\end{array}$ & $\begin{array}{c}0.0025 \\
(0.0071)\end{array}$ \\
\hline $\operatorname{Adv}_{\mathrm{NP}, \mathrm{t}-1}$ & $\begin{array}{c}0.7716^{* * *} \\
(0.1727)\end{array}$ & $\begin{array}{l}-0.1089 \\
(0.3722)\end{array}$ & $\begin{array}{c}0.0055 \\
(0.0071)\end{array}$ \\
\hline \multicolumn{4}{|c|}{ Panel C: 2004-2012 } \\
\hline $\operatorname{Adv}_{\mathrm{NP}, \mathrm{t}-1}$ & $\begin{array}{l}0.2379^{*} \\
(0.1392)\end{array}$ & $\begin{array}{l}-0.0566 \\
(0.1886)\end{array}$ & $\begin{array}{c}0.0058 \\
(0.0051)\end{array}$ \\
\hline $\mathrm{Adv}_{\mathrm{NP}, \mathrm{t}-1}$ & $\begin{array}{l}0.2662^{*} \\
(0.1366)\end{array}$ & $\begin{array}{c}0.0701 \\
(0.1668)\end{array}$ & $\begin{array}{c}0.0020 \\
(0.0048)\end{array}$ \\
\hline \multicolumn{4}{|c|}{ Panel D: NYSE/AMEX } \\
\hline $\mathrm{Adv}_{\mathrm{NP}, \mathrm{t}}$ & $\begin{array}{c}0.3238^{* *} \\
(0.1283)\end{array}$ & $\begin{array}{c}0.0931 \\
(0.2848)\end{array}$ & $\begin{array}{l}-0.0016 \\
(0.0046)\end{array}$ \\
\hline $\operatorname{Adv}_{N P, t-1}$ & $\begin{array}{c}0.4844^{* * *} \\
(0.1188)\end{array}$ & $\begin{array}{c}0.1756 \\
(0.2644) \\
\end{array}$ & $\begin{array}{c}0.0052 \\
(0.0044)\end{array}$ \\
\hline \multicolumn{4}{|c|}{ Panel E: NASDAQ } \\
\hline $\mathrm{Adv}_{\mathrm{NP}, \mathrm{t}}$ & $\begin{array}{c}0.2903 \\
(0.2347)\end{array}$ & $\begin{array}{c}0.2667 \\
(0.3659)\end{array}$ & $\begin{array}{l}0.0147^{*} \\
(0.0088)\end{array}$ \\
\hline $\operatorname{Adv}_{N P, t-1}$ & $\begin{array}{c}0.3860 \\
(0.2395)\end{array}$ & $\begin{array}{c}-0.7171^{* *} \\
(0.3079)\end{array}$ & $\begin{array}{c}0.0009 \\
(0.0084)\end{array}$ \\
\hline
\end{tabular}




\begin{tabular}{|c|c|c|c|}
\hline & $\begin{array}{c}(1) \\
\ln \left(\text { Turnover }_{t}\right)\end{array}$ & $\begin{array}{c}(2) \\
\ln \left(\text { EffSpr }_{\mathrm{t}}\right)\end{array}$ & $\begin{array}{c}(3) \\
\text { Return }_{\mathrm{t}} \\
\text { excess }\end{array}$ \\
\hline \multicolumn{4}{|c|}{ Panel F: Adv with scalar $=0.1$} \\
\hline $\operatorname{Adv}_{\mathrm{NP}, \mathrm{t}}$ & $\begin{array}{c}0.2463 * * * \\
(0.0925)\end{array}$ & $\begin{array}{c}0.0830 \\
(0.1858)\end{array}$ & $\begin{array}{c}0.0024 \\
(0.0037)\end{array}$ \\
\hline $\operatorname{Adv}_{N P, t-1}$ & $\begin{array}{c}0.3530^{* * *} \\
(0.0902)\end{array}$ & $\begin{array}{l}-0.0971 \\
(0.1663)\end{array}$ & $\begin{array}{c}0.0039 \\
(0.0036)\end{array}$ \\
\hline \multicolumn{4}{|c|}{ Panel G: Adv with scalar $=0.5$} \\
\hline $\operatorname{Adv}_{N P, t}$ & $\begin{array}{c}0.3341^{* * * *} \\
(0.1210)\end{array}$ & $\begin{array}{c}0.1296 \\
(0.2458)\end{array}$ & $\begin{array}{c}0.0028 \\
(0.0050)\end{array}$ \\
\hline $\operatorname{Adv}_{N P, t-1}$ & $\begin{array}{c}0.4799^{* * *} \\
(0.1182)\end{array}$ & $\begin{array}{l}-0.1230 \\
(0.2202)\end{array}$ & $\begin{array}{c}0.0053 \\
(0.0047)\end{array}$ \\
\hline \multicolumn{4}{|c|}{ Panel H: Adv with mean instead of median } \\
\hline $\operatorname{Adv}_{\mathrm{NP}, \mathrm{t}}$ & $\begin{array}{c}0.1665 \\
(0.1113)\end{array}$ & $\begin{array}{c}0.0430 \\
(0.2418)\end{array}$ & $\begin{array}{c}0.0051 \\
(0.0042)\end{array}$ \\
\hline $\operatorname{Adv}_{N P, t-1}$ & $\begin{array}{c}0.0498 \\
(0.1000)\end{array}$ & $\begin{array}{l}-0.0869 \\
(0.2188)\end{array}$ & $\begin{array}{c}0.0141^{* * * *} \\
(0.0040)\end{array}$ \\
\hline \multicolumn{4}{|c|}{ Panel I: $\operatorname{Ln}(1+\$$ Advertising $) / 1000$} \\
\hline $\operatorname{Adv}_{\mathrm{NP}, \mathrm{t}}$ & $\begin{array}{l}-0.0790 \\
(0.1639)\end{array}$ & $\begin{array}{l}-0.0826 \\
(0.4529)\end{array}$ & $\begin{array}{c}0.0013 \\
(0.0046)\end{array}$ \\
\hline $\operatorname{Adv}_{N P, t-1}$ & $\begin{array}{c}0.2176 \\
(0.1438)\end{array}$ & $\begin{array}{l}-0.2048 \\
(0.3784)\end{array}$ & $\begin{array}{l}-0.0026 \\
(0.0044)\end{array}$ \\
\hline \multicolumn{4}{|c|}{ Panel J: $\mathrm{I}_{\$ A_{i} 0} / 1000$} \\
\hline $\operatorname{Adv}_{\mathrm{NP}, \mathrm{t}}$ & $\begin{array}{l}-0.0962 \\
(1.4794)\end{array}$ & $\begin{array}{c}1.1630 \\
(3.8824)\end{array}$ & $\begin{array}{c}0.0190 \\
(0.0424)\end{array}$ \\
\hline $\operatorname{Adv}_{\mathrm{NP}, \mathrm{t}-1}$ & $\begin{array}{l}2.4710^{*} \\
(1.3036)\end{array}$ & $\begin{array}{l}-0.5718 \\
(3.2244)\end{array}$ & $\begin{array}{l}-0.0066 \\
(0.0407)\end{array}$ \\
\hline
\end{tabular}

IA. 66 


\begin{tabular}{|c|c|c|c|}
\hline & $\begin{array}{c}(1) \\
\ln \left(\text { Turnover }_{t}\right)\end{array}$ & $\begin{array}{c}(2) \\
\ln \left(\text { EffSpr }_{t}\right)\end{array}$ & $\begin{array}{l}(3) \\
\text { Return }_{t} \\
\text { excess }\end{array}$ \\
\hline \multicolumn{4}{|c|}{$\begin{array}{l}\text { Panel K: Permco and Day Fixed Effects, } \\
\text { Permco and Day Clustered Standard-Errors }\end{array}$} \\
\hline $\operatorname{Adv}_{N P, t}$ & $\begin{array}{c}0.2278^{* *} \\
(0.1167)\end{array}$ & $\begin{array}{c}0.1191 \\
(0.2354)\end{array}$ & $\begin{array}{c}0.0018 \\
(0.0048)\end{array}$ \\
\hline $\operatorname{Adv}_{N P, t-1}$ & $\begin{array}{c}0.2552^{* *} \\
(0.1098)\end{array}$ & $\begin{array}{l}-0.0846 \\
(0.2141)\end{array}$ & $\begin{array}{c}0.0063 \\
(0.0047)\end{array}$ \\
\hline \multicolumn{4}{|c|}{ Panel L: Dependent Variables Normalized with Lag 7} \\
\hline $\operatorname{Adv}_{\mathrm{NP}, \mathrm{t}}$ & $\begin{array}{c}0.1650 \\
(0.1253)\end{array}$ & $\begin{array}{c}0.1242 \\
(0.2337)\end{array}$ & $\begin{array}{c}0.0039 \\
(0.0060)\end{array}$ \\
\hline $\operatorname{Adv}_{\mathrm{NP}, \mathrm{t}-1}$ & $\begin{array}{c}0.4420^{* * *} \\
(0.1233)\end{array}$ & $\begin{array}{l}-0.1209 \\
(0.2154)\end{array}$ & $\begin{array}{c}0.0109^{* *} \\
(0.0056)\end{array}$ \\
\hline \multicolumn{4}{|c|}{ Panel M: Weekly Instead of Daily } \\
\hline $\operatorname{Adv}_{\mathrm{NP}, \mathrm{t}}$ & $\begin{array}{c}0.1571 \\
(0.1513)\end{array}$ & $\begin{array}{l}-0.4434 \\
(0.2953)\end{array}$ & $\begin{array}{c}0.0191 \\
(0.0184)\end{array}$ \\
\hline $\operatorname{Adv}_{N P, t-1}$ & $\begin{array}{l}-0.0925 \\
(0.1462)\end{array}$ & $\begin{array}{c}0.2086 \\
(0.2923)\end{array}$ & $\begin{array}{c}0.0241 \\
(0.0181)\end{array}$ \\
\hline $\operatorname{Adv}_{\mathrm{NP}, \mathrm{t}-2}$ & $\begin{array}{l}-0.0157 \\
(0.1511) \\
\end{array}$ & $\begin{array}{l}-0.4058 \\
(0.3067) \\
\end{array}$ & $\begin{array}{l}-0.0066 \\
(0.0183) \\
\end{array}$ \\
\hline \multicolumn{4}{|c|}{ Panel N: Daily Fama-MacBeth instead of Panel Regressions } \\
\hline $\operatorname{Adv}_{N P, t}$ & & & $\begin{array}{c}0.0003 \\
(0.0047)\end{array}$ \\
\hline $\operatorname{Adv}_{\mathrm{NP}, \mathrm{t}-1}$ & & & $\begin{array}{c}0.0063 \\
(0.0046)\end{array}$ \\
\hline
\end{tabular}

IA. 67 
Table C30: Monthly Return Regressions

In this table, we report results from Fama and MacBeth (1973) (panel) regressions of this month's return on stock characteristics in Specifications (1) to (3) ((4) to (6)). $\Delta \ln \left(1+A d v_{T V, t}\right)$ is the log-change of tv-advertising expenditures from the month before the return-period to the month of the return period. $\Delta \ln \left(1+\mathrm{Adv}_{\mathrm{TV}, \mathrm{t}-1}\right)$ is the log-change of tv-advertising expenditures from to the month before the return period from the previous month. $\Delta \ln \left(1+\mathrm{Adv}_{\mathrm{NP}, \mathrm{t}}\right)$ and $\Delta \ln \left(1+\operatorname{Adv}_{N P, t-1}\right)$ are the analogous log-changes for newspaper advertising. We divide log-changes in advertising by 1,000 to improve the readability of coefficients. Beta is the market-beta based on daily stock and value-weighted market returns over the last 12 months. $\ln ($ Size $)$ is the $\log$ of market capitalization. $\ln (\mathrm{B} / \mathrm{M})$ is the $\log$ of the

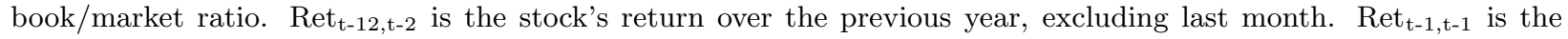

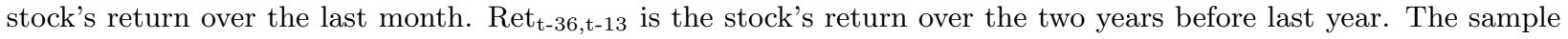
covers all $\geq \$ 5$ U.S. common stocks traded on the NYSE, AMEX and NASDAQ from 3/1995 to 12/2012. Firms without any advertising in the two months before month $t-1$ are excluded. Standard-errors in Fama-MacBeth regressions are based on Newey and West (1987) standard errors with one lag and are reported in parentheses. For panel regressions we use firm and month fixed effects and double-clustered standard errors. $1 / 2 / 3$ stars denote significance at the $10 / 5 / 1 \%$-level.

\begin{tabular}{|c|c|c|c|c|c|c|}
\hline & (1) & $(2)$ & (3) & (4) & $(5)$ & (6) \\
\hline$\Delta \ln \left(1+\mathrm{Adv}_{\mathrm{TV}, \mathrm{t}}\right) / 1000$ & $\begin{array}{c}0.1299 \\
(0.1178)\end{array}$ & & $\begin{array}{c}0.0326 \\
(0.1673)\end{array}$ & $\begin{array}{c}0.0749 \\
(0.1526)\end{array}$ & & $\begin{array}{c}0.0669 \\
(0.1529)\end{array}$ \\
\hline$\Delta \ln \left(1+\mathrm{Ad}_{\mathrm{TV}, \mathrm{t}-1}\right) / 1000$ & $\begin{array}{c}-0.0640 \\
(0.1335)\end{array}$ & & $\begin{array}{c}0.1638 \\
(0.2103)\end{array}$ & $\begin{array}{c}-0.0367 \\
(0.1717)\end{array}$ & & $\begin{array}{l}-0.0342 \\
(0.1714)\end{array}$ \\
\hline$\Delta \ln \left(1+\mathrm{Ad}_{\mathrm{NP}, \mathrm{t}}\right) / 1000$ & & $\begin{array}{c}0.1398 \\
(0.0947)\end{array}$ & $\begin{array}{c}0.0922 \\
(0.1156)\end{array}$ & & $\begin{array}{c}0.1602 \\
(0.1154)\end{array}$ & $\begin{array}{c}0.1581 \\
(0.1158)\end{array}$ \\
\hline$\Delta \ln \left(1+\mathrm{Ad}_{\mathrm{NP}, \mathrm{t}-1}\right) / 1000$ & & $\begin{array}{c}0.0066 \\
(0.0881)\end{array}$ & $\begin{array}{l}-0.0737 \\
(0.1033)\end{array}$ & & $\begin{array}{c}-0.0636 \\
(0.1105)\end{array}$ & $\begin{array}{l}-0.0632 \\
(0.1102)\end{array}$ \\
\hline Beta & $\begin{array}{c}0.0011 \\
(0.0031)\end{array}$ & $\begin{array}{c}0.0025 \\
(0.0032)\end{array}$ & $\begin{array}{c}0.0034 \\
(0.0033)\end{array}$ & $\begin{array}{c}-0.0024 \\
(0.0030)\end{array}$ & $\begin{array}{c}-0.0024 \\
(0.0030)\end{array}$ & $\begin{array}{c}-0.0024 \\
(0.0030)\end{array}$ \\
\hline $\ln ($ Size $)$ & $\begin{array}{l}-0.0006 \\
(0.0005)\end{array}$ & $\begin{array}{l}-0.0010 \\
(0.0006)\end{array}$ & $\begin{array}{l}-0.0009 \\
(0.0006)\end{array}$ & $\begin{array}{c}-0.0278^{* * *} \\
(0.0026)\end{array}$ & $\begin{array}{c}-0.0278^{* * *} \\
(0.0026)\end{array}$ & $\begin{array}{c}-0.0278^{* * *} \\
(0.0026)\end{array}$ \\
\hline $\ln (\mathrm{B} / \mathrm{M})$ & $\begin{array}{c}0.0003 \\
(0.0008)\end{array}$ & $\begin{array}{l}-0.0003 \\
(0.0010)\end{array}$ & $\begin{array}{c}0.0002 \\
(0.0010)\end{array}$ & $\begin{array}{c}0.0010 \\
(0.0021)\end{array}$ & $\begin{array}{c}0.0010 \\
(0.0021)\end{array}$ & $\begin{array}{c}0.0010 \\
(0.0021)\end{array}$ \\
\hline $\operatorname{Ret}_{\mathrm{t}-12, \mathrm{t}-2}$ & $\begin{array}{l}0.0072^{* *} \\
(0.0035)\end{array}$ & $\begin{array}{l}0.0089^{* *} \\
(0.0037)\end{array}$ & $\begin{array}{l}0.0087^{* *} \\
(0.0042)\end{array}$ & $\begin{array}{l}0.0131^{* *} \\
(0.0046)\end{array}$ & $\begin{array}{l}0.0131^{* *} \\
(0.0046)\end{array}$ & $\begin{array}{l}0.0131^{* *} \\
(0.0046)\end{array}$ \\
\hline $\operatorname{Ret}_{\mathrm{t}-1, \mathrm{t}-1}$ & $\begin{array}{c}-0.0264^{* * *} \\
(0.0073)\end{array}$ & $\begin{array}{l}-0.0157^{*} \\
(0.0085)\end{array}$ & $\begin{array}{l}-0.0144 \\
(0.0092)\end{array}$ & $\begin{array}{l}-0.0109 \\
(0.0140)\end{array}$ & $\begin{array}{l}-0.0110 \\
(0.0140)\end{array}$ & $\begin{array}{l}-0.0110 \\
(0.0140)\end{array}$ \\
\hline $\operatorname{Ret}_{\mathrm{t}-36, \mathrm{t}-13}$ & $\begin{array}{l}-0.0011 \\
(0.0011)\end{array}$ & $\begin{array}{l}-0.0002 \\
(0.0013)\end{array}$ & $\begin{array}{c}0.0001 \\
(0.0014)\end{array}$ & $\begin{array}{l}0.0039^{*} \\
(0.0021)\end{array}$ & $\begin{array}{l}0.0039^{*} \\
(0.0021)\end{array}$ & $\begin{array}{l}0.0039^{*} \\
(0.0021)\end{array}$ \\
\hline Average $R^{2}$ & $9.37 \%$ & $10.90 \%$ & $13.73 \%$ & $20.70 \%$ & $20.70 \%$ & $20.70 \%$ \\
\hline Fama-MacBeth & Yes & Yes & Yes & No & No & No \\
\hline Firm FEs & No & No & No & Yes & Yes & Yes \\
\hline Month FEs & No & No & No & Yes & Yes & Yes \\
\hline
\end{tabular}


Table C31: Impact on Financial Markets - TV Advertising: Alternative Liquidity Proxies

The analysis is done for 1995-2012 (1996-2010) common stocks from NYSE, AMEX and NASDAQ for Turnover and Returns (TAQ-based data), excluding stocks with last-week prices below 5 USD. Turnover is daily trading volume over shares outstanding. RelSpr is the relative spread, defined as daily transaction-weighted average of ask minus bid quotes relative to prevailing quote-midpoints. PrcImp is the price impact, defined as transaction-weighted average of 5 -minute impacts on quote-midpoints relative to prevailing quote-midpoints. IntAmi is the intraday Amihud measure, defined as transaction-weighted average of 5-minute impacts on quote-midpoints relative to prevailing quote-midpoints scaled by transaction volume (in shares). Adv is abnormal advertising. EA is an earnings announcement dummy. News is a national newspaper article dummy. Turnover ${ }_{t-7, t-36}$ is the trading volume over the 4 weeks up to t-7, divided by average shares outstanding. Return $n_{t-7, t-36}$ is the holding period return over the 4 weeks up to t-7. ReaVolat-7,t-36 is realized volatility, defined as average absolute return during the 4 weeks up to t-7. MarketCap is the firm's market capitalization. LDV is the relative spread in column (1), the price impact in column (2), the intraday Amihud measure in column (3) and the absolute return in column (4). Standard errors are shown in parentheses and clustered by firm for the panel-regressions. $1 / 2 / 3$ stars denote significance at the $10 / 5 / 1 \%$-level.

\begin{tabular}{lccc}
\hline & $(1)$ & $(2)$ & $(3)$ \\
& $\ln \left(\right.$ RelSpr $\left._{\mathrm{t}}\right)$ & $\ln \left(\right.$ PrcImpt $\left._{\mathrm{t}}\right)$ & $\ln \left(\right.$ IntAmi $\left._{\mathrm{t}}\right)$ \\
\hline $\mathrm{Adv}_{\mathrm{t}}$ & $-0.3891^{* * *}$ & -0.2419 & -0.3233 \\
& $(0.1330)$ & $(0.4562)$ & $(0.5082)$ \\
$\mathrm{Adv}_{\mathrm{t}-1}$ & $-0.2724^{*}$ & -0.4185 & -0.5294 \\
& $(0.1409)$ & $(0.4412)$ & $(0.4995)$ \\
$\mathrm{Adv}_{\mathrm{t}-2}$ & -0.1264 & -0.4839 & -0.5993 \\
& $(0.1180)$ & $(0.3767)$ & $(0.4276)$ \\
$\mathrm{Adv}_{\mathrm{t}-3}$ & $-0.2992^{* * *}$ & -0.3430 & -0.4198 \\
& $(0.1024)$ & $(0.3211)$ & $(0.3586)$ \\
$\mathrm{EA}_{\mathrm{t}}$ & $0.1210^{* * *}$ & $0.2808^{* * *}$ & $0.24233^{* *}$ \\
& $(0.0032)$ & $(0.0069)$ & $(0.0070)$ \\
Newst & $0.0191^{* * *}$ & $0.0949^{* * *}$ & $0.1031^{* * *}$ \\
& $(0.0026)$ & $(0.0092)$ & $(0.0105)$ \\
$\ln \left(\right.$ Turnover $\left._{\mathrm{t}-7, \mathrm{t}-36}\right)$ & $-0.0735^{* * *}$ & -0.0150 & $-0.0919^{* * *}$ \\
& $(0.0029)$ & $(0.0110)$ & $(0.0123)$ \\
Return $_{\mathrm{t}-7, \mathrm{t}-36}$ & $-0.0297^{* * *}$ & -0.0023 & $-0.2247^{* * *}$ \\
& $(0.0046)$ & $(0.0137)$ & $(0.0161)$ \\
$\ln ($ ReaVolat-7,t-36 $)$ & $0.0703^{* * *}$ & $0.1993^{* * *}$ & $0.3240^{* * *}$ \\
& $(0.0033)$ & $(0.0120)$ & $(0.0133)$ \\
$\ln \left(\right.$ MarketCap $\left._{\mathrm{t}-7}\right)$ & $-0.0972^{* * *}$ & 0.0070 & $-0.3009^{* * *}$ \\
& $(0.0045)$ & $(0.0139)$ & $(0.0177)$ \\
(LDV & & $\left.0.3176^{* * *}\right)$ & $0.3215^{* * *}$ \\
& $0.6757^{* * *}$ & $(0.0062)$ & $(0.0064)$ \\
\hline Firm-FEs & $(0.0044)$ & YES & YES \\
Week-FEs & YES & YES & YES \\
Day-of-Week-FEs & YES & YES & YES \\
\hline $\mathrm{R}^{2}$ & 0.85 & 0.39 & 0.43 \\
No. obs. & $2,414,059$ & $2,363,849$ & $2,363,849$ \\
\hline
\end{tabular}


Table C32: Impact on Financial Markets - Newspaper Advertising: Alternative Liquidity Proxies

The analysis is done for 1995-2012 (1996-2010) common stocks from NYSE, AMEX and NASDAQ for Turnover and Returns (TAQ-based data), excluding stocks with last-week prices below 5 USD. Turnover is daily trading volume over shares outstanding. RelSpr is the relative spread, defined as daily transaction-weighted average of ask minus bid quotes relative to prevailing quote-midpoints. PrcImp is the price impact, defined as transaction-weighted average of 5-minute impacts on quote-midpoints relative to prevailing quote-midpoints. IntAmi is the intraday Amihud measure, defined as transaction-weighted average of 5-minute impacts on quote-midpoints relative to prevailing quote-midpoints scaled by transaction volume (in shares). Adv is abnormal advertising. EA is an earnings announcement dummy. News is a national newspaper article dummy. Turnover ${ }_{t-7, t-36}$ is the trading volume over the 4 weeks up to t-7, divided by average shares outstanding. Return $n_{t-7, t-36}$ is the holding period return over the 4 weeks up to t-7. ReaVolat-7,t-36 is realized volatility, defined as average absolute return during the 4 weeks up to t-7. MarketCap is the firm's market capitalization. LDV is the relative spread in column (1), the price impact in column (2), the intraday Amihud measure in column (3) and the absolute return in column (4). Standard errors are shown in parentheses and clustered by firm for the panel-regressions. $1 / 2 / 3$ stars denote significance at the $10 / 5 / 1 \%$-level.

\begin{tabular}{lccc}
\hline & $(1)$ & $(2)$ & $(3)$ \\
& $\ln \left(\right.$ RelSpr $\left._{\mathrm{t}}\right)$ & $\ln \left(\right.$ PrcImpt $\left._{\mathrm{t}}\right)$ & $\ln \left(\right.$ IntAmi $\left._{\mathrm{t}}\right)$ \\
\hline $\mathrm{Adv}_{\mathrm{t}}$ & -0.1288 & -0.0656 & -0.2101 \\
& $(0.0822)$ & $(0.2288)$ & $(0.2558)$ \\
$\mathrm{Adv}_{\mathrm{t}-1}$ & 0.0067 & -0.1682 & $-0.4515^{*}$ \\
& $(0.0730)$ & $(0.2152)$ & $(0.2440)$ \\
$\mathrm{Adv}_{\mathrm{t}-2}$ & -0.0723 & -0.2431 & $-0.4232^{*}$ \\
& $(0.0790)$ & $(0.2249)$ & $(0.2546)$ \\
$\mathrm{Adv}_{\mathrm{t}-3}$ & -0.0533 & -0.0406 & -0.1414 \\
& $(0.0797)$ & $(0.2143)$ & $(0.2366)$ \\
$\mathrm{EA}_{\mathrm{t}}$ & $0.1191^{* * *}$ & $0.2674^{* * *}$ & $0.2276^{* * *}$ \\
& $(0.0029)$ & $(0.0063)$ & $(0.0063)$ \\
Newst & $0.0226^{* * *}$ & $0.0909^{* * *}$ & $0.0932^{* * *}$ \\
& $(0.0025)$ & $(0.0094)$ & $(0.0107)$ \\
$\ln \left(\right.$ Turnover $\left._{\mathrm{t}-7, \mathrm{t}-36}\right)$ & $-0.0793^{* * *}$ & $-0.0248^{* * *}$ & $-0.0835^{* * *}$ \\
& $(0.0026)$ & $(0.0093)$ & $(0.0104)$ \\
Return $_{\mathrm{t}-7, \mathrm{t}-36}$ & $-0.0239^{* * *}$ & -0.0082 & $-0.2105^{* * *}$ \\
& $(0.0040)$ & $(0.0114)$ & $(0.0130)$ \\
$\ln ($ ReaVolat-7,t-36 $)$ & $0.0720^{* * *}$ & $0.1943^{* * *}$ & $0.3078^{* * *}$ \\
& $(0.0033)$ & $(0.0100)$ & $(0.0111)$ \\
$\ln \left(\right.$ MarketCap $\left._{\mathrm{t}-7}\right)$ & $-0.0954^{* * *}$ & 0.0041 & $-0.3265^{* * *}$ \\
& $(0.0041)$ & $(0.0116)$ & $(0.0145)$ \\
(LDV & & $\left.0.3364^{* * *}\right)$ & $0.3399^{* * *}$ \\
& $0.6731^{* * *}$ & $(0.0057)$ & $(0.0058)$ \\
\hline Firm-FEs & $(0.0040)$ & YES & YES \\
Week-FEs & YES & YES & YES \\
Day-of-Week-FEs & YES & YES & YES \\
\hline $\mathrm{R}^{2}$ & 0.84 & 0.42 & 0.48 \\
No. obs. & $2,673,159$ & $2,638,861$ & $2,638,861$ \\
\hline
\end{tabular}


Table C33: Impact on Financial Markets - TV Advertising: Order Imbalances and Volatility

The analysis is done for 1995-2012 (1996-2010) common stocks from NYSE, AMEX and NASDAQ for Turnover and Returns (TAQ-based data), excluding stocks with last-week prices below 5 USD. OIB is the order imbalance, i.e., the signed difference between buys and sells in one day relative to the total transaction value. Buys (Sells) are the total traded value (in \$) in buy (sell) transactions over a day (classified according to Lee and Ready, 1991). Abs(Return) is the absolute value of the raw return. Adv is abnormal advertising. EA is an earnings announcement dummy. News is a national newspaper article dummy. Turnover ${ }_{t-7, t-36}$ is the trading volume over the 4 weeks up to t-7, divided by average shares outstanding. Return $n_{t-7, t-36}$ is the holding period return over the 4 weeks up to t-7. ReaVolat-7,t-36 is realized volatility, defined as average absolute return during the 4 weeks up to t-7. MarketCap is the firm's market capitalization. LDV is the order imbalance in column (1), the log of one plus the number of buys in column (2) and the log of one plus the number of sells in column (3). Standard-errors are shown in parentheses and clustered by firm for the panel-regressions. Fama-MacBeth regression standard-errors are Newey-West corrected (5 lags). 1/2/3 stars denote significance at the $10 / 5 / 1 \%$-level.

\begin{tabular}{lcccc}
\hline & $(1)$ & $(2)$ & $(3)$ & $(4)$ \\
& OIB $_{\mathrm{t}}$ & $\ln \left(1+\mathrm{Buys}_{\mathrm{t}}\right)$ & $\ln (1+\mathrm{Sells} \mathrm{t})$ & $\ln \left(\mathrm{Abs}\left(\operatorname{Return}_{\mathrm{t}}\right)\right)$ \\
\hline $\mathrm{Adv}_{\mathrm{t}}$ & -0.1380 & $0.4792^{* *}$ & $0.8861^{* *}$ & $-0.6479^{* *}$ \\
& $(0.0925)$ & $(0.2440)$ & $(0.4216)$ & $(0.3030)$ \\
$\mathrm{Adv}_{\mathrm{t}-1}$ & -0.0656 & 0.3660 & 0.4473 & 0.4155 \\
& $(0.0951)$ & $(0.2470)$ & $(0.3927)$ & $(0.3143)$ \\
$\mathrm{Adv}_{\mathrm{t}-2}$ & -0.0540 & -0.0026 & 0.1483 & $-0.6627^{* *}$ \\
& $(0.0843)$ & $(0.2218)$ & $(0.3504)$ & $(0.2876)$ \\
$\mathrm{Adv}_{\mathrm{t}-3}$ & -0.0425 & $0.3593^{*}$ & 0.2390 & $-0.9777^{* * *}$ \\
& $(0.0764)$ & $(0.1930)$ & $(0.3255)$ & $(0.2578)$ \\
$\mathrm{EA}_{\mathrm{t}}$ & $0.0071^{* * *}$ & $0.5203^{* * *}$ & $0.5287^{* * *}$ & $0.4859^{* * *}$ \\
& $(0.0013)$ & $(0.0094)$ & $(0.0102)$ & $(0.0107)$ \\
Newst & 0.0002 & $0.1729^{* * *}$ & $0.1814^{* * *}$ & $0.1098^{* * *}$ \\
& $(0.0009)$ & $(0.0069)$ & $(0.0076)$ & $(0.0052)$ \\
$\ln \left(\right.$ Turnover $\left._{\mathrm{t}-7, \mathrm{t}-36)}\right)$ & $0.0041^{* * *}$ & $0.6419^{* * *}$ & $0.6339^{* * *}$ & -0.0041 \\
& $(0.0014)$ & $(0.0064)$ & $(0.0110)$ & $(0.0042)$ \\
Return $_{\mathrm{t}-7, \mathrm{t}-36}$ & $0.0105^{* * *}$ & $-0.1711^{* * *}$ & $-0.1581^{* * *}$ & $-0.2741^{* * *}$ \\
& $(0.0027)$ & $(0.0108)$ & $(0.0132)$ & $(0.0097)$ \\
$\ln \left(\right.$ ReaVola $\left._{\mathrm{t}-7, \mathrm{t}-36)}\right)$ & -0.0021 & $-0.0442^{* * *}$ & $-0.0347^{* * *}$ & $0.3943^{* * *}$ \\
& $(0.0016)$ & $(0.0057)$ & $(0.0091)$ & $(0.0062)$ \\
$\ln ($ MarketCapt-7 $)$ & $0.0028^{*}$ & $0.0325^{* * *}$ & $0.0578^{* * *}$ & $-0.0806^{* * *}$ \\
& $(0.0016)$ & $(0.0068)$ & $(0.0105)$ & $(0.0050)$ \\
LDV & $0.0885^{* * *}$ & $0.1723^{* * *}$ & $0.1947^{* * *}$ & $0.0336^{* * *}$ \\
& $(0.0024)$ & $(0.0034)$ & $(0.0083)$ & $(0.0010)$ \\
\hline Firm-FEs & YES & YES & YES & YES \\
Week-FEs & YES & YES & YES & YES \\
Day-of-Week-FEs & YES & YES & YES & YES \\
\hline $\mathrm{R}^{2}$ & 0.05 & 0.65 & 0.52 & 0.20 \\
No. obs. & $2,377,750$ & $2,377,750$ & $2,377,750$ & $2,634,197$ \\
\hline
\end{tabular}

IA.71 
Table C34: Impact on Financial Markets - Newspaper Advertising: Order Imbalances and Volatility

The analysis is done for 1995-2012 (1996-2010) common stocks from NYSE, AMEX and NASDAQ for Turnover and Returns (TAQ-based data), excluding stocks with last-week prices below 5 USD. OIB is the order imbalance, i.e., the signed difference between buys and sells in one day relative to the total transaction value. Buys (Sells) are the total traded value (in \$) in buy (sell) transactions over a day (classified according to Lee and Ready, 1991). Abs(Return) is the absolute value of the raw return. Adv is abnormal advertising. EA is an earnings announcement dummy. News is a national newspaper article dummy. Turnover ${ }_{t-7, t-36}$ is the trading volume over the 4 weeks up to t-7, divided by average shares outstanding. Return $n_{t-7, t-36}$ is the holding period return over the 4 weeks up to t-7. ReaVolat-7,t-36 is realized volatility, defined as average absolute return during the 4 weeks up to t-7. MarketCap is the firm's market capitalization. LDV is the order imbalance in column (1), the log of one plus the number of buys in column (2) and the log of one plus the number of sells in column (3). Standard errors are shown in parentheses and clustered by firm for the panel-regressions. Fama-MacBeth regression standard-errors are Newey-West corrected (5 lags). 1/2/3 stars denote significance at the $10 / 5 / 1 \%$-level.

\begin{tabular}{|c|c|c|c|c|}
\hline & $\begin{array}{l}(1) \\
\text { OIB }_{\mathrm{t}}\end{array}$ & $\begin{array}{c}(2) \\
\ln (1+\text { Buyst })\end{array}$ & $\begin{array}{c}(3) \\
\ln (1+\text { Sellst })\end{array}$ & $\begin{array}{c}(4) \\
\ln \left(\operatorname{Abs}\left(\text { Return }_{t}\right)\right)\end{array}$ \\
\hline $\mathrm{Adv}_{\mathrm{t}}$ & $\begin{array}{c}0.0160 \\
(0.0505)\end{array}$ & $\begin{array}{c}0.2279 \\
(0.1412)\end{array}$ & $\begin{array}{c}0.1941 \\
(0.1848)\end{array}$ & $\begin{array}{c}0.3170 \\
(0.1968)\end{array}$ \\
\hline $\mathrm{Adv}_{\mathrm{t}-1}$ & $\begin{array}{l}-0.0336 \\
(0.0436)\end{array}$ & $\begin{array}{c}0.6290 * * * \\
(0.1340)\end{array}$ & $\begin{array}{c}0.7522^{* * *} \\
(0.1745)\end{array}$ & $\begin{array}{l}-0.0070 \\
(0.1915)\end{array}$ \\
\hline $\mathrm{Adv}_{\mathrm{t}-2}$ & $\begin{array}{l}-0.0786 \\
(0.0517)\end{array}$ & $\begin{array}{c}0.4943^{* * *} \\
(0.1420)\end{array}$ & $\begin{array}{c}0.7591^{* * *} \\
(0.1834)\end{array}$ & $\begin{array}{l}0.3632^{*} \\
(0.2095)\end{array}$ \\
\hline $\mathrm{Adv}_{\mathrm{t}-3}$ & $\begin{array}{c}0.0122 \\
(0.0506)\end{array}$ & $\begin{array}{c}0.1963 \\
(0.1439)\end{array}$ & $\begin{array}{c}0.2769 \\
(0.1915)\end{array}$ & $\begin{array}{c}0.2680 \\
(0.2071)\end{array}$ \\
\hline $\mathrm{EA}_{\mathrm{t}}$ & $\begin{array}{c}0.0109 * * * \\
(0.0012)\end{array}$ & $\begin{array}{c}0.5019 * * * \\
(0.0088)\end{array}$ & $\begin{array}{c}0.4860 * * * \\
(0.0093)\end{array}$ & $\begin{array}{c}0.4784^{* * *} \\
(0.0099)\end{array}$ \\
\hline News $_{t}$ & $\begin{array}{c}0.0010 \\
(0.0008)\end{array}$ & $\begin{array}{c}0.1680^{* * *} \\
(0.0068)\end{array}$ & $\begin{array}{c}0.1704^{* * *} \\
(0.0068)\end{array}$ & $\begin{array}{c}0.1118^{* * *} \\
(0.0054)\end{array}$ \\
\hline $\ln$ (Turnover $\left._{\mathrm{t}-7, \mathrm{t}-36}\right)$ & $\begin{array}{c}0.0031^{* *} \\
(0.0012)\end{array}$ & $\begin{array}{c}0.6321^{* * *} \\
(0.0059)\end{array}$ & $\begin{array}{c}0.6887^{* * *} \\
(0.0079)\end{array}$ & $\begin{array}{c}0.0051 \\
(0.0036)\end{array}$ \\
\hline Return $_{\mathrm{t}-7, \mathrm{t}-36}$ & $\begin{array}{c}0.0091 * * * \\
(0.0022)\end{array}$ & $\begin{array}{c}-0.1475^{* * *} \\
(0.0096)\end{array}$ & $\begin{array}{c}-0.1492^{* * *} \\
(0.0104)\end{array}$ & $\begin{array}{c}-0.2682^{* * *} \\
(0.00840)\end{array}$ \\
\hline $\ln \left(\right.$ ReaVola $\left._{\mathrm{t}-7, \mathrm{t}-36}\right)$ & $\begin{array}{c}-0.0028^{* *} \\
(0.0014)\end{array}$ & $\begin{array}{c}-0.0383^{* * *} \\
(0.0051)\end{array}$ & $\begin{array}{l}-0.0133^{*} \\
(0.0072)\end{array}$ & $\begin{array}{c}0.3920 * * * \\
(0.0054)\end{array}$ \\
\hline $\ln ($ MarketCapt-7) & $\begin{array}{c}0.0053 * * * \\
(0.0013)\end{array}$ & $\begin{array}{c}0.0450^{* * *} \\
(0.0062)\end{array}$ & $\begin{array}{c}0.0580 * * * \\
(0.0071)\end{array}$ & $\begin{array}{c}-0.0752^{* * *} \\
(0.0045)\end{array}$ \\
\hline $\mathrm{LDV}_{\mathrm{t}-7}$ & $\begin{array}{c}0.0780^{* * *} \\
(0.0018)\end{array}$ & $\begin{array}{c}0.1783^{* * *} \\
(0.0031)\end{array}$ & $\begin{array}{c}0.1370^{* * *} \\
(0.0048)\end{array}$ & $\begin{array}{c}0.0324^{* * *} \\
(0.0009)\end{array}$ \\
\hline Firm-FEs & YES & YES & YES & YES \\
\hline Week-FEs & YES & YES & YES & YES \\
\hline Day-of-Week-FEs & YES & YES & YES & YES \\
\hline $\mathrm{R}^{2}$ & 0.06 & 0.67 & 0.56 & 0.21 \\
\hline No. obs. & $2,635,668$ & $2,635,668$ & $2,635,668$ & $2,860,958$ \\
\hline
\end{tabular}

IA.72 
Table C35: Panel VAR with stock returns and advertising - Channels

This table reports the results of panel VAR models with monthly stock returns and different measures of advertising as the components. The measure of advertising is $\Delta$ Ads $(\mathrm{TV}+\mathrm{NP})$, which is the log difference of the sum of TV and newspaper advertising, in VAR1, $\Delta$ Ads (TV), which is the log difference of TV advertising, in VAR2, and $\Delta$ Ads (NP), which is the log difference of newspaper advertising, in VAR3. The analysis is done for $1995-2012$ common stocks from NYSE, AMEX and NASDAQ, excluding stocks with prices below 5 USD in the month before the estimation period and those with no advertising in the two months before the estimation period. The model is estimated following the extension of standard vector autoregression to the panel context by Holtz-Eakin, Newey, and Rosen (1988) and using the program developed by Love and Zicchino (2006) and Abrigo and Love (2016). It takes firm fixed effects into account by forward orthogonal deviations and month fixed effects by monthly demeaning of the variables. The $\chi^{2}$ statistics and associated p-values are for the Granger causality test that all lags of a variable are jointly zero. The tests have twelve degrees of freedom. Standard errors are clustered by firm and shown in parentheses. $1 / 2 / 3$ stars denote significance at the $10 / 5 / 1 \%$-level.

\begin{tabular}{|c|c|c|c|c|c|c|}
\hline & \multicolumn{2}{|c|}{ VAR1: $\Delta$ Ads $(\mathrm{TV}+\mathrm{NP})$} & \multicolumn{2}{|c|}{ VAR2: $\Delta$ Ads $(\mathrm{TV})$} & \multicolumn{2}{|c|}{ VAR3: $\Delta$ Ads (NP) } \\
\hline & $\begin{array}{l}\text { Return }_{\mathrm{t}} \\
(1)\end{array}$ & $\begin{array}{c}\Delta \text { Ads }(\mathrm{TV}+\mathrm{NP})_{\mathrm{t}} \\
(2)\end{array}$ & $\begin{array}{l}\text { Return }_{t} \\
(3)\end{array}$ & $\begin{array}{c}\Delta \text { Ads (TV) } \mathrm{t} \\
(4)\end{array}$ & $\begin{array}{l}\text { Return }_{\mathrm{t}} \\
(5)\end{array}$ & $\begin{array}{c}\Delta \text { Ads }(\mathrm{NP})_{\mathrm{t}} \\
(6)\end{array}$ \\
\hline \multicolumn{7}{|l|}{ Return } \\
\hline Lag 1 & $-0.0305^{* * *}$ & $0.1599^{* * *}$ & $-0.0298^{* * *}$ & $0.1607^{* *}$ & $-0.0255^{* * *}$ & $0.1828^{* * *}$ \\
\hline Lag 2 & $-0.0215^{* * *}$ & $0.1165^{*}$ & $-0.0196 * * *$ & $0.1909^{* * *}$ & $-0.0288^{* * *}$ & $0.1581^{* *}$ \\
\hline Lag 3 & 0.0003 & $0.0954^{*}$ & $0.0120^{* * *}$ & 0.0493 & $-0.0073^{*}$ & $0.1525^{* *}$ \\
\hline Lag 4 & -0.0013 & 0.0567 & -0.0037 & 0.1079 & -0.0010 & -0.0500 \\
\hline Lag 5 & 0.0003 & $0.1913^{* * *}$ & $0.0094^{* *}$ & 0.1106 & -0.0006 & $0.2439 * * *$ \\
\hline Lag 6 & $0.0070^{*}$ & $0.0949^{*}$ & 0.0040 & $0.1149^{*}$ & 0.0025 & $0.1996 * * *$ \\
\hline Lag 7 & $0.0194 * * *$ & $0.2329 * * *$ & $0.0182^{* * *}$ & $0.2244^{* * *}$ & $0.0204^{* * *}$ & $0.2684^{* * *}$ \\
\hline Lag 8 & 0.0039 & 0.0732 & $0.0105^{* * *}$ & 0.0688 & -0.0033 & 0.0751 \\
\hline Lag 9 & $-0.0082^{* *}$ & 0.0695 & -0.0056 & 0.0692 & $-0.0158^{* * *}$ & -0.0180 \\
\hline Lag 10 & $-0.0115^{* * *}$ & 0.0322 & $-0.0222^{* * *}$ & 0.0660 & $-0.0115^{* * *}$ & 0.0163 \\
\hline Lag 11 & $0.0135^{* * *}$ & 0.0888 & $0.0148^{* * *}$ & $0.1541^{* *}$ & $0.0178^{* * *}$ & 0.0876 \\
\hline Lag 12 & $0.0065^{* *}$ & $0.1245^{* *}$ & $0.0097^{* *}$ & $0.1343^{* *}$ & 0.0012 & 0.1189 \\
\hline \multicolumn{7}{|l|}{$\Delta$ Ads } \\
\hline Lag 1 & 0.0000 & $-0.5561 * * *$ & -0.0002 & $-0.3830 * * *$ & 0.0002 & $-0.6683^{* * *}$ \\
\hline Lag 2 & -0.0002 & $-0.4519^{* * *}$ & $-0.0005^{* * *}$ & $-0.3625^{* * *}$ & 0.0001 & $-0.5417 * * *$ \\
\hline Lag 3 & -0.0002 & $-0.3864^{* * *}$ & $-0.0005^{* * *}$ & $-0.3084^{* * *}$ & 0.0002 & $-0.4563 * * *$ \\
\hline Lag 4 & $-0.0004^{* * *}$ & $-0.3286 * * *$ & $-0.0007 * * *$ & $-0.2685^{* * *}$ & 0.0000 & $-0.3819^{* * *}$ \\
\hline Lag 5 & -0.0002 & $-0.2844^{* * *}$ & $-0.0005^{* * *}$ & $-0.2316^{* * *}$ & 0.0002 & $-0.3170^{* * *}$ \\
\hline Lag 6 & -0.0000 & $-0.2376^{* * *}$ & -0.0002 & $-0.1881^{* * *}$ & 0.0002 & $-0.2517 * * *$ \\
\hline Lag 7 & -0.0001 & $-0.2178^{* * *}$ & -0.0003 & $-0.1840^{* * *}$ & 0.0002 & $-0.2194 * * *$ \\
\hline Lag 8 & -0.0000 & $-0.2019^{* * *}$ & -0.0002 & $-0.1724^{* * *}$ & 0.0001 & $-0.1931 * * *$ \\
\hline Lag 9 & -0.0001 & $-0.1912^{* * *}$ & $-0.0004^{* *}$ & $-0.1667^{* * *}$ & 0.0000 & $-0.1744^{* * *}$ \\
\hline Lag 10 & -0.0001 & $-0.1774^{* * *}$ & -0.0002 & $-0.1575 * * *$ & -0.0001 & $-0.1612^{* * *}$ \\
\hline Lag 11 & 0.0001 & $-0.1171^{* * *}$ & -0.0001 & $-0.0935^{* * *}$ & 0.0001 & $-0.1172^{* * *}$ \\
\hline Lag 12 & 0.0000 & $0.0305^{* * *}$ & -0.0001 & $0.1157^{* * *}$ & 0.0000 & 0.0025 \\
\hline$\chi^{2}$-stat $($ Return $=0)$ & - & 40.83 & - & 34.86 & - & 43.99 \\
\hline $\mathrm{p}$-value $($ Return $=0)$ & - & 0.00 & - & 0.00 & - & 0.00 \\
\hline$\chi^{2}$-stat $(\Delta$ Ads $=0)$ & 13.59 & - & 31.21 & - & 11.97 & - \\
\hline $\mathrm{p}$-value $(\Delta \mathrm{Ads}=0)$ & 0.33 & - & 0.00 & - & 0.45 & - \\
\hline $\mathrm{N}$ & 183,003 & 183,003 & 126,248 & 126,248 & 136,961 & 136,961 \\
\hline
\end{tabular}

